Natália Tasso Signorelli

\title{
Indirect investigations of the Atlantic Meridional Overturning changes in the South Atlantic Ocean in numerical models for the 20th century
}

\author{
Master thesis submitted to Instituto Oceanográfico \\ of Universidade de São Paulo, in partial fulfillment \\ of the requirements for the degree of Master of Sci- \\ ence in Oceanography, with emphasis in Physical \\ Oceanography.
}

Advisor:

Prof. ${ }^{a}$ Dr. ${ }^{a}$ Ilana E. K. C. Wainer 
Universidade de São Paulo

Instituto Oceanográfico

\title{
Indirect investigations ofthe Atlantic Meridional Overturning changes in the South Atlantic Ocean in numerical models for the 20th century
}

\begin{abstract}
Natália Tasso Signorelli
Master thesis submitted to Instituto Oceanográfico of Universidade de São Paulo, in partial fulfillment of the requirements for the degree of Master of Science in Oceanography, with emphasis in Physical Oceanography.
\end{abstract}

Evaluated in _ _ _ _ _ by:

Prof(a). Dr(a).

Grade

Prof(a). Dr(a). 
"O que sabemos é uma gota; o que ignoramos é um oceano."

Isaac Newton (1642-1727) 
À minha mãe e meu pai, pelo amor incondicional, pelo exemplo de vida e família. 


\section{Acknowledgements}

Dois anos e meio depois e cá estou eu novamente tentando por em papel a imensa gratidão que eu sinto por cada um daqueles que contribuiram para que esse trabalho deixasse de ser apenas uma ideia... e fazer isso sem escrever demais e chorar demais.

Pai, mãe. Vocês vão ser sempre os primeiros. E os mais importantes. Obrigada pelo carinho, pelo amor, pela paciência, pelos bons exemplos... pelo apoio, moral e financeiro. Aqui e do outro lado do oceano. Há quase oito anos vocês me deixaram aqui no IO pra virar adulta, oceanógrafa (aquela profissão que vocês nunca tinham ouvido falar, mas já que eu queria, né...). Não cumpriria mais essa etapa da minha vida se não fosse toda a base que vocês me deram. Vocês são minha inspiração, meu orgulho, meu tudo.

Minha família buscapé preferida... Vó , vô, tios, tias.. Bia! Cada qual no seu jeitinho, único, contribuiram e contribuem pras minhas conquistas. Obrigada por vibrarem com as minhas vitórias.

Minha orientadora, Ilana, que depois de tanto tempo já ganhou status de mãe. E que me abriu as portas, me apoiou nas minhas aventuras e nos meu sonhos e me mostrou o mundo científico. Obrigada por acreditar e confiar em mim.

Meninas da Toca, de antes, de hoje e de sempre: Ju, Cá, Nati, Paty, Carol's... Que transformaram com brigadeiro, filmes, e por vezes, alguma dose de álcool, todas as minhas noites de desespero em boas risadas. Que aguentaram bravamente a minha TPM, o meu mau humor de noites mal dormidas e minha mania de organização. Dads queridas! Quem diria que um grupo de e-mails de "Damas Atrás de Diversão" ia diminuir as distâncias, por vezes ocêanicas, e me dar "inteiramente grátis" seis confidentes e momentos memoráveis. Dani, minha Magrela, Six... minha família linda, que cuidou de mim até no Velho Mundo.

Galera do Lab. OC ${ }^{2}$... Zé, Bruno, Thiagão, Dani, Mineiro, que me acolheram no seleto grupo dos menininhos (e eu nem me obrigaram a usar bigodes postiços). Obrigada. Marina, eu juro que a Chuva não é culpa minha! Martim, O-tel... seus sacaneadores de carteirinha! Augusto, que tornou a minha vida no lab muito mais divertida! Senti muito a sua falta!

Meus amigos, companheiros de Mestrado, de listas infinitas e provas devastadoras! Césinha, Maca, Cunhas, Cá, Beto (que saudade!), Gil, Tainá, Ju, Lu. Obrigada por me doar um pouquinho da sua sabedoria. Meus professores, claro... que com as mesmas listas infinitas e as provas devastadoras me instigaram a ir mais longe e aprender mais sempre. Vocês também são parte muito importante da oceanógrafa que sou.

Danilo! Eu tive que separar um parágrafo especial pra você dessa vez (se bem que você merecia uma página toda!). Obrigada, meu amigo, por tudo. Pelo ombro amigo, pelo companheirismo, pelos 
chocolates nos dias ruins e principalmente, por me ensinar tanto! Nem posso acreditar na sorte que eu tive de ter você na minha turma, no mesmo lab... Essa dissertação não seria a mesma sem sua mente brilhante pra achar soluções rápidas para os meus problemas que sempre pareciam insolúveis.

Thanks Anne-Marie and Julie. When I left Brazil, I could not expect to learn so much! This six months were a unforgettable challenge. I have no words to say how grateful I am for this experience.

Matthew, Patri, Luz, Maribel, Nico... I'm so happy to have met you guys! My days in France would not be the same without you. Brest would be more gray and colder.

Meus amigos campineiros, Mari, Naty, Cacá, Rafa... que me deixam com mais saudades do interior. E que me dão a segurança de que eu sempre vou ter abraços fortes, taças de vinho e muita risada sempre que quiser ou precisar voltar.

Agradeço também à Fundação de Amparo à Pesquisa do Estado de São Paulo (FAPESP) que financiou meus projetos e meus sonhos (processos 2010/13741-0 e 2012/12269-1) e tornou a realização desse trabalho possível.

Por fim, a todos aqueles que de uma maneira ou de outra me ajudaram a construir esse trabalho e a passar por essa etapa da minha vida, meu eterno e sincero obrigada. 


\section{Summary}

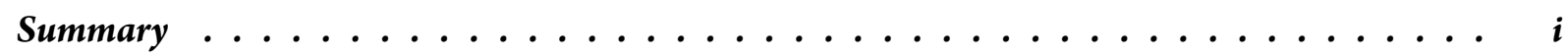

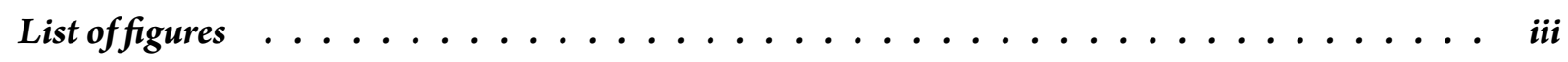

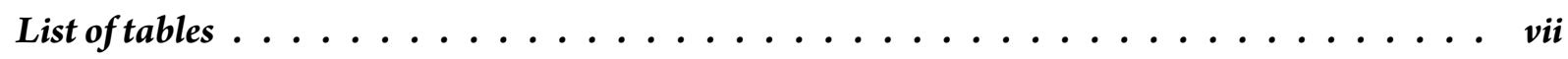

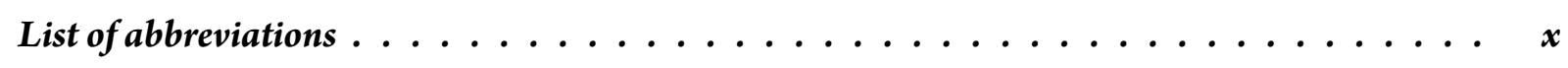

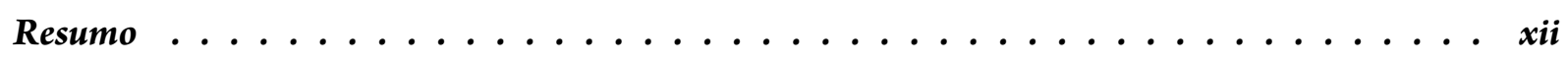

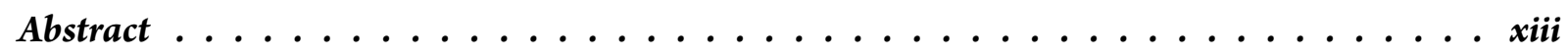

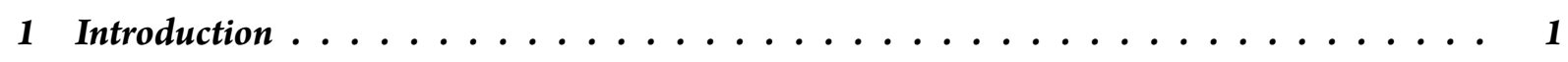

1.1 Atlantic Meridional Overturning Circulation . . . . . . . . . . . . . . 2

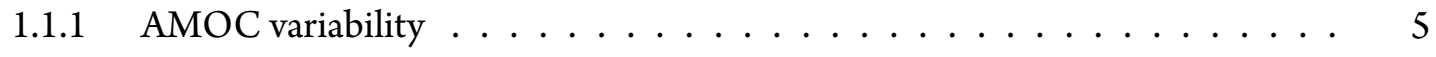

1.1.1.1 Atlantic Multidecadal Oscillation ............ 6

1.1.1.2 North Atlantic Oscillation . . . . . . . . . . . . . 7

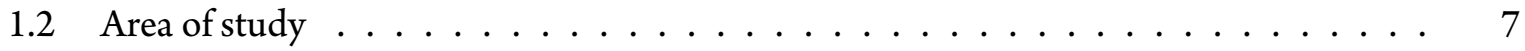

1.2.1 The South Atlantic system of currents . . . . . . . . . . . . 7

1.2.1.1 South Equatorial Current bifurcation . . . . . . . . . 10

1.2.1.2 The North Brazil Undercurrent . . . . . . . . . . . . . . . . . 13

1.2.1.3 The Intermediate Western Boundary Current . . . . . . . . . 14

1.2.2 The South Atlantic water masses structure . . . . . . . . . . . . . . . . . 14

1.2.2.1 South Atlantic Central Water . . . . . . . . . . . . . . 17

1.2.2.2 Antarctic Intermediate Water . . . . . . . . . . . . . . 17

1.2.3 The South Atlantic and the Meridional Overturning Circulation . . . . . . 18

1.3 Ocean General Circulation Models . . . . . . . . . . . . . . . . . . . . 21

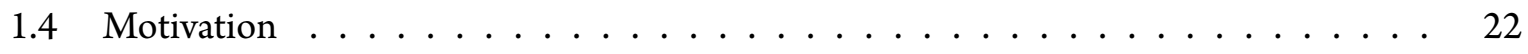

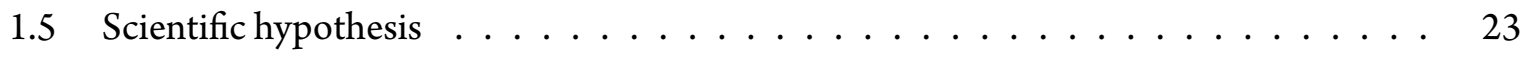

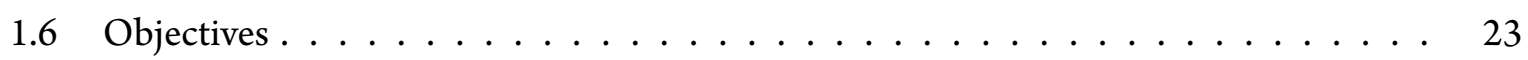

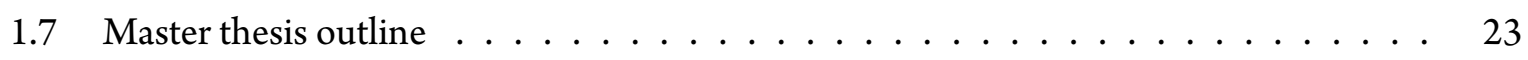

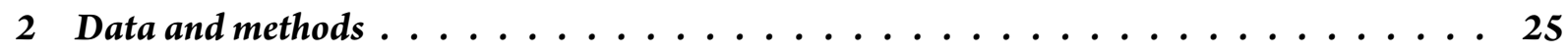

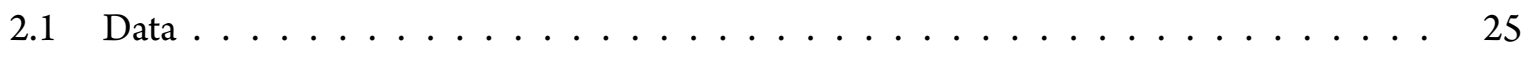

2.1.1 Simple Ocean Data Assimilation . . . . . . . . . . . . . . . . 25

2.1.2 The ocean component of Community Climate System Model . . . . . . 25 
2.1.3 Nucleus for European Modelling of the Ocean . . . . . . . . . . . . . . . 26

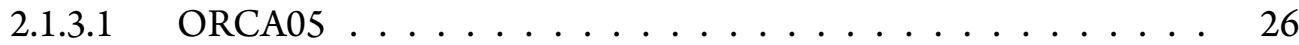

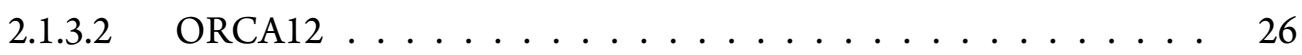

2.1.4 Coordinated Ocean-ice Reference Experiments . . . . . . . . . . . . . . 27

2.1.5 Climate timeseries . . . . . . . . . . . . . . . . . . . . 27

2.2 Methods ........................... 27

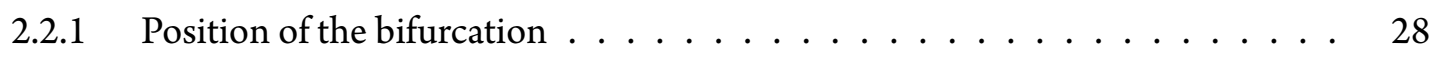

2.2.2 Volume transports . . . . . . . . . . . . . . 28

2.2.2.1 Sverdrup transport . . . . . . . . . . . . . . . . . 29

2.2.3 South Atlantic Meridional Overturning Cell _ . . . . . . . . . . . . 31

2.2.3.1 Hamming filter . . . . . . . . . . . . . . . . 31

2.2 .4 Correlations . . . . . . . . . . . . . . . . . 32

2.2 .5 Taylor's Diagram . . . . . . . . . . . . . . . . . . . 32

2.2 .6 Optimum Multiparameter . . . . . . . . . . . . . . . . 33

2.2.6.1 Potential vorticity . . . . . . . . . . . . 36

2.2 .7 Neutral density . . . . . . . . . . . . . . . . . . . . . 37

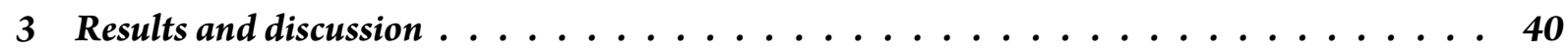

3.1 South Equatorial Current Bifurcation and its link with the AMOC . . . . . . . . 40

3.1 .1 Validation . . . . . . . . . . . . . . . . 42

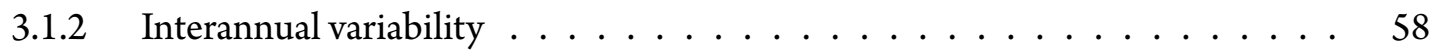

3.1.2.1 South Equatorial Currents bifurcation . . . . . . . . . . 58

3.1.2.2 Western Boundary Currents . . . . . . . . . . . . . . 62

3.1.2.3 South Atlantic Meridional Overturning Circulation . . . . . . . . 69

3.2 Changes in the water masses linked to AMOC . . . . . . . . . . . . 77

3.2 .1 Validation . . . . . . . . . . . . . . . . . . 77

3.2.2 Water masses variability . . . . . . . . . . . . . . . . 84

3.2.2.1 South Atlantic Central Water . . . . . . . . . . . . . . . . 88

3.2.2.2 Antarctic Intermediate Water . . . . . . . . . . . . . . . . 102

4 Conclusion ............................ 116

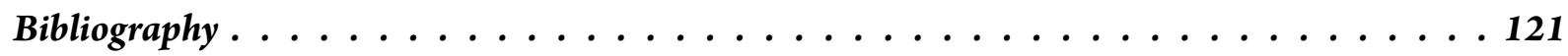




\section{List offigures}

Figure 1 - Schematic of the AMOC in the South Atlantic Ocean. . . . . . . . . . . . . 3

Figure 2 - Thermal and salinity fields for the on-state of the AMOC produced by Sévellec \& Fedorov (2011) using a latitude-depth model of ocean meridional circulation. . . . 4

Figure 3 - AMOC variability adapted from Bingham et al. (2007). . . . . . . . . . . . 5

Figure 4 - AMO Index from NOAA, between 1948 and 2007 . . . . . . . . . . . . 6

Figure 5 - NAO Index from NOAA, between 1948 and 2007. . . . . . . . . . . . 7

Figure 6 - Superficial South Atlantic Circulation diagram. . . . . . . . . . . . . . 8

Figure 7 - Intermediate depths South Atlantic circulation diagram. . . . . . . . . . . . 9

Figure 8 - Deep and bottom South Atlantic Ocean circulation diagram. . . . . . . . . . . . 10

Figure 9 - Annual mean geostrophic meridional velocity observed by Rodrigues, Rothstein \& Winbush (2007). . . . . . . . . . . . . . . . . . 11

Figure 10 - Time-depth plot of the SEC bifurcation latitude $\left({ }^{\circ} \mathrm{S}\right)$ determined by the location of zero meridional velocity averaged over a $2^{\circ}$ longitude band off the South American coast observed by Rodrigues, Rothstein \& Winbush (2007) . . . . . . . . . . . . . 12

Figure 11 - Seasonal variability of the latitude position compared to the NBUC transport, as related by Rodrigues, Rothstein \& Winbush (2007) . . . . . . . . . . . . . . 13

Figure 12 - T-S diagram, representing the most important South Atlantic water masses. . . . . 14

Figure 13 - WOCE potential temperature and salinity sections at $25^{\circ} \mathrm{W}$. Adapted from Schlitzer (2000). . . . . . . . . . . . . . . . . . . 15

Figure 14 - Maps of the salinity minimum produced by the intermediate waters. . . . . . . . 16

Figure 15 - Schematic of the AMOC in the South Atlantic Ocean. . . . . . . . . . . . . . 19

Figure 16 - AMOC variability adapted from Rabe, Schott \& Köhl (2008) . . . . . . . . . . . 20

Figure 17 - Four degrees of longitude band off the Brazilian coast area used to determine the SEC bifurcation position. . . . . . . . . . . . . . . . . 28

Figure 18 - Sverdrup transport (Sv), calculated using Equation 2.12, where blue is clockwise and yellow-red is counterclockwise circulation. Data are from the NCEP reanalysis 1968-1996 (KALNAY et al., 1996). Adapted from Talley et al. (2011). . . . . . . 31

Figure 19 - Position of the sections used to calculate the water masses distribution using OMP. 34

Figure 20 - Averaged maximum mixed layer depth . . . . . . . . . . . . . 35

Figure 21 - Time averaged temperature-salinity diagram at $25^{\circ} \mathrm{S}$ and $25^{\circ} \mathrm{W}$ to exemplify the calculus of the source water types parameters. . . . . . . . . . . . . . 36 
Figure 22 - Density and vorticity profiles in the first $2000 \mathrm{~m}$ at $25^{\circ} \mathrm{W}$ and $25^{\circ} \mathrm{S} \ldots \ldots$. . . . 38

Figure 23 - Potential (a) and neutral (b) densities calculated near South America coast (section A17). Adapted from Koltermann, Gouretski \& Jancke (2011) . . . . . . . . . . .

Figure 24 - Climatological meridional velocity within the $4^{\circ}$ longitude band off South America

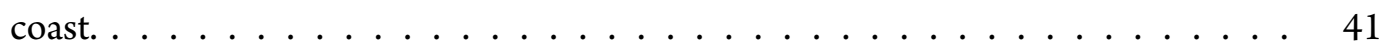

Figure 25 - Sverdrup transport (Sv) calculated using the wind stress curl (Section 2.2.2.1). . . 42

Figure 26 - Averaged summer and winter meridional velocity within the $4^{\circ}$ longitude band off South America coast section. . . . . . . . . . . . . . . . . . 4 43

Figure 27 - Seasonal cycle of the position of the bifurcation of SEC . . . . . . . . . . 45

Figure 28 - Seasonal variability of the SEC bifurcation position, averaged in the top $200 \mathrm{~m}$. . . 46

Figure 29 - Seasonal variability of the SEC bifurcation position, averaged between 500 and $1000 \mathrm{~m} \ldots \ldots \ldots \ldots$. . . . . . . . . . . . . . . 46

Figure 30 - Month averages of zero position of wind stress curl in the South Atlantic. . . . . 47

Figure 31 - Correlation between the bifurcation position in the top $200 \mathrm{~m}$ and the wind stress

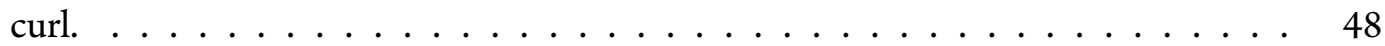

Figure 32 - Time averages of meridional velocities $\left(\mathrm{m} \cdot \mathrm{s}^{-1}\right)$ at $11^{\circ} \mathrm{S} \ldots \ldots \ldots$. . . . . . 49

Figure 33 - Seasonal cycle of the volume transport of NBUC at $11^{\circ} \mathrm{S} . \ldots \ldots$. . . . . . . 50

Figure $34-$ Time averages of meridional velocities $\left(\mathrm{m} \cdot \mathrm{s}^{-1}\right)$ at $27^{\circ} \mathrm{S} \ldots \ldots \ldots \ldots$. . . . . 51

Figure 35 - Seasonal cycle of the volume transport of $\mathrm{BC}$ at $27^{\circ} \mathrm{S} \ldots \ldots \ldots$. . . . . . . . 52

Figure 36 - Time averages of zonal velocities $\left(\mathrm{m} \cdot \mathrm{s}^{-1}\right)$ at $25^{\circ} \mathrm{W} \ldots \ldots \ldots$

Figure 37 - Seasonal cycle of the volume transport of SEC at $25^{\circ} \mathrm{W} . \ldots \ldots 4$

Figure 38 - Seasonal cycle of the volume transport of SEC at $25^{\circ} \mathrm{W}$, between $29^{\circ} \mathrm{S}$ and $25^{\circ} \mathrm{S} . \ldots 55$

Figure 39 - Correlations at zero lag of seasonal time series of wind stress curl with the transport of NBUC at $11^{\circ} \mathrm{S}$ and the transport of BC at $27^{\circ} \mathrm{S} . \ldots \ldots 57$

Figure 40 - Position of the bifurcation of SEC time series (annual averages) calculated at top $1000 \mathrm{~m} \ldots \ldots \ldots$. . . . . . . . . . . . . . . . 59

Figure 41 - SEC bifurcation position time series, averaged in the top $200 \mathrm{~m} . \ldots$. . . . . . . 60

Figure 42 - Variability of the SEC bifurcation position, averaged between $500 \mathrm{~m}$ and $1000 \mathrm{~m}$. . $\quad 61$

Figure 43 - Correlation between the bifurcation position in the top $200 \mathrm{~m}$ and the wind stress

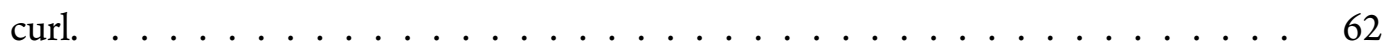

Figure 44 - Correlation between the bifurcation position between $500 \mathrm{~m}$ and $1000 \mathrm{~m}$ and the wind stress curl. . . . . . . . . . . . . . . . . . . . . . . 63

Figure 45 - Volume transport time series of NBUC at $11^{\circ} \mathrm{S} \ldots \ldots \ldots$. . . . . . . . . . 64

Figure $46-$ Volume transport time series of IWBC at $27^{\circ}$ S . . . . . . . . . . . . 65

Figure 47 - Correlation between transports and the wind stress curl. . . . . . . . . . . . 66

Figure 48 - Anomalies of the NBUC (black) and Sverdrup interior transport (dashed) for (a) SODA, (b) CCSM, (c) ORCA05 and (d) ORCA12. . . . . . . . . . . . . . . 67 
Figure 49 - Climatological averages of South Atlantic Meridional Overturning Circulation. . . 70

Figure $50-$ SAMOC time series at $11^{\circ} \mathrm{S} \ldots \ldots \ldots \ldots \ldots \ldots$

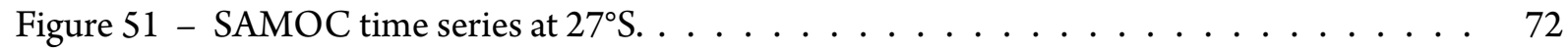

Figure 52 - AMOC, Sverdrup interior and NBUC transport anomalies at $11^{\circ} \mathrm{S} . \ldots . \ldots 74$

Figure 53 - Relationship between $\mathrm{NAO}$ and AMOC at $11^{\circ} \mathrm{S} \ldots \ldots \ldots$

Figure 54 - Temperature-salinity diagram using time-longitude averaged data at $11^{\circ} \mathrm{S}$ (a) and $27^{\circ} \mathrm{S}(\mathrm{b}) \ldots \ldots \ldots \ldots \ldots \ldots$. . . . . . . . . . . . . . . . . . . . . .

Figure $55-$ Climatological salinity at $11^{\circ} \mathrm{S} \ldots \ldots \ldots \ldots \ldots$

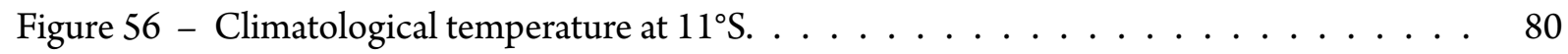

Figure $57-$ Climatological salinity at $27^{\circ} \mathrm{S} \ldots \ldots \ldots \ldots \ldots$

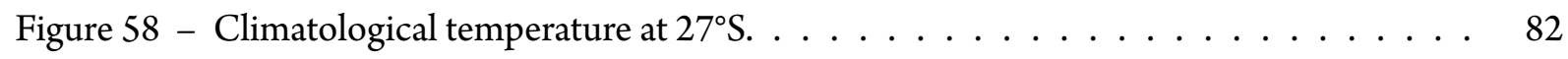

Figure 59 - Taylor's Diagram for salinity and temperature data at $11^{\circ} \mathrm{S}$ and $27^{\circ} \mathrm{S}$. . . . . . . 83

Figure 60 - Velocity and density fields superimposed at $11^{\circ} \mathrm{S} \ldots \ldots \ldots$. . . . . . . 84

Figure 61 - Velocity and density fields superimposed at $27^{\circ} \mathrm{S} \ldots \ldots \ldots$. . . . . . . 85

Figure 62 - Climatological section of fractional contribution from SACW at $11^{\circ} \mathrm{S}$. . . . . . 89

Figure 63 - Mass conservation residual fit (\%) for the OMP analysis at $11^{\circ} \mathrm{S} . \ldots . . . . .990$

Figure 64 - Climatological section of fractional contribution from SACW at $27^{\circ}$ S. . . . . . . 91

Figure 65 - Mass conservation residual fit (\%) for the OMP analysis at $27^{\circ} \mathrm{S} \ldots \ldots$. . . . . 92

Figure 66 - Hovmoller of anomalies of SACW depth core. . . . . . . . . . . . . . 93

Figure 67 - Time series of the anomalies of SACW depth core. . . . . . . . . . . . . . . 94

Figure 68 - Hovmöller of anomalies of the salinity projected in the $\gamma_{n_{25.5}} \mathrm{~kg} \cdot \mathrm{m}^{-3}$ neutral surface at $11^{\circ} \mathrm{S}$ and $27^{\circ}$ S. . . . . . . . . . . . . . . . . . . . . 95

Figure 69 - Time series of the salinity anomalies projected in the $\gamma_{n_{25.5}}$ neutral surface, related to $\mathrm{SACW}$, at $11^{\circ} \mathrm{S}$ and $27^{\circ} \mathrm{S} \ldots \ldots \ldots \ldots$. . . . . . . . . . . . . 96

Figure 70 - Hovmöller of the anomalies of the temperature projected in the $\gamma_{n_{25.5}}$ neutral surface, related to SACW, at $11^{\circ} \mathrm{S}$ and $27^{\circ} \mathrm{S} \ldots \ldots \ldots$. . . . . . . . . . 97

Figure 71 - Time series of the temperature anomalies projected in the $\gamma_{n_{25.5}}$ neutral surface, related to SACW, at $11^{\circ} \mathrm{S}$ and $27^{\circ} \mathrm{S} \ldots \ldots \ldots \ldots$. . . . . . . . . . . 98

Figure 72 - Hovmöller of anomalies of the salinity projected in the $\gamma_{n_{27.0}} \mathrm{~kg} \cdot \mathrm{m}^{-3}$ neutral surface at $11^{\circ} \mathrm{S}$ and $27^{\circ}$ S. . . . . . . . . . . . . . . . . . . . . 100

Figure 73 - Time series of the salinity anomalies projected in the $\gamma_{n_{27.0}}$ neutral surface, related to SACW, at $11^{\circ} \mathrm{S}$ and $27^{\circ} \mathrm{S} \ldots \ldots \ldots \ldots 10 \ldots$

Figure 74 - Hovmöller of the anomalies of the temperature projected in the $\gamma_{n_{27.0}}$ neutral surface, related to SACW, at $11^{\circ} \mathrm{S}$ and $27^{\circ} \mathrm{S} . \ldots \ldots \ldots$

Figure 75 - Time series of the temperature anomalies projected in the $\gamma_{n_{27.0}}$ neutral surface, related to SACW, at $11^{\circ} \mathrm{S}$ and $27^{\circ} \mathrm{S} \ldots \ldots \ldots \ldots$

Figure 76 - Climatological section of fractional contribution from AAIW at $11^{\circ}$ S. . . . . . 105

Figure 77 - Mass conservation residual fit $(\%)$ for the second OMP analysis at $11^{\circ} \mathrm{S} \ldots \ldots 6$ 
Figure 78 - Climatological section of fractional contribution from AAIW at $27^{\circ}$ S. . . . . . 107

Figure 79 - Mass conservation residual fit $(\%)$ for the second OMP analysis at $27^{\circ} \mathrm{S} \ldots \ldots$

Figure 80 - Hovmöller of the vertical extension of the AAIW core . . . . . . . . . . . 109

Figure 81 - Hovmöller of the anomalies of the vertical extension of the AAIW core. . . . . . . 110

Figure 82 - Time series of the anomalies of the vertical extension of the AAIW core. . . . . . 111

Figure 83 - Hovmöller of anomalies of the salinity projected in the $\gamma_{n_{A A I W}} \mathrm{~kg} \cdot \mathrm{m}^{-3}$ neutral surface at $11^{\circ} \mathrm{S}$ and $27^{\circ} \mathrm{S} . \ldots \ldots \ldots \ldots \ldots \ldots$

Figure $84-$ Time series of the salinity anomalies projected in the $\gamma_{n_{A A I W}}$ neutral surface, at $11^{\circ} \mathrm{S}$ and $27^{\circ}$ s. . . . . . . . . . . . . . . . . . . . . . . . . 114

Figure 85 - Hovmöller of anomalies of the salinity projected in the $\gamma_{n_{\text {AAIW }}} \mathrm{kg} \cdot \mathrm{m}^{-3}$ neutral surface at $11^{\circ} \mathrm{S}$ and $27^{\circ} \mathrm{S} . \ldots \ldots \ldots \ldots \ldots \ldots \ldots$ 


\section{List of tables}

Table 1 - Density layers of water masses that contribute to SACW formation, from Donners, Drijfhout \& Hazeleger (2005) . . . . . . . . . . . . . . . . . .

Table 2 - Bifurcation position, in ${ }^{\circ} \mathrm{S}$, means for each dataset in different layers, compared to Rodrigues, Rothstein \& Winbush $(2007)^{1}$. . . . . . . . . . . . . . . . 41

Table 3 - Meridional volume transport of NBUC at $11^{\circ}$ S . . . . . . . . . . . . . . 49

Table $4-$ Meridional volume transport of BC at $27^{\circ} \mathrm{S} . \ldots \ldots \ldots$. . . . . . . . 51

Table 5 - Zonal volume transport of SEC at $25^{\circ} \mathrm{W}$, between $13^{\circ} \mathrm{S}$ and $9^{\circ} \mathrm{S} . \ldots \ldots$. . . . . . . 54

Table 6 - Zonal volume transport of the SEC at $25^{\circ} \mathrm{W}$, between $29^{\circ} \mathrm{S}$ and $25^{\circ} \mathrm{S} . \ldots \ldots 5$

Table 7 - Correlation between monthly averages of the transport of NBUC at $11^{\circ} \mathrm{S}$ and seasonal transports of SEC at $25^{\circ} \mathrm{W}$, between $13^{\circ} \mathrm{S}$ and $9^{\circ} \mathrm{S} \ldots \ldots \ldots 56$

Table 8 - Correlation between monthly averages of the transport of $\mathrm{BC}$ at $27^{\circ} \mathrm{S}$ and seasonal transports of SEC at $25^{\circ} \mathrm{W}$, between $13^{\circ} \mathrm{S}$ and $9^{\circ} \mathrm{S} \ldots \ldots \ldots . \ldots 56$

Table 9 - Correlation between monthly averages of the bifurcation position in the top $200 \mathrm{~m}$ and seasonal transports of NBUC at $11^{\circ}$ S . . . . . . . . . . . 58

Table 10 - Correlation between monthly averages of the bifurcation position in the top $200 \mathrm{~m}$ and seasonal transports of SEC at $25^{\circ} \mathrm{W}$, between $13^{\circ} \mathrm{S}$ and $9^{\circ} \mathrm{S} . \ldots \ldots$. . . . . 58

Table 11 - Correlation between monthly averages of the bifurcation position in the bottom $500 \mathrm{~m}$ and seasonal transports of SEC at $25^{\circ} \mathrm{W}$, between $27^{\circ} \mathrm{S}$ and $23^{\circ} \mathrm{S} . \ldots . . .58$

Table 12 - Correlation between annual averages of the bifurcation position averaged in the top 200m. . . . . . . . . . . . . . . . . . . 60 60

Table 13 - Correlation between annual averages of the bifurcation position averaged between

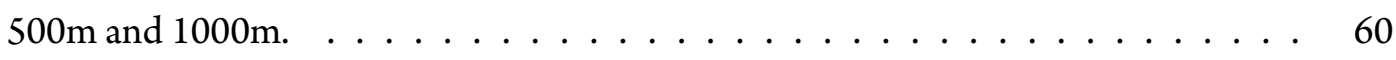

Table 14 - Trends of the SEC bifurcation position. . . . . . . . . . . . . . 61

Table 15 - Correlation between annual averages of NBUC transport anomaly in the top $1000 \mathrm{~m}$. 63

Table 16 - Correlation between annual averages of IWBC transport anomaly in the top $1000 \mathrm{~m} . \quad 64$

Table 17 - Trends of NBUC and IWBC transports. . . . . . . . . . . . . . . 65

Table 18 - Correlation between annual averages of NBUC transport anomalies in the top $1000 \mathrm{~m}$ and the Sverdrup interior transport. . . . . . . . . . . . . . . . . 68

Table 19 - Correlation between annual averages of northward transport and the bifurcation position. . . . . . . . . . . . . . . . . . . . 69

Table 20 - South Atlantic MOC vertical maximum $(\mathrm{Sv})$ averages at $11^{\circ} \mathrm{S}$ and $27^{\circ} \mathrm{S} . \quad \ldots \quad \ldots \quad 70$ 
Table 21 - Correlation between annual averages of SAMOC at $11^{\circ} \mathrm{S} . \ldots \ldots$. . . . . . 71

Table 22 - Correlation between annual averages of SAMOC at $27^{\circ}$ S. . . . . . . . . . . 72

Table 23 - Correlation between annual averages of SAMOC, NBUC and Sverdrup interior trans-

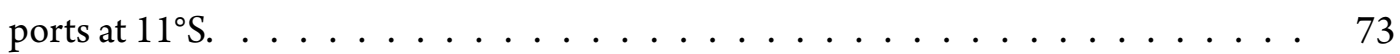

Table 24 - Correlation between annual averages of SAMOC and IWBC transports at $27^{\circ} \mathrm{S}$. . 75

Table 25 - Trends of South Atlantic MOC vertical maximum $\left(\mathrm{Sv} \cdot \mathrm{y}^{-1}\right)$ at $11^{\circ} \mathrm{S}$ and $27^{\circ} \mathrm{S}$. . . . 75

Table 26 - Trends of South Atlantic MOC vertical maximum at $11^{\circ} \mathrm{S}$ and $27^{\circ} \mathrm{S} . \quad \ldots \ldots$

Table 27 - Correlation between annual averages of SAMOC and bifurcation position. . . . . 75

Table 28 - Source water type parameters for each model at $11^{\circ} \mathrm{S} . \ldots \ldots 6$

Table 29 - Source water type parameters for each model at $27^{\circ} \mathrm{S} . \ldots \ldots 6$

Table 30 - Temperature and salinity characteristics of the source water masses according to the literature . . . . . . . . . . . . . . . . . . . . . . . 87

Table 31 - Potential vorticity characteristics of the source water masses according to the literature. 87

Table 32 - Neutral isopycnals calculated in each model for each water masses, using the methodology of Jackett \& McDougall (1997) and Serazin (2011). . . . . . . . . . . . 88

Table 33 - Correlation between annual averages of the SACW core vertical position. . . . . . . 92

Table 34 - Correlation between annual averages of the SACW core vertical position. . . . . . . 94

Table 35 - Trends of the position of the SACW core ( $80 \%$ contour $)\left(\mathrm{m} \cdot \mathrm{y}^{-1}\right)$ at $11^{\circ} \mathrm{S}$ and $27^{\circ} \mathrm{S} . \quad 94$

Table 36 - Correlation between annual averages the salinity projected in the neutral surface of $\gamma_{n_{25.5}}$ related to the SACW at $11^{\circ}$ S. . . . . . . . . . . . . . 96

Table 37 - Correlation between annual averages the salinity projected at the neutral surface of $\gamma_{n_{25.5}}$ related to the SACW at $27^{\circ}$ S. . . . . . . . . . . . . .

Table 38 - Trends of the salinity projected in the neutral isopycnal $\left(\gamma_{n_{25.5}}\right)$ related to the SACW

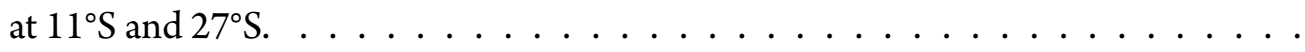

Table 39 - Correlation between annual averages the salinity projected at the neutral surface of $\gamma_{n_{25.5}}$ and the SACW core position, at $11^{\circ} \mathrm{S}$ and $27^{\circ} \mathrm{S} . \ldots \ldots \ldots$

Table 40 - Correlation between annual averages the salinity projected in the neutral surface of $\gamma_{n_{27.0}}$ related to the SACW at $11^{\circ} \mathrm{S} . \ldots \ldots \ldots . \ldots \ldots$

Table 41 - Correlation between annual averages the salinity projected at the neutral surface of $\gamma_{n_{27.0}}$ related to the SACW at $27^{\circ} \mathrm{S} . \ldots \ldots \ldots \ldots \ldots$

Table 42 - Trends of the salinity projected in the neutral isopycnal $\left(\gamma_{n_{27.0}}\right)$ related to the SACW at $11^{\circ} \mathrm{S}$ and $27^{\circ} \mathrm{S} . \ldots \ldots \ldots \ldots \ldots \ldots \ldots$

Table 43 - Correlation between annual averages the salinity projected at the neutral surface of $\gamma_{n_{27.0}}$ and the SACW core position, at $11^{\circ} \mathrm{S}$ and $27^{\circ} \mathrm{S} . \ldots \ldots \ldots$

Table 44 - Correlation between annual averages of the vertical extension of the AAIW core at

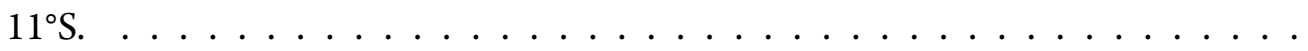

Table 45 - Correlation between annual averages of the vertical extension of the AAIW core at $27^{\circ} \mathrm{S}$. 
Table 46 - Trends of the vertical extension of the AAIW core at $11^{\circ} \mathrm{S}$ and $27^{\circ} \mathrm{S} . \ldots \ldots \ldots$

Table 47 - Correlation between annual averages the salinity projected in the neutral surface of $\gamma_{n_{A A I W}}$ at $11^{\circ}$ S. . . . . . . . . . . . . . . . . . . . 112

Table 48 - Correlation between annual averages the salinity projected at the neutral surface of $\gamma_{n_{A A I W}}$ at $27^{\circ}$ S. . . . . . . . . . . . . . . . . . . . 112

Table 49 - Trends of the salinity projected in the neutral isopycnal $\left(\gamma_{n_{\text {AAIW }}}\right)$ at $11^{\circ} \mathrm{S}$ and $27^{\circ} \mathrm{S} . \quad . \quad 114$

Table 50 - Correlation between the annual averages of the salinity projected at the neutral surface of $\gamma_{n_{A A I W}}$ and changes in the vertical extension of the AAIW core at $11^{\circ} \mathrm{S}$ and $27^{\circ}$ S. . . . . . . . . . . . . . . . . . . . . 115 


\section{List of abbreviations}

\begin{tabular}{|c|c|}
\hline AABW & Antarctic Bottom Water \\
\hline AAIW & Antarctic Intermediate Water \\
\hline AMO & Atlantic Meridional Oscillation \\
\hline AMOC & Atlantic Meridional Overturning Circulation \\
\hline $\mathrm{BC}$ & Brazil Current \\
\hline CCSM & Community Climate System Model \\
\hline CORE & Coordinated Ocean-ice Reference Experiments \\
\hline cSEC & central band of the South Equatorial Current \\
\hline DWBC & Deep Western Boundary Current \\
\hline ENSO & El Niño Southern Oscillation \\
\hline GFDL & Geophysical Fluid Dynamics Laboratory \\
\hline IPCC & Intergovernmental Panel on Climate Change \\
\hline IPO & Interdecadal Pacific Oscillation \\
\hline ITCZ & Intertropical Convergence Zone \\
\hline IWBC & Intermediate Western Boundary Current \\
\hline ISACW & light South Atlantic Central Water \\
\hline NADW & North Atlantic Deep Water \\
\hline $\mathrm{NAO}$ & North Atlantic Oscillation \\
\hline NBC & North Brazil Current \\
\hline NBUC & North Brazil Undercurrent \\
\hline NEB & North East Brazilian \\
\hline $\mathrm{NH}$ & Northern Hemisphere \\
\hline
\end{tabular}


NOAA National Oceanic and Atmospheric Administration

OCCAM Ocean Circulation and Climate Advanced Modelling project

OGCM Ocean General Circulation Models

OMP Optimum Multiparameter

POP Ocean Parallel Program

RMS Root-mean-square

SA South Atlantic

SAC South Atlantic Current

SACW South Atlantic Central Water

SACZ South Atlantic Convergence Zone

SAMW Subantarctic Mode Water

SASM South America summer monsoon

SASTMW South Atlantic Subtropical Mode Water

SEC South Equatorial Current

SECC South Equatorial Countercurrent

SH South Hemisphere

SODA Simple Ocean Data Assimilation

SST Sea surface temperature

SvIT Sverdrup interior transport

SWT Source Water Type

TW Tropical Water

UCDW Upper Circumpolar Deep Water

WBC Western Boundary Currents 


\section{Resumo}

O Oceano Atlântico tem papel importante na variabilidade da AMOC, uma vez que inclui dois dos seus principais fluxos de retorno: a NBUC e a IWBC, com origem na bifurcação da SEC e que transportam, principalmente, a SACW e a AAIW. Uma das hipóteses deste trabalho é que, analisando a variabilidade desta bifurcação é possível obter um indicator de mudanças na AMOC. Quatro resultados de modelos oceânicos, com diferentes resoluções espaciais e forçantes foram utilizados. Os resultados mostram que mudanças na bifurcação estão ligadas às mudanças nas correntes e que são, ambas, forçadas pelo vento. Correlações entre a bifurcação da SEC na superfície e a AMOC também foram observadas e os resultados sugerem que isso acontece por meio da NBUC. Outra hipótese é que, num cenário de aquecimento global, uma intensificação do ciclo hidrológico poderia gerar modificações nas massas d'água ligadas à AMOC e contribuir para a sua variabilidade. O núcleo da SACW tem ficado mais raso e essas alterações parecem estar ligadas ao aumento da salinidade projetada nas superficies neutras. Já o núcleo da AAIW tem diminuído em virtude do aumento da salinidade em $11^{\circ} \mathrm{S}$, enquanto o oposto é observado em $27^{\circ} \mathrm{S}$.

Palavras-chave: Oceano Atlântico, Célula de Revolvimento Meridional, bifurcação da Corrente Sul Equatorial, Água Central do Atlântico Sul, Água Intermediária Antártica. 


\section{Abstract}

The South Atlantic has a relevant role on the AMOC variability as it includes two main conduits of its upper-ocean return flow: the NBUC and the IWBC that carry, mainly, the SACW and the AAIW and are originated from the bifurcation of the SEC. One of the hypotheses of this work is that analyzing the bifurcation variability it is possible to get an index of the AMOC changes. Another hypothesis is that in a global warming scenario, changes in the hydrological cycle would drive modifications in the water masses that are part of the AMOC, and thus, contribute to its variability. Four global model results were used, with different forcing and spatial resolution. Results show that changes in the bifurcation are linked to modifications in the currents both caused by variations in the wind stress curl. Good correlations were found between the SEC bifurcation at the surface and the AMOC. The NBUC seems to be the link between them. Shallowing of the SACW core is related to an increase of the salinity on neutral surfaces. The AAIW is occupying less space in the water column due to an increasing of the salinity in the neutral surfaces at $11^{\circ} \mathrm{S}$, while the opposite happens at $27^{\circ} \mathrm{S}$.

Keywords: South Atlantic, Meridional Overturning Circulation, South Equatorial Current bifurcation, South Atlantic Central Water, Antarctic Intermediate Water 


\section{Introduction}

Changes in the Atlantic Meridional Overturning Circulation (AMOC) have been observed and its weakening is projected for the next century, as suggested by the climate model scenarios compiled for the Fourth Intergovernmental Panel on Climate Change (IPCC) assessment reports (IPCC, 2007; MEEHL et al., 2007).

Few studies have been applied in the South Atlantic, despite its role in AMOC variability. The South Atlantic (SA) connects the North Atlantic to the Indian and Pacific Oceans, exporting about 15 Sv North Atlantic Deep Water. It is through the SA where this southward outflow is compensated by northward inflows of upper and intermediate waters (GARZOLI; MATANO, 2011).

Close to Brazilian shelf, the flow of the North Brazil Undercurrent is responsible for most of the upper-ocean return flow of the MOC (TALLEY, 2003; GANACHAUD, 2003; LUMPKIN; SPEER, 2003). The Intermediate Western Boundary Current is also an important component. Both of these western boundary currents originate from the bifurcation of the South Equatorial Current (SEC) in surface and intermediate depths, respectively (RODRIGUES; ROTHSTEIN; WINBUSH, 2007). Studying the variability of these systems allows one to obtain indices of AMOC variability and changes, as showed by Chang et al. (2008), Rabe, Schott \& Köhl (2008), Zhang et al. (2011).

Not only changes in the western boundary currents in the South Atlantic influence the AMOC variability. The water masses carried by these flows, such as the South Atlantic Central Water and the Antarctica Intermediate Water (AAIW) (WIENDERS; ARHAN; MERCIER, 2000), are modified within the South Atlantic basin with potential impact on the AMOC (WEIJER et al., 2002).

Climate change projections show an intensified hydrological cycle (IPCC, 2007; McCARTHY et al., 2012), and one of the impacts expected is the decrease of AAIW salinity, (McCARTNEY, 1977; TALLEY, 1996; SANTOSO; ENGLAND, 2004; GARABATO et al., 2009).

Shifts in the salinity of the AAIW can drive changes in the stability of the AMOC: Manabe \& Stouffer (1988) noted that when the NADW is weak it can be associated with a shallow AAIW reverse cell inside the Atlantic, where cool fresh intermediate water replenishes the departure of warm saline thermocline water from the Atlantic. Saenko, Weaver \& Gregory (2003), Gregory, Saenko \& Weaver (2003), Sijp \& England (2006) discuss the active role of this reverse cell in the suppression of NADW formation, and thus, interrupting the flow of AMOC.

However, little is known about how the AAIW varies on intradecadal and interannual timescales in the South Atlantic and there appears to be a disagreement between the studies related to its salinity trends (e.g. Arbic \& Owens (2001), Curry, Dickson \& Yashayaev (2003), Aoki, Bindoff \& Church (2005), McCarthy, McDonagh \& King (2011), Schmidtko \& Johnson (2012)). 
This work analyzes the outputs of four different ocean models, attempting to understand the link between the South Atlantic and the AMOC variations looking at both the SEC bifurcation (and the associated western boundary fluxes) and the relevant water masses.

This Chapter is primally concerned with describing the Atlantic Meridional Overturning Circulation along with what is known about its variability and its relationship with the South Atlantic Ocean.

\subsection{Atlantic Meridional Overturning Circulation}

The Atlantic Meridional Overturning Circulation (here after, AMOC) is the large-scale ocean circulation of mass resulting from different forcings. It summarises the system of currents that together comprise a net northward upper ocean transport and southward deep ocean transport (Figure 1). As buoyant upper ocean water flows northward, heat and freshwater are gradually lost to the atmosphere until, on reaching high latitudes, it sinks into the deep ocean and flows southward to complete an overturning cell (GANACHAUD; WUNSCH, 2000; WUNSCH, 2002) (Figure 2).

The AMOC dominates the Atlantic ocean northward transport of heat (VELLINGA; WOOD, 2002; WOOD; VELLINGA; THORPE, 2003) and it is important for local and global climate (KNIGHT et al., 2005; SROKOSZ et al., 2012). For example, at $35^{\circ} \mathrm{N}$ the ocean is estimated to make up more than $20 \%$ of the combined atmosphere-ocean northward heat transport (TRENBERTH; CARON, 2001).

The AMOC is defined as the double integral of the meridional velocity at each latitude, or

$$
\psi_{M O C}(y, z)=\int_{x_{e}, y}^{x_{w}, y} \int_{-H}^{z} v(x, y, z) \cdot \mathrm{d} z \mathrm{~d} x
$$

where $v$ is the meridional velocity at cartesian location $(x, y, z)$. Horizontal and vertical integration limits are respectively from the eastern $\left(x_{e}(y, z)\right)$ and western $\left(x_{w}(y, z)\right)$ boundaries, and from the botton $-H$ to the depth $z$. This is known as depth space overturning.

Figure 2c shows an example of mean AMOC (in Sv; $1 \mathrm{~Sv}=10^{6} \mathrm{~m}^{3} \cdot \mathrm{s}^{-1}$ ), obtained by Sévellec \& Fedorov (2011), in their latitude-depth model of the ocean meridional circulation. Zonally-integrated meridional mass transport, which follows streamlines, is northwards in the upper (low density) ocean, southwards in the deep (dense) ocean and near-vertical at high latitudes. In other words, as described by Sévellec \& Fedorov (2011), the circulation is dominated by a clockwise cell that originates in the Northern Hemisphere, penetrates to about $3000 \mathrm{~m}$, and is more intense near the surface and along the northern boundary of the basin. In the abyssal ocean (below $3000 \mathrm{~m}$ ) a second, counter-clockwise cell is evident. At the location of the circumpolar channel occurs another intense clockwise cell-the Deacon cell (e.g. Speer, Rintoul \& Sloyan (2000)). In low latitudes, there is a signature of the wind-driven shallow subtropical cells in the upper ocean.

Climate models predict a slowing down of the AMOC over the $21^{\text {st }}$ century due to an increase in high latitude buoyancy (IPCC, 2007; MEEHL et al., 2007). The added input of heat and fresh water 


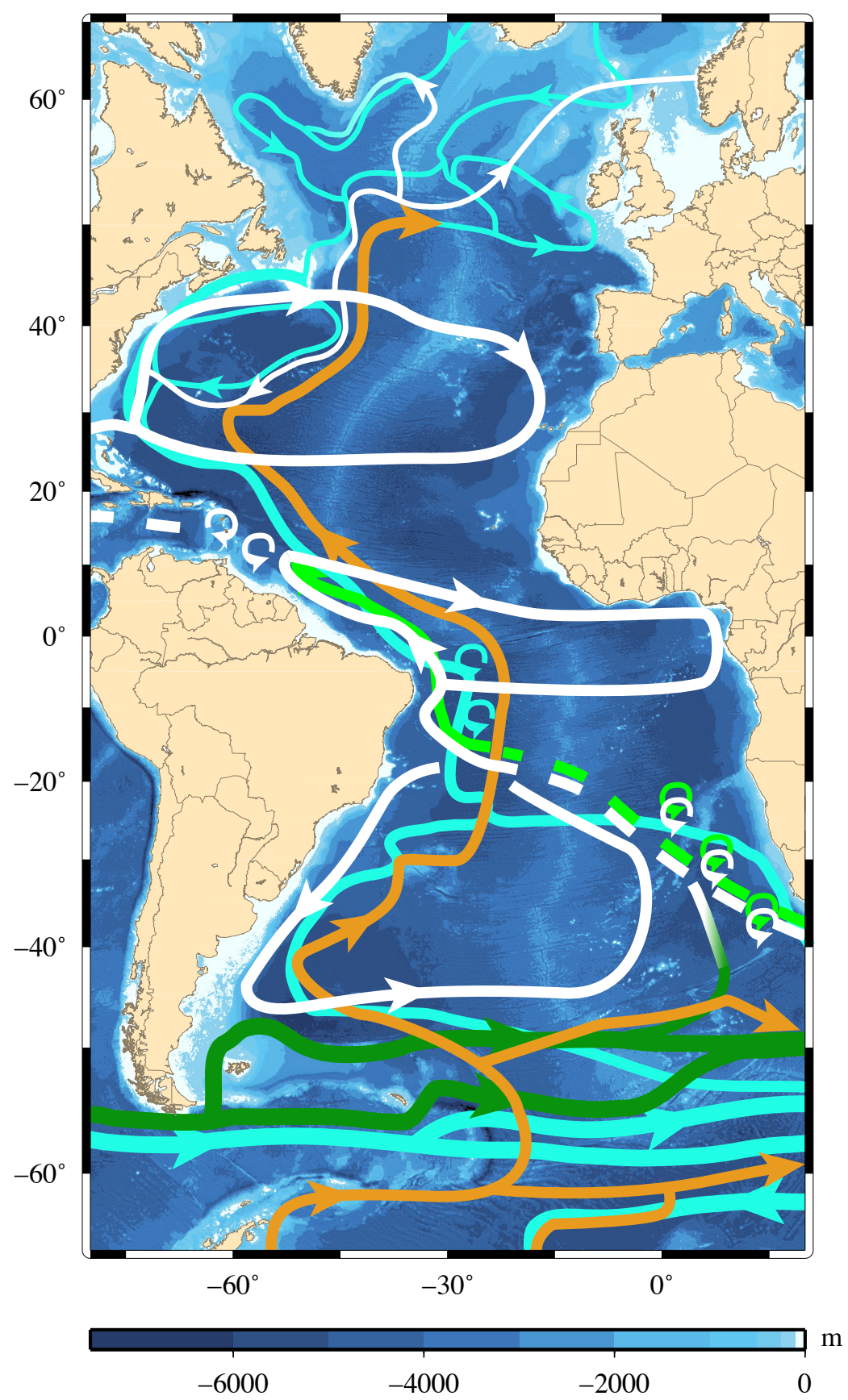

Figure 1: Schematic of the AMOC in the South Atlantic Ocean with white arrows indicating surface flows, orange intermediate flows, green and cyan deep flows. Adapted from Lumpkin \& Speer (2007), Speich, Blanke \& Cai (2007), Garzoli \& Matano (2011).

(due to the melting of land and sea ice and the enhanced hydrological cycle) predicted for a warmer climate is expected to inhibit convective overturning and slow the flux of upper ocean water into the deep ocean. Hansen et al. (2001) reported a $20 \%$ reduction in the overflow of deep waters through the Greenland-Scotland Ridge (that feeds the densest portion of the MOC cell). Bryden, Longworth \& Cunningham (2005) suggest, based on five hydrographic snapshots, that the strength of MOC has decreased by more than $30 \%$ over the last five decades. Sévellec \& Fedorov (2011) found that in their 

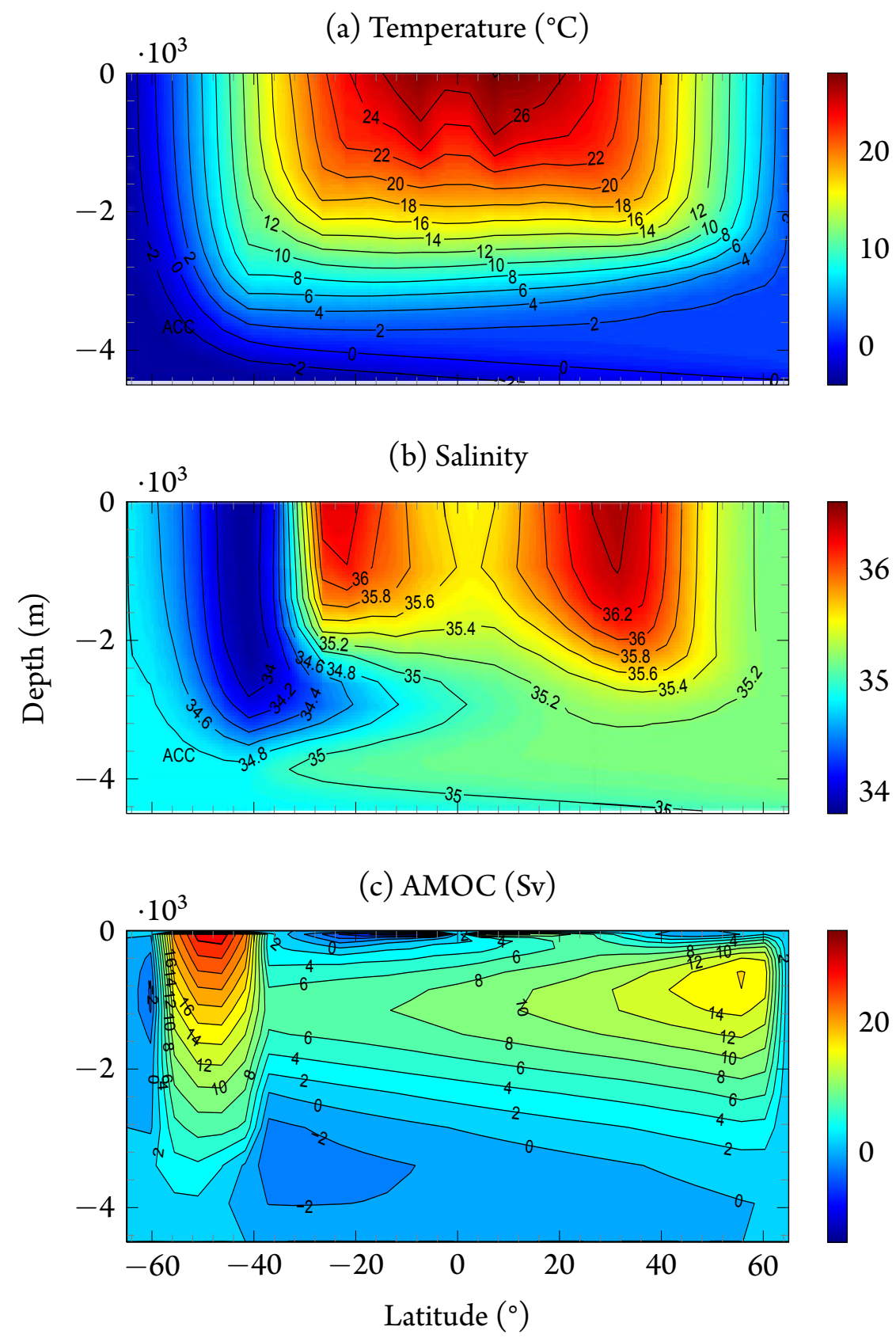

Figure 2: Thermal (a) and salinity (b) fields for the on-state of the AMOC (c) produced by Sévellec \& Fedorov (2011) using a latitude-depth model of ocean meridional circulation.

idealised model, the AMOC reduces $0.7 \mathrm{~Sv}$ for a $10 \mathrm{~cm} \cdot \mathrm{y}^{-1}$ increase in freshwater fluxes. Also, the paleoclimate records suggest that past slowdowns of the MOC triggered ice ages with dramatic decreases of the temperature in the western Europe and beyond (SPEICH; GARZOLI; PIOLA, 2010; GARZOLI; MATANO, 2011).

Those evidences motivated a large number of studies, focusing mainly in the North Atlantic (BIASTOCH et al., 2008). Although the contribution of the South Atlantic (here after SA) to the AMOC was implicit in the early Meteor observations (WÜST, 1935), there is still uncertainties relative to the ab- 
solute magnitude of the SA inter-ocean fluxes (RUIJTER et al., 1999; GARZOLI; BARINGER, 2007). According to Garzoli \& Matano (2011), the SA is not just a passive conduit of the remotely formed water masses: its circulation influences significantly their structure through air-sea interactions, mixing, subduction and advection processes.

How the strength and variability of the AMOC are set by the sum of the various currents and processes is not yet fully understood (LOZIER, 2010; KUHLBRODT et al., 2007). There are indications that the AMOC strength is determined by the strength of convective mixing (BÖNING et al., 2006; LATIF et al., 2006), diapycnal mixing (MUNK; WUNSCH, 1998) and Southern Ocean Ekman induced upwelling (TOGGWEILER; SAMUELS, 1995). Causes of AMOC variability remain poorly understood partly because of the complex spatial distribution and variable nature of the currents and processes involved, and also due to the great gaps in our understanding of the SA variability (GARZOLI; MATANO, 2011).

\subsubsection{AMOC variability}

Despite the shortcomings in the knowledge of AMOC strength and variability, it is known that it fluctuates in several timescales. Recent studies from the RAPID hydrographic observation program (e.g. Cunningham et al. (2007), Kanzow et al. (2007)) have revealed that the AMOC at $26.5^{\circ} \mathrm{N}$ undergoes large variations on weekly to intra-annual timescales. Ocean models suggest that large AMOC variability exists at flow-frequencies up to multi-decadal in period (BAILEY; RHINES; HÄKKINEN, 2005; BINGHAM et al., 2007; HODSON; SUTTON, 2012) (Figure 3b).
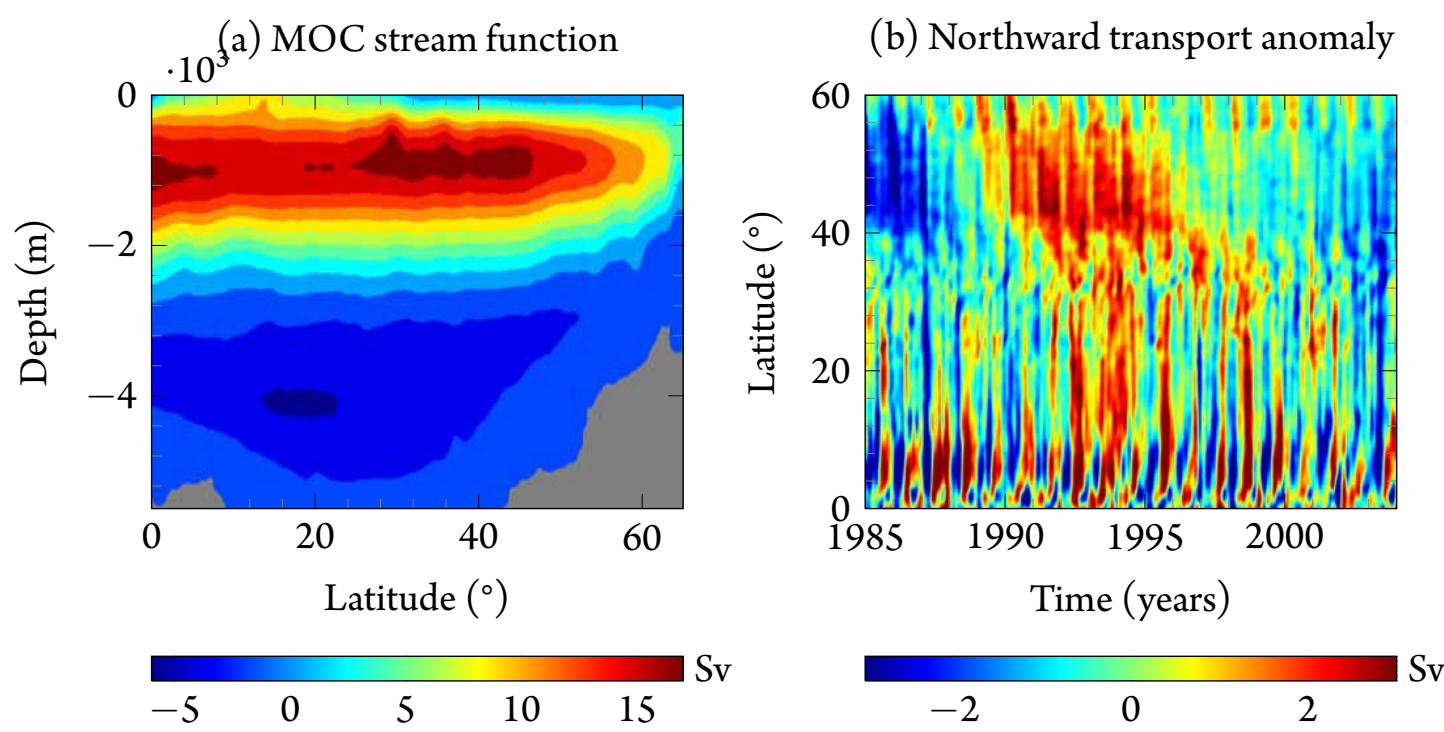

Figure 3: AMOC variability. Time-averaged overturning stream function (a) and northward transport anomaly between $100 \mathrm{~m}$ and $1000 \mathrm{~m}$ depth (b) produced by Bingham et al. (2007) a run of the OCCAM described by Coward \& Cuevas (2005).

According to Biastoch et al. (2008), short timescale variability is largely a response to Ekman trans- 
port and eddy variability. Ekman transport fluctuations modify the ageostrophic meridional transport, which is compensated barotropically at depth (JAYNE; MAROTZKE, 2001). Eddies modify the eastern to western boundary density gradients and therefore the geostrophic currents (THOMMAS, 2012).

Long timescale variability of the AMOC is mostly the result of relatively slow oceanic adjustment mechanisms (HODSON; SUTTON, 2012) that respond to atmospheric forcing. Climate model simulations suggest that these AMOC fluctuations are linked to decadal climate variability, such as NAO, AMO, ENSO, which have important socio-economic impacts including rainfall over Africa, India, North and South America and Atlantic hurricane activity (KNIGHT; FOLLAND; SCAIFE, 2006; ZHANG; DELWORTH, 2006; SMITH et al., 2010). A brief description of the relevant modes of the variability follows:

\subsubsection{Atlantic Multidecadal Oscillation}

The Atlantic Multidecadal Oscillation (AMO) is a near-global scale mode of observed multidecadal climate variability with alternating warm and cool phases over large parts of the Northern Hemisphere (KNIGHT; FOLLAND; SCAIFE, 2006). It is an ongoing series of long-duration changes in the sea surface temperature of the North Atlantic Ocean, with a period of around 65 years (DELWORTH; MANN, 2000; CHIESSI et al., 2009) (Figure 4).

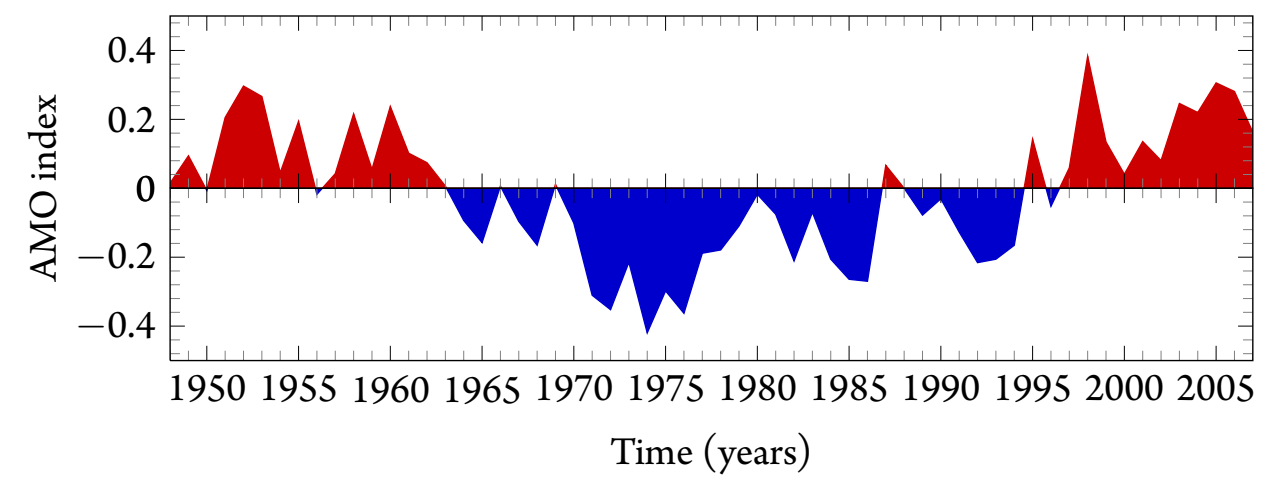

Figure 4: AMO Index from the National Oceanic and Atmospheric Administration (NOAA), between 1948 and 2007.

Many examples of regional multidecadal climate variability in the $20^{\text {th }}$ century have been related to AMO, such as variations in Atlantic sea surface temperatures (SSTs), particularly North East Brazilian (NEB) (FOLLAND et al., 2001) and African Sahel (FOLLAND; PARKER; PALMER, 1986; ROWELL et al., 1995; ROWELL, 2003), rainfall and Atlantic hurricanes (GOLDENBERG et al., 2001).

Also, AMO index is used as a proxy for the strength of the AMOC (ANDRONOVA; SCHLESINGER, 2000; KNIGHT et al., 2005; STOUFFER et al., 2006; CHIESSI et al., 2009; MEDHAUG; FUREVIK, 2011).

While anthropogenic factors appear to have become dominant in the late $20^{\text {th }}$, the ostensibly natural temperature swings of the AMO have alternately disguised and accentuated the secular trend (EN- 
FIELD; MESTAS-NUFIEZ; TRIMBLE, 2001).

\subsubsection{North Atlantic Oscillation}

The North Atlantic Oscillation is a large-scale out of phase relationship between the North Atlantic regions of subtropical high surface pressure (centered near the Azores) and subpolar-low surface pressure (extending south and east of Greenland) (LAMB; PEPPLER, 1987). It is important for setting the strength and position of the westerly winds (HURRELL, 1995).

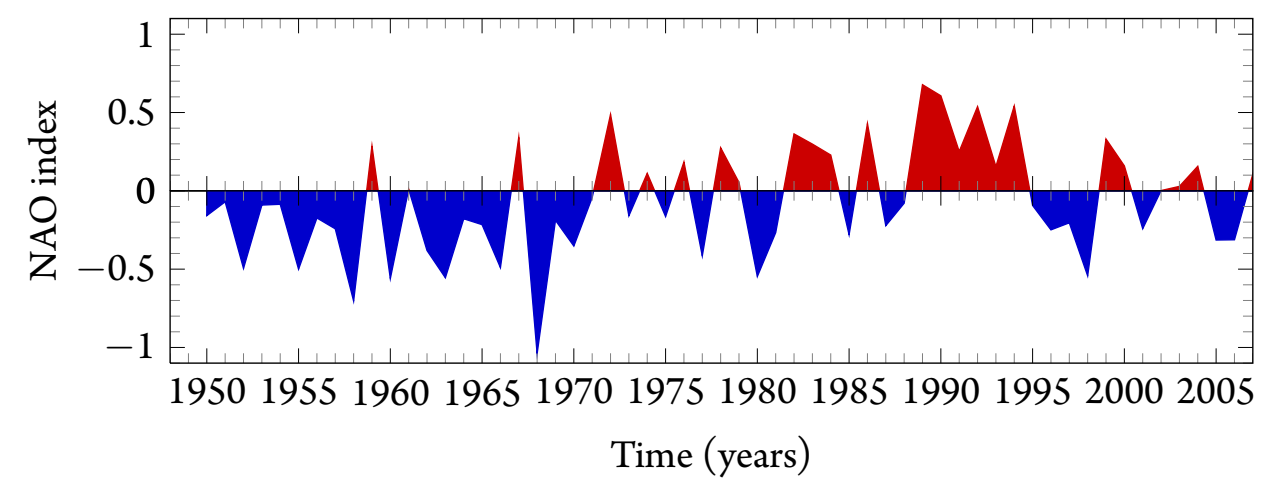

Figure 5: NAO Index from the National Oceanic and Atmospheric Administration (NOAA), between 1948 and 2007.

Eden \& Willebrand (2001) claim that the strength of the MOC is largely determined by the strength of the NAO. They relate the changing strength of the MOC to a deepening and then shoaling of the mixed layer in the Labrador Sea, resulting from the increasing and then decreasing strength of the NAO. Böning et al. (2006), Huang et al. (2012) also suggest that the decadal variability of the subpolar gyre and AMOC near $48^{\circ} \mathrm{N}$ is largely driven by changes in both heat flux and wind stress associated with this index, mainly variations by about 5 years.

Besides, surface temperatures over the Northern Hemisphere $(\mathrm{NH})$ are likely to be warmer now than at any other time over the past millennium. The rate of warming has been specially high in the past 40 years or so. A substantial fraction of this most recent warming is accounted for a remarkable upward trend in the NAO (KERR, 2000; HURRELL; KUSHNIR; VISBECK, 2011) (Figure 5) and can be associated with intensified westerly wind and surface heat flux anomalies (HOERLING; HURRELL; XU, 2001).

\subsection{Area of study}

\subsubsection{The South Atlantic system of currents}

As described above, the South Atlantic (SA) is important for climate system (LEVITUS, 1984) as it transports large amounts of heat due to the presence of the larger meridional branch of thermohaline 
circulation (GORDON; GREENGROVE, 1986). Its large-scale circulation is given by the South Atlantic Subtropical Gyre. At the surface, it consists of Benguela, South Atlantic, South Equatorial and Brazil Currents (STRAMMA; ENGLAND, 1999a). Figure 6 shows schematic pathways of the main SA current system.

As described by Stramma \& Schott (1999), Stramma et al. (2005), Rodrigues, Rothstein \& Winbush (2007), near $14^{\circ}$ S, the SEC reaches Brazil shelf region and bifurcates into the NBUC to the north and the $\mathrm{BC}$, to the south (Figure 6).

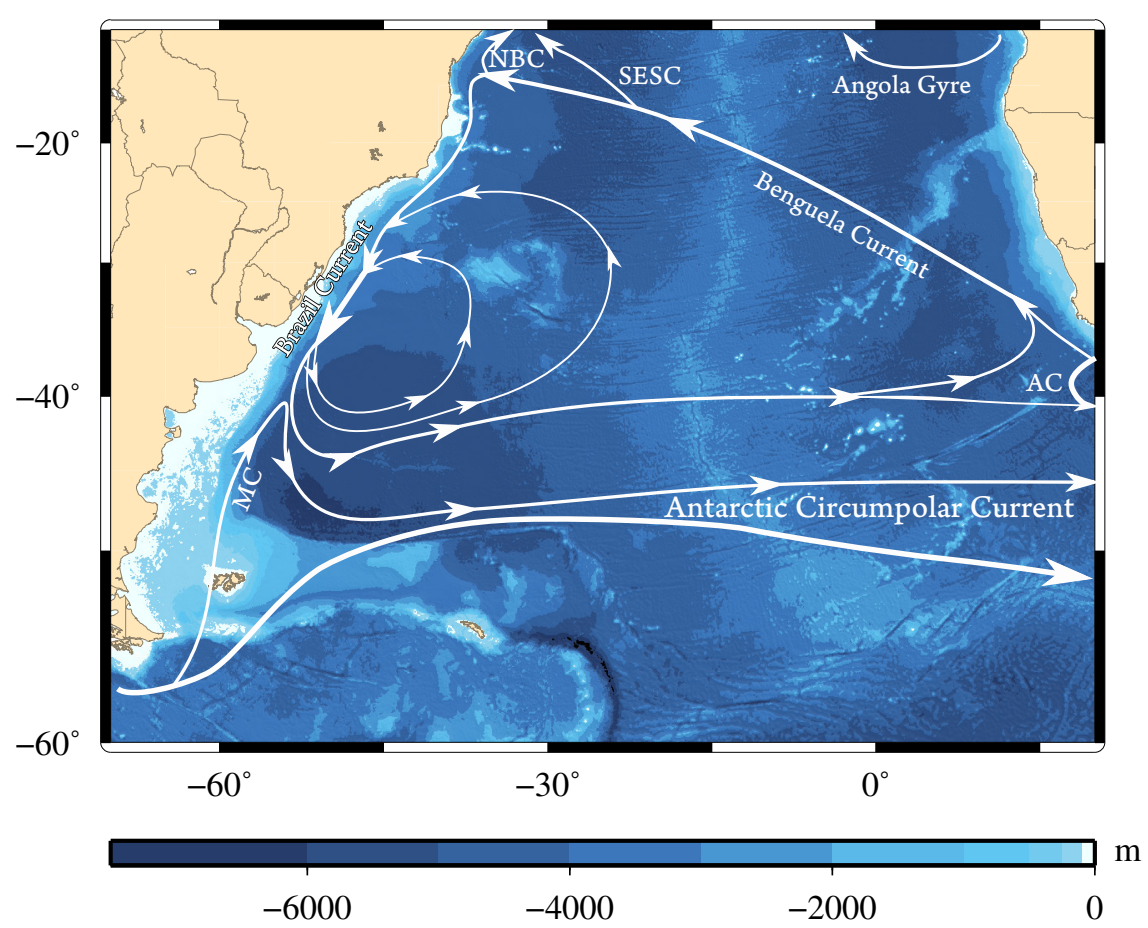

Figure 6: Superficial South Atlantic Circulation diagram, adapted from Stramma \& England (1999a). MC: Malvinas Current; NBC: North Brazil Current; SESC: South branch of South Equatorial Current; AC: Agulhas Current.

The northward limb feeds into the NBUC (STRAMMA; SCHOTT, 1999; SCHOTT et al., 2005) and - as a western boundary current — carries warm waters of South Atlantic origin across the Equator and into the NH. It also supplies the eastward flow of the South Equatorial Countercurrent (SECC) which partially recirculates into the central band of the SEC (cSEC). In addition, in the 50-300m depth range, the NBUC seems to play an important role in the Atlantic Equatorial Gyre (SCHOTT et al., 2005).

At intermediate depths, the Subtropical Gyre differs substantially, as shown in Figure 7. According to Boebel et al. (1999), fresh waters are injected at the intermediate South Atlantic circulation by vigorous eddy motion at the Brazil-Malvinas region (BOEBEL et al., 1999), and subsequently flow eastward carried by the South Atlantic Current (SAC) (PETERSON; STRAMMA, 1990).

At the eastern boundary, there is some input of Pacific intermediate waters (STRAMMA; ENGLAND, 1999a; SCHMID; SIEDLER; ZENK, 2000). Part of this flows to the northwest, next to $30^{\circ} \mathrm{S}$ 


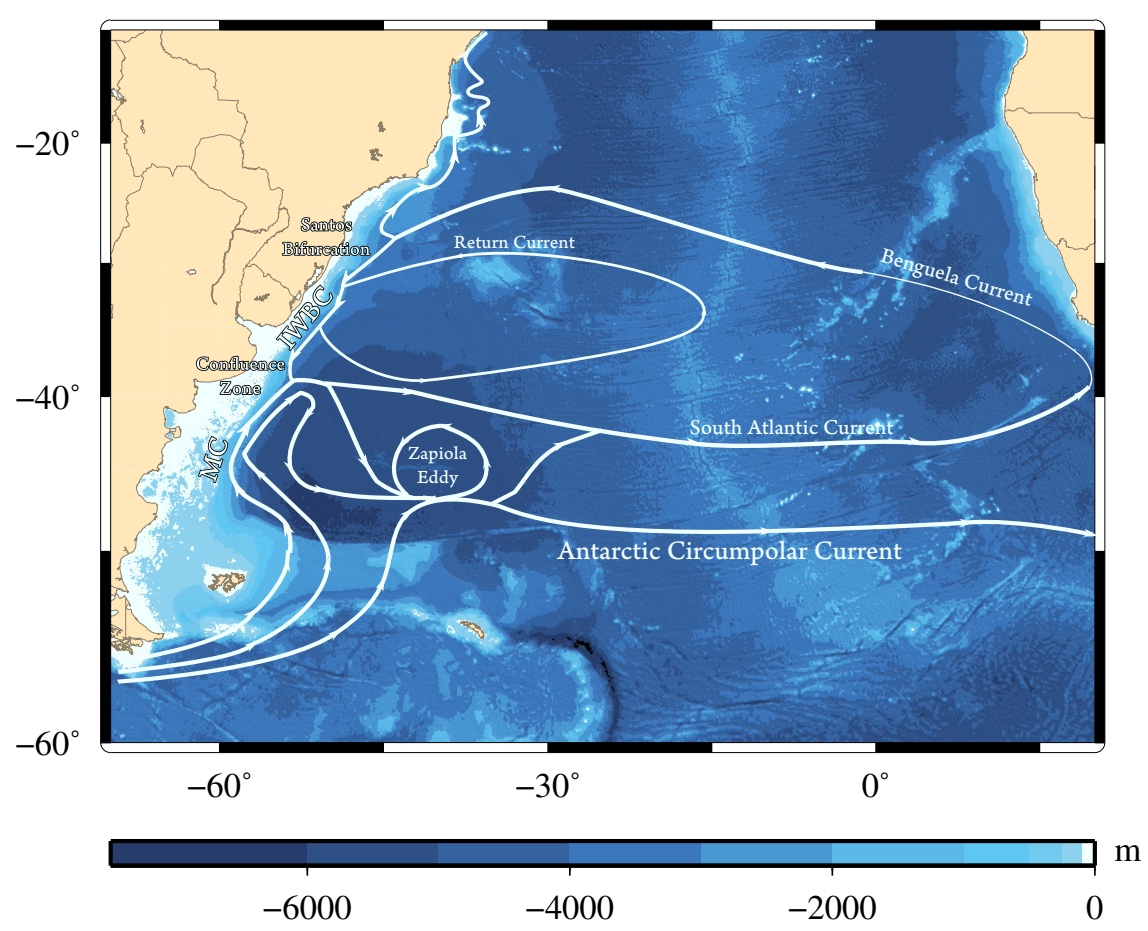

Figure 7: Intermediate depths South Atlantic circulation diagram, adapted from Boebel et al. (1999) and Stramma \& England (1999a). MC: Malvinas Current; IWBC: Intermediate Western Boundary Current.

(BOEBEL et al., 1999). At the Santos Bifurcation, $\sim 28^{\circ} S$, the South Equatorial Current bifurcates into two fluxes: Intermediate Western Boundary Current (IWBC, which flows to north), (SILVEIRA; CALADO; CASTRO, 2004) and another one to south (BOEBEL et al., 1999).

The IWBC, as part of the AMOC, is one of the ways which the Antarctic Intermediate Water (AAIW, better described in Section 1.2.2) enters into the tropical waters regime (SCHMITZ, 1995; BOEBEL et al., 1999; SILVEIRA; CALADO; CASTRO, 2004).

Under the AAIW, about 20Sv of NADW the Deep Western Boundary Current (DWBC) transports North Altlantic Deep Water (NADW) across the Equator to the Southern Hemisphere (SH) (GOURIOU et al., 2001; SCHOTT et al., 2002; DENGLER et al., 2004). The DWBC flows southward close to the east coast of the South America (STRAMMA; ENGLAND, 1999a). Its flow across the Equator is of fundamental interest because it is a major component of the export of cold water from the North Atlantic to the rest of the planet (McCARTNEY, 1993) (Figure 8).

Bellow the NADW, one finds the Antarctic Bottom Water (AABW). Between $35^{\circ} \mathrm{S}$ and $40^{\circ} \mathrm{S}$ it bifurcates, with one branch flowing through the Vema Channel into the Brazil Basin and the other flowing east then south (COLES et al., 1996; STRAMMA; ENGLAND, 1999a) (Figure 8). 


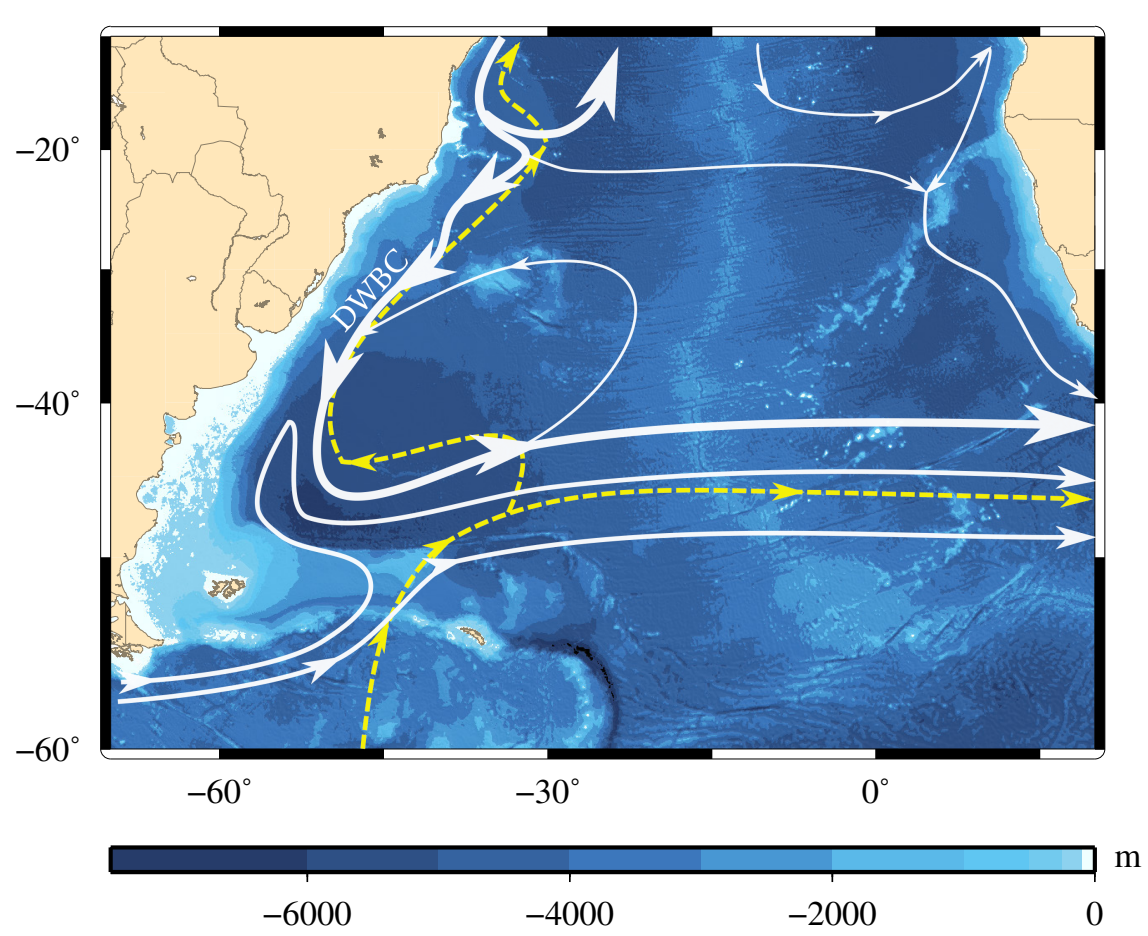

Figure 8: Depp and bottom South Atlantic Ocean circulation diagram, adapted from Stramma \& England (1999a). White lines indicate the NADW preferential flux at 2000m. In yellow, AABW preferential flow, below NADW. DWBC: Deep Western Boundary Current.

\subsubsection{South Equatorial Current bifurcation}

The SEC forms the northern part of the SA Subtropical Gyre, carrying subtropical water from the Benguela Current region toward the Brazil shelf around $14^{\circ} \mathrm{S}$, where it bifurcates. A small part of the water flows northward to form the $\mathrm{BC}$, whereas the bulk of the flow contributes for the NBUC and the SECC (STRAMMA; SCHOTT, 1999; WIENDERS; ARHAN; MERCIER, 2000; STRAMMA et al., 2005; RODRIGUES; ROTHSTEIN; WINBUSH, 2007).

The bifurcation of the SEC close to Brazilian coast can have important implications on climate variability. According to Talley (2003), Ganachaud (2003), Lumpkin \& Speer (2003), the SEC/NBUC system is one of the main routes for upper-ocean return flow of the AMOC. Besides, according to Malanotte-Rizzoli et al. (2000), Zhang, McPhaden \& Johns (2003) it is also related to the subtropicaltropical mass exchange, the Subtropical Cells (STC). Observations (WILSON; JOHNS; MOLINARI, 1994; SCHOTT; STRAMMA; FISCHER, 1995; ZHANG; MCPHADEN; JOHNS, 2003; GOES et al., 2005) and modelling studies (HARPER, 2000; MALANOTTE-RIZZOLI et al., 2000; INUI et al., 2002; LAZAR et al., 2002; HAZELEGER; VRIES; FRIOCOURT, 2003; LAZAR; SOLOMON, 2006) show that in the Atlantic Ocean, most of the water encountered in the equatorial thermocline comes from the South Atlantic through the low-latitude WBC (NBUC/NBC). Moreover, the variability in the bifurcation latitude and in the transport of the currents can impact other remote regions downstream of the NBUC and BC, for instance the NBC rings (JOHNS; ZANTOPP; GONI, 2003) and the 
Brazil-Malvinas Confluence (VIVIER; PROVOST, 1999) regions, respectively.

The Sverdrup theory predicts that the latitude of the SEC bifurcation at the coast of South America should be $14^{\circ} \mathrm{S}$, which coincides with the northern edge of the South Atlantic Subtropical Gyre. In fact, there is a southward deepening of the SEC bifurcation along the shoreline (Figure 9). Previous observational studies suggest that the SEC bifurcation occurs at $14^{\circ}-16^{\circ} \mathrm{S}$ in the surface layer $(100 \mathrm{~m})$, at $20^{\circ}-24^{\circ} \mathrm{S}$ in the thermocline $(400-500 \mathrm{~m})$, and at $26^{\circ}-28^{\circ} \mathrm{S}$ in the intermediate layer $(600$ 1200m) (STRAMMA; ENGLAND, 1999a; BOEBEL et al., 1999; WIENDERS; ARHAN; MERCIER, 2000; RODRIGUES; ROTHSTEIN; WINBUSH, 2007). From numerical model results, the bifurcation point in the near-surface layer at the western boundary of the South Atlantic occurs at $18^{\circ} \mathrm{S}$ in the simulations by Harper (2000) and at $17^{\circ} \mathrm{S}$ in those by Malanotte-Rizzoli et al. (2000). Silva et al. (2009), using a regional model found that the bifurcation occurs between $13^{\circ} \mathrm{S}-24^{\circ} \mathrm{S}$ in the first $500 \mathrm{~m}$.

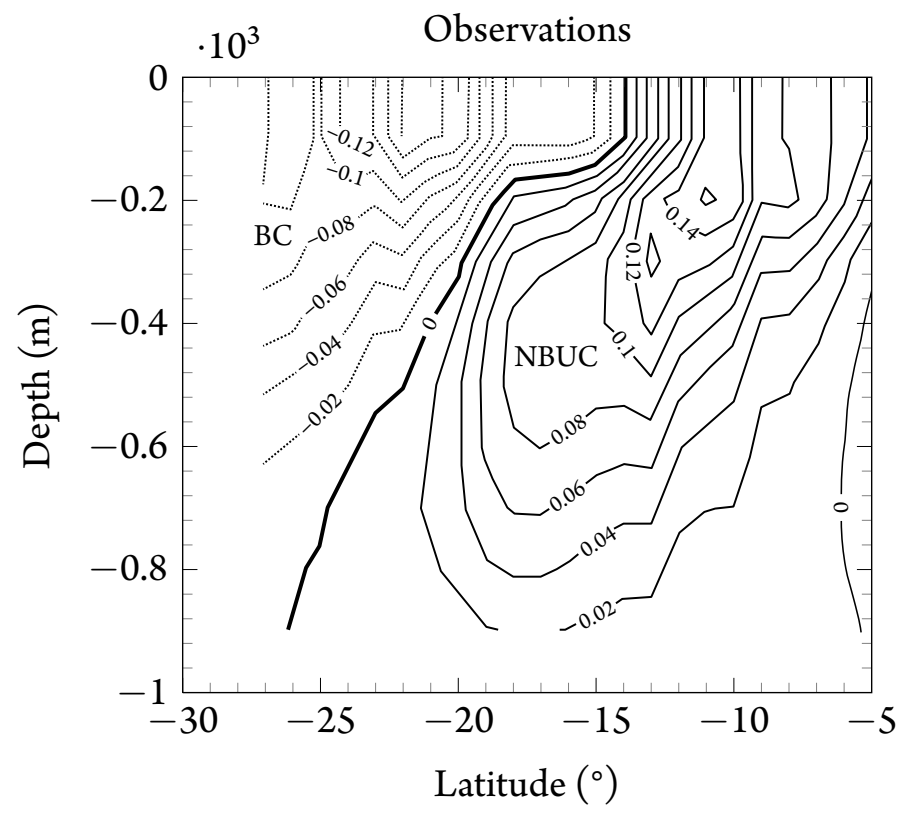

Figure 9: Annual mean geostrophic meridional velocity observed by Rodrigues, Rothstein \& Winbush (2007). The velocities $\left(\mathrm{m} \cdot \mathrm{s}^{-1}\right)$ were averaged within a $2^{\circ}$ longitude band off the South American coast. Positive (negative) values indicate northward (southward) flow associated with the NBUC (BC), and the contour of zero velocity represents the bifurcation of the SEC.

\subsection{South Equatorial Current bifurcation variability}

Besides its poleward depth increase along the Brazilian coastline, there is a change of the SEC bifurcation position over time. Earlier studies were focused only in seasonal time scales. Rodrigues, Rothstein \& Winbush (2007), Silva et al. (2009) describe that, in the near-surface layer, the bifurcation has its northernmost (southernmost) position during the austral winter (summer). At intermediate depths, though, a semi-annual variability is observed (Figure 10). 


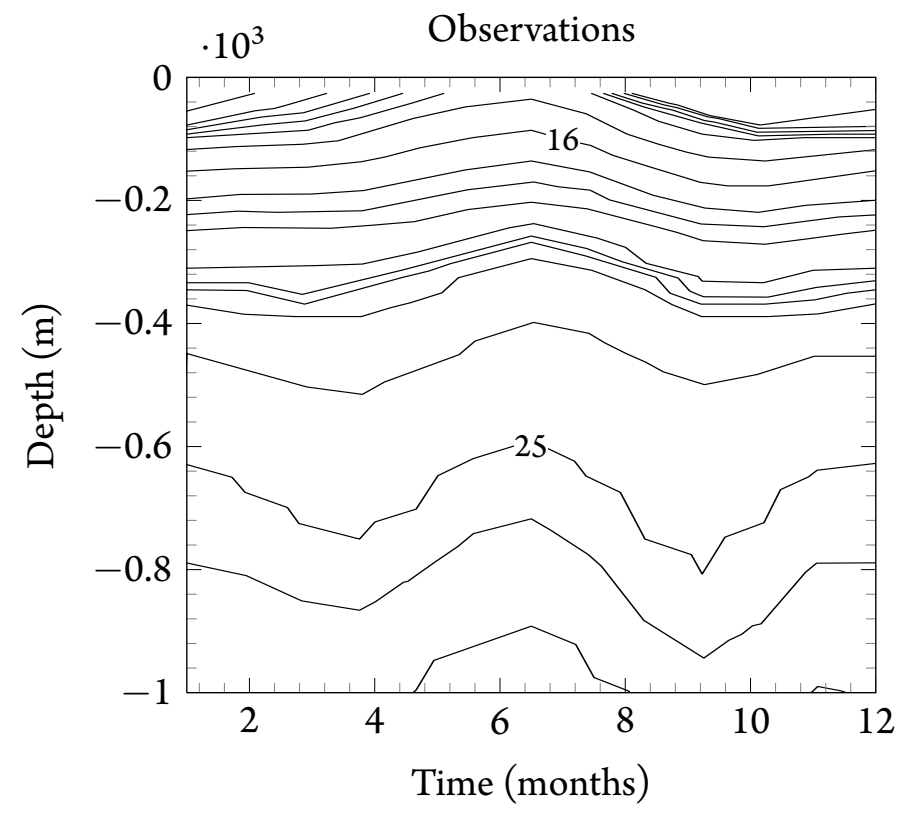

Figure 10: Time-depth plot of the SEC bifurcation latitude ( $\left.{ }^{\circ} S\right)$, from Rodrigues, Rothstein \& Winbush (2007) determined by the location of zero meridional velocity averaged over a $2^{\circ}$ longitude band off the South American coast for each month of the year (observations). Contours at every $1^{\circ}$.

According to Rodrigues, Rothstein \& Winbush (2007), changes in the bifurcation position are linked to the variability of the wind, specially due to the seasonal meridional movement of the Atlantic ITCZ complex. As a consequence, the bifurcation region is exposed to negative wind stress curl and associated weaker Ekman pumping from February to August and to positive wind stress curl and stronger Ekman suction from September to January. Also, local positive (negative) wind stress curl produces an anomalous anticyclonic (cyclonic) circulation, which southward (northward) component near the western boundary causes the SEC bifurcation to occur at lower (higher) latitude during the austral spring/summer (winter) months.

\subsection{South Equatorial Current bifurcation and boundary currents}

Seasonal changes in the SEC bifurcation leads to shifts in the boundary currents transports (RODRIGUES; ROTHSTEIN; WINBUSH, 2007). As the SEC bifurcates in its southernmost (northernmost) position in winter (summer) time, the NBUC transport increases (decreases, Figure 11) and the BC transport decreases (increases) (SCHOTT et al., 2005; RODRIGUES; ROTHSTEIN; WINBUSH, 2007; SILVA et al., 2009).

This seasonal cycle of the NBUC transport is very sensitive to latitude: at $10^{\circ} \mathrm{S}$ the maximum transport is achieved during the austral fall/winter months (April-July), whereas at $6^{\circ} \mathrm{S}$ the maximum transport happens during summer. The difference between the NBUC transports along $6^{\circ} \mathrm{S}$ and $10^{\circ} \mathrm{S}$ reaches its minimum of 3Sv in June-July when the SEC weakens and the SEC bifurcation is in its southern- 

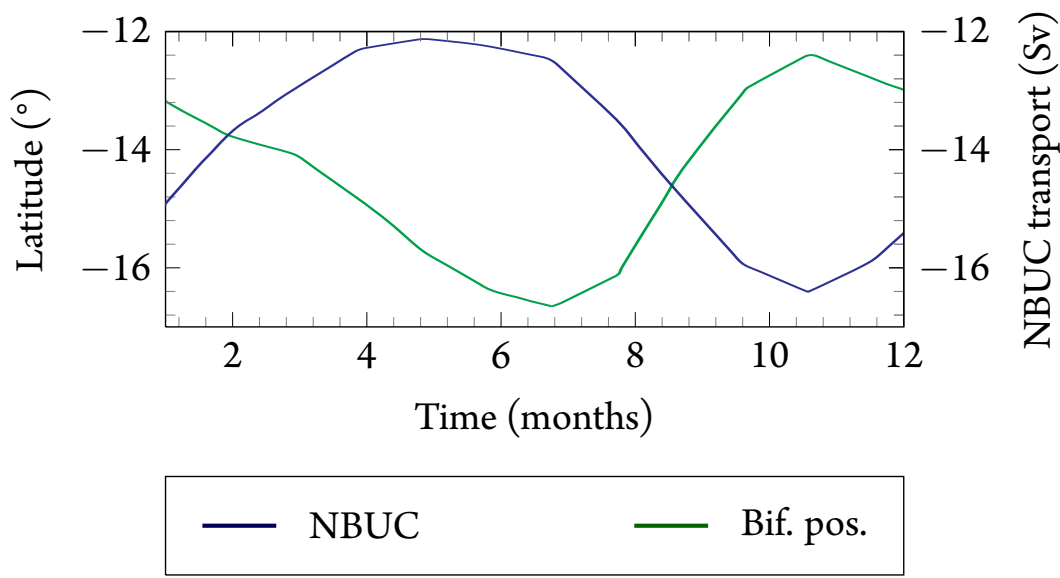

Figure 11: Seasonal variability of the latitude position, averaged in the top $200 \mathrm{~m}$ (Figure 9) versus the NBUC transport at $10^{\circ} \mathrm{S}$. Adapted from Rodrigues, Rothstein \& Winbush (2007).

most position. Conversely, this transport difference reaches its maximum of $8 \mathrm{~Sv}$ in October-November when the cSEC intensifies and the SEC bifurcation is in its northernmost position (RODRIGUES; ROTHSTEIN; WINBUSH, 2007).

\subsubsection{The North Brazil Undercurrent}

The North Brazil Undercurrent is a robust boundary current flowing along the Brazilian continental slope (SILVEIRA; MIRANDA; BROWN, 1994). This subsurface flow, proposed by Schott \& Böning (1991), was first described (as NBUC) by Stramma, Fischer \& Reppin (1995) using velocity data. It is a strong western boundary current, with a nearshore core position, approximately $50 \mathrm{~km}$ from Brazilian coast, reaching down about $900 \mathrm{~m}$ in depth, with maximum speed of about $0.65 \mathrm{~m} \cdot \mathrm{s}^{-1}$ at 180 to $250 \mathrm{~m}$ on average (SCHOTT et al., 2005; VELEDA et al., 2012).

As mentioned before, the NBUC originates south of $10^{\circ} \mathrm{S}$ from the SEC bifurcation (e.g. Stramma \& England (1999a), Boebel et al. (1999), Harper (2000), Wienders, Arhan \& Mercier (2000), Schott et al. (2005), Rodrigues, Rothstein \& Winbush (2007), Silva et al. (2009), Veleda et al. (2012)) and the bifurcation position has a direct effect in this current seasonal variability. Previous studies, using mooring data at $11^{\circ} \mathrm{S}$ show that the NBUC core has a dominant fluctuation with a periodicity of two months (SCHOTT et al., 2005; SCHUCKMANN, 2006).

Longer timescale variability of the NBUC was already described in the literature. Zhang et al. (2011), using historical data, observed a multidecadal change in this current transport, indicating a weakening in the 1970s and 1980s compared to the high transports in the early 1960s and 1990s. Despite of the limited data coverage, these results indicates a link between the NBUC variability and the Labrador Sea Water thickness. These authors also show that the time series of the NBUC is significantly correlated with the AMO index, at zero lag, suggesting a direct connection with the AMOC. 


\subsubsection{The Intermediate Western Boundary Current}

The Intermediate Western Boundary current originates at $\sim 28^{\circ} S$ where the SEC bifurcates at intermediate layers (BOEBEL et al., 1999; SILVEIRA; CALADO; CASTRO, 2004). Part flows southward and contributes to the $\mathrm{BC}$ flux, part flows northward, contributing to the AMOC return flow (SCHMITZ, 1995; McCARTHY et al., 2012).

This boundary current is well defined along relatively smooth isobaths from $27^{\circ} \mathrm{S}$ to the VictoriaTrindade Rigde at $20^{\circ} 30^{\prime} S$ (LEGEAIS; OLLITRAULT; ARHAN, 2013), usually with velocities greater than $0.3 \mathrm{~m} \cdot \mathrm{s}^{-1}$ (SILVEIRA; CALADO; CASTRO, 2004). Sharp variations of the continental slope orientation cause a partial water scape from the boundary at $20^{\circ} \mathrm{S}$, resulting in a weaker IWBC on average, and strong offshore mesoscale activity. The current is well defined between $15^{\circ} \mathrm{S}$ and $5^{\circ} \mathrm{S}$ (LEGEAIS; OLLITRAULT; ARHAN, 2013).

Besides its important role, there is still much to be uncovered about the IBWC.

\subsubsection{The South Atlantic water masses structure}

The water masses structure of the SAO, as shown in Figure 12, is composed by Tropical Water TW, the South Atlantic Central Water (SACW), Antarctic Intermediate Water, North Atlantic Deep Water (NADW) and the Antarctic Bottom Water (AABW).

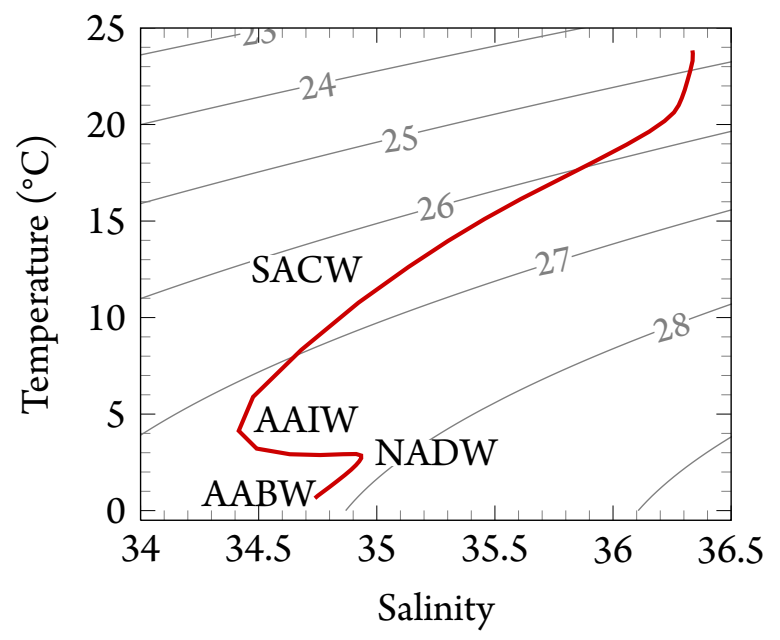

Figure 12: T-S diagram, representing the most important South Atlantic water masses. Original data from Simple Ocean Data Assimilation System, version 2.2.4 (SODA, Carton \& Giese (2008)) at $25^{\circ} \mathrm{S}$ and $25^{\circ} \mathrm{W}$.

The SACW is a water mass with substantially uniform properties (STRAMMA; ENGLAND, 1999a), with temperatures between $5^{\circ} \mathrm{C}$ and $20^{\circ} \mathrm{C}$, and salinity varying from 34.3 to 36 (TOMCZAK; GODFREY, 1994) (Figure 13). 


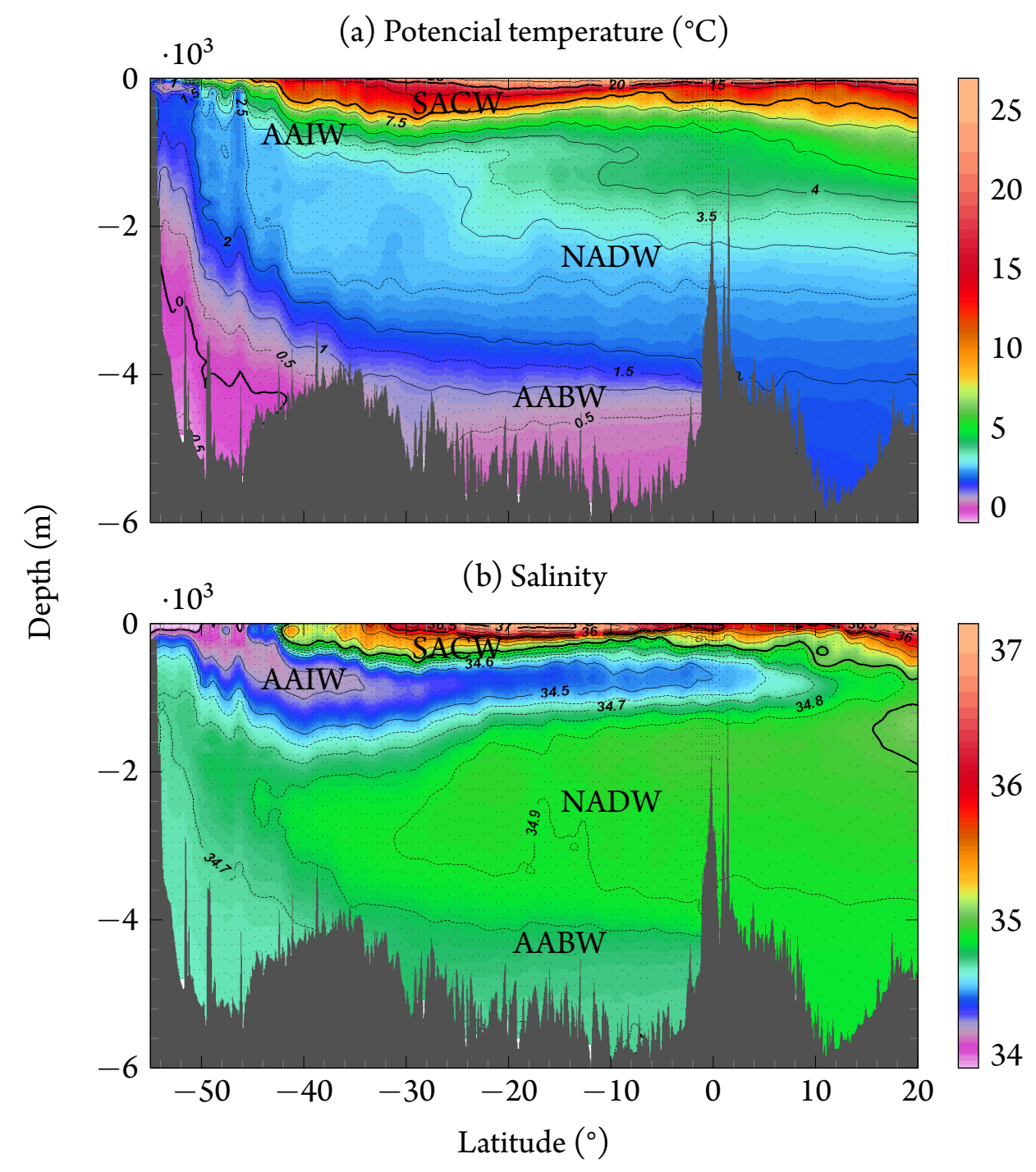

Figure 13: WOCE potential temperature (a) and salinity (b) sections at $25^{\circ} \mathrm{W}$ (section A16). Adapted from Schlitzer (2000).

The $27.1 \mathrm{~kg} \cdot \mathrm{m}^{-3}$ and (in the tropics) and $27.05 \mathrm{~kg} \cdot \mathrm{m}^{-3}$ (in the subtropics) isopycnals mark the transition between the SACW and the AAIW (STRAMMA; ENGLAND, 1999a). According to Silveira, Calado \& Castro (2004), close to the Brazilian coast, this interface occurs between 500-750m.

The AAIW is found mainly between $500-1500 \mathrm{~m}$ and marked by the vertical salinity minimum (Figures 12 and 13) and densities close to $27.3 \mathrm{~kg} \cdot \mathrm{m}^{-3}$ (PICKARD; EMERY; TALLEY, 2007).

First described by Wüst (1935), the AAIW flows northward (MÜLLER et al., 1998; CIRANO et al., 2006), mainly via IWBC (as described in Section 1.2.1) and can be observed all the way to $20^{\circ} \mathrm{N}$ (TALLEY; SPRINTALL, 2005). Along the way, its salinity slowly increases (Figure 14) and its concentration of oxygen decreases (STRAMMA; ENGLAND, 1999a; SCHMID; SIEDLER; ZENK, 2000).

Below the AAIW, the Upper Circumpolar Deep Water (UCDW) takes place. In the tropics, according to Stramma \& England (1999b), at about 1000m depth, it is the deepest water mass of the upper 

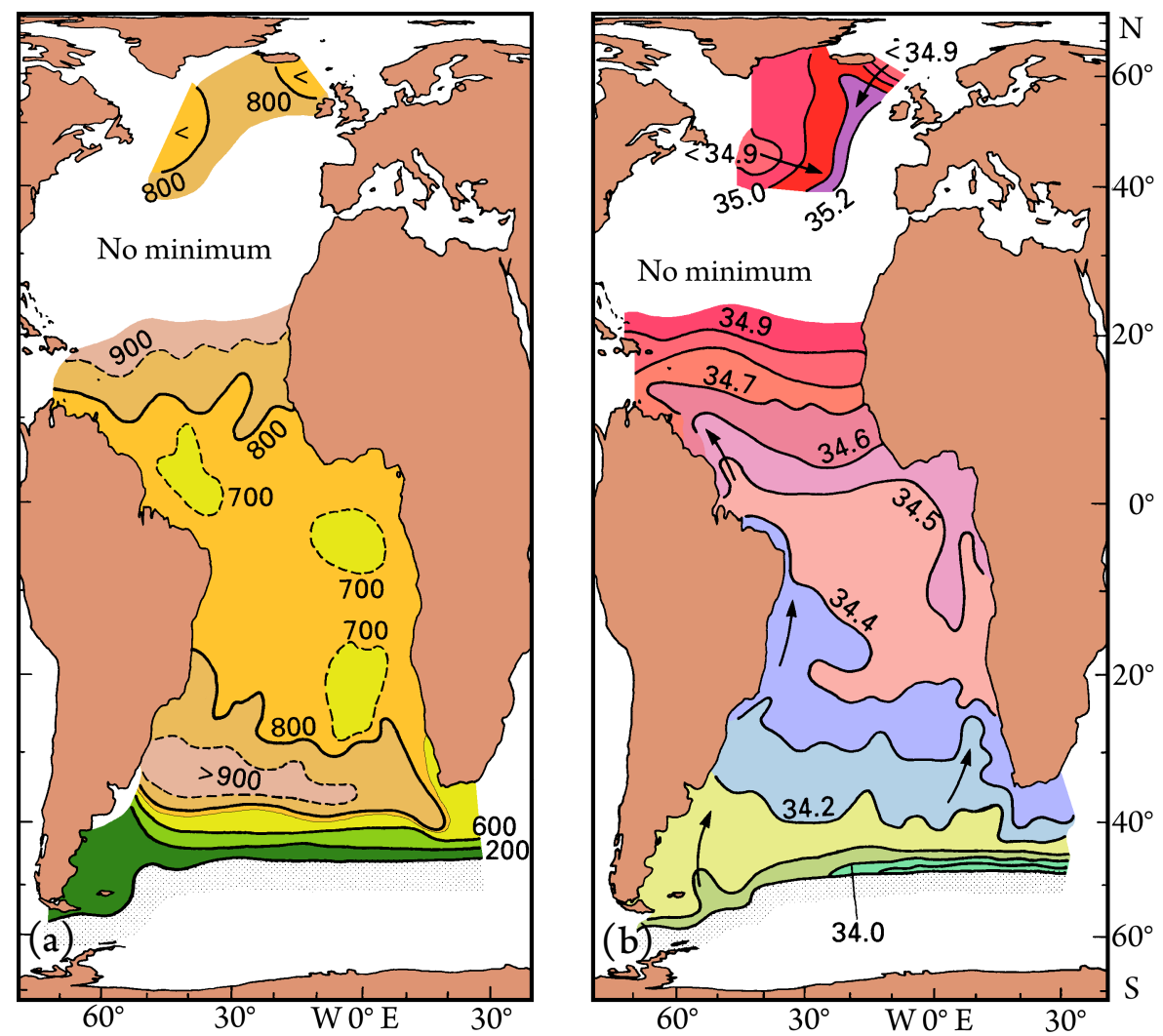

Figure 14: Maps of the salinity minimum produced by the intermediate waters, mainly AAIW. Depth of the minimum (a), salinity at the depth of the minimum (b). Adapted from Tomczak \& Godfrey (2003).

ocean with a net northward transport. According to Santoso, England \& Hirst (2005), it contributes further to a lighter AAIW.

The NADW is identified by the subsurface salinity maximum (Figures 12 and 13) at depths of $\sim 2000 \mathrm{~m}$. Its thickness decreases along the way and its flux is strongly influenced by topography (STRAMMA; ENGLAND, 1999a). Thus the NADW flow occurs mainly by the western boundary of the basin until $\sim 45^{\circ} S$ (PETERSON; WHITWORTH-III, 1989), where the Antarctic Circumpolar Current (ACC) makes it flows eastward (STRAMMA; ENGLAND, 1999a). The NADW then mixes with the Circumpolar Deep Water (CDW), changing its temperature and salinity characteristics (PROVOST et al., 1995).

Finally, bellow 3500m there is the AABW (HOGG; OWENS, 1999) (Figure 13). With temperatures between $-0.4^{\circ} \mathrm{C}$ and $0.2^{\circ} \mathrm{C}$ and uniform salinity (between 34.66 and 34.68) (COLES et al., 1996), this water mass is formed in the Southern Ocean, specially at the Weddell Sea (CARMACK; FOSTER, 1975). Its northward flux, through the Atlantic Ocean western boundary (Figure 8), is also highly influenced by the bathymetry (STRAMMA; ENGLAND, 1999a).

These water masses (AABW and NADW) are very important for the ocean ventilation (MEREDITH et al., 2000), as they are part of thermohaline circulation (CARMACK; FOSTER, 1975; FAHRBACH et al., 1995; KERR, 2006). 


\subsubsection{South Atlantic Central Water}

The South Atlantic Central Water is found south of about $15^{\circ} \mathrm{N}$, and shows rather uniform properties throughout its range (STRAMMA; ENGLAND, 1999a). According to McCartney (1982) and Donners, Drijfhout \& Hazeleger (2005), the SACW is a combination of light South Atlantic Central Water (ISACW), South Atlantic Subtropical Mode Water (SASTMW), and Subantarctic Mode Water (SAMW). Their density layers are shown in Table 1.

Table 1: Density layers of water masses that contribute to SACW formation, from Donners, Drijfhout \& Hazeleger (2005).

\begin{tabular}{cc}
\hline & $\begin{array}{c}\text { Density layer } \\
\left(\mathrm{kg} \cdot \mathrm{m}^{-3}\right)\end{array}$ \\
\hline ISACW & $25.5-26.2$ \\
SASTMW & $26.2-26.6$ \\
SAMW & $26.6-27.0$ \\
\hline
\end{tabular}

The SAMW is formed at the Brazil-Malvinas Confluence (GORDON, 1981). It exhibits a basinwide influence at mid-pycnocline, detectable at low latitudes. In the South Atlantic, the SAMW is weaker in strength compared to other basins and its influence is laterally restricted to only the western sector of the subtropical gyre (McCARTNEY, 1982). It is responsible for a high-salinity variety of SACW (STRAMMA; ENGLAND, 1999a).

The SASTMW consists of a light variety of subtropical mode waters (PROVOST et al., 1999), formed mainly in the Brazil Current overshoot, and $13^{\circ} \mathrm{C}$ mode water, presumably formed by mixing in Agulhas rings (TOMCZAK; GODFREY, 1994). Then it is transported by the SAC (STRAMMA; PETERSON, 1990) to the eastern boundary where it is mixed to the Indian Central Waters brought by the Agulhas Current (STRAMMA; ENGLAND, 1999a), which forms part of the ISACW (TOMCZAK; GODFREY, 1994). So, the Benguela Current and the SAC carry it to the Brazilian shelf, via SEC, where it is finally transported by the BC. Also, the SACW is carried towards the equator with the NBUC and the NBC (STRAMMA; SCHOTT, 1999).

Previous studies related to the SACW were concerned mainly with its formation processes and properties, and information about its variability and changes is scarce. Durack \& Wijffels (2010), using observations, showed that, the salinity on the $26.75 \mathrm{~kg} \cdot \mathrm{m}^{-3}$ isopycnal, decreased 0.2 between 1950 and 2008 close to the Brazilian coast. Results of Arbic \& Owens (2001) show a warming of the water column in the depth of the SACW.

\subsubsection{Antarctic Intermediate Water}

The Antarctic Intermediate Water is a very prominent water mass that lies above the deep water and spreads below the subtropical thermocline in the $\mathrm{SH}$, marked by the vertical salinity minimum (e.g. Talley (1996)). According to McCartney (1977) it is formed primarily in the southeast Pacific Ocean 
just equatorward of the ACC. Pickard, Emery \& Talley (2007) also suggested it is formed north of the Subantarctic Front, near the Drake Passage. Its properties are consequence of three different physical processes: convection, subduction (TOMCZAK, 1999) and subsurface mixing (SØRENSEN; RIBBE; SHAFFER, 2001).

Due to its importance for the global climate, there have been many investigations, both regional and global, into intermediate-depth potential temperature and salinity changes on isobars and isopycnals in the southern oceans (BINDOFF; CHURCH, 1992; JOHNSON; ORSI, 1997; WONG; BINDOFF; CHURCH, 2001; AOKI; BINDOFF; CHURCH, 2005; BÖNING et al., 2008; GOES et al., 2008; DURACK; WIJFFELS, 2010; HELM; BINDOFF; CHURCH, 2010; SCHMIDTKO; JOHNSON, 2012). These studies uniformly find a warming trend.

Freshening of AAIW has been observed in the Pacific (WONG; BINDOFF; CHURCH, ) and the Indian Oceans (BINDOFF; MCDOUGALL, 2000; BRYDEN; MCDONAGH; KING, 2003; MCDONAGH; KING, 2005). However, in the South Atlantic the situation is not as clear. Curry, Dickson \& Yashayaev (2003) found that AAIW salinity had decreased on isopycnals from the 1950s-1960s to the 1980s-1990s. Arbic \& Owens (2001), McCarthy, McDonagh \& King (2011) noted an increase in AAIW salinity at $24^{\circ} \mathrm{S}$ from 1958 to 1983 . These differences have been linked to changes in the hydrological cycle and in the circulation.

As mentioned by McCarthy et al. (2012), little is known about how AAIW varies on intradecadal and interannual timescales, and theses changes in AAIW salinity are still under discussion. Also, according to the authors, higher frequency variability could well be the cause for disagreement between studies.

\subsubsection{The South Atlantic and the Meridional Overturning Circulation}

The SAO is an important part of AMOC. Its mean meridional circulation structure involves a deep southward flow of cold and salty North Atlantic Deep Water (NADW) along the eastern coast of South America. This water mass is cooled primarily by evaporation before it sinks to the deep ocean (GORDON, 1986). This southward flux is compensated by the net northward flow through the SA and across the equator of surface, intermediate and bottom water layers (BROECKER, 1991; SCHMITZ, 1995; SPEICH et al., 2002; GARZOLI; MATANO, 2011).

The SAO is the only basin extending to high latitudes in which the heat transport is equatorward (GARZOLI; MATANO, 2011). Although this distinct heat flux was recognized by the middle of the last century (MODEL, 1950), the sources for the upper waters are still under discussion. A portion is produced locally (STRAMMA; ENGLAND, 1999a), but most of them are thought to originate in the Pacific and Indian Oceans (GORDON; GREENGROVE, 1986; RINTOUL, 1991; GORDON et al., 1992; STRAMMA; ENGLAND, 1999a; SCHMID; SIEDLER; ZENK, 2000; GARZOLI et al., 2013). In this sense, the SA provides the gateway by which the AMOC connects with the rest of the globe.

The South Atlantic Subtropical Gyre also plays an important role in the AMOC return flow, through 


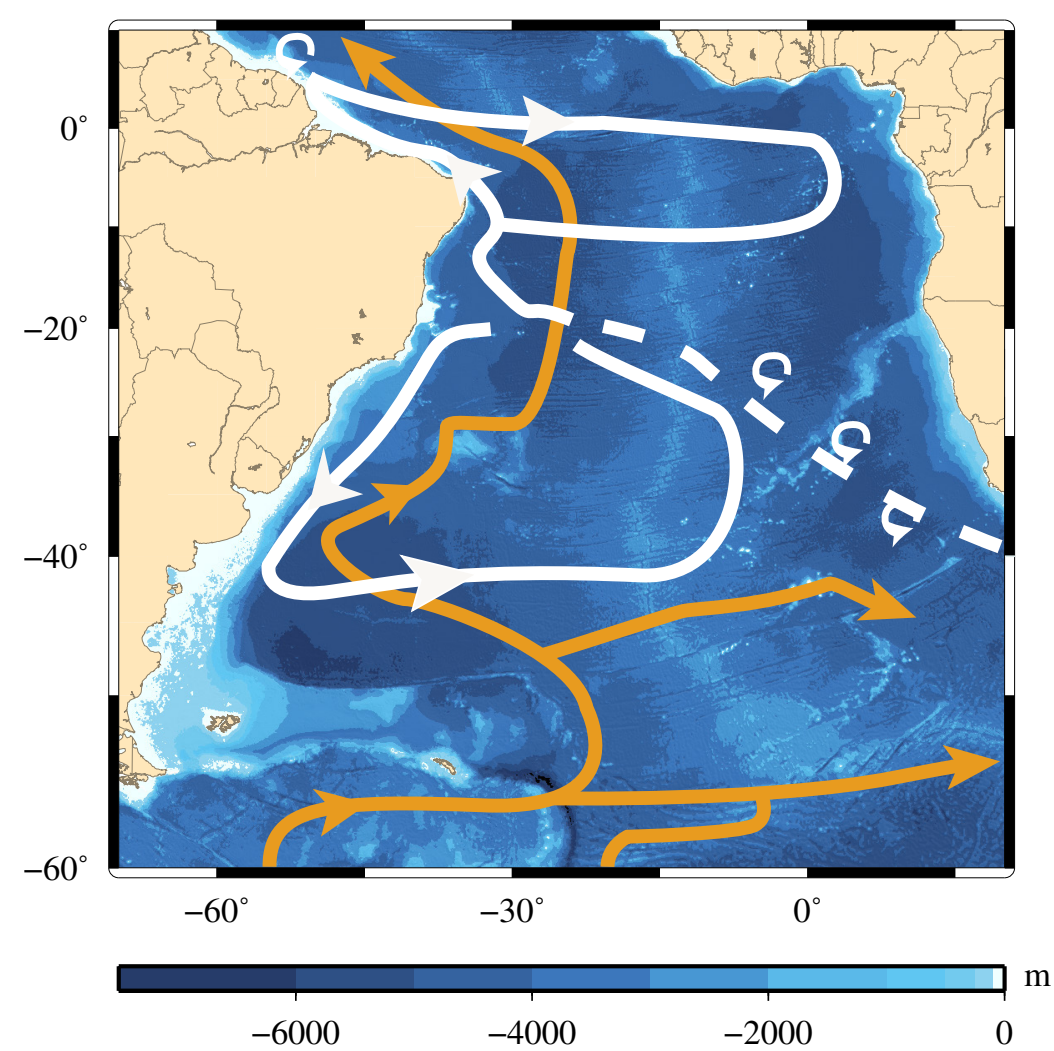

Figure 15: Schematic of the AMOC in the South Atlantic Ocean with white arrowns indicating surface flows, linked to NBUC and orange ones the intermediate flows, linked to IWBC. Adapted from Lumpkin \& Speer (2007), Speich, Blanke \& Cai (2007), Garzoli \& Matano (2011).

the western boundary currents, such as North Brazil Undercurrent (NBUC) and the Intermediate Western Boundary Current (IWBC) (SCHMITZ, 1995; BOEBEL et al., 1999; TALLEY, 2003; GANACHAUD, 2003; LUMPKIN; SPEER, 2003; SILVEIRA; CALADO; CASTRO, 2004) (Figure 15). Vellinga \& Wu (2004) showed, using a coupled General Circulation Model that the NBC is stronger during decades of stronger AMOC composites than during weaker composites. Rabe, Schott \& Köhl (2008), comparing the AMOC at $10^{\circ} \mathrm{S}$ with the NBUC in the 50 year ECCO data assimilation system, observed that in their model, at time scales longer than 4 years, the NBUC variability explains $63 \%$ of AMOC variance (Figure 16). Chang et al. (2008), in an idealised North Atlantic "water hosing” coupled model experiment, showed that a dramatic change of NBUC transport is concurrent with a significant weakening of the AMOC, both following a significantly reduced deep water formation at high latitudes. Zhang et al. (2011), in a modelling study, reveal that, in periods longer than 10 years, the correlation between the NBUC and AMOC transport variability is $80 \%$ at zero lag.

Paleoclimate studies also show a strong relationship between the SAO and the AMOC. Model simulation of deglacial events suggests that during a meltwater event a weakened thermohaline overturning causes a reduced northward advection of warm, saline surface water, which consequently leads to a warming of the upper layers in the tropical ocean (MANABE; STOUFFER, 1997). Correspondingly, 


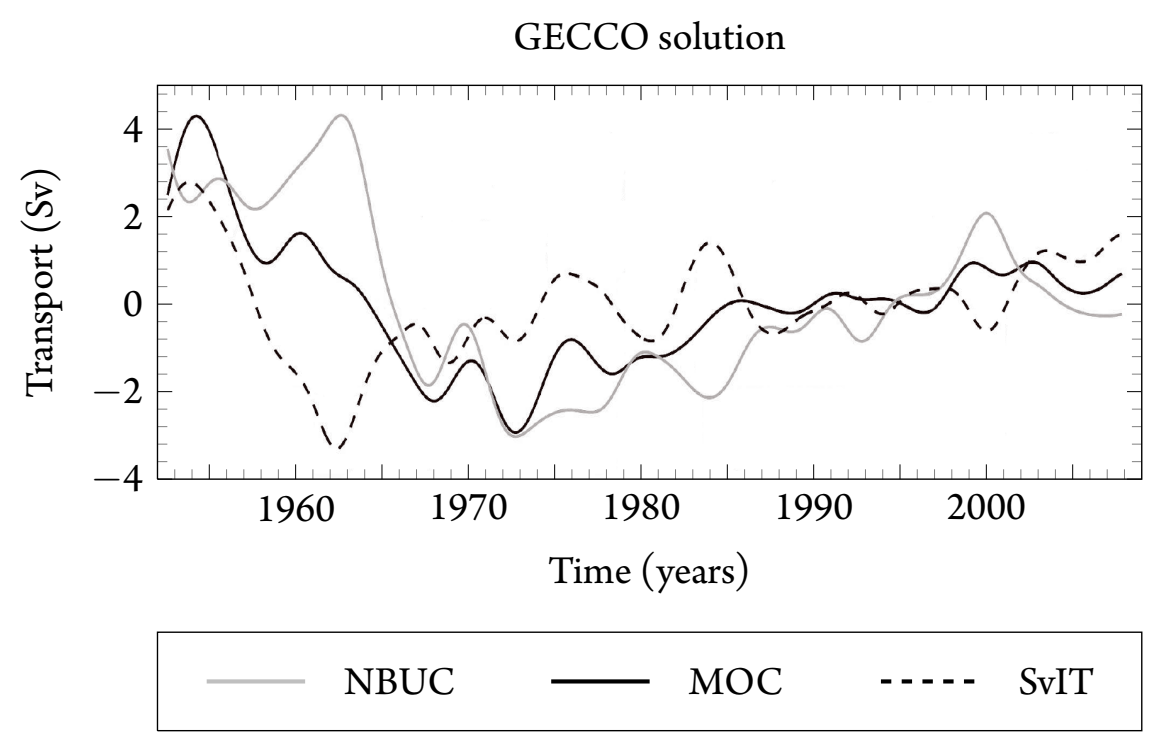

Figure 16: MOC (solid black), NBUC (gray), and Sverdrup interior (SvTI, dashed) transport anomalies at $10^{\circ} \mathrm{S}$. Time series with variabilities longer than 4 years. Adapted from Rabe, Schott \& Köhl (2008).

during an intensification of the MOC, net heat loss and cooling of the Southern Hemisphere is observed, which is related to a stronger compensatory cross-equatorial northward heat transport (CROWLEY, 1992). Direct oceanographic studies and also coupled GCM results (ARZ; PÄTZOLD; WEFER, 1999) demonstrate the significance of the western South Atlantic boundary currents, such as North Brazil Current (NBC), NBUC and Brazil Current (BC) within this connection.

Also in a paleoclimate study, Chiessi et al. (2009) proposes that this relationship between WBC and AMOC could lead changes in the South American summer monsoon (SASM) and South Atlantic Convergence Zone (SACZ). With a weakening of the AMOC and the NBUC during negative AMO phases, and the consequent increase of the South Atlantic sea surface temperatures (ARZ; PÄTZOLD; WEFER, 1999), there is an enhancement in the SACZ activity and rainfall over the southeastern South America.

Moreover, another mechanism that might link AMO and SASM/SACZ involves the position of the Intertropical Convergence Zone (ITCZ) in the equatorial Atlantic. Modelling results of Zhang \& Delworth (2005) show that during periods of weak AMOC, the ITCZ is shifted to the south causing a positive anomaly in moisture transport into the Amazon basin. According to the authors, the equatorial anomalies would enhance convection in the Amazon, causing an intensification of the northwesterly South American low-level jet that transports the Amazon moisture and forms the SACZ (MARENGO et al., 2004) which would increase the precipitation in the southeastern South America.

Changes in the salinity or temperature of the water masses in the SA also have implications in the AMOC variability. Manabe \& Stouffer (1988) observed that the stability of the AMOC is linked to a shallower or deeper AAIW reverse cell. Vries \& Weber (2005) show, with modelling studies, that it is mainly a result of a salt feedback in the ocean. which determines whether the thermohaline circulation 
is monostable or bistable (DRIJFHOUT; WEBER; SWALUW, 2011; GARZOLI et al., 2013).

\subsection{Ocean General Circulation Models}

An Ocean General Circulation Model (OGCM) is a mathematical representation of the large-scale circulation of a planetary ocean, that responds according to the physical laws of conservation of mass, momentum, energy, and other properties and in which the fluxes from the atmosphere are imposed.

They enable us to study the ocean globally, providing uniform data resolution in space and time, and for this reason they are very useful when observations are scarce, often not synoptic and collected using a range of methodologies. Moreover, climate runs of OGCMs are excellent tools to study the ocean response to the increasing greenhouse gas concentrations, such as those described in the IPCC Fourth Assessment Report (IPCC, 2007). Running an OGCM under prescribed forcing scenarios can indicate which processes and regions are likely to be more affected, providing a starting place for the design of observational programs or mitigation policies.

In dealing with an under-sampled natural fluid system, it is extremely helpful to invoke the simulation capability of supercomputers to improve understanding of basic processes and their interconnectedness, as well as to help interpret sparse observations (SEMTNER, 1995).

One of the first significant modelling effort extended over the decade of the 1960s at the Geophysical Fluid Dynamics Laboratory (GFDL) (BRYAN, 1969). Bryan built an ocean model that was to be used with atmospheric models to study climate. The first application with specified global geometry was done in the early 1970s (COX, 1975). Cox designed a $2^{\circ}$ latitude-longitude grid with up to 12 vertical levels at each point. The model was run for hundreds of hours on the fastest available computer but had only reached a few simulated years after many months. By the mid-1980s, progress had been made in simulating more aspects of real-world ocean circulation, much of it resulting from increases in computing power (SEMTNER, 1995). Nowadays, an increasing model fidelity to real world processes is being achieved with enhanced temporal and spatial resolutions. Even having observed such progress, high resolution, eddy resolving OGCMs are still limited to computer power.

Such models depend on parameterisations of many unresolved ocean processes (GRIFFIES, 2004). Despite this, as shown by Delworth \& Mann (2000), state of the art climate models are able to reproduce magnitudes and patterns of decadal variability seen in observations. However, as pointed out by Thommas (2012), it is important to be aware of some of their shortcomings:

- Eddies affect the AMOC by modifying the east-west density gradient in the ocean (BIASTOCH et al., 2008), the pathways of currents (GARY et al., 2011) and recirculations Lozier (2010). In this sense, according to (MARSH et al., 2009), models with resolved eddies have been shown to better represent the time-mean and variable structure of the AMOC; 
- According to Biastoch et al. (2008), high latitude processes associated with deep water formation require submesoscale resolution. In consequence, low-resolution models can have a too-shallow overturning (SAUNDERS et al., 2008);

- Deep ocean circulation is too weak in almost all ocean models because of the long model spin-up time required for the deep ocean to reach equilibrium (WUNSCH, 2011).

\subsection{Motivation}

The South Atlantic Ocean plays a unique role in the global energy balance, transporting, as part of the AMOC, heat from the poles to the equator (e.g., Talley (2003)) as upper layer water spreads northward to compensate for the southward export of colder NADW (BROECKER, 1991; SCHMITZ, 1995; SPEICH et al., 2002; GARZOLI; MATANO, 2011; GARZOLI et al., 2013). This northward flux is a complex mixture of waters originating from the Indian and Pacific oceans (GORDON; GREENGROVE, 1986; RINTOUL, 1991; GORDON et al., 1992; STRAMMA; ENGLAND, 1999a; SCHMID; SIEDLER; ZENK, 2000), blended together in the South Atlantic and overlain by large-scale gyre circulations.

The mechanisms and pathways of mass and heat transport in the global ocean are due in large part to the wind-driven and buoyancy-driven components of the MOC. Associated with the strong thermohaline (buoyancy driven) circulation in the Atlantic Ocean, heat and salt are exchanged between the hemispheres (GARZOLI et al., 2013). Vries \& Weber (2005) showed from modelling studies that the instability of the AMOC results from salt feedback in the ocean. According to the authors, when we intensify the hydrological cycle, the AMOC transports fresher waters. Also, the AMOC weakens, as more salt flows out of the Atlantic via the Brazil Current and less salt flows equatorward inhibiting the NADW production. Besides, "excess" salt flowing out via the Brazil Current recirculates awhile in the Subtropical Gyre thereby increasing the local salinity, causing the feedback.

Wind-driven variations of the AMOC are associated, in the South Atlantic, for example, with changes in the transport of the NBUC/NBC. In a modelling study, Vellinga \& Wu (2004) observed that the $\mathrm{NBC}$ is stronger during decades of stronger AMOC composites than during weaker composites. Chang et al. (2008), in an idealised North Atlantic "water hosing" coupled model experiment, showed that a dramatic change of NBC transport is concurrent with a significant weakening of the AMOC, both following a significantly reduced deep water formation at high latitudes. Also using a coupled model, Zhang et al. (2011), showed that the correlation between the NBC and the AMOC transport variability (with periods bigger than 10 years) reaches its maximum value of 0.8 at zero lag.

These and other studies suggest that both changes in the Western Boundary Currents (WBC) and in the water masses that they carry affect the AMOC variability. In a future climate scenario in which a weakening of the AMOC is predict for the $21^{\text {st }}$ century, it is necessary to better understand the associated physical process that impacts on the AMOC variability. 


\subsection{Scientific hypothesis}

The variability and the changes in the bifurcation of the South Equatorial Current (SEC), in surface or intermediate depths, are still not well described in literature, specially in longer timescales.

Since it originates the NBUC in surface and the IWBC at intermediate depths, that are part of the upper branch of the thermohaline circulation in the South Atlantic, it is indispensable to understand properly the mechanisms that drive its (seasonal, interannual and multidecadal) variability.

Therefore, the hypothesis is that, by observing and analyzing the SEC bifurcation, it is possible to get an index of AMOC variability and changes. Since the bifurcation is under different regimes in the surface and intermediate depths with distinct impacts in its variability, at least in seasonal timescales (RODRIGUES; ROTHSTEIN; WINBUSH, 2007), both the NBUC and the IWBC systems should contribute to understand the AMOC variances, particularly in timescales longer than a year.

Another hypothesis is that, in a future climate scenario of global warming, changes in the hydrological cycle would drive modifications in the salinity of the water masses that are part of the AMOC, and thus, contribute to its variability.

\subsection{Objectives}

Based on the hypotheses described above, the main goal of this work is to access the variability of the South Equatorial Bifurcation, in interannual and longer timescales, and verify if it can be used as evidence or index of Atlantic Meridional Overturning Cell changes and variability.

Also, this work aims to verify, in interannual and longer timescales, changes in the water masses related to the upper branch of the AMOC: SACW and AAIW.

More specifically, this project aims to:

- analyze models results, compared to the reanalysis, checking:

- the position of the bifurcation, and their changes over the time;

- changes in the main currents (transports);

- correlate them with wind stress and other climate indices, such as North Atlantic Oscillation.

- the core of these water masses, isolating it using the OMP analysis;

- changes in the salinity and temperature projected onto the main neutral surfaces;

- correlate them with changes in the core of the water masses.

\subsection{Master thesis outline}

In this master thesis, many models simulations are used to investigate changes in the AMOC variability. Chapter 2 describes the model outputs and the analysis used in this investigation. Chapter 3 
brings the results, split in two main sections: in Section 3.1, changes in the WBC are investigated by looking to the interannual variability of the South Equatorial Current Bifurcation (SEC); Section 3.2 addresses changes in the properties of the water masses carried by these currents. Chapter 4 concludes the thesis. 


\section{Data and methods}

To address the variability of South Equatorial Current bifurcation in the South Atlantic Ocean, the results of four different general ocean models are analyzed. These are described in Section 2.1. Then, Section 2.2 presents the methods.

\section{$2.1 \quad$ Data}

\subsubsection{Simple Ocean Data Assimilation}

The Simple Ocean Data Assimilation, version 2.2.4 (SODA) is a reanalysis of ocean climate variability. It begins with a state forecast produced by an ocean general circulation model based on Parallel Ocean Program numerics (POP) (SMITH; DUKOWICZ; MALONE, 1992) with the average $0.25^{\circ} \times 0.4^{\circ}$ horizontal resolution and 40 vertical levels with $10 \mathrm{~m}$ spacing near the surface. This ocean model is forced by 20Crv2 winds (COMPO et al., 2011) and is continuously corrected by contemporaneous observations, with corrections estimated every 10 days. The observation set includes the historical archive of hydrographic profiles supplemented by ship intake measurements, moored hydrographic observations, and remotely sensed SST and sea level. See Carton et al. (2000a), Carton et al. (2000b), Carton \& Giese (2006) and Carton \& Giese (2008) for more details.

This dataset contains monthly global information such as temperature, salinity, wind stress, sea surface height. The output is monthly and mapped onto a uniform $0.5^{\circ} \times 0.5^{\circ} \times 40$-level grid. The time series is from 1871 to 2008 . In this work only data between 1948 and 2007 are used.

\subsubsection{The ocean component of Community Climate System Model}

The Community Climate System Model (CCSM), version 4.0, is a global model developed by the National Center for Atmospheric Research (NCAR). As it is a complex coupled model (more details in Vertenstein et al. (2010)), the results analyzed in this work are a result of a simulation in which the ocean component was coupled to a dynamic and hydrodynamic sea-ice model ${ }^{1}$ (CLIVAR, 2010), forced by CORE (Section 2.1.4) dataset.

The ocean component, POP, solves the primitive equations in general orthogonal coordinates in the horizontal with hydrostatic and Boussinesq approximations. For further details, see Danabasoglu et al. (2012).

1 CICE - The Los Alamos sea ice model - http://oceans11.lanl.gov/trac/CICE 
This run was initialised from resting state, with temperature and salinity data of Levitus set, atmospheric data from CORE-II and river discharges based on estimates of Dai \& Trenberth (2002), (CLIVAR, 2010). The spin-up time was 500 years (KERR; WAINER; MATA, 2009). More details are available in Collins et al. (2006).

This dataset has monthly data with $1^{\circ}$ of spacial resolution and 60 vertical levels, from 1948 to 2007 .

\subsubsection{Nucleus for European Modelling of the Ocean}

The Nucleus for European Modelling of the Ocean (NEMO) is a primitive equation model adapted to regional and global ocean circulation problems (MADEC, 2008). In DRAKKAR runs, the ocean componet OPA (Ocean Parallélisé) (DELECLUSE; IMBARD; LEVY, 1998) is coupled to a multilayer sea-ice model LIM (Louvain-la-Neuve Sea Ice Model) (FICHEFET; MAQUEDA, 1999; VANCOPPENOLLE et al., 2009), using the quasi-isotropic global ORCA grid (for a better description, see Bernard et al. (2006)).

\subsubsection{ORCA05}

One of the DRAKKAR ${ }^{2}$ products is the ORCA05 dataset. It is a global ocean model coupled to a sea-ice model with a nominal grid resolution of $0.5^{\circ} \times 0.5^{\circ}$ that reasonably resolves western boundary current structures and captures the different processes of deep-water formation due to the thermohaline and wind forcing, but that does not resolve mesoscale processes. In the vertical 46 levels (with 10 levels in the upper $100 \mathrm{~m}$ and $250 \mathrm{~m}$ resolution at depth) are used, whereby the bottom cells are allowed to be partially filled (BIASTOCH et al., 2008; BIASTOCH; BÖNING; LUTJEHARMS, 2008).

This run was inicialised using temperature and salinity climatological fields, and it was integrated from 1948 to 2007. The forcings, as described in Brodeau et al. (2010), are a combination of ERA-40 reanalysis, satellite and CORE (LARGE; YEAGER, 2009) data.

\subsubsection{ORCA12}

ORCA12 is a high-resolution simulation produced by DRAKKAR. It is similar to ORCA05, but it has $1^{\circ} / 12$ of horizontal resolution (between $50^{\circ} \mathrm{S}$ and $50^{\circ} \mathrm{N}$ ) and 46 vertical levels. The first baroclinic Rossby deformation radius is larger than $20 \mathrm{~km}$ in this latitude band (CHELTON et al., 1998), hence this simulation can be considered as fully eddy-resolving (DESHAYES et al., 2012).

The simulation starts in 1989 and ends in 2007 . The output data were monthly averaged. The simulation starts from another simulation (C-HR), and is forced by ERA-Interim (DESHAYES et al., 2012) with corrections of the large-scale shortwave flux bias toward GEWEX observations (DEE et al., 2011) and with corrections of precipitations toward GPCP data (BOLVIN; GU, 2009). This first simulation

2 Drakkar: Multi-scale Ocean modelling project - http://wwz.ifremer.fr/lpo/La-recherche/Projets-encours/DRAKKAR-Ocean 
(C-HR) starts from rest and climatological temperature and salinity and is forced by CORE-II data (Section 2.1.4). More details are available in Deshayes et al. (2012).

\subsubsection{Coordinated Ocean-ice Reference Experiments}

The Coordinated Ocean-ice Reference Experiments (CORE), version 2, developed by the World Climate Research Program (WCRP) as part of the Climate Variability and Predictability (CLIVAR) project, is a dataset created to be used in ice models as forcing.

This set contains global sea-air fluxes related to the variability of interannual ocean models, such as momentum, heat and fresh water fluxes, from 1948 to 2007. More information can be found in Large \& Yeager (2009).

\subsubsection{Climate timeseries}

$\mathrm{AMO}^{3}$ and $\mathrm{NAO}^{4}$ timeseries were obtained from the National Oceanic and Atmospheric Administration website (NOAA).

The AMO timeseries were calculated from the Kaplan SST dataset, that interpolates back in time using EOF projection, optimal interpolation, Kalman filter, forecast, KF analysis, and an optimal smoother (KAPLAN et al., 1998; ENFIELD; MESTAS-NUFIEZ; TRIMBLE, 2001).

The NAO timeseries used here are historical data, since 1950. Indices are standardised by the 19812010 climatology. The procedure used to calculate NAO indices is based on the Rotated Principal Component Analysis (RPCA) used by Barnston \& Livezey (1987). The RPCA technique is applied to monthly standardised $500 \mathrm{mb}$ height anomalies in the analysis region $20^{\circ} \mathrm{N}-90^{\circ} \mathrm{N}$ between January 1950 and December 2000.

\subsection{Methods}

Current speed and wind stress data are analyzed to access the variability of the South Equatorial Current (SEC) Bifurcation in the South Atlantic Ocean.

Three main sections were chosen: $11^{\circ} \mathrm{S}, 27^{\circ} \mathrm{S}$ and $25^{\circ} \mathrm{W}$. As described in Section 1.2, close to $11^{\circ} \mathrm{S}$, the SEC bifurcates at the surface resulting in the North Brazil Undercurrent (NBUC, flowing northward) and the Brazil Current (BC, flowing southward). At the Brazilian continental slope, in intermediate depths, near $27^{\circ} \mathrm{S}$, the SEC bifurcates, originating the Intermediate Western Boundary Current (IBWC, flowing northward) while the western boundary currents flows farther south at $\sim 40-30^{\circ} \mathrm{S}$ (BOEBEL et al., 1997). The section at $25^{\circ} \mathrm{W}$ was used to monitor the South Equatorial Current (SEC).

$\begin{array}{ll}3 & \text { http://www.esrl.noaa.gov/psd/data/timeseries/AMO/ } \\ 4 & \text { http://www.cpc.ncep.noaa.gov/data/teledoc/nao.shtml }\end{array}$ 


\subsubsection{Position of the bifurcation}

To trace the bifurcation at depths we followed the methodology proposed by Rodrigues, Rothstein $\&$ Winbush (2007). In their paper, the authors averaged the meridional velocities within a $2^{\circ}$ longitude band off the Brazilian coast.

In this work the position of the SEC bifurcation was determined as the zero contour line (Figure 9) in a section constructed from the average of $4^{\circ}$ longitude band off the Brazilian coast (Figure 17).

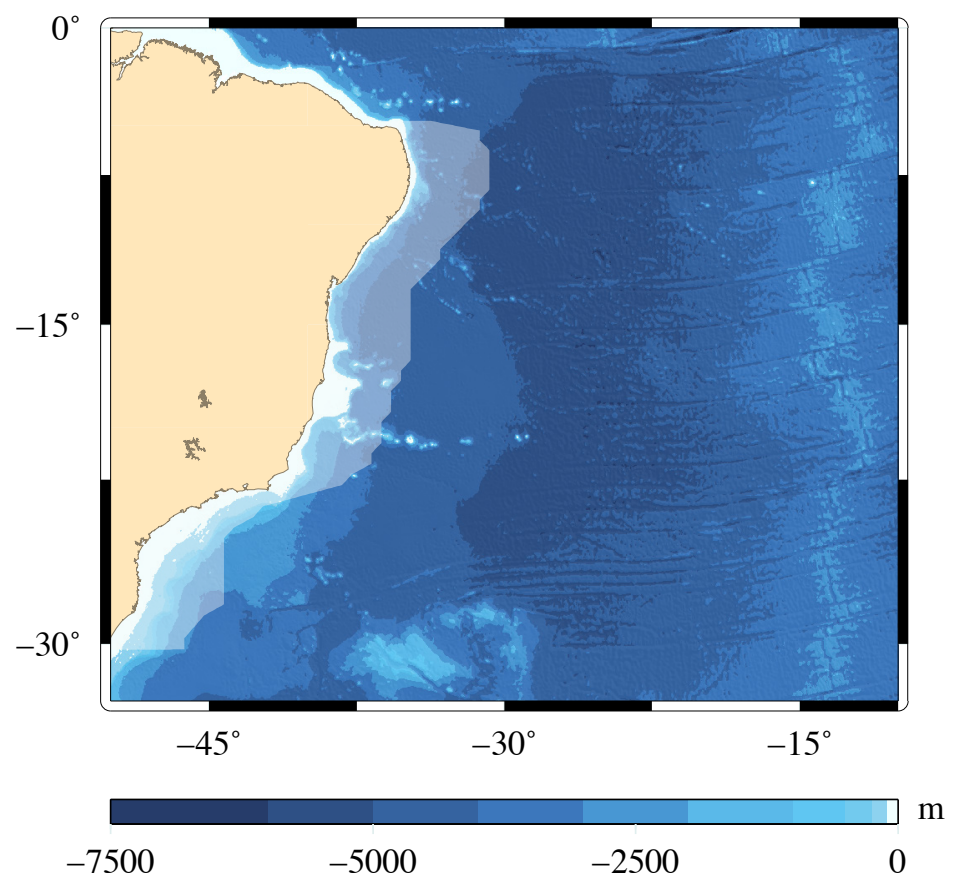

Figure 17: The white shaded area represents the $4^{\circ}$ longitude band off the Brazilian coast area where the meridional velocities were averaged to determine the SEC bifurcation position, following Rodrigues, Rothstein \& Winbush (2007).

\subsubsection{Volume transports}

Volume transports were calculated at $11^{\circ} \mathrm{S}, 27^{\circ} \mathrm{S}$ and $25^{\circ} \mathrm{W}$, following Equation 2.1, where $\mathrm{d} x$ and $\mathrm{d} z$ are the horizontal and the vertical dimensions of the model cell.

$$
\tau_{S v}(x, t)=\iint_{-H}^{0} v(x, t) \cdot \mathrm{d} z \mathrm{~d} x
$$

At $11^{\circ} \mathrm{S}$, the length of the section is a function of the climatological (average for the whole period) width of NBUC, and only positive (northward) velocities were used in this analysis. So, for the datasets SODA, ORCA05 and ORCA12, the zonal transports were calculated between $37.5^{\circ} \mathrm{W}$ and $34^{\circ} \mathrm{W}$. For CCSM, the section started at $37.5^{\circ} \mathrm{W}$ and extend until $32^{\circ} \mathrm{W}$.

At $27^{\circ} \mathrm{S}$, the parameter was the climatological width of Brazil Current. Only negative velocities (southward) were used to calculate the transport of the BC. At intermediate depths, positive (north- 
ward) velocities were used to calculate the IWBC volume transport. The sections limits were $48^{\circ} \mathrm{W}$ and $45^{\circ} \mathrm{W}$ to SODA, ORCA05 and ORCA12 datasets. For CCSM, they were $48^{\circ} \mathrm{W}$ and $43.5^{\circ} \mathrm{W}$.

At $25^{\circ} \mathrm{W}$, the volume transport of the SEC were calculated in two $5^{\circ}$ sections centered in $11^{\circ} \mathrm{S}$ and $27^{\circ} \mathrm{S}$. In these sections, only negative (westward) velocities were used.

\subsubsection{Sverdrup transport}

The Sverdrup's Theory of the oceanic circulation (SVERDRUP, 1947) describes the transports in the ocean interior by relating the curl of the wind stress to mass transport within the upper ocean. $\mathrm{He}$ assumed that the flow is stationary, that lateral friction and molecular viscosity are small, and that turbulence near the sea surface can be described using an eddy viscosity. He also assumed that the flow is baroclinic and that the wind-driven circulation vanishes at some depth of no motion. In the subtropics Sverdrup theory is believed to hold to a good order of approximation in the interior (east of the western boundary current), where the ocean is in linear vorticity balance and there is a presumed level of no motion.

The following description was adapted from Stewart (2008).

The horizontal components of the momentum equation are:

$$
\begin{aligned}
& \frac{\partial p}{\partial x}=f \rho v+\frac{\partial}{\partial z}\left(A_{z} \frac{\partial u}{\partial z}\right) \\
& \frac{\partial p}{\partial y}=-f \rho u+\frac{\partial}{\partial z}\left(A_{z} \frac{\partial v}{\partial z}\right)
\end{aligned}
$$

where:

- $p$ is the pression $(\mathrm{Pa})$;

- $u, v$ are the horizontal velocities $\left(\mathrm{m} \cdot \mathrm{s}^{-1}\right)$;

- $A_{z}$ is the coefficient of eddy viscosity $\left(\mathrm{kg} \cdot(\mathrm{m} \cdot \mathrm{s})^{-1}\right)$.

Sverdrup integrated these equations from the surface to a depth $-D$ equal to or greater than the depth at which the horizontal pressure gradient becomes zero. He defined:

$$
\begin{array}{ll}
\frac{\partial P}{\partial x}=\int_{-D}^{0} \frac{\partial p}{\partial x} \cdot \mathrm{d} z & M_{x}=\int_{-D}^{0} \rho u \cdot \mathrm{d} z \\
\frac{\partial P}{\partial y}=\int_{-D}^{0} \frac{\partial p}{\partial y} \cdot \mathrm{d} z & M_{v}=\int_{-D}^{0} \rho v \cdot \mathrm{d} z
\end{array}
$$

where $M_{x}, M_{y}$ are the mass transports in the wind-driven layer extending down to an assumed depth of no motion. 
The horizontal boundary condition at the sea surface is the wind stress, and the boundary at depth $-D$ is zero stress because the currents go to zero:

$$
\begin{array}{ll}
\left(A_{z} \frac{\partial u}{\partial z}\right)_{0}=\tau_{x} & \left(A_{z} \frac{\partial u}{\partial z}\right)_{-D}=0 \\
\left(A_{z} \frac{\partial v}{\partial z}\right)_{0}=\tau_{y} & \left(A_{z} \frac{\partial v}{\partial z}\right)_{-D}=0
\end{array}
$$

where $\tau_{x}$ and $\tau_{y}$ are the components of the wind stress.

Using these definitions and boundary conditions, Equations 2.2 and 2.3 become:

$$
\begin{aligned}
& \frac{\partial P}{\partial z}=f \cdot M_{y}+\tau_{x} \\
& \frac{\partial P}{\partial z}=-f \cdot M_{x}+\tau_{y}
\end{aligned}
$$

In a similar way, Sverdrup integrated the continuity equation over the same vertical depth, assuming the vertical velocity at the surface and at depth $-D$ are zero, to obtain:

$$
\frac{\partial M_{x}}{\partial x}+\frac{\partial M_{y}}{\partial y}=0
$$

Differentiating Equation 2.8 with respect to $y$ and Equation 2.9 with respect to $x$, subtracting, and using Equation 2.10 gives:

$$
\begin{aligned}
\beta M_{y} & =\frac{\partial \tau_{x}}{\partial y}-\frac{\partial \tau_{y}}{\partial x} \\
M y & =\frac{\nabla \times \tau}{\beta}
\end{aligned}
$$

where:

- $\beta$ is the rate of change of Coriolis parameter with latitude $(\mathrm{m} \cdot \mathrm{s})^{-1}$;

- $\nabla \times \tau$ is the vertical component of the curl of the wind stress $\left(\mathrm{N} \cdot \mathrm{m}^{-3}\right)$.

The Equation 2.11 means that the northward mass transport $\left(\mathrm{kg} \cdot(\mathrm{m} \cdot \mathrm{s})^{-1}\right)$ of wind driven currents is equal to the curl of the wind stress.

However, in this work we calculated the volume transports $\left(\mathrm{m}^{2} \cdot \mathrm{s}^{-1}\right)$ :

$$
M y=\frac{\nabla \times \tau}{\rho \beta}
$$

So, the Sverdrup balance (Equation 2.12) refers to the balance between vorticity input to the ocean by the wind and advection of planetary vorticity in the ocean interior. The meridional Sverdrup transports are cumulative from the western boundary, as in Figure 18. 


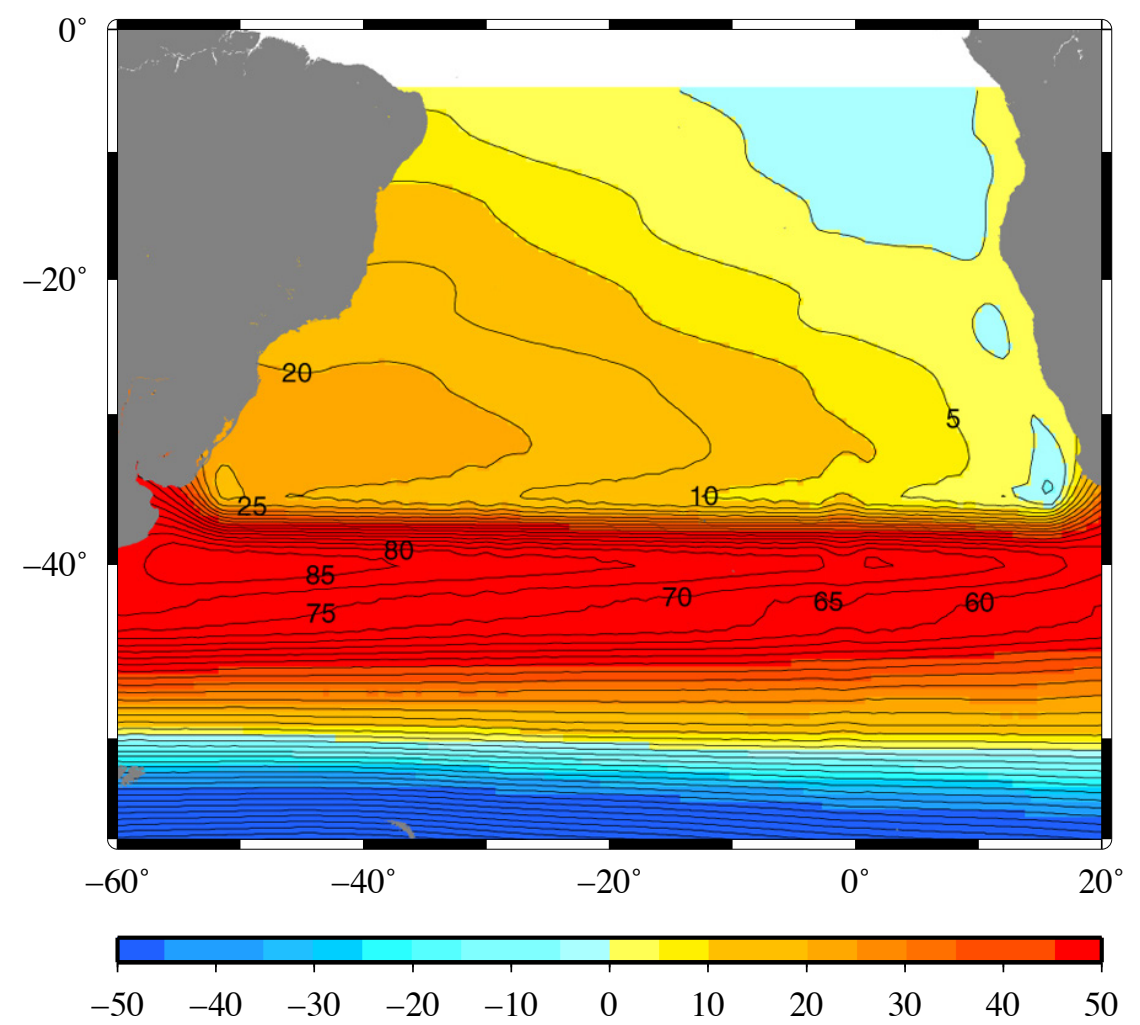

Figure 18: Sverdrup transport (Sv), calculated using Equation 2.12, where blue is clockwise and yellow-red is counterclockwise circulation. Data are from the NCEP reanalysis 19681996 (KALNAY et al., 1996). Adapted from Talley et al. (2011).

\subsubsection{South Atlantic Meridional Overturning Cell}

The South Atlantic part of the Meridional Overturning Cell transport, defined here as the maximum zonally integrated transport from the bottom, was calculated as described in Chapter 1 (Equation 1.1), between $0^{\circ}$ and $30^{\circ} \mathrm{S}$ and $50^{\circ} \mathrm{W}$ to $10^{\circ} \mathrm{W}$.

Only the vertical maximums of the AMOC at $11^{\circ} \mathrm{S}$ and $27^{\circ} \mathrm{S}$ were used.

\subsubsection{Hamming filter}

AMOC time series were filtered using a 4 and 10-year Hamming filter. This kind of window, proposed by Richard Hamming is optimised to minimise the maximum (nearest) side lobe.

The coefficients of a Hamming window are computed from the following equation (OPPENHEIM; SCHAFER, 1989):

$$
w(n)=0.54-0.46 \cdot \cos \left(2 \pi \frac{n}{N}\right), \quad 0 \leq n \leq N
$$

where $\mathrm{N}$ is the length of the window minus 1 .

The filtered time series is a result of a convolution between the original series and the filter $(w)$. 


\subsubsection{Correlations}

Correlation quantifies the strength of a linear relationship between two variables. Two variables that are uncorrelated are not necessarily independent, however, because they might have a nonlinear relationship. Here, correlations between two detrended time series $(x, y)$ were calculated using Pearson's product-moment coefficient (RODGERS; NICEWANDER, 1988):

$$
R=\frac{\sigma(x, y)}{\sigma_{x} \sigma_{y}}
$$

where:

- $\sigma(x, y)$ is the covariance between $x$ and $y$;

- $\sigma_{x}$ and $\sigma_{y}$ are the standard deviation of $x$ and $y$.

The covariance $\left(\sigma_{(x, y)}\right)$ is defined as:

$$
\sigma_{(x, y)}=\sqrt{\frac{\sum_{i=1}^{n}\left(x_{i}-\bar{x}\right)^{2}-\left(y_{i}-\bar{y}\right)^{2}}{n-1}}
$$

And the standard deviation $\left(\sigma_{x}\right)$ :

$$
\sigma_{x}=\sqrt{\frac{\sum_{i=1}^{n}\left(x_{i}-\bar{x}\right)^{2}}{n-1}}
$$

To define whether the correlations with zero lag were significant, a t-test was applied, in which the probability of getting a correlation as large as the observed value by a random chance, when the true correlation is zero, is calculated.

This probability ( $p$-value) is computed by transforming the correlation to create a t-statistic having $N-2$ degrees of freedom, where $N$ is the number of data points in the series. The confidence bounds are based on an asymptotic normal distribution (Equation 2.17), with an approximate variance equal to $\frac{1}{(\mathrm{~N}-3)}$. These bounds are accurate for large samples when the series have a multivariate normal distribution.

$$
p \text {-value }=0.5 \cdot \ln \left(\frac{1+R}{1-R}\right)
$$

Using a confidence limit of $95 \%$, a correlation is significant when the $p$-value is smaller than 0.05 .

\subsubsection{Taylor's Diagram}

Taylor's Diagrams (TAYLOR, 2001) provide a visual framework for comparing model results to a reference model or, most commonly, to observations, summarising how closely a pattern (or a set 
of patterns) matches the reference. The similarity between two patterns is quantified in terms of their correlation, their centered root-mean-square (RMS) difference and the amplitude of their variations (represented by their standard deviations).

It is built in polar coordinates: its angles are the arccosine of the correlation and its radius are the standard deviation. Because the different variables may have widely varying numerical values the model results are normalised by the reference variables. The ratio of the normalised variances indicates the relative amplitude of the model and observed variations. The RMS determines the distance between each data plotted, excluding the average variances.

The reason that each point in the two-dimensional space of the Taylor diagram can represent three different statistics simultaneously (i.e., the centered RMS difference, the correlation, and the standard deviation) is that these statistics are related by the following formula (TAYLOR, 2001):

$$
E^{2}=\sigma_{f}^{2}+\sigma_{r}^{2}-2 \sigma_{f} \sigma_{r} R
$$

where

- $R$ is the correlation coefficient between the test and reference fields;

- $E$ 'is the centered RMS difference between the fields;

- $\sigma_{f}$ and $\sigma_{r}$ are the variances of the test and reference fields, respectively.

These diagrams are especially useful in evaluating multiple aspects of complex models or in gauging the relative skill of many different models (e.g. IPCC (2001)).

\subsubsection{Optimum Multiparameter}

The Optimum Multiparameter (OMP) is a method described by Tomczak (1981) and Tomczak \& Large (1989), based on the assumption that the processes involving water masses are linear and all the parameters are affected equally. In this sense, the physical and chemical properties of a water sample is a consequence of mixing of several different Source Water Type (SWT) with identical exchange coefficients for all parameters (KLEIN; TOMCZAK, 1994; KERR, 2006). It assumes that the water mass properties in the formation regions are invariable in time and analyzes time variations in the residual error fields (POOLE; TOMCZAK, 1999).

This method solves a linear system establishing the percentage of each water type (no mixing) in the sample (Equations 2.19 and 2.20). For example, measured temperature at location $(k)$ can be represented by:

$$
T_{m}(k)=x_{1}(k) T_{1}+x_{2}(k) T_{2}+\cdots+x_{n_{s}}(k) T_{n_{s}}+\epsilon_{T}(k)
$$

where:

- $x_{i}$ is the $i$ th SWT contribution of fraction;

- $T_{i}$ its temperature $\left(i=1, \ldots, n_{s}\right)$; 
- $\epsilon_{T}(k)$ the disturbing noise.

If enough properties are measured, the unknown fractions $\left(x_{1}, \ldots, x_{n_{s}}\right)$ at the point $k$ can be estimated by simultaneously optimising all mixing equations (like Equation 2.19) and the balance equation:

$$
x_{1}(k)+\cdots+x_{n_{s}}(k)=1
$$

The procedure can be repeated for all grid points, resulting in optimal values for the SWT at each sampling location. Its core is defined as the area were the percentage of the SWT is greater than $80 \%$.

In this work, OMP was used to produce a correct description of the SAWC and AAIW distribution at $11^{\circ} \mathrm{S}$ and $27^{\circ} \mathrm{S}$, between $37.5-30^{\circ} \mathrm{W}$ and $48.5-40^{\circ} \mathrm{W}$, respectively (Figure 19), once they are the main water masses carried by the WBC related to the return flow of the AMOC.

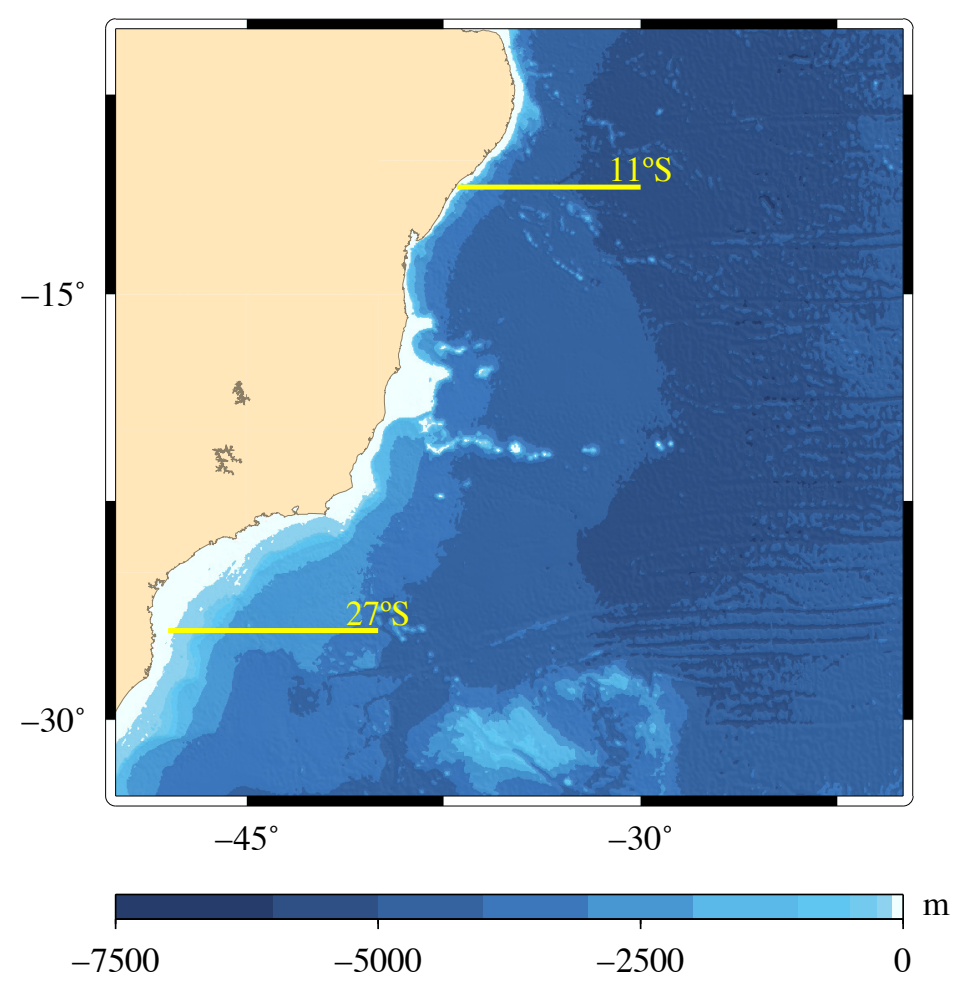

Figure 19: Position of the sections used to calculate the water masses distribution using OMP, between $37.5-30^{\circ} \mathrm{W}$ at $11^{\circ} \mathrm{S}$ and between $48.5-40^{\circ} \mathrm{W}$, at $27^{\circ} \mathrm{S}$.

As discussed in Section 1.2.2, the SACW is a combination of three water masses: 1SACW, SASTMW and SAMW (their density layers are shown in Table 1). However, according to Klein \& Tomczak (1994) and Poole \& Tomczak (1999), in the South Atlantic its salinity-temperature relationship can be approximated by a straight line (Figure 21), and thus, two water types are sufficient to represent the SACW (the end-points of the linear section). The AAIW, is more uniform in its formation region and can be represented by a single water type (TOMCZAK; LIEFRINK, 2005).

OMP analysis produces better results when applied to water masses with reasonably conserved properties. Within the mixed layer, the hydrographic properties of a water parcel are strongly influ- 
enced by the atmosphere through air-sea interaction and by sunlight via near-surface biological processes. Once removed from the mixed layer, the temperature and salinity of a water parcel are conserved, which means that these properties remain constant unless mixing occurs with another water parcel (POOLE; TOMCZAK, 1999). Therefore, to avoid the mixed layer (Figure 20), only salinity, temperature and potential vorticity fields below $150 \mathrm{~m}\left(\right.$ at $\left.11^{\circ} \mathrm{S}\right)$ and $200 \mathrm{~m}\left(\right.$ at $27^{\circ} \mathrm{S}$ ) were used.

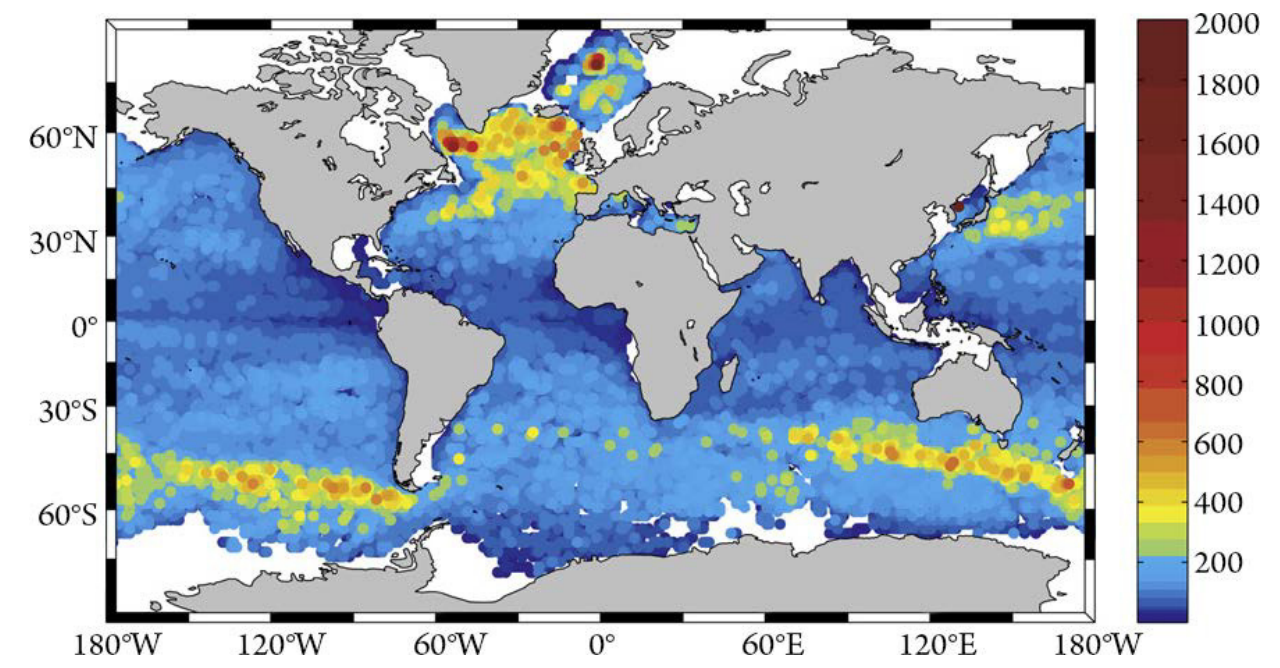

Figure 20: Averaged maximum mixed layer depth, using the 5 deepest mixed layers in $1 \times 1$ bins from the Argo profiling float data set (2000-2009) and fitting the mixed layer structure as in Holte \& Talley (2009). Adapted from Talley et al. (2011).

Thus, two source waters represent the SACW, ISACW and SAMW, based on the results Donners, Drijfhout \& Hazeleger (2005) (Table 1). Salinity and temperature for these water masses were calculated using the longitude-time averaged temperature-salinity diagram, as shown in Figure 21a.

AAIW source water type salinity and temperature were calculated using the mixing triangle (MAMAYEV, 1975). The tangent lines were calculated at the points where the longitude-averaged temperaturesalinity diagram crosses the isopycnal related to the interface of the water masses (Figure 21)b.

But, below AAIW there is the UCDW, and to correctly isolate the intermediate water mass is necessary to account its mixture with the deep water.

The optimal solution for this problem would be isolate the three water masses (i.e., four SWT) in the same water analysis. However, as heighlighted by Brauwere et al. (2007), the number of unknown fractions $\left(n_{s}\right)$ may not exceed the number of measured variables $\left(n_{v}\right)+1$. Otherwise, there is an infinite number of solutions which are all equally good. In this work, besides temperature and salinity data, only the potential vorticity is available (Section 2.2.6.1), which makes impossible to separate SACW, AAIW and UCDW at once.

To make the analysis possible, the water column was divided into parts, as follows. First, the SACW (i.e. a mixture of ISACW and SAMW) was isolated from AAIW. Only data below the maximum mixing layer and between the densities of $25.5 \mathrm{~kg} \cdot \mathrm{m}^{-3}$ and $27.5 \mathrm{~kg} \cdot \mathrm{m}^{-3}$ were used. The goal was to obtain a good description of the SACW core. Second, data at depths shallower than $2000 \mathrm{~m}$ and with densities 
(a) SACW

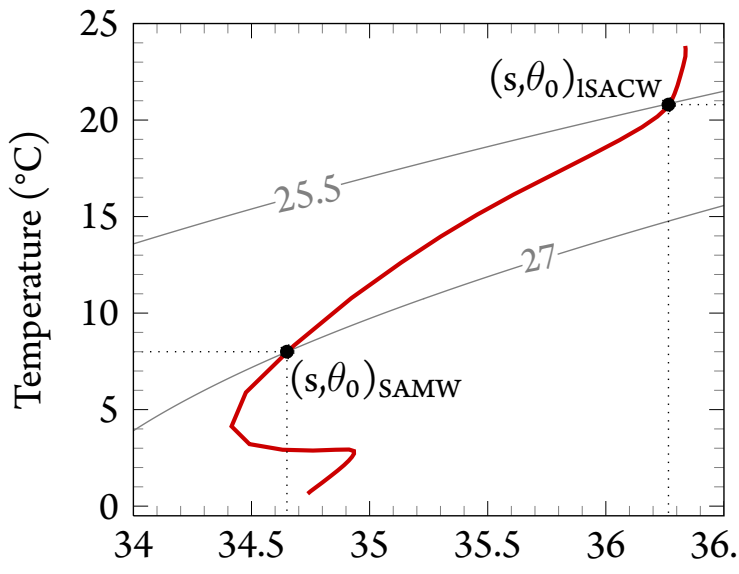

(b) AAIW

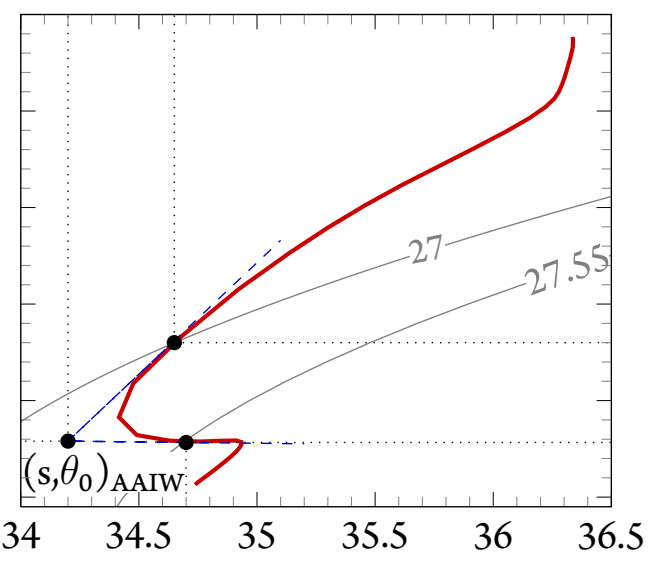

Salinity

Figure 21: Time averaged temperature-salinity diagram at $25^{\circ} \mathrm{S}$ and $25^{\circ} \mathrm{W}$. Original data from the Simple Ocean Data Assimilation System, version 2.2.4 (SODA, Carton \& Giese (2008)). SACW STW termohaline indices (a). Gray contours represent the common end-points regarding Keffer (1985) and Donners, Drijfhout \& Hazeleger (2005) density layer definitions. AAIW STW thermohaline indices (b). Gray contours indicate the density limits between SACW, AAIW and NADW. Blue dashed lines indicate the tangents used to generate the mixing triangle. For both plots, black points and black dotted lines indicate the salinity and temperature data used as water types parameters.

greater than $26.7 \mathrm{~kg} \cdot \mathrm{m}^{-3}$ were used to separate AAIW. Only the lower part of the SACW was used since it was not the main objective of the analysis, and so, the upper limit of AAIW layer in this case is SAMW. According to McCartney (1982), mode waters are homogeneous and thus, one STW is enough to represent it. The isopycnal $26.6 \mathrm{~kg} \cdot \mathrm{m}^{-3}$, the upper limit of this water mass layer, was chosen to obtain the index. The lower limit is the UCDW. To characterise this water mass, the isopycnal $27.75 \cdot \mathrm{kg}^{-3}$, the lower limit of its layer was chosen.

A complete list of the parameters, with their weights, selected empirically, is presented in Tables 28 and 29, in Section 3.2.2.

\subsubsection{Potential vorticity}

The third parameter used in OMP analysis is the potential vorticity once it is conserved along a fluid trajectory. According to Pedlosky (1987), it is defined as:

$$
\Pi=\frac{\zeta+f}{H}
$$

where:

- $\Pi$ is the potential vorticity $(\mathrm{m} \cdot \mathrm{s})^{-1}$;

- $\zeta$ is the relative vorticity $\left(\mathrm{s}^{-1}\right)$; 
- $f$ is the planetary vorticity, related to the Coriolis parameter $\left(\mathrm{s}^{-1}\right)$;

- $H$ is the depth $(\mathrm{m})$.

For baroclinic flow in a continuously stratified fluid, the potential vorticity can be written as:

$$
\Pi=\frac{\zeta+f}{\rho} \frac{\partial p}{\partial z}
$$

where:

- $\rho$ is the density $\left(\mathrm{kg} \cdot \mathrm{m}^{-3}\right)$;

- $\frac{\partial p}{\partial z}$ is pressure variation with depth $\left(\mathrm{N} \cdot \mathrm{m}^{-3}\right)$.

Assuming the horizontal gradients of density are small compared with the vertical ones, which is a good assumption in the thermocline, and also that in most of the interior of the ocean, $f \gg \zeta$, Equation 2.22 is written, according to Pedlosky (1996), as:

$$
\Pi=\frac{f}{\rho} \frac{\partial p}{\partial z}
$$

This allows the potential vorticity of various layers of the ocean to be determined directly from hydrographic data without knowledge of the velocity field.

Using Equation 2.23 and the longitude-time averaged salinity and temperature data, the potential vorticity profile is calculated, and the value for each source water found (Figure 22).

\subsubsection{Neutral density}

A parcel of water moves locally along a path of constant density keeping below less dense water and above more dense water. More precisely, it moves along a path of constant potential density $\sigma_{z}$ referenced to the local depth $z$. Such a path is called a neutral path (EDEN; WILLEBRAND, 1999). A neutral surface element is the surface tangent to the neutral paths through a point in the water. No work is required to move a parcel on this surface because there is no buoyancy force acting on the parcel as it moves, if we ignore friction (McDOUGALL, 1987; STEWART, 2008).

Jackett \& McDougall (1997) developed a practical neutral density variable $\gamma_{n}$ and surface that stays within a few tens meters of an ideal surface anywhere in the world. The neutral density values were then used to label the data in the Levitus atlas. This prelabeled data set is used to calculate $\gamma_{n}$ at new locations where the potential temperature $\left(\theta_{0}\right)$ and the salinity $(S)$ are measured as a function of depth by interpolation to the four closest points in the Levitus atlas. Recently, Serazin (2011) has made some improvements, applying new equations of the thermodynamic properties of seawater (TEOS- $10^{5}$ ), and each $\gamma_{n}$ surface is calculated using specific equations for each ocean basin. Through this practice, neutral density $\gamma_{n}$ is a function of salinity, temperature potential, pressure, longitude, and latitude.

\footnotetext{
5 International Thermodynamic Equation Of Seawater, available in www.TEOS-10.org.
} 


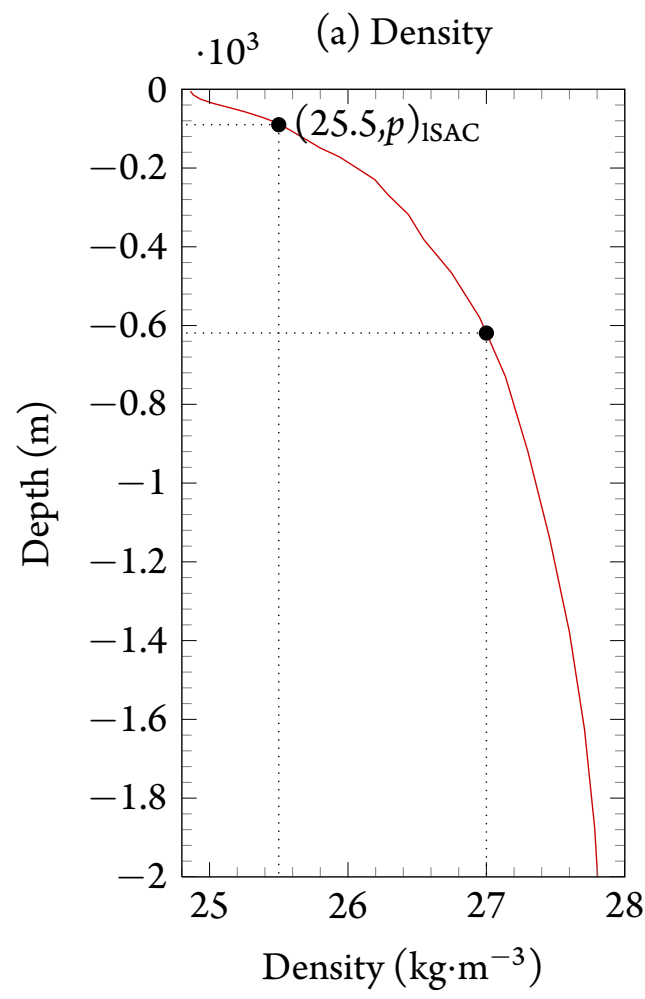

(b) Vorticity

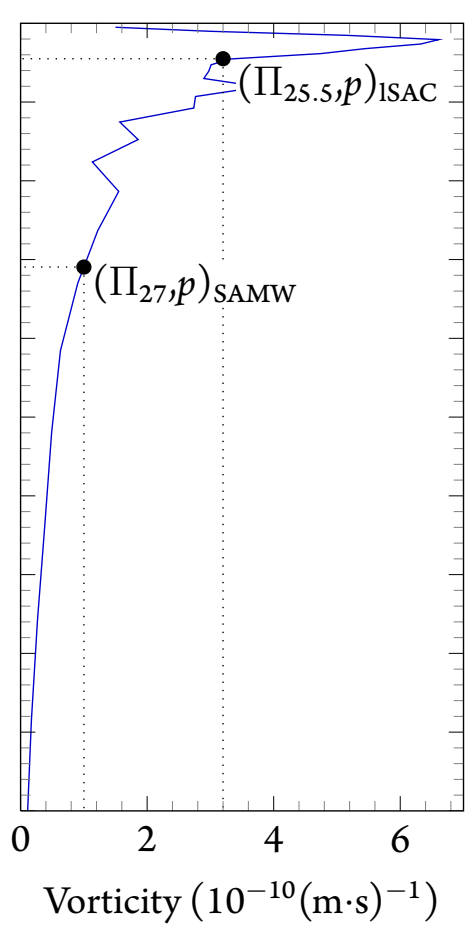

Figure 22: Density (a) and vorticity (b) profiles in the first $2000 \mathrm{~m}$ at $25^{\circ} \mathrm{W}$ and $25^{\circ} \mathrm{S}$, constructed using the time-averaged temperature and salinity data from SODA 2.2.4 (CARTON; GIESE, 2006; CARTON; GIESE, 2008).

According to McDougall (1987), The neutral surface defined above differs from the potential density surfaces because the compressibility of the seawater is a function of salinity and potential temperature, or, equivalently, because $\frac{\alpha}{\beta}$ is dependent on pressure, where $\alpha$ is the thermal expansion coefficient and $\beta$ is the haline contraction coefficient (Figure 23). It also differs only slightly from an ideal neutral surface. If a parcel moves around a gyre on the neutral surface and returns to its starting location, its depth at the end will differ by around $10 \mathrm{~m}$ from the depth at the start. If potential density surfaces are used, the difference can be hundreds of meters, a far larger error (STEWART, 2008).

In this work, we calculated the salinity and the temperature in the neutral surfaces that corresponds to SACW and AAIW in each model, in the sections shown in Figure 19, using the same indices calculated to the OMP analysis (Section 2.2.6), i.e., temperature and salinity that correspond to the $25.5 \mathrm{~kg} \cdot \mathrm{m}^{-3}$ and $27 \mathrm{~kg} \cdot \mathrm{m}^{-3}$ isopycnals for SACW and the results of the mixing triangle for AAIW. 


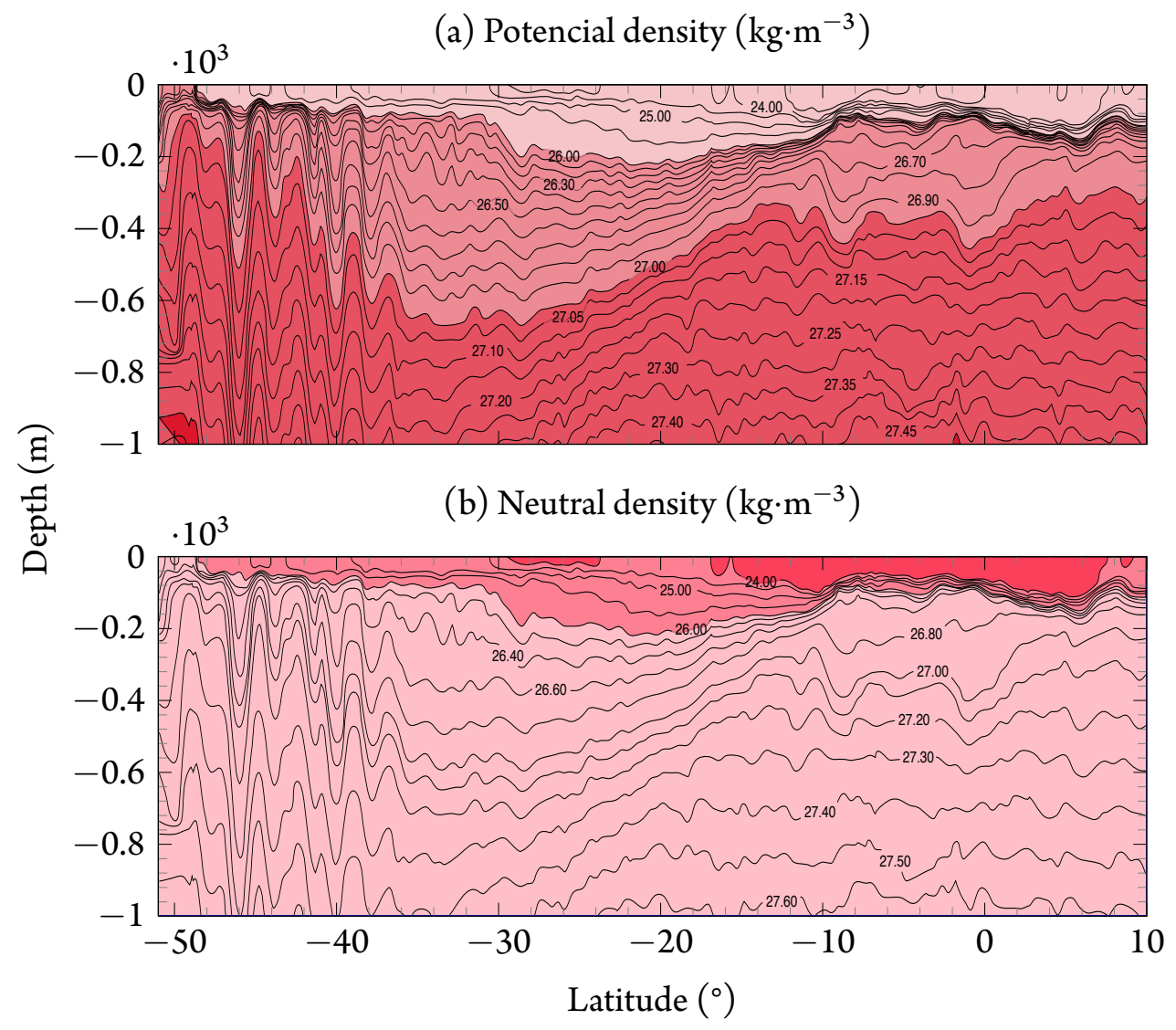

Figure 23: Potential (a) and neutral (b) densities calculated near South America coast (section A17). Adapted from Koltermann, Gouretski \& Jancke (2011). 


\section{Results and discussion}

This chapter presents and discusses the results, splitted in two main sections: Section 3.1 studies the SEC bifurcation variability at interannual time scales, both at the surface and intermediate depths and its relationship with the WBC and AMOC changes. Following, the results related to changes in the water masses are presented and discussed in Section 3.2.

\subsection{South Equatorial Current Bifurcation and its link with the AMOC}

To study the variability of the SEC bifurcation and its relationship to the AMOC, we based our analysis in the methodology proposed by Rodrigues, Rothstein \& Winbush (2007), starting with a section of meridional velocities within a $4^{\circ}$ longitude band off the South America coast (Figure 17). Its climatological values are shown in Figure 24. It should be noted that SODA, CCSM and ORCA05 results correspond to an average of the velocities from 1948 to 2007, while ORCA12 results cover the period from 1989 to 2007.

The first important thing to notice here is that the intensity of the northward flow is stronger in the reanalysis (Figure 24a) than in the other three model outputs, specially at intermediate depths (under $600 \mathrm{~m}$ ) where the flux of the IWBC is dominant. It is also clear that in ORCA05 model has the strongest and deepest Brazil Current (BC), and so, the bifurcation does not extend beyond $24^{\circ} \mathrm{S}$ (Figure 24c) where the Vitória Trindade Ridge is located (SILVA et al., 2009). According to Danabasoglu et al. (2013), compared to other models forced by CORE-II data, ORCA05 has a weak AMOC which can be linked to the weak northward flow observed in this work. This suggests a longer influence of the AMOC in the bifurcation position at intermediate depths.

Except for ORCA05 results, the models reproduce well the bifurcation position observed in previous studies (STRAMMA; ENGLAND, 1999a; BOEBEL et al., 1999; WIENDERS; ARHAN; MERCIER, 2000). The authors found a poleward depth increase of the southern branch of SEC (sSEC) bifurcation along the Brazilian coastline. Their observations suggest that the SEC bifurcation occurs at $14^{\circ}-16^{\circ} \mathrm{S}$ in the surface layer $(0-100 \mathrm{~m})$, at $20^{\circ}-24^{\circ} \mathrm{S}$ in the thermocline $(400-500 \mathrm{~m})$, and at $26^{\circ}-28^{\circ} \mathrm{S}$ in the intermediate layer $(600-1200 \mathrm{~m})$. Table 2 shows the mean bifurcation position for each model results compared to Rodrigues, Rothstein \& Winbush (2007). The results presented in Table 2 agree with those found by these authors.

Using the wind stress curl applied to the Sverdrup Theory (Equation 2.12), the bifurcation position at the surface (here taken as the zero velocity contour) was calculated (Figure 25). As expected, all the forcing respond well to the literature (e.g. Talley et al. (2011)) with transports maximum (around 25Sv, 


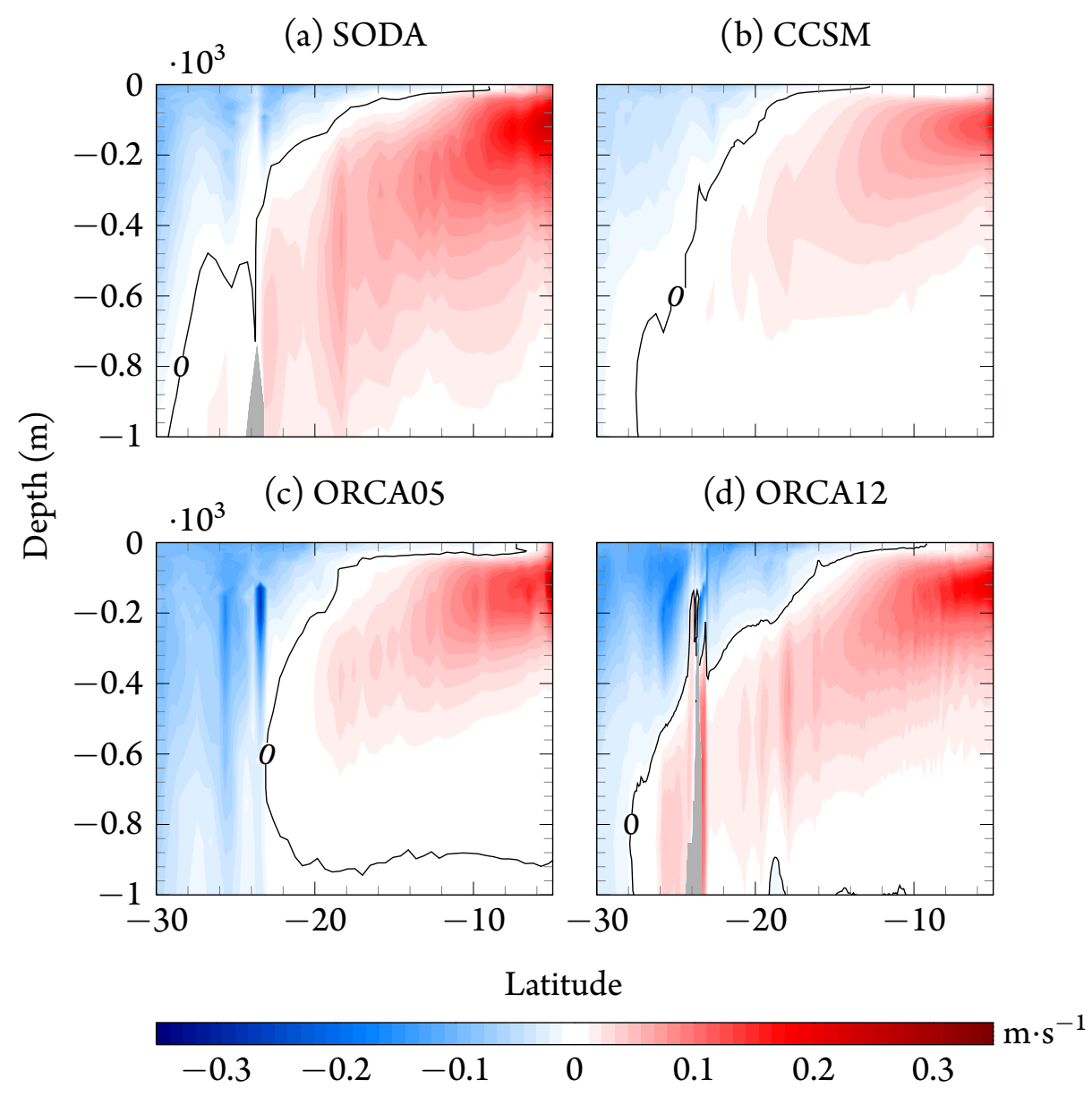

Figure 24: Climatological meridional velocity within the $4^{\circ}$ longitude band off South America coast for SODA (a), CCSM (b), ORCA05 (c) and ORCA12 (d) datasets. Black contours indicate the position of the bifurcation.

Table 2: Bifurcation position, in ${ }^{\circ} \mathrm{S}$, means for each dataset in different layers, compared to Rodrigues, Rothstein \& Winbush $(2007)^{1}$.

\begin{tabular}{cccccc}
\hline $\begin{array}{c}\text { Layers } \\
(\mathrm{m})\end{array}$ & ${ }^{1}$ Literature & $\begin{array}{c}\text { SODA } \\
\text { Position and standard deviation in }{ }^{\circ} \mathrm{S}\end{array}$ & CRCA12 \\
\hline $0-100$ & $14-16$ & $15.2 \pm 3.2$ & $17.7 \pm 2.1$ & $14.4 \pm 4.0$ & $14.2 \pm 2.1$ \\
$100-500$ & $14-20$ & $22.8 \pm 1.6$ & $22.2 \pm 1.4$ & $20.8 \pm 1.3$ & $22.2 \pm 2.8$ \\
$500-1000$ & $21-28^{2}$ & $27.6 \pm 1.2$ & $26.6 \pm 0.9$ & $22.5 \pm 0.2$ & $26.8 \pm 0.5$ \\
\hline
\end{tabular}

${ }^{1}$ Rodrigues, Rothstein \& Winbush (2007): the depth range is $500-1200 \mathrm{~m}$.

at $30^{\circ} \mathrm{S}$ ) and the bifurcation close to $14^{\circ} \mathrm{S}$, agreeing with the Sverdrup's Theory. Results from CCSM and ORCA05, both forced by CORE data, show some significant differences in the bifurcation position. This result is consistent to those found in the top $100 \mathrm{~m}$, using average of the meridional velocities within the $4^{\circ}$ longitude band off the Brazilian coast (Table 2) and manifest the importance of the wind in the bifurcation position. 
(a) SODA

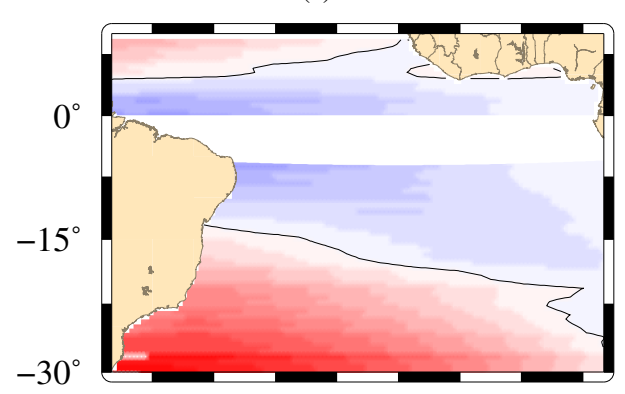

(c) ORCA05

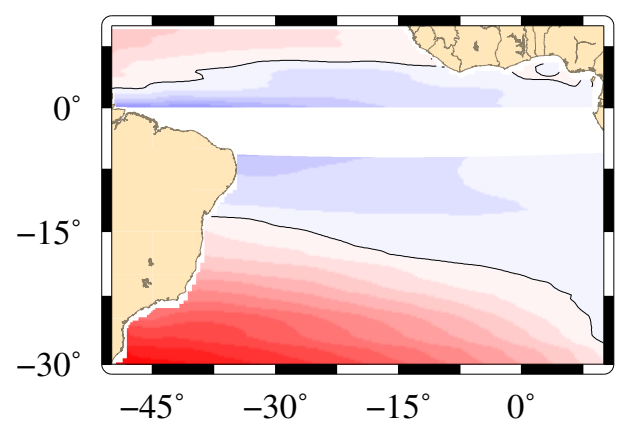

(b) CCSM

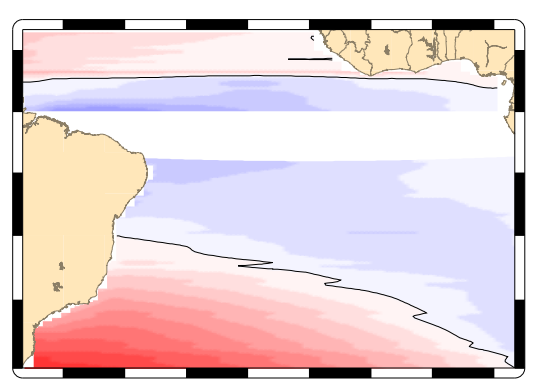

(d) ORCA12
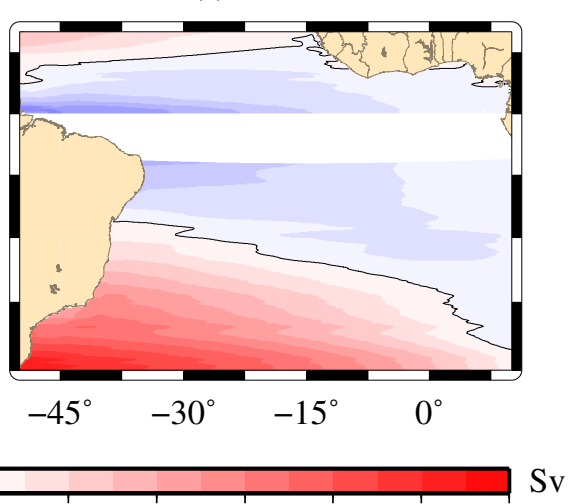

Figure 25: Sverdrup transport (Sv) calculated using the wind stress curl (Section 2.2.2.1).

Based in this main results, this Section is structured as follows: Section 3.1.1 shows the validation results, when we reproduce other analysis done by Rodrigues, Rothstein \& Winbush (2007) at seasonal timescales; Section 3.1.2 shows the results for SEC bifurcation and its relationship with wind stress curl and the climate indices; Section 3.1.2.3 shows the results of AMOC and its relationship with the currents.

\subsubsection{Validation}

Initial analysis with the model outputs aimed at reproducing, the results obtained by Rodrigues, Rothstein \& Winbush (2007).

Figure 26 shows the climatological summer and winter sections of meridional velocity within the $4^{\circ}$ longitude band off South America coast. It is possible to see differences in the position of the bifurcation, predominantly in the surface layer (top $200 \mathrm{~m}$ ). This seasonal cycle dependence of the position of the bifurcation, mainly in the first 100m was described by Schott et al. (2005), Rodrigues, Rothstein \& Winbush (2007), Silva et al. (2009). In Figure 26, during the summer (monthly averages of January, February and March) the bifurcation, in the top $100 \mathrm{~m}$, is north of $10^{\circ} \mathrm{S}$ while in the winter time (July, August and September) it is mainly south of this latitude. The changes in the bifurcation position below $500 \mathrm{~m}$, are not clear in this figure.

The seasonality of the bifurcation can be clearly seen in Figure 27. CCSM, ORCA05 and ORCA12 

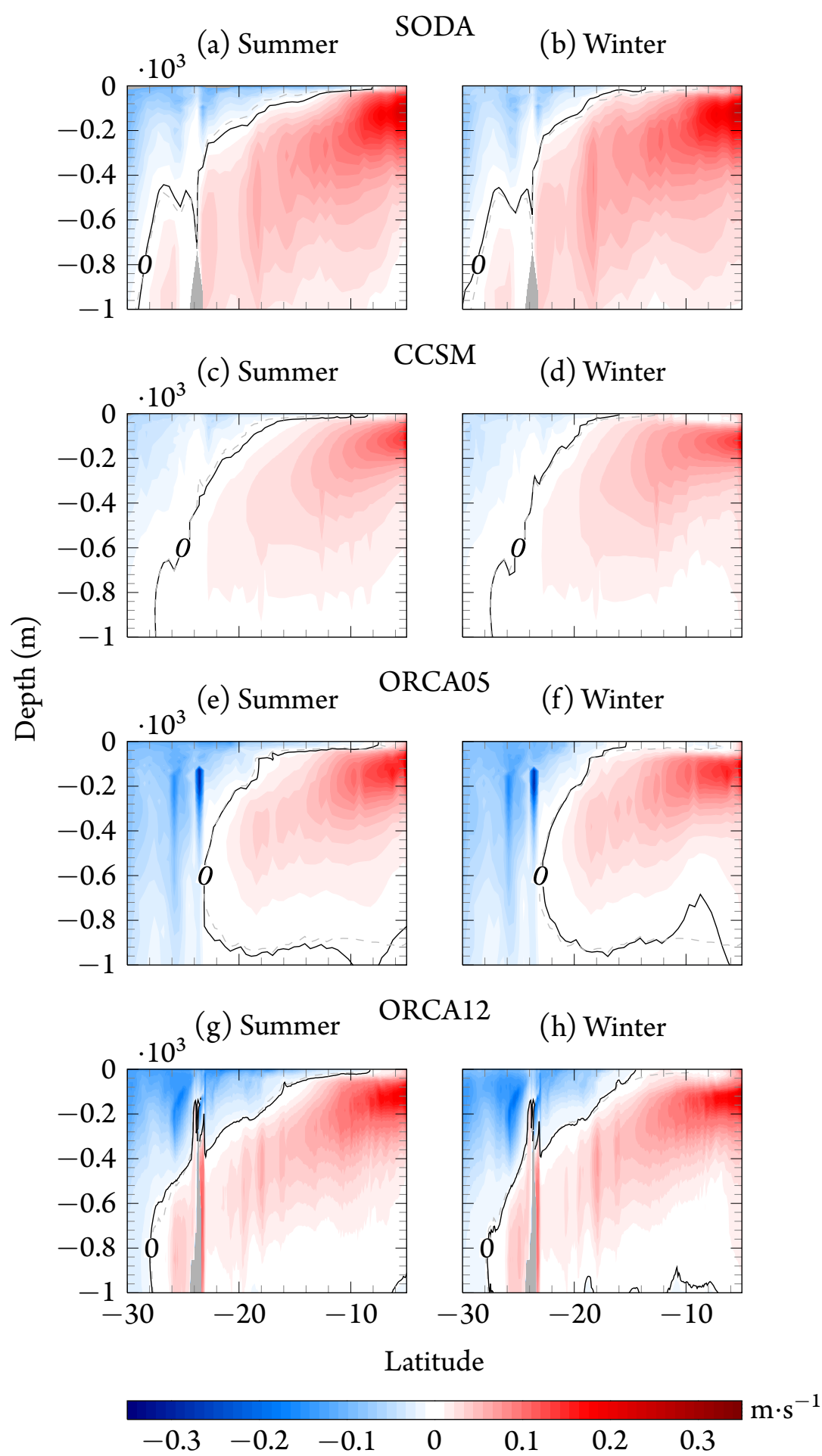

Figure 26: Averaged summer and winter meridional velocity within the $4^{\circ}$ longitude band off South America coast section for SODA (a,b), CCSM (c,d), ORCA05 (e,f) and ORCA12 (g,h) datasets. Black contours lines indicate the position of the bifurcation. Gray dashed contours are the climatological reference (Figure 24).

results agree with SODA in the top 100m: the bifurcation reaches its northermost position during the winter and the southernmost during the summer. It also confirms the results of Rodrigues, Rothstein 
\& Winbush (2007).

Differently from the surface, the variability at intermediate layers has a semi-annual cycle in SODA (Figure 27a). Different regimes in the bifurcation variability at the surface and at intermediate layers were described by Rodrigues, Rothstein \& Winbush (2007) and, according to the authors, it is a result of a combination of both direct and remote wind forcing, and could be also, related to AMOC variability. CCSM fails to reproduce this variability, while ORCA05, despite its underestimated southward bifurcation extension (Figures 24 and 26), reproduces it better, although they are both forced by CORE-II (Section 2.1.4). ORCA12 shows a higher frequency variability. All models in this study show big differences when compared to the observations and the SODA reanalysis. This can also related with dissimilar variability of the SEC, that will be discussed later. Another explanation for the observed differences could be variations of kinetic energy and buoyancy fluxes. Further analysis is necessary to test this hypothesis and to understand the mechanisms that drive the different responses for each model output.

Figure 28 shows the average position of the bifurcation in the top $200 \mathrm{~m}$. It is possible to note that CCSM, ORCA05 and ORCA12 have the same variability, but, while the southernmost bifurcation position was expected to happen between June and July (Rodrigues, Rothstein \& Winbush (2007)), it happens a month earlier. In SODA reanalysis results the averaged bifurcation position in the top $200 \mathrm{~m}$ has an influence of the semi-annual variability, and the southernmost position of the bifurcation occurs in September. In a similar way, Figure 29 shows a seasonal cycle for the bifurcation position averaged between 500 and 1000m. As it was shown in Figure 27, ORCA05 underestimates the southward extension of the bifurcation, and, because of that, it has the northernmost position values. SODA, CCSM and ORCA12, in general, agree with respect to the averaged position at intermediate depth, but, they have big differences in the seasonal variability. Rodrigues, Rothstein \& Winbush (2007) show that, at intermediate depths, the bifurcation variability has a semi-annual cycle, which SODA reproduces well, showing two maxima (during May and November) and two minima (March and August). CCSM shows an annual cycle, similar to that found at the surface (Figure 28), while ORCA05 and ORCA12 approach the reanalysis.

As described above, it is known that the bifurcation position at seasonal timescales has a strong influence of the wind stress curl. Figure 30 shows, for each dataset, the monthly mean position of the zero wind stress curl contour. It is possible to observe the meridional excursion of the zero wind stress curl line through the bifurcation region during the year, related to the seasonal movement of the Atlantic ITCZ. The model results agree well with the SODA reanalysis and with the results of Rodrigues, Rothstein \& Winbush (2007): the southern zero line is almost horizontal during the winter, while its inclination is bigger during summer and spring. As consequence, the bifurcation is exposed to negative (positive) wind stress curl and associated weaker (stronger) Ekman pumping from February to August (September to January).

The time series of the bifurcation position averaged in the top $200 \mathrm{~m}$ and the wind stress curl at each grid point were correlated at zero lag to better discuss their link at seasonal time scales. The results can be 


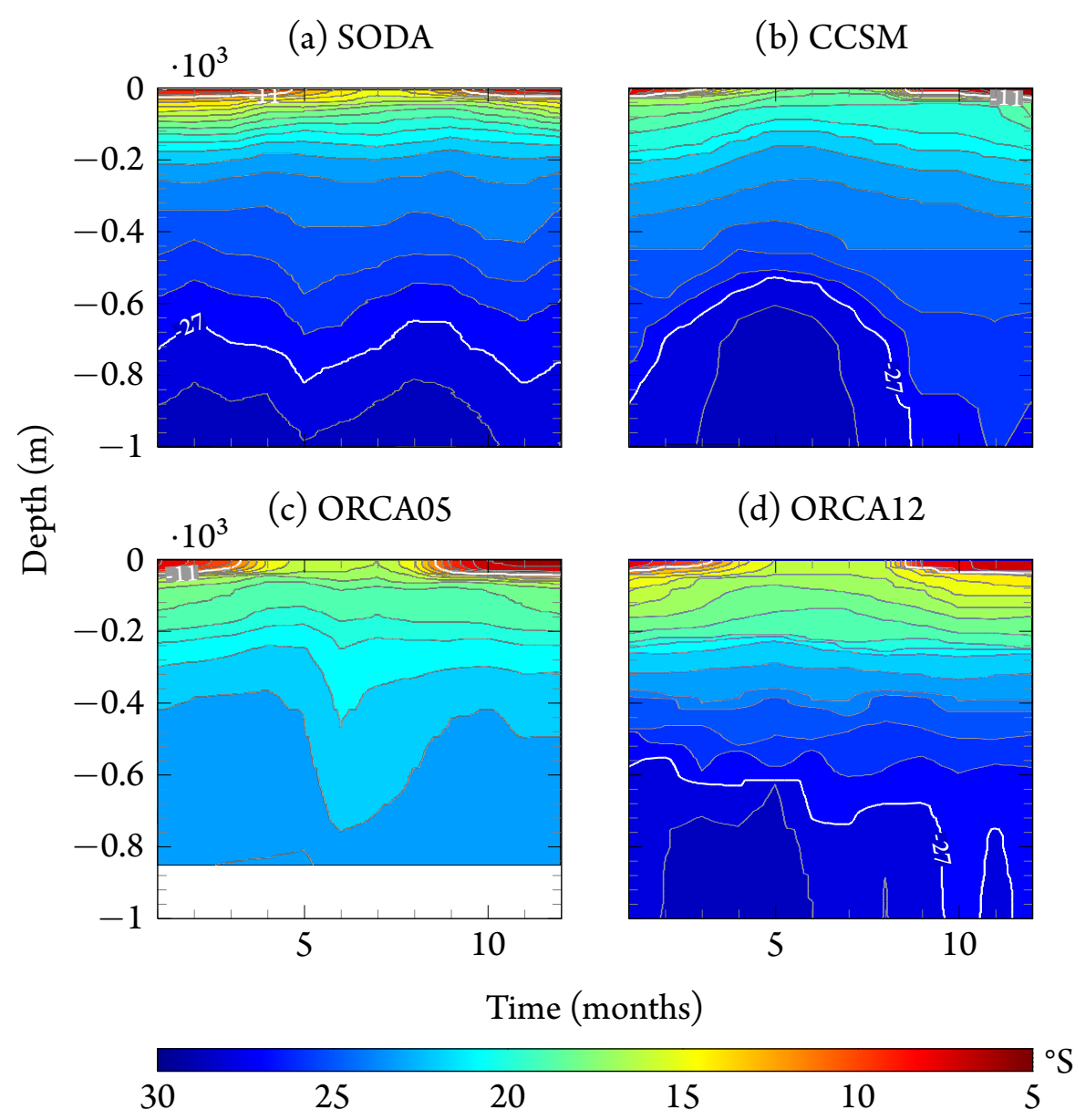

Figure 27: Seasonal cycle of the position of the bifurcation of SEC, for SODA (a), CCSM (b), ORCA05 (c) and ORCA12 (d) datasets, calculated at top 1000m using the zero contour line of meridional velocity, as proposed by Rodrigues, Rothstein \& Winbush (2007) (Section 2.2.1), between $30^{\circ} \mathrm{S}$ and $5^{\circ} \mathrm{S}$. Contours at every $1^{\circ}$. White contours show the depth of the bifurcation at $11^{\circ} \mathrm{S}$ and $27^{\circ} \mathrm{S}$.

seen in Figure 31. The correlations are strong in a large part of the area, but only correlation coefficients statistically significant at the $95 \%$ level are considered. Big differences can be seen between the SODA reanalysis results and the models, specially in the southern limit of the area. In the models, it is possible to observe a east-west dipole in correlation, in the same way found by Rodrigues, Rothstein \& Winbush (2007), centered around $10^{\circ} \mathrm{W}$, with positive correlations close to the Brazilian coast and negative ones in the east part of the basin (less significant in SODA). It is not clear if changes in the wind stress over the bifurcation region are more important than those in the central and eastern side of the basin as discussed by Rodrigues, Rothstein \& Winbush (2007).

Based on literature information and in the results of Figure 24, two main sections were chosen to access the variability of the bifurcation position: $11^{\circ} \mathrm{S}$ (Figure 32 ) and $27^{\circ} \mathrm{S}$ (Figure 34). A section in $25^{\circ} \mathrm{W}$ (Figure 36) is also used to monitor the South Equatorial Current (SEC).

It is easy to note the effect of different model resolutions. In the CCSM model, the NBUC and the 

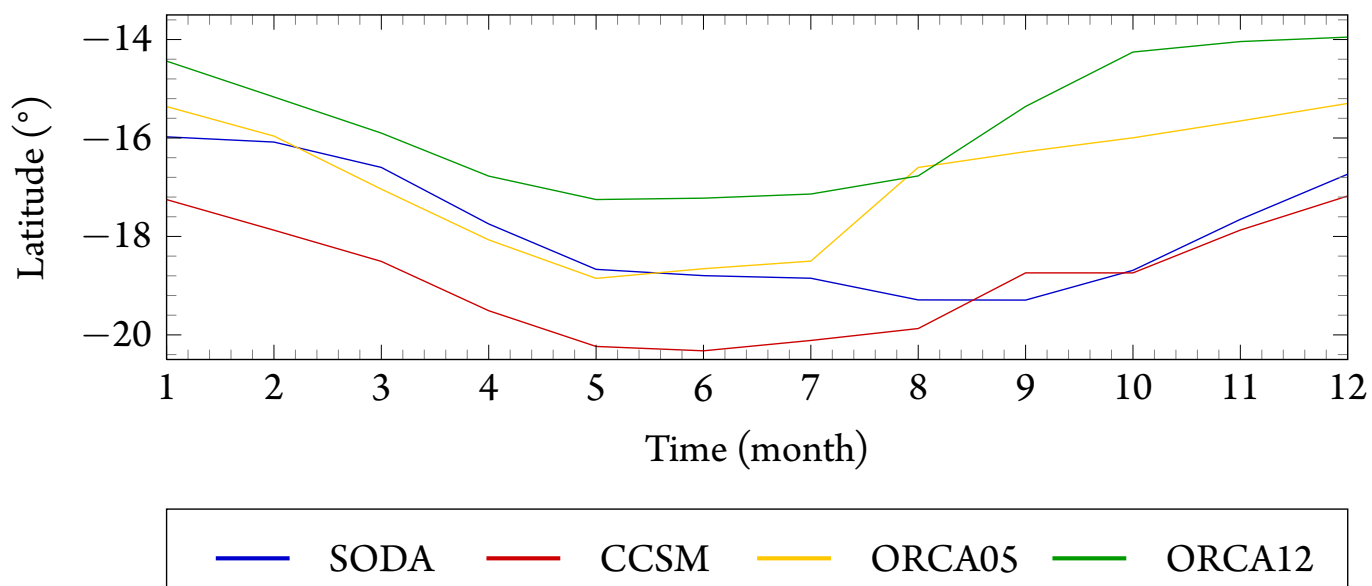

Figure 28: Seasonal variability of the SEC bifurcation position, averaged in the top 200m, for SODA (blue), CCSM (red), ORCA05 (yellow) and ORCA12 (green) datasets, calculated using the zero contour line of meridional velocity, as proposed by Rodrigues, Rothstein \& Winbush (2007).

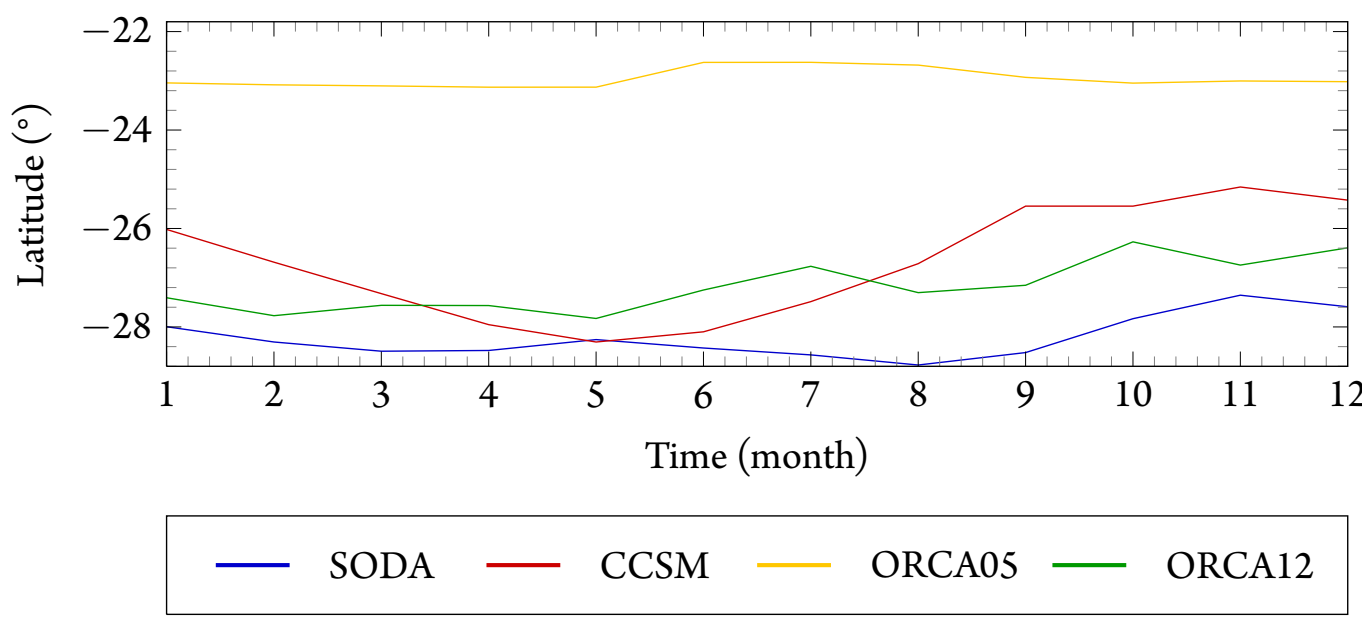

Figure 29: Seasonal variability of the SEC bifurcation position, averaged between 500 and $1000 \mathrm{~m}$, for SODA (blue), CCSM (red), ORCA05 (yellow) and ORCA12 (green) datasets, calculated using the zero contour line of meridional velocity, as proposed by Rodrigues, Rothstein \& Winbush (2007).

BC are 1.5 times larger (Figures 32b and 34) than in the other datasets. ORCA12 (Figure 32d) has the strongest velocities.

In Figure 32, there is also a recirculation cell, formed by the NBUC and an adjacent southward flux, described in Schott et al. (2005) at $11^{\circ} \mathrm{S}$, from observational data. Comparing the results of this work to those found by the authors between 2000 and 2004, ORCA12 is the model simulation that best reproduces the observed velocity section, with velocities $\sim 50 \mathrm{~cm} \cdot \mathrm{s}^{-1}$ at the NBUC core and $12 \mathrm{~cm} \cdot \mathrm{s}^{-1}$ for the offshore recirculation. In ORCA05, the NBUC is shallower than in the other model results, once again, agreeing with the weak MOC found by Danabasoglu et al. (2013).

The volume transport of the NBUC was calculated using only the positive (northward) velocities 

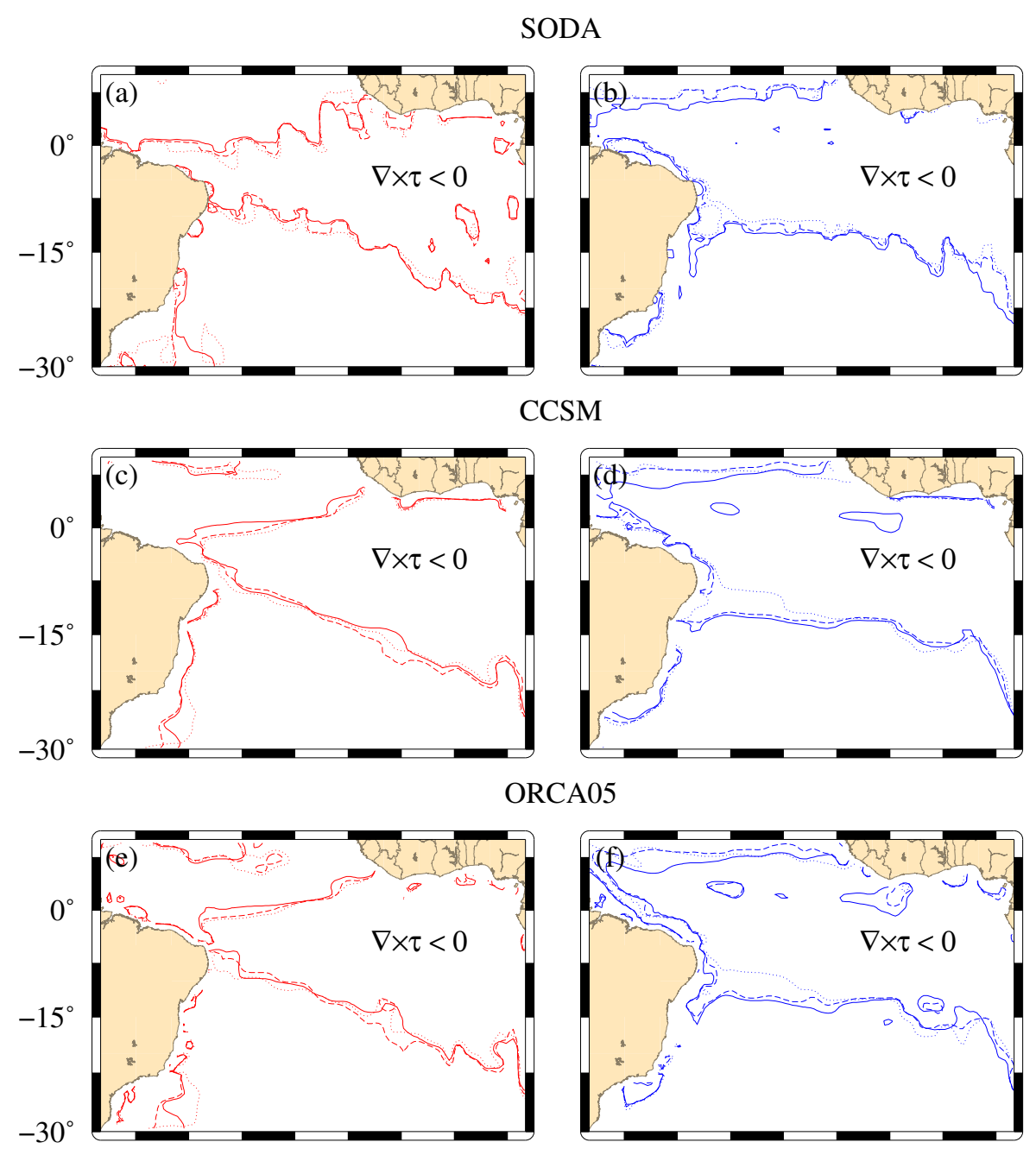

ORCA12
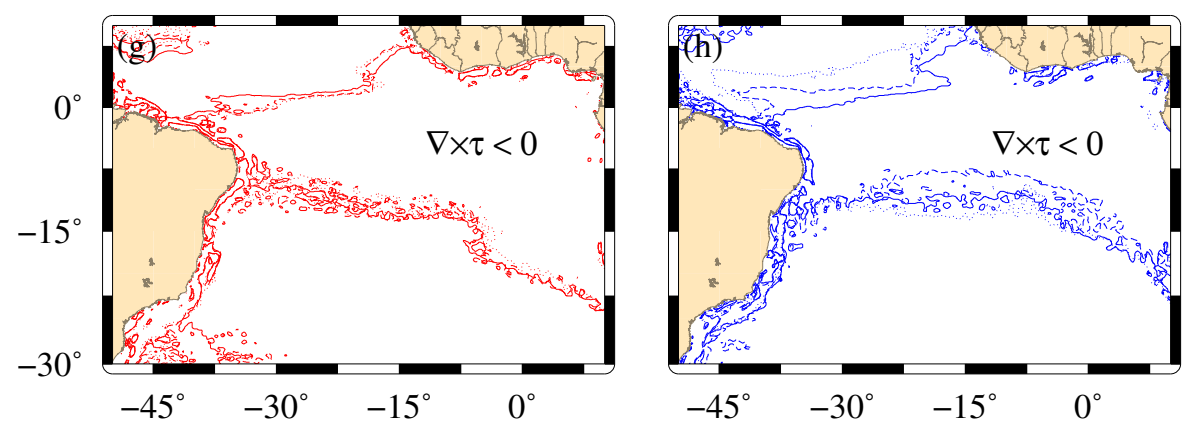

Figure 30: Month averages of zero position of wind stress curl, for SODA (a,b), CCSM (c,d), ORCA05 (e,f) and ORCA12 (g,h) datasets. Red contours are the averages for January (solid line), February (dashed) and March (dotted). Blue ones, averages for July (solid line), August (dashed) and September (dotted).

at $11^{\circ} \mathrm{S}$ (Section 2.2.2). Its seasonality is shown in Figure 33. SODA and ORCA05 have the strongest and the weakest NBUC transports respectively. Averaged values are shown in Table 3.

The seasonal cycle shows that the lowest transport values of NBUC are found during November and December while the maximum transport occurs in June. This variability was described by Schott 
(a) SODA

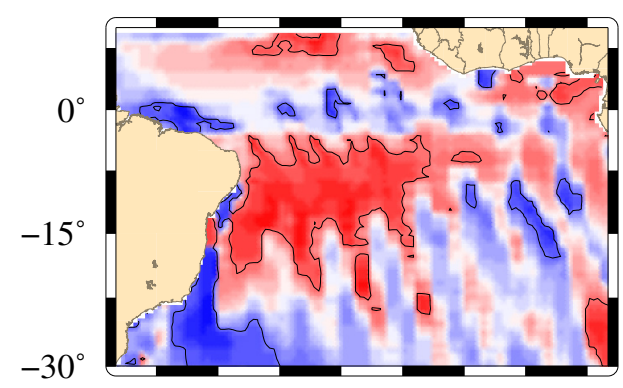

(c) ORCA05

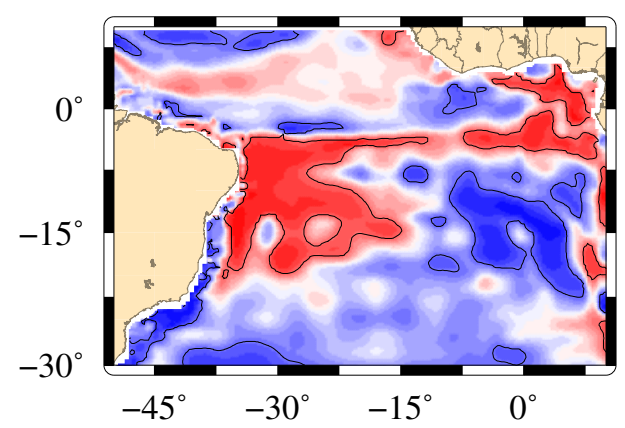

$-45^{\circ}-30^{\circ}-15^{\circ} \quad 0^{\circ}$ (b) CCSM

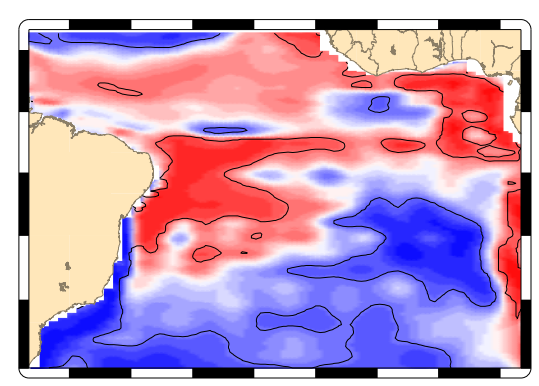

(d) ORCA12
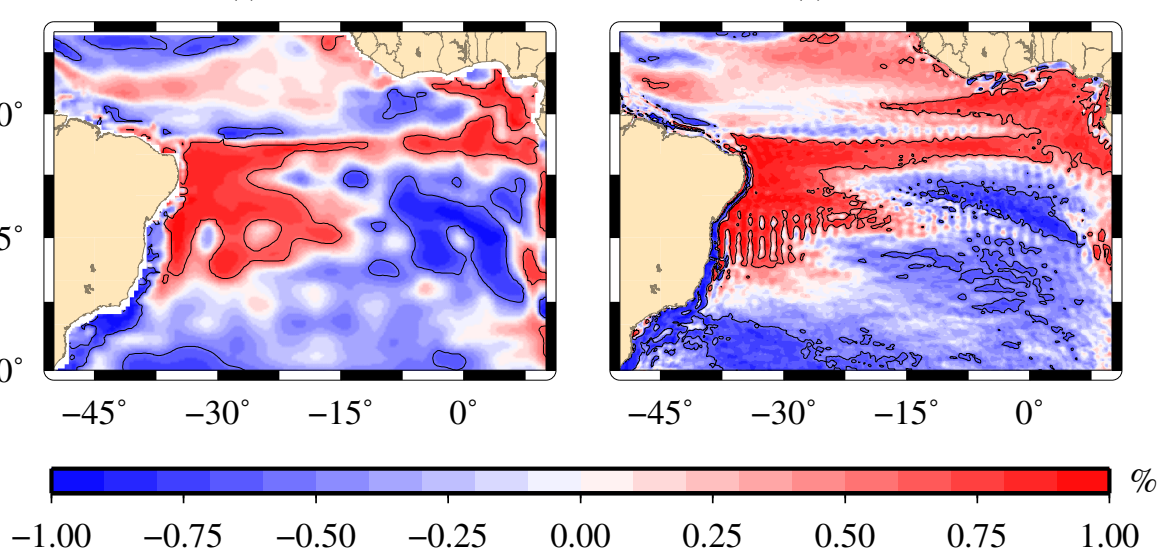

Figure 31: Correlation between the seasonal cycles of bifurcation position in the top 200m (calculated using the zero contour line of meridional velocity, as proposed by Rodrigues, Rothstein \& Winbush (2007)) and of the wind stress curl for SODA (a), CCSM (b), ORCA05 (c) and ORCA12 (d). Black contours mark the areas where the correlations coefficients are statistically significant at $95 \%$.

et al. (2005) and by Schott et al. (1993), Johns et al. (1998) from observations at $5^{\circ} \mathrm{S}$ and is related to the position of the bifurcation (RODRIGUES; ROTHSTEIN; WINBUSH, 2007; SILVA et al., 2009). When the bifurcation is in its southernmost position (during winter, Figures 27 and 28), the northward flux of NBUC is maximum, and the opposite occurs during summer time. The seasonal cycle found here does not correlate with the NBC transport seasonal time series calculated by Johns et al. (1998) at $\sim 5^{\circ} \mathrm{N}$.

CCSM and ORCA12 climatological NBUC transports at $11^{\circ} \mathrm{S}$, showed in Table 3 are closer to the ones described by Silva et al. (2009), using a regional model, between $14^{\circ} \mathrm{S}$ and $8^{\circ} \mathrm{S}$. Schott et al. (2005), from observations, in this latitude found a NBUC transport of $21.7 \mathrm{~Sv} \pm 4.1 \mathrm{~Sv}$.

In Figure 34, in spite of the difference in horizontal resolution, CCSM results (Figure 34b) are closer to the SODA reanalysis (Figure 34a) than ORCA05 (Figure 34c). In the ORCA05 results, the BC is much deeper than in the others and the Intermediate Western Boundary Current (IWBC) is extremely weak. This result is consistent with the shallowest and the weakest northward flow observed in Figure 24, and also agrees with Danabasoglu et al. (2013). ORCA12 (Figure 34d), as in the section at $11^{\circ} \mathrm{S}$ (Figure 32d), has the strongest surface current.

According to Evans \& Signorini (1985), Campos, Gonçalves \& Ikeda (1995), Silveira et al. (2000), 


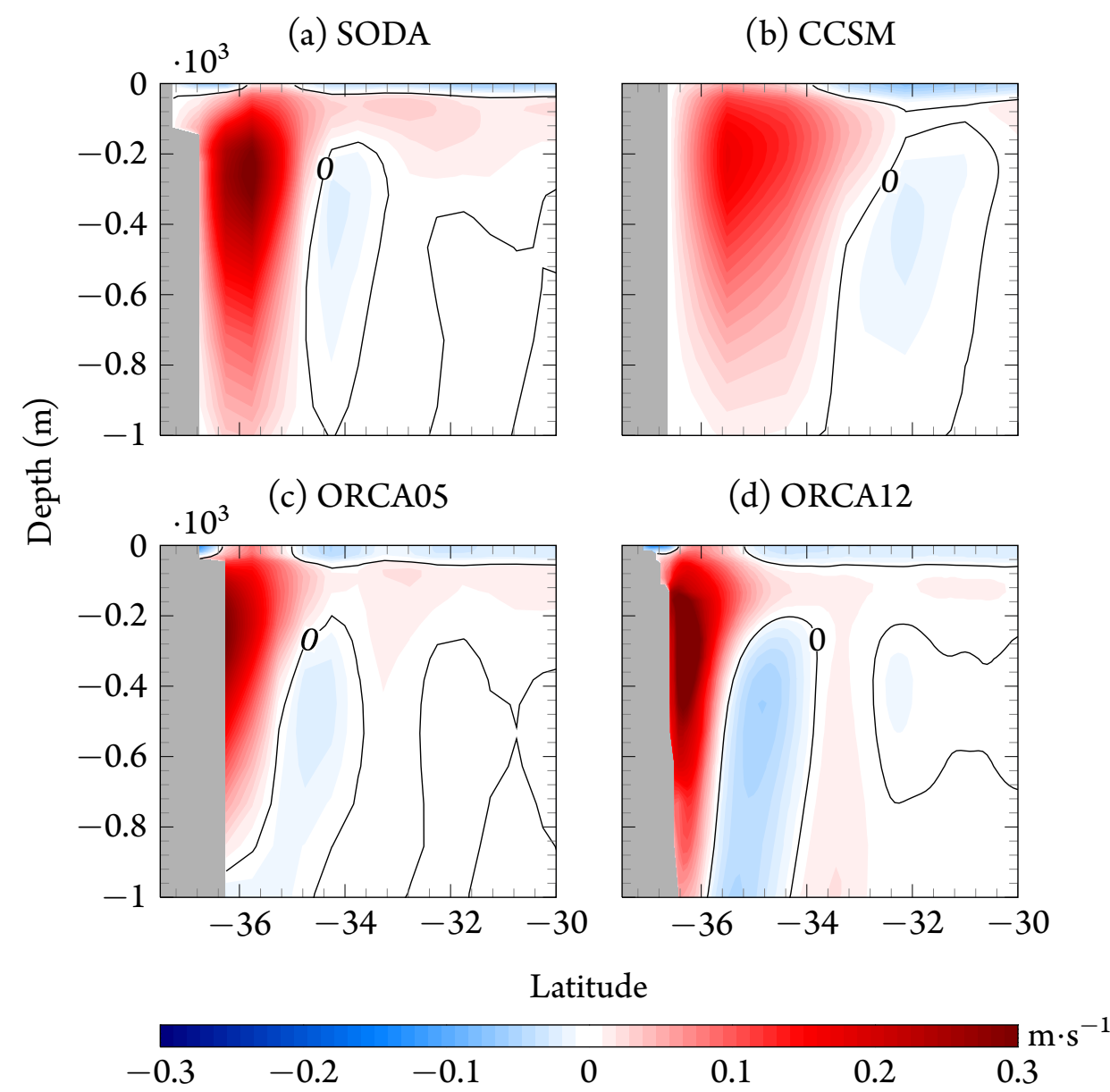

Figure 32: Time averages of meridional velocities $\left(\mathrm{m} \cdot \mathrm{s}^{-1}\right)$ at $11^{\circ} \mathrm{S}$, for SODA (a), CCSM (b), ORCA05 (c) and ORCA12 (d) datasets. Black contours indicates the $0 \mathrm{~m} \cdot \mathrm{s}^{-1}$ line.

Table 3: Meridional volume transport (Sv) of NBUC at $11^{\circ} \mathrm{S}$, in the top $1000 \mathrm{~m}$, calculated in the sections shown in Figure 34.

\begin{tabular}{ccccc}
\hline & SODA & CCSM & ORCA05 & ORCA12 \\
& \multicolumn{4}{c}{ Sv $)$} \\
\hline average & $25.9 \pm 2.0$ & $22.1 \pm 1.8$ & $15.5 \pm 1.8$ & $22.2 \pm 1.1$ \\
summer & $25.2 \pm 3.7$ & $21.3 \pm 2.7$ & $14.8 \pm 2.7$ & $22.6 \pm 3.6$ \\
winter & $26.6 \pm 3.9$ & $23.1 \pm 2.8$ & $16.2 \pm 2.6$ & $22.6 \pm 3.5$ \\
\hline
\end{tabular}

at $28^{\circ} \mathrm{S}$, the $B C$ extends until $750 \mathrm{~m}$. Close to this latitude, its mean observed velocities reaches $50 \mathrm{~cm} \cdot \mathrm{s}^{-1}$ (MÜLLER et al., 1998; SILVEIRA et al., 2000). So, SODA and CCSM results reproduce better the vertical extent of the $\mathrm{BC}$ while ORCA12 shows mean velocities closer to the results found in the literature.

The IWBC is a narrow and weak western boundary current, with velocities that are hardly bigger than $30 \mathrm{~cm} \cdot \mathrm{s}^{-1}$, and the curent flow rapidly accelerates away from the formation region, at the Santos Bifurcation (BOEBEL et al., 1999; SILVEIRA; CALADO; CASTRO, 2004). According to Legeais, 
(a) SODA

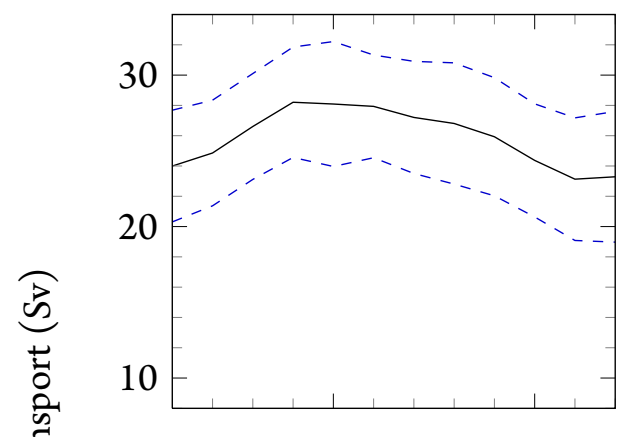

(c) ORCA05

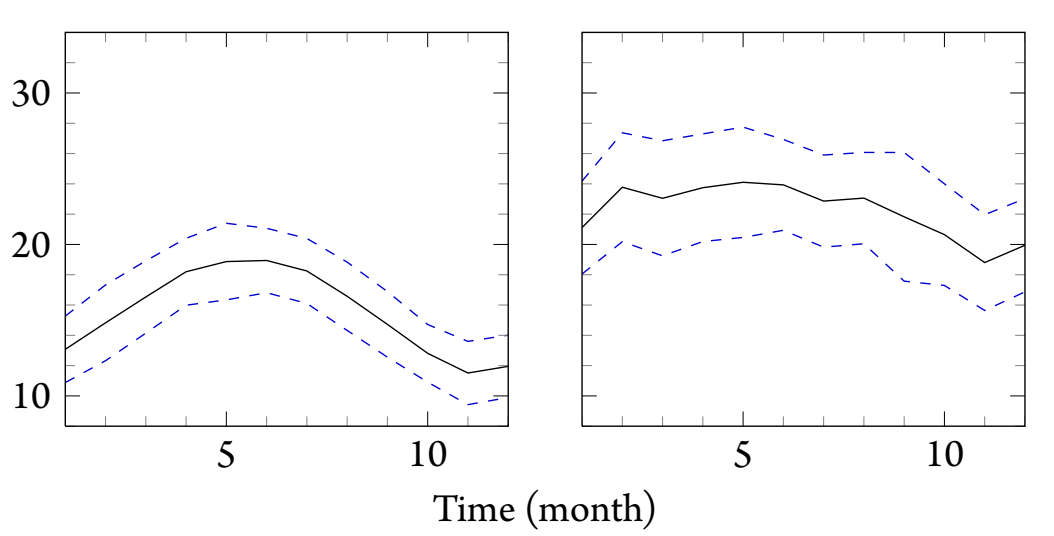

(b) CCSM

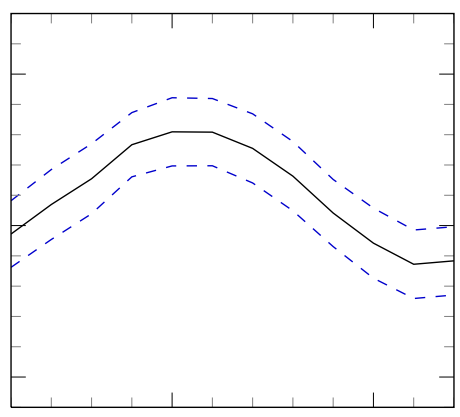

(d) ORCA12

Figure 33: Seasonal cycle of the volume transport (Sv) of NBUC at $11^{\circ} \mathrm{S}$, for SODA (a), CCSM (b), ORCA05 (c) and ORCA12 (d) datasets, calculated at the top $1000 \mathrm{~m}$ as shown on Figure 32. The dashed blue lines indicate the standard deviation for each month.

Ollitrault \& Arhan (2013), close to this latitude, at $26^{\circ} \mathrm{S}$, the current reaches velocities above $15 \mathrm{~cm} \cdot \mathrm{s}^{-1}$.

As the transports calculated in Figure 35 depend on the sections showed in Figure 34, ORCA05 has the strongest southward flux (while it had the weakest northward transports at $11^{\circ} \mathrm{S}$, as shown in Figure 33). In fact, the average transports for the ORCA05 results at $27^{\circ} \mathrm{S}$ is twice the value calculated for CCSM and SODA (Table 4). The volume transport of BC is maximum during the summer (Figure 35), while the bifurcation is further north (Figures 27 and 28), and the northward transport of NBUC is minimum (Figure 33). This behaviour was documented by Schott et al. (2005), Rodrigues, Rothstein \& Winbush (2007), Silva et al. (2009). Observing Figure 35, it is clear that neither SODA nor ORCA12 show a well marked seasonal cycle.

Although the BC seen from ORCA05 results is the one that most differs from the SODA reanalysis, its transport value in the top $1000 \mathrm{~m}$ is the closest to those found in the literature (Table 4). According to Müller et al. (1998), at $28^{\circ} \mathrm{S}$ the BC transport is $16 \mathrm{~Sv}$.

In Figure 36, the main difference between the SODA reanalysis (Figure 36a) and the model results is the intensity of the zonal velocities of SEC (stronger in SODA). As described by Stramma (1991), the south sSEC has velocities $\sim 10 \mathrm{~cm} \cdot \mathrm{s}^{-1}$. According to the same authors, south of $10^{\circ} \mathrm{S}$, west of Green- 


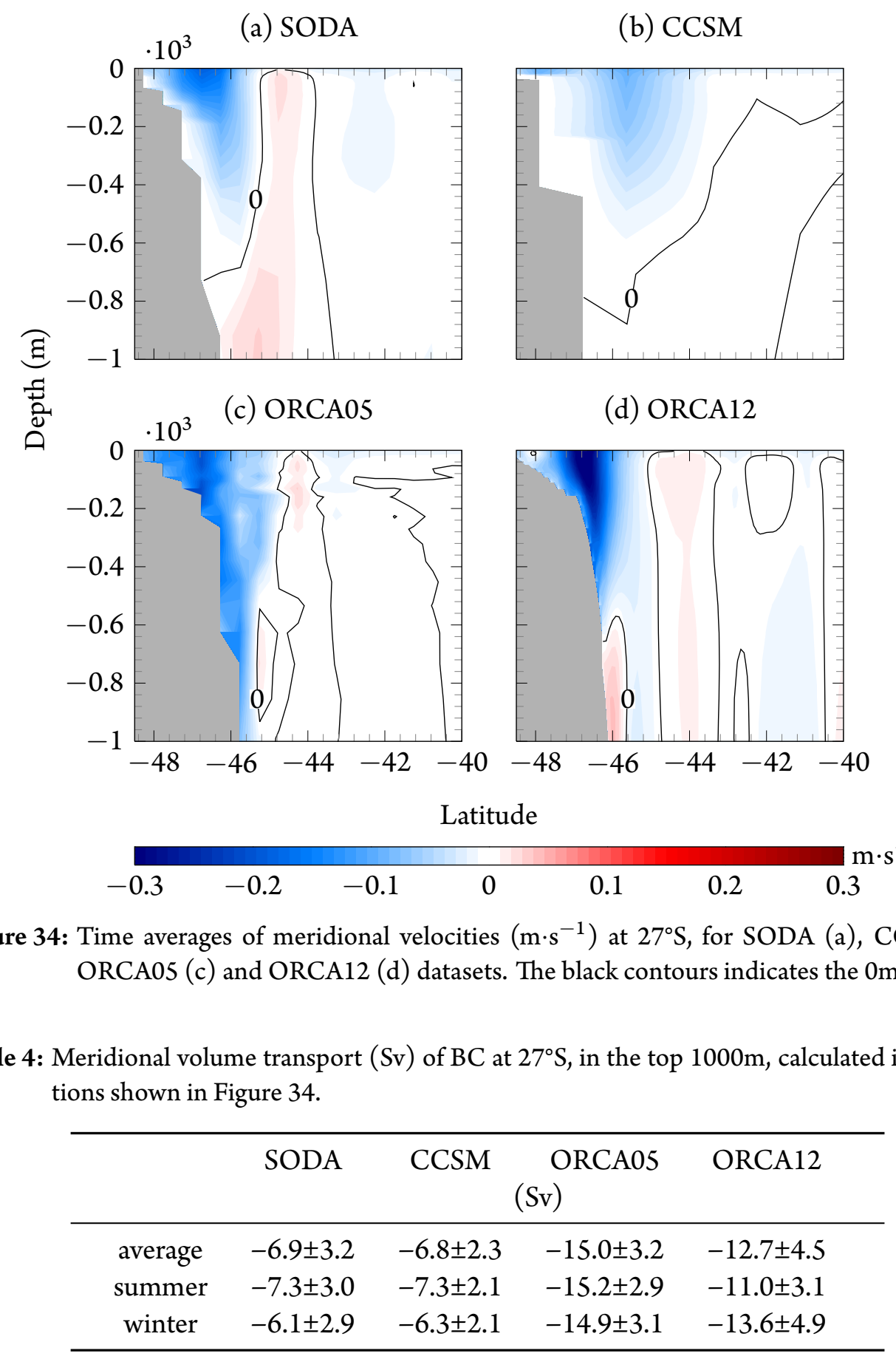

which Meridian, the SEC is a broad and sluggish flow. One can identify in this section two near-surface cores of sSEC, speacially in the SODA reanalysis (Figure 36a): $\sim 18^{\circ} \mathrm{S}$ and $\sim 13,5^{\circ} \mathrm{S}$. These cores were observed by Stramma (1991), Stramma \& England (1999b), Lumpkin \& Garzoli (2005), Silva et al. (2009). According to Wienders, Arhan \& Mercier (2000), the poleward boundary of the SEC's southern branch is at $25^{\circ} \mathrm{S}$ through the whole thickness of the subtropical gyre, but the latitude of the northern boundary varies from $7.5^{\circ} \mathrm{S}$ at the surface and in the western South Atlantic, to $27^{\circ} \mathrm{S}$ at $1400 \mathrm{~m}$ depth and 
(a) SODA

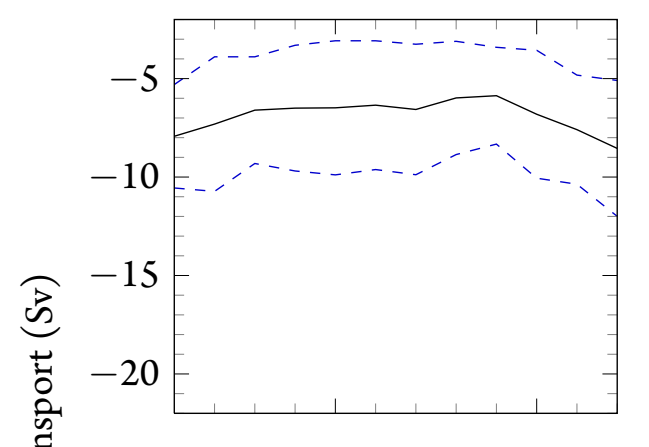

(c) ORCA05

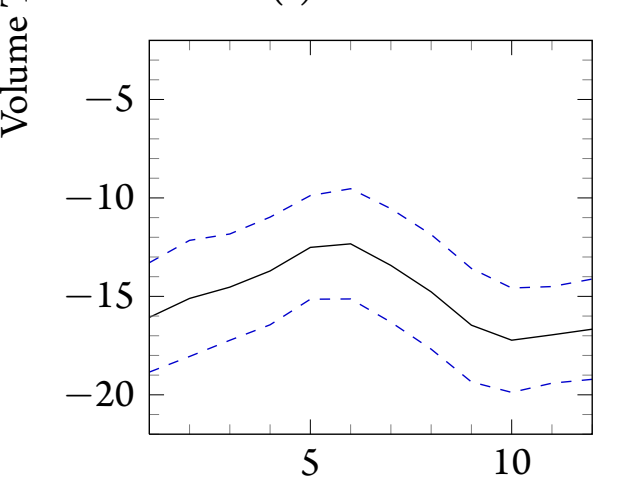

Time (month)

(b) CCSM

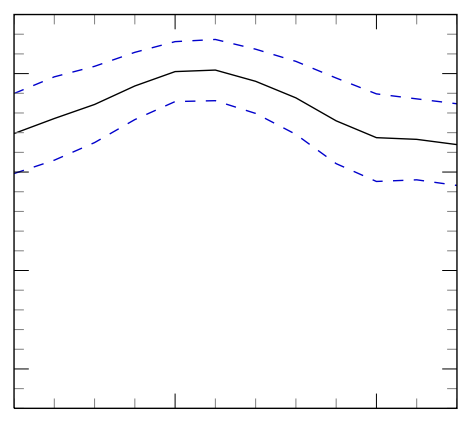

(d) ORCA12

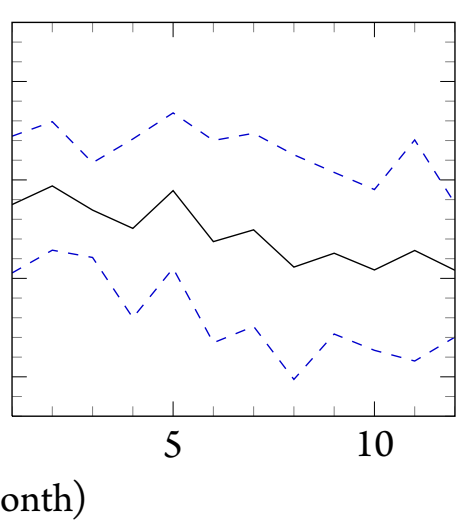

Figure 35: Seasonal cycle of the volume transport (Sv) of BC at $27^{\circ} \mathrm{S}$, for SODA (a), CCSM (b), ORCA05 (c) and ORCA12 (d) datasets, calculated at the top $1000 \mathrm{~m}$ as shown on Figure 34. The dashed blue lines indicate the standard deviation for each month.

in the eastern basin. A third core is observed in the north limit of the section, and corresponds to the south part of the central branch of the SEC (cSEC) (LUMPKIN; GARZOLI, 2005).

Between the sSEC and cSEC, a near surface eastward core is identified in almost all the datasets (Figure 36a,b,c) and also by Silva et al. (2009). It is the upper core of the South Equatorial Countercurrent (SECC) (BONHOURE et al., 2004). Under the SEC, we find an eastward flux, continuous in CCSM and ORCA05 results (Figure 36b,c) while it appears as several branchs in the SODA reanalysis and ORCA12 results (Figure 36a,d). The same branches were observed by Silva et al. (2009), in their $1 \% 12$ regional model.

As described in Section 2.2.2, the transports of the SEC were calculated for different regions, centered in the latitude of the two main sections: between $13^{\circ} \mathrm{S}$ and $9^{\circ} \mathrm{S}$ and between $29^{\circ} \mathrm{S}$ and $25^{\circ} \mathrm{S}$.

Figure 37 and Table 5 show the seasonal cycle of the SEC transport, between $13^{\circ} \mathrm{S}$ and $9^{\circ} \mathrm{S}$. Observing the time series, it is possible to verify that the ORCA05 results have the lowest volume transport and the reanalysis the largest. ORCA12 results have the smallest amplitude variability. In this area, the transport calculated is a mix of the cSEC (between SEC $\left(3^{\circ} \mathrm{S}-5^{\circ} \mathrm{S}\right)$ and the South Equatorial Counter Current $\left(6^{\circ} S-9^{\circ} S\right)$, according to Molinari, Voituriez \& Duncan (1981), Peterson \& Stramma (1990), 


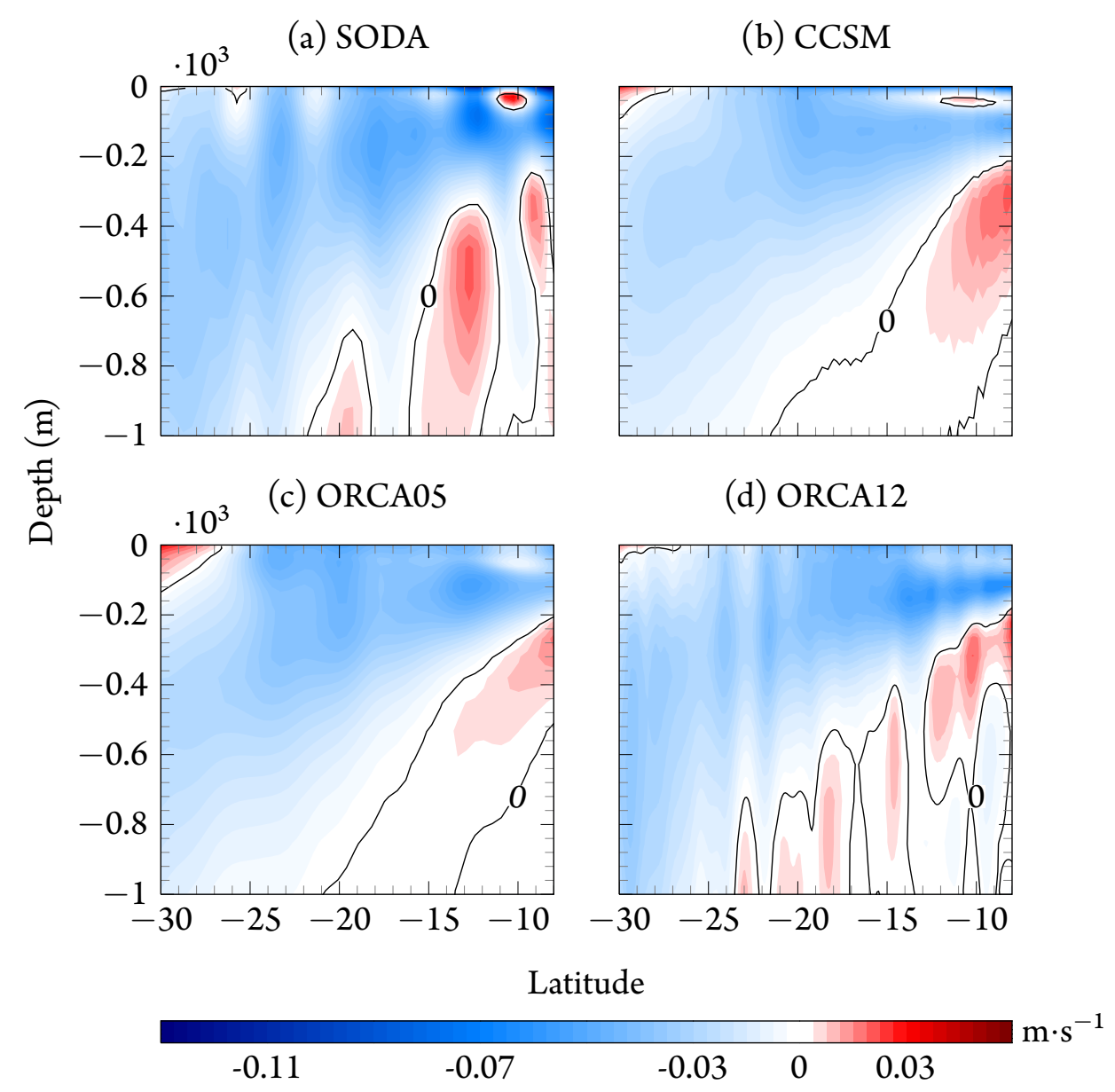

Figure 36: Time averages of zonal velocities $\left(\mathrm{m} \cdot \mathrm{s}^{-1}\right)$ at $25^{\circ} \mathrm{W}$, for SODA (a), CCSM (b), ORCA05 (c) and ORCA12 (d) datasets. The black contours indicates the $0 \mathrm{~m} \cdot \mathrm{s}^{-1}$ line.

Stramma (1991)) and sSEC (south of the SECC). The transport of cSEC is about $17 \mathrm{~Sv}$ in the first $200 \mathrm{~m}$ with typical variation between 7 to $26 \mathrm{~Sv}$ (MOLINARI, 1982), while the transport of sSEC in the top $500 \mathrm{~m}$ is about 20Sv (BONHOURE et al., 2004). Also, in all the datasets, the SEC is weaker between May and June, while its maximum occurs between August and October in the SODA reanalysis, and between October and November in the models. The results of Molinari (1983), Stramma (1991), the SEC is stronger during the austral winter (July and August), which makes the SODA results closer to the observations.

Figure 38 shows the SEC transport, between $25^{\circ} \mathrm{S}$ and $29^{\circ} \mathrm{S}$. CCSM and ORCA05 results show that the strongest values of SEC transport occur during winter. SODA seems to have a semi-annual cycle, but the high standard deviation in the last 3 months masks it.

Table 6 shows the averages for the SEC transport. SODA and ORCA12 show similar results, but they are much smaller than those found in the literature. According to Bonhoure et al. (2004), the sSEC transport measured in the upper and intermediate layers is 49Sv. As the limit of the sSEC is usually between $10^{\circ} \mathrm{S}$ and $25^{\circ} \mathrm{S}$, such differences can be related to the area where the transports were calculated. Boebel et al. (1999) found that near 30S, the sSEC (called by the authors "Return Current") transports 
(a) SODA

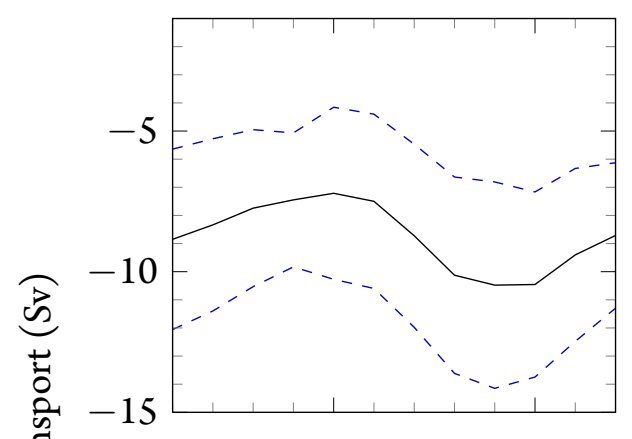

(c) ORCA05

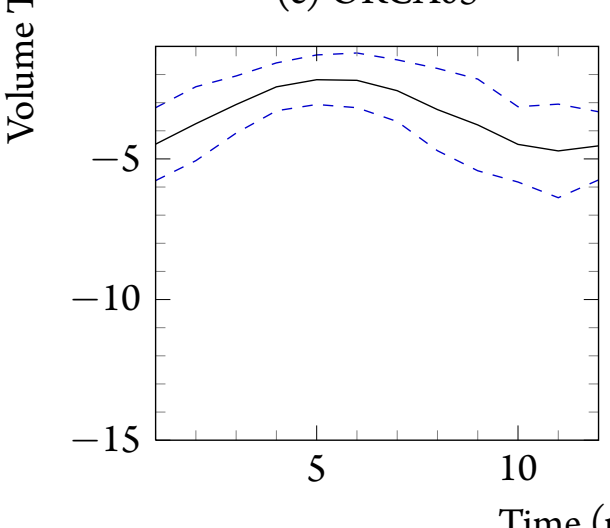

(b) CCSM

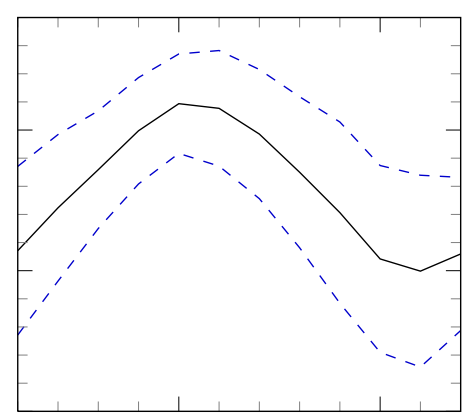

(d) ORCA12

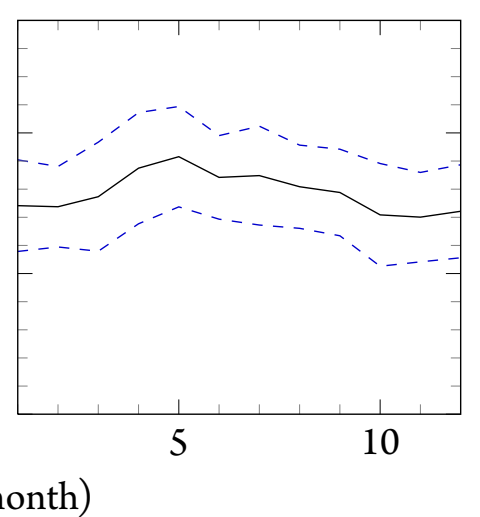

Figure 37: Seasonal cycle of the volume transport (Sv) of SEC at $25^{\circ} \mathrm{W}$, for SODA (a), CCSM (b), ORCA05 (c) and ORCA12 results, calculated at the top $1000 \mathrm{~m}$ as shown on Figure 36, between $13^{\circ} \mathrm{S}$ and $9^{\circ} \mathrm{S}$. The dashed blue lines indicate the standard deviation for each month.

Table 5: Zonal volume transport (Sv) of SEC at $25^{\circ} \mathrm{W}$, in the top $1000 \mathrm{~m}$, between $13^{\circ} \mathrm{S}$ and $9^{\circ} \mathrm{S}$ calculated in the sections shown in Figure 36.

\begin{tabular}{ccccc}
\hline & SODA & CCSM & $\begin{array}{c}\text { ORCA05 } \\
(\text { Sv })\end{array}$ & ORCA12 \\
\hline average & $-8.8 \pm 3.3$ & $-7.1 \pm 3.4$ & $-3.5 \pm 1.6$ & $-7.1 \pm 1.8$ \\
summer & $-8.3 \pm 3.0$ & $-7.8 \pm 2.8$ & $-3.8 \pm 1.3$ & $-7.5 \pm 1.7$ \\
winter & $-9.8 \pm 3.5$ & $-6.5 \pm 3.0$ & $-3.2 \pm 1.5$ & $-6.8 \pm 1.6$ \\
\hline
\end{tabular}

$12 \pm 3 \mathrm{~Sv}$, which is closer to the results obtained in this work.

As both the NBUC and the BC originates from the bifurcation of the SEC close to $11^{\circ} \mathrm{S}$, the seasonal time series of the transports of these currents at $11^{\circ} \mathrm{S}$ (Figure 33) and $27^{\circ} \mathrm{S}$ (Figure 35) respectively were also correlated with the seasonal time series of the SEC at $25^{\circ} \mathrm{W}$, between $13^{\circ} \mathrm{S}$ and $9^{\circ} \mathrm{S}$ (Figure 37). The results are shown in Tables 7 and 8 . The results from all the models present high, positive correlations between the transports of the SEC and the NBUC (Table 7): which means that, when the SEC flux is minimum (or, more positive values), the NBUC transport is maximum (also more positive values) 
(a) SODA

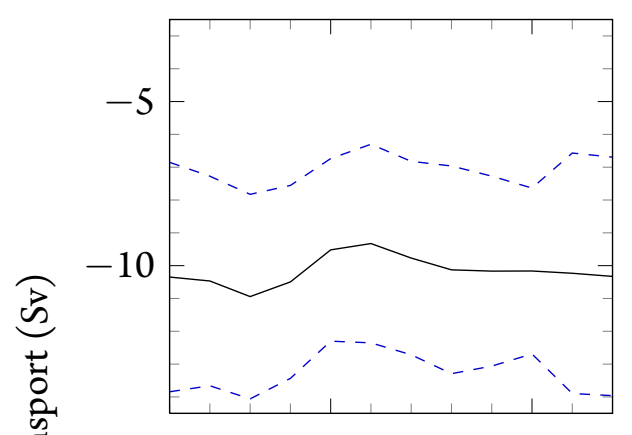

(c) ORCA05

草

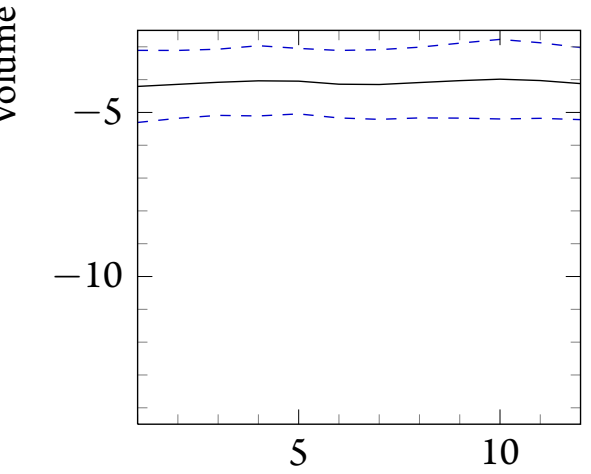

(b) CCSM

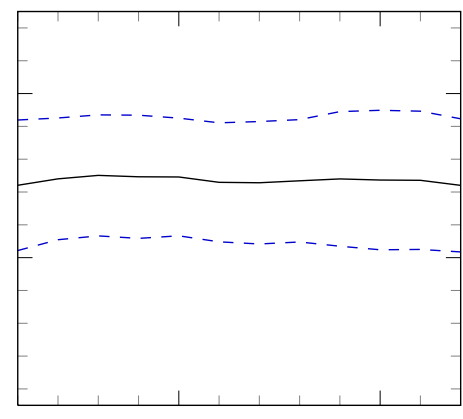

(d) ORCA12

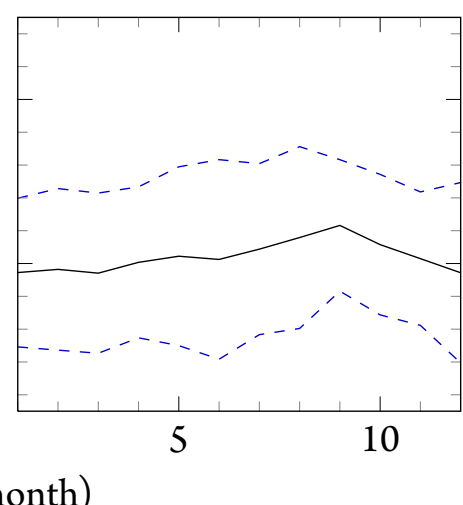

Figure 38: Seasonal cycle of the volume transport (Sv) of SEC at $25^{\circ} \mathrm{W}$, for SODA (a), CCSM (b), ORCA05 (c) and ORCA12 (d) datasets, calculated at the top $1000 \mathrm{~m}$ as shown on Figure 36 , between $29^{\circ} \mathrm{S}$ and $25^{\circ} \mathrm{S}$. The dashed blue lines indicate the standard deviation for each month.

Table 6: Zonal volume transport of SEC at $25^{\circ} \mathrm{W}$, in the top $1000 \mathrm{~m}$, between $29^{\circ} \mathrm{S}$ and $25^{\circ} \mathrm{S}$ calculated in the sections shown in Figure 36.

\begin{tabular}{ccccc}
\hline & SODA & CCSM & ORCA05 & ORCA12 \\
& & \multicolumn{2}{c}{$(\mathrm{Sv})$} & \\
\hline average & $-10.2 \pm 3.1$ & $-7.6 \pm 1.9$ & $-4.1 \pm 1.6$ & $-9.8 \pm 2.5$ \\
summer & $-10.6 \pm 3.0$ & $-7.6 \pm 1.8$ & $-4.1 \pm 1.1$ & $-10.2 \pm 2.2$ \\
winter & $-10.0 \pm 2.8$ & $-7.7 \pm 1.9$ & $-4.1 \pm 1.2$ & $-9.2 \pm 2.2$ \\
\hline
\end{tabular}

while the $\mathrm{BC}$ transport decreases. Only the low resolution models show correlations between the SEC and BC (Table 7). This is because the seasonal cycle of the transport of the BC in SODA and ORCA12 at $27^{\circ} \mathrm{S}$ is not well marked as in the other two models, which can indicate an influence of other physical processes, as mesoscale activity (ORCA12).

According to Rodrigues, Rothstein \& Winbush (2007), since the bifurcation latitude variability is a manifestation of changes in the flow of the currents involved, the local component of the forcing, responsible for most of the variability in the sSEC bifurcation (Figure 30), explains the decrease in the 
Table 7: Correlation between monthly averages of the transport of NBUC at $11^{\circ} \mathrm{S}$ (Figure 33) and seasonal transports of SEC at $25^{\circ} \mathrm{W}$, between $13^{\circ} \mathrm{S}$ and $9^{\circ} \mathrm{S}$ (Figure 37 ).

\begin{tabular}{ccccc}
\hline & SODA & CCSM & ORCA05 & ORCA12 \\
\hline correlation & 0.40 & 0.99 & 0.99 & 0.79 \\
p-value & 0.20 & $<0.01$ & $<0.01$ & $<0.01$ \\
\hline
\end{tabular}

Table 8: Correlation between monthly averages of the transport of $\mathrm{BC}$ at $27^{\circ} \mathrm{S}$ (Figure 35) and seasonal transports of SEC at $25^{\circ} \mathrm{W}$, between $13^{\circ} \mathrm{S}$ and $9^{\circ} \mathrm{S}$ (Figure 37).

\begin{tabular}{ccccc}
\hline & SODA & CCSM & ORCA05 & ORCA12 \\
\hline correlation & -0.15 & 0.99 & 0.96 & 0.12 \\
p-value & 0.64 & 0.01 & $<0.01$ & 0.70 \\
\hline
\end{tabular}

transport of both SEC and BC during winter and the subsequent increase in summer. This can be seen in Figure 39, in which the transports where correlated to the wind stress curl between $30^{\circ} \mathrm{S}$ and $10^{\circ} \mathrm{N}$ and $50^{\circ} \mathrm{W}$ to $10^{\circ} \mathrm{E}$.

The negative and significant correlations between seasonal transports at $11^{\circ} \mathrm{S}$ and wind stress curl time series are larger than 50\% in all the datasets in the northwest South Atlantic (Figure 39a,c,e,g), reaching $15^{\circ} \mathrm{W}$. These high negative correlations in the west part of South Atlantic extends from 18 $15^{\circ} \mathrm{S}$ to $3^{\circ} \mathrm{S}$. It has also a positive correlation with the southeast part of the area. These regions of high correlations are consistent to those found in Figure 30 (correlation between wind stress curl and the bifurcation position in the surface), suggesting a strong relationship between wind stress curl, bifurcation position and NBUC transports. In fact, as shown in Table 9, and as predicted in the literature (RODRIGUES; ROTHSTEIN; WINBUSH, 2007; SILVA et al., 2009), the correlations between the bifurcation position and the northward transports of the NBUC are greater than $80 \%$ in all models. Also, the bifurcation position and the transports at $25^{\circ} \mathrm{W}$ are well correlated. All these results clearly suggest the dominance of the Sverdrup balance as the main dynamical processes controlling the phenomena in the surface.

The correlations between the seasonal transport at $27^{\circ} \mathrm{S}$ and the wind stress show the same pattern described above (Figure 39b,d,f) except for ORCA12 results (Figure 39h) where no significant correlations with the local wind stress curl were found. Looking at Figure 35d, that shows the transport of the $\mathrm{BC}$, it can be seen that the seasonal cycle is influenced by a high frequency variability, that can be a result of the mesoscale activity considering that ORCA12 is a high resolution model and the $\mathrm{BC}$ was calculated in $27^{\circ} \mathrm{S}$, far away from the bifurcation region.

The situation, however, is not as clear at intermediate depths. There is no significant correlations between the SEC transports at $25^{\circ} \mathrm{W}$, between $27^{\circ} \mathrm{S}$ and $23^{\circ} \mathrm{S}$ and the bifurcation position (Table 11), even for SODA, that responds well to the observations (RODRIGUES; ROTHSTEIN; WINBUSH, 


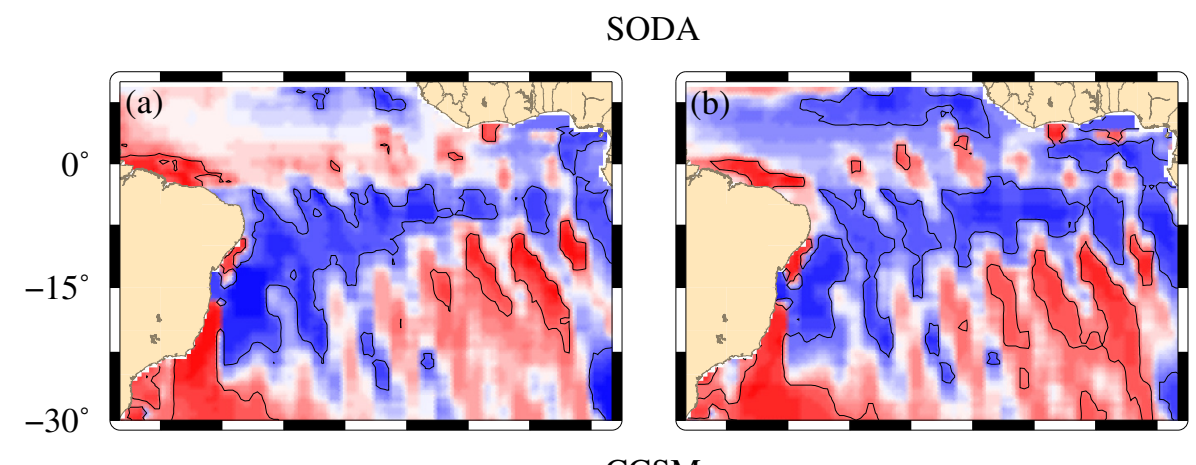

CCSM

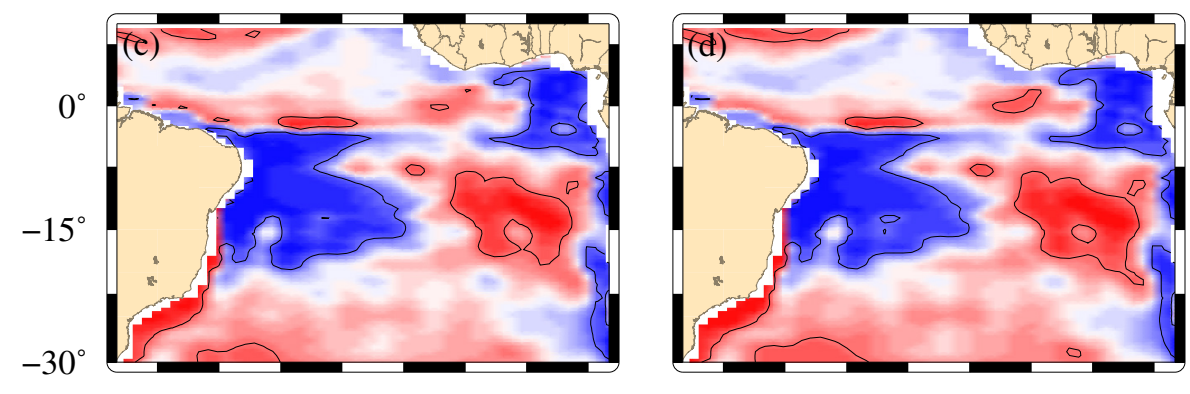

ORCA05

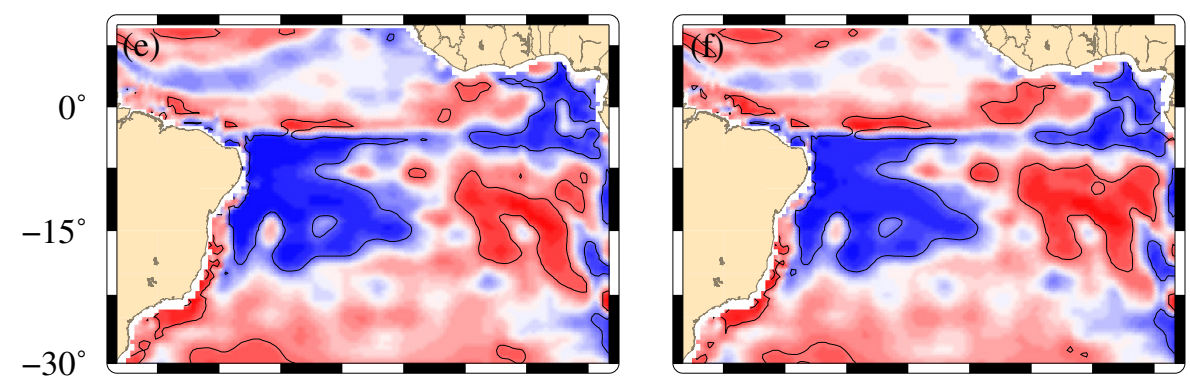

ORCA12

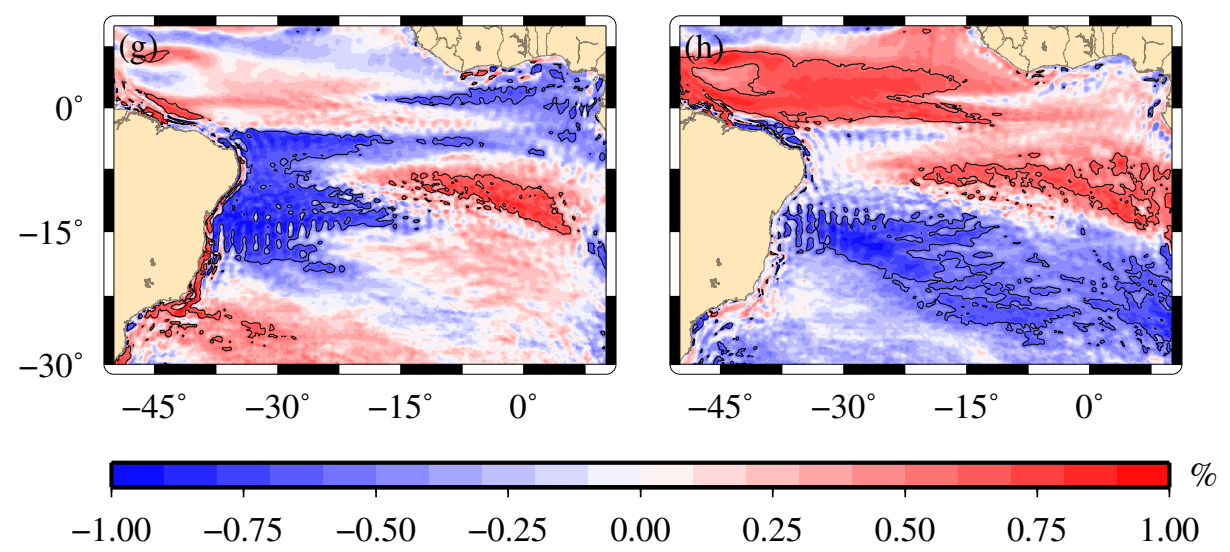

Figure 39: Correlations at zero lag of seasonal time series of wind stress curl with the transport of NBUC at $11^{\circ} \mathrm{S}$ (left panels) and the transport of BC at $27^{\circ} \mathrm{S}$ (right panels), for SODA (a,b), CCSM (c,d), ORCA05 (e,f) and ORCA12 (g,h) datasets. Black contours mark the areas where the results are significant ( $p$-value is lower than 0.05 ).

2007). Huge differences between CCSM and ORCA05 suggests that the wind stress is not the mechanism controlling the bifurcation position at intermediate depths. 
Table 9: Correlation between monthly averages of the bifurcation position in the top 200m (Figure 28 and seasonal transports of NBUC at $11^{\circ} \mathrm{S}$ (Figure 33).

\begin{tabular}{ccccc}
\hline & SODA & CCSM & ORCA05 & ORCA12 \\
\hline correlation & -0.92 & -0.87 & -0.94 & -0.86 \\
p-value & $<0.01$ & $<0.01$ & $<0.01$ & $<0.01$ \\
\hline
\end{tabular}

Table 10: Correlation between monthly averages of the bifurcation position in the top $200 \mathrm{~m}$ (Figure 28 and seasonal transports of SEC at $25^{\circ} \mathrm{W}$, between $13^{\circ} \mathrm{S}$ and $9^{\circ} \mathrm{S}$ (Figure 37).

\begin{tabular}{ccccc}
\hline & SODA & CCSM & ORCA05 & ORCA12 \\
\hline correlation & 0.33 & -0.86 & -0.96 & -0.92 \\
p-value & 0.29 & $<0.01$ & $<0.01$ & $<0.01$ \\
\hline
\end{tabular}

Table 11: Correlation between monthly averages of the bifurcation position in the bottom $500 \mathrm{~m}$ (Figure 29) and seasonal transports of SEC at $25^{\circ} \mathrm{W}$, between $27^{\circ} \mathrm{S}$ and $23^{\circ} \mathrm{S}$ (Figure 38).

\begin{tabular}{ccccc}
\hline & SODA & CCSM & ORCA05 & ORCA12 \\
\hline correlation & -0.11 & -0.40 & -0.33 & 0.43 \\
p-value & 0.73 & 0.20 & 0.30 & 0.16 \\
\hline
\end{tabular}

\subsubsection{Interannual variability}

This section shows the results related to the interannual variability of the SEC bifurcation. To avoid the influence of the seasonal cycle, all the results are annual.

\subsubsection{South Equatorial Currents bifurcation}

The section of annual averages of meridional velocities within a $4^{\circ}$ longitude band off South America (exemplified in Figure 24) was used to determine the SEC bifurcation position (Figure 40). The deeper the bifurcation, the greater the amplitude of the variability in each latitude. This is a new result, so, there is no comparison with the literature.

Following the same methodology, the bifurcation position was averaged in the top $200 \mathrm{~m}$ and between $500 \mathrm{~m}$ and $1000 \mathrm{~m}$. Figure 41 shows the annual means of the averaged top $200 \mathrm{~m}$ bifurcation position. As already described in Figure 28, ORCA05 and ORCA12 display the northernmost bifucation latitude and the CCSM run the southernmost. Forced by the same dataset, CORE-II (Section 2.1.4), despite of the differences in mean latitude position, ORCA05 and CCSM show similar time series (Table 12), which did not happen in seasonal time scales (Figure 27). Comparing all the time series, we found good correlations between CCSM and ORCA05 (almost 80\%), and between SODA and ORCA12 (more than 67\%), indicating that these models have similar variability. Unexpectedly, no cor- 


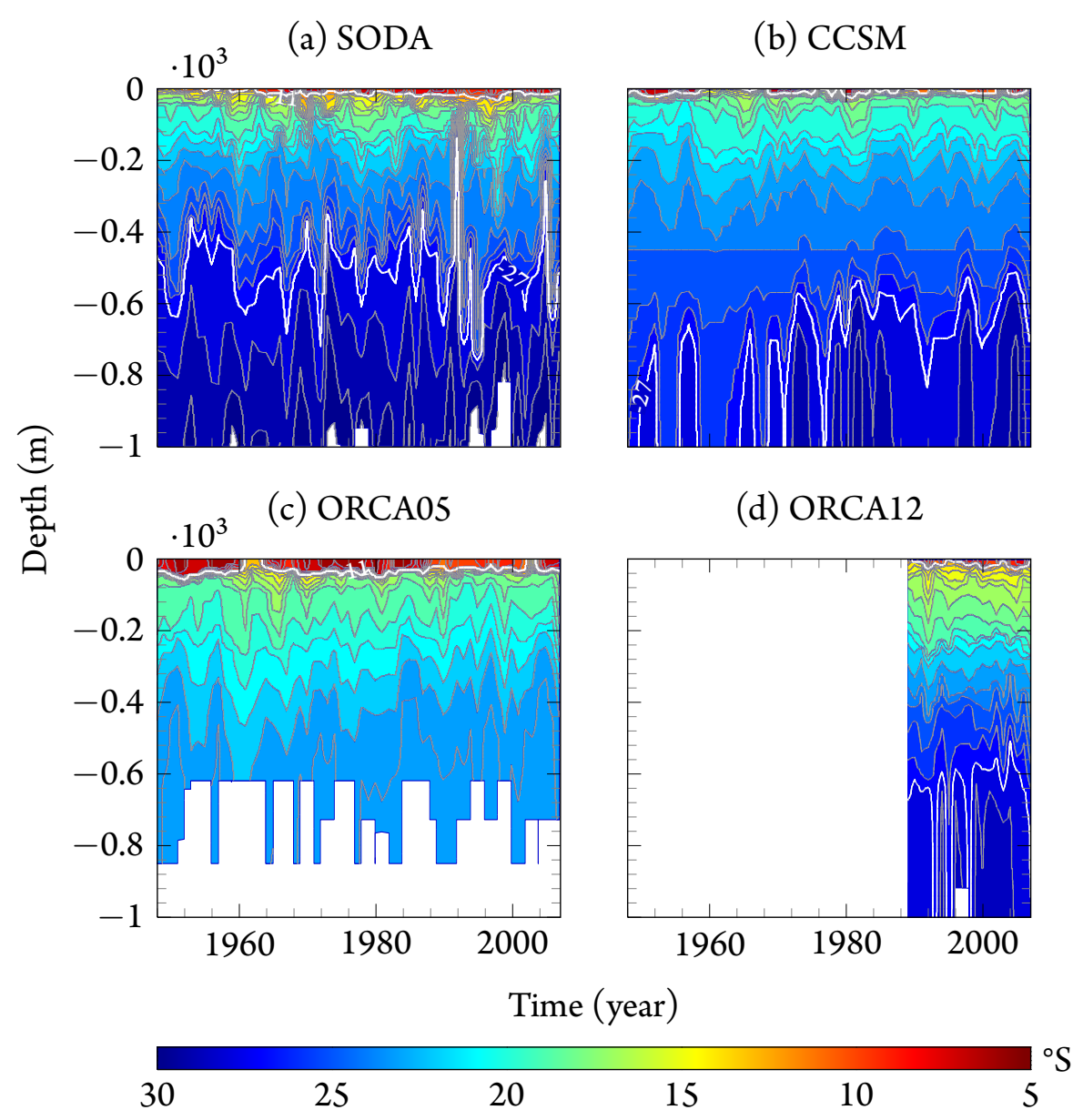

Figure 40: Position of the bifurcation of SEC time series (annual averages), for SODA (a), CCSM (b), ORCA05 (c) and ORCA12 datasets, calculated at top 1000m, using the zero contour line of meridional velocity, as proposed by Rodrigues, Rothstein \& Winbush (2007) (Section 2.2.1), between $30^{\circ} \mathrm{S}$ and $5^{\circ} \mathrm{S}$. Contours are every $1^{\circ}$.

relations between CORE-II forced models and the SODA reanalysis were found. Except for ORCA05, the datasets showed a positive trend (Table 14), indicading an equatorward movement of the bifurcation position, which corroborates with recent studies showing a scenario of expansion (40\%) of the subtropical gyre (GARZOLI; MATANO, 2011).

As already discussed in the beginning of this chapter, ORCA05 underestimates the southern limit of the bifurcation position, and its mean latitude, between $500 \mathrm{~m}$ and $1000 \mathrm{~m}$, does not reach $25^{\circ} \mathrm{S}$. According to Müller et al. (1998), Stramma \& England (1999b), Boebel et al. (1999) south of SEC bifurcation, the IWBC goes south, enjoying $\mathrm{BC}$, and both currents can be seen as one, with an increased vertical extension. It also explains the inexistent IWBC in ORCA05 results at $27^{\circ} \mathrm{S}$, and because of that, the IWBC transports will not be analyzed in this model output.

Between $500 \mathrm{~m}$ and $1000 \mathrm{~m}$, only the models forced by CORE-II data showed a similar variability (Table 13). ORCA12 and SODA show good correlations, but they were not statistically significant at $95 \%$. Also, differently from the top $200 \mathrm{~m}$, at intermediate depths, the bifurcation is going south (Ta- 


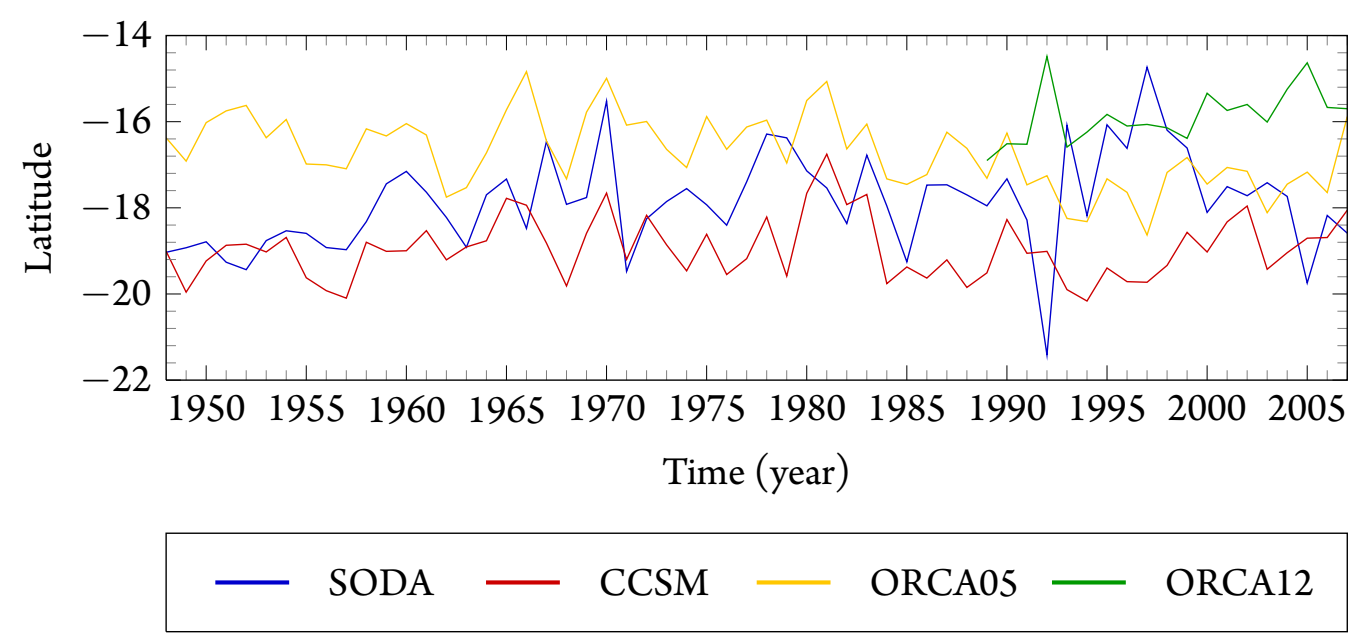

Figure 41: SEC bifurcation position time series, averaged in the top $200 \mathrm{~m}$, for SODA (blue), CCSM (red), ORCA05 (yellow) and ORCA12 (green) datasets, calculated using the zero contour line of meridional velocity, as proposed by Rodrigues, Rothstein \& Winbush (2007).

Table 12: Correlation between annual averages of the bifurcation position averaged in the top $200 \mathrm{~m}$ (Figure 41).

\begin{tabular}{ccccccccc}
\hline & \multicolumn{2}{c}{ SODA } & \multicolumn{2}{c}{ CCSM } & \multicolumn{2}{c}{ ORCA05 } & \multicolumn{2}{c}{ ORCA12 $^{1}$} \\
& $\mathrm{R}^{2}$ & $\mathrm{p}$-value & $\mathrm{R}^{2}$ & $\mathrm{p}$-value & $\mathrm{R}^{2}$ & $\mathrm{p}$-value & $\mathrm{R}^{2}$ & $\mathrm{p}$-value \\
\hline SODA & & & $7.6 \%$ & 0.56 & $6.9 \%$ & 0.59 & $-67.3 \%$ & $<0.01$ \\
CCSM & $7.6 \%$ & 0.56 & & & $78.7 \%$ & $<0.01$ & $10.8 \%$ & 0.66 \\
ORCA05 & $6.9 \%$ & 0.59 & $78.7 \%$ & $<0.01$ & & & $5.0 \%$ & 0.84 \\
ORCA12 $^{1}$ & $-67.3 \%$ & $<0.01$ & $10.8 \%$ & 0.66 & $5.0 \%$ & 0.84 & & \\
\hline
\end{tabular}

${ }^{1}$ Correlations done using the period between 1989 and 2007.

ble 14).

Table 13: Correlation between annual averages of the bifurcation position averaged between $500 \mathrm{~m}$ and $1000 \mathrm{~m}$ (Figure 42).

\begin{tabular}{ccccccccc}
\hline & \multicolumn{2}{c}{ SODA } & \multicolumn{2}{c}{ CCSM } & \multicolumn{2}{c}{ ORCA05 } & \multicolumn{2}{c}{ ORCA12 $^{1}$} \\
& $\mathrm{R}^{2}$ & $\mathrm{p}$-value & $\mathrm{R}^{2}$ & $\mathrm{p}$-value & $\mathrm{R}^{2}$ & $\mathrm{p}$-value & $\mathrm{R}^{2}$ & $\mathrm{p}$-value \\
\hline SODA & & & $20.4 \%$ & 0.11 & $-2.3 \%$ & 0.85 & $26.6 \%$ & 0.27 \\
CCSM & $20.4 \%$ & 0.11 & & & $50 \%$ & $<0.01$ & $8.6 \%$ & 0.73 \\
ORCA05 & $-2.3 \%$ & 0.85 & $50 \%$ & $<0.01$ & & & $30.3 \%$ & 0.21 \\
ORCA12 $^{1}$ & $26.6 \%$ & 0.27 & $8.6 \%$ & 0.73 & $30.3 \%$ & 0.21 & & \\
\hline
\end{tabular}

${ }^{1}$ Correlations done using the period between 1989 and 2007.

The seasonality of the bifurcation position is dominated by the wind stress curl (RODRIGUES; ROTHSTEIN; WINBUSH, 2007). This hypothesis was also tested at interannual timescales, since 


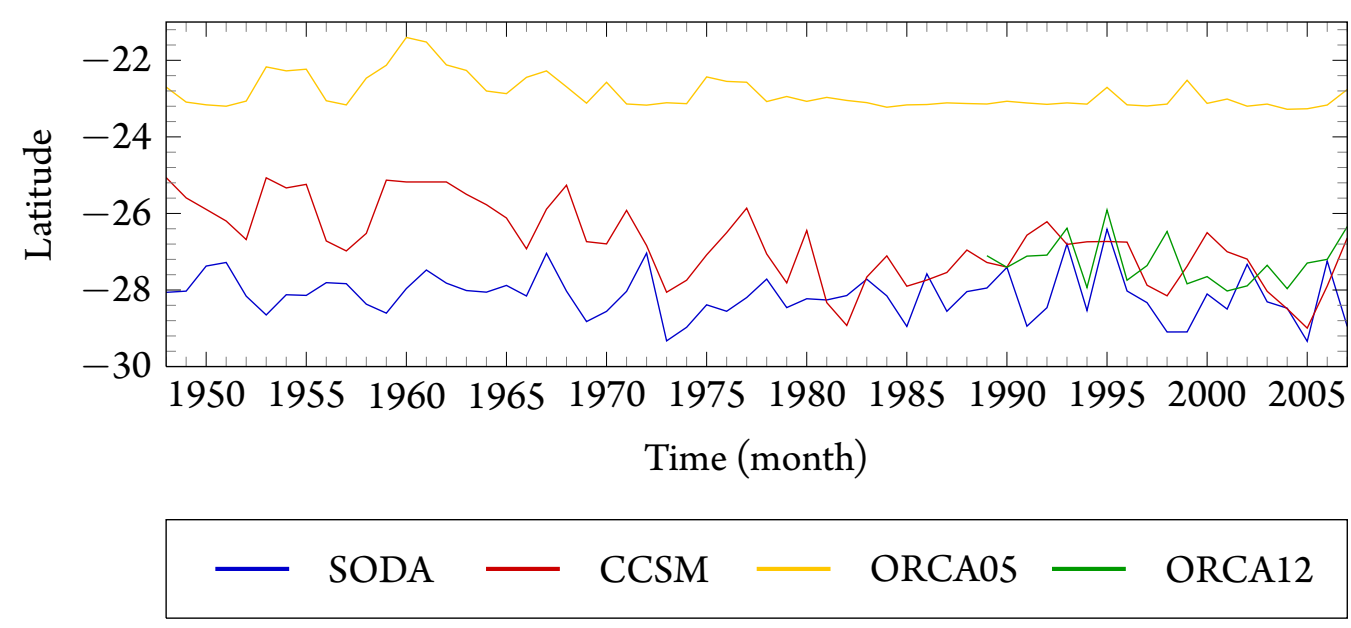

Figure 42: Variability of the SEC bifurcation position, averaged between $500 \mathrm{~m}$ and $1000 \mathrm{~m}$, for SODA (blue), CCSM (red), ORCA05 (yellow) and ORCA12 (green) datasets, calculated using the zero contour line of meridional velocity, as proposed by Rodrigues, Rothstein \& Winbush (2007).

Table 14: Trends of the SEC bifurcation position (Figures 41 and 42 ), in ${ }^{\circ} \cdot y^{-1}$.

\begin{tabular}{ccccc}
\hline & SODA & CCSM & ORCA05 & ORCA12 \\
& & $\left({ }^{\circ} \cdot \mathrm{y}^{-1}\right)$ & \\
\hline top $200 \mathrm{~m}$ & $0.02 \pm 0.008$ & $0.02 \pm 0.005$ & $-0.02 \pm 0.006$ & $0.06 \pm 0.02$ \\
between $500 \mathrm{~m}$ and $1000 \mathrm{~m}$ & $-0.001 \pm 0.006$ & $-0.04 \pm 0.005$ & $-0.01 \pm 0.005$ & $-0.02 \pm 0.03$ \\
\hline
\end{tabular}

significant correlations were found mainly between the models forced by CORE, suggesting a strong link with the wind stress curl (Table 12 and Figure 42).

Considering the top $200 \mathrm{~m}$ (Figure 43), significant and negative correlations, between $10^{\circ} \mathrm{S}$ and $15^{\circ} \mathrm{S}$ (the same region observed by those authors) and close to the equator were found in CCSM, ORCA05 and ORCA12 results, with no correspondences to the SODA reanalysis. Also, there are good similarities between the two datasets forced by CORE-II. As both datasets have resemblant bifurcation position time series (Figure 41 and Table 12) it suggests an influence of the Sverdrup dynamics having influence in the position of the bifurcation variability at interannual time scales. However, it does not seem to be the case for SODA, as significative correlations with the wind stress are virtually absent (Figure 43a).

At intermediate depths, there is also a good correlation between CCSM and ORCA05 bifurcation time series (Table 13), suggesting again a link with the forcing. Figure 44. In these models, there is a dipole in the correlations, centered around $20^{\circ} \mathrm{S}$, with negative correlations in the southernmost limit of the area.However, these correlations have no correspondences in SODA and ORCA12 models. 
(a) SODA

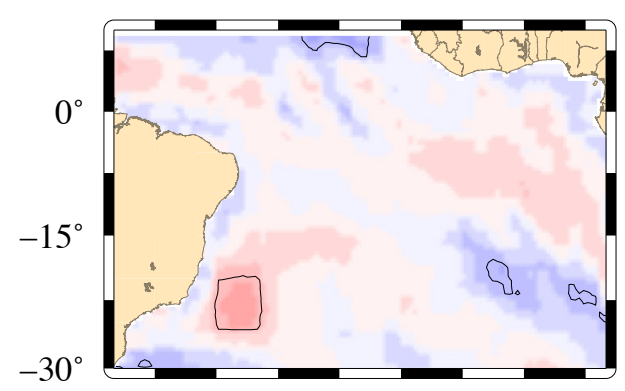

(c) ORCA05 (b) CCSM

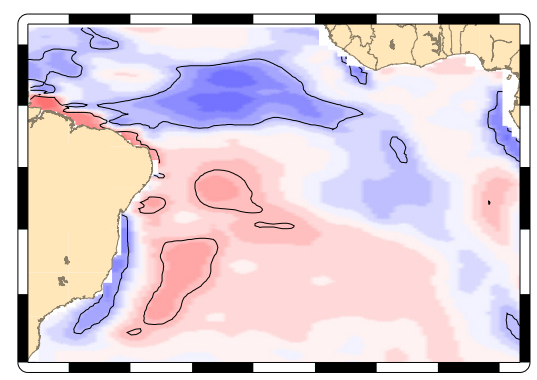

(d) ORCA12

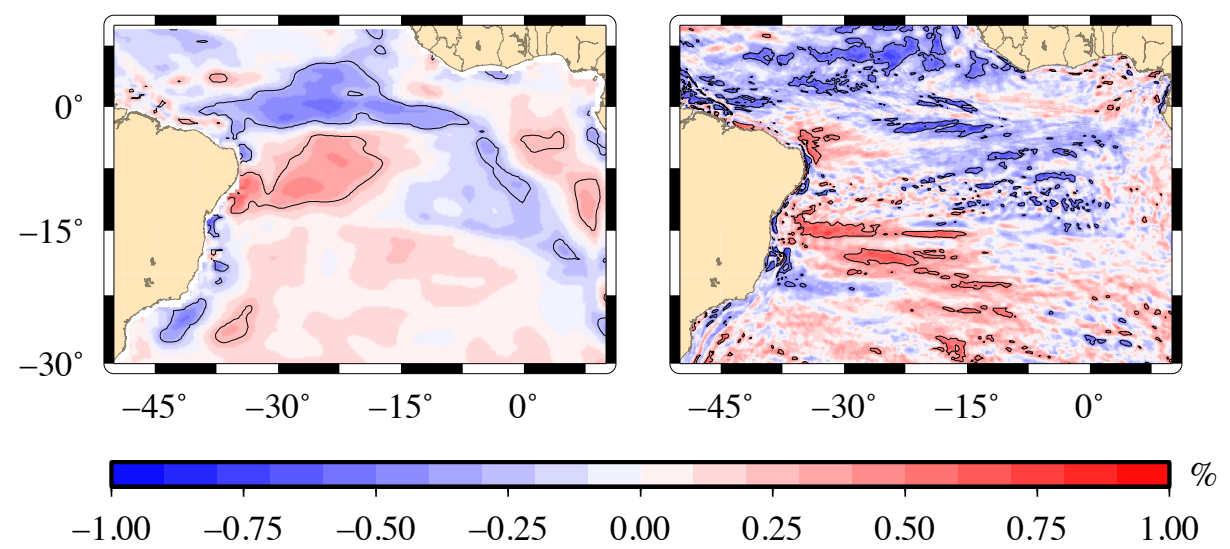

Figure 43: Correlation between the annual means of the bifurcation position in the top 200m (calculated using the zero contour line of meridional velocity, as proposed by Rodrigues, Rothstein \& Winbush (2007)) and of the wind stress curl for SODA (a), CCSM (b), ORCA05 (c) and ORCA12 (d). Black contours mark the areas where the correlations coefficients are statistically significant at $95 \%$.

\subsubsection{Western Boundary Currents}

Figures 45 and 46, show the transport of NBUC and IWBC, linked to the AMOC, calculated using only northward (positive) meridional velocities at $11^{\circ} \mathrm{S}$ and $27^{\circ} \mathrm{S}$, respectively. Due to the bifurcation position, which is located further north of $27^{\circ} S$ the IWBC transport in ORCA05 output was not calculated, since, as discussed in Section 3.1.1, the IWBC transport, in this model is southward.

The time series of the NBUC transport are shown in Figure 45. It is easy to observe that all the models have similar variability. Table 15 presents the correlation between the time series. The results, between the reanalysis and all the models are greater than 30\%. Between ORCA05 and CCSM, it is almost $90 \%$. These results suggest a link with wind stress curl and hence, with the Sverdrup balance. Also, from the anomalies (Figure 45b) we found a positive trend that is presented in Table 17.

Figure 46 shows the time series of the meridional transport anomalies of the Intermediate Western Boundary Current. Correlating the time series, no significant similarities, considering the confidence interval of $95 \%$, between them were found (Table 16). Both SODA and CCSM datasets show a positive trend, indicating a strengthening of the volume transport in the 60 years of run, but comparing to the results found for the NBUC (Table 17), the trends found at intermediate depths are only 25\% of those 
(a) SODA

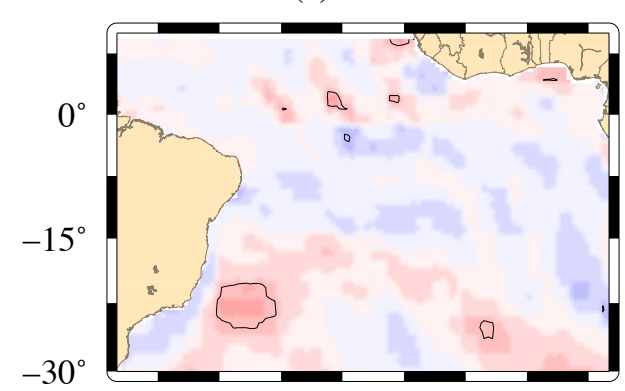

(c) ORCA05 (b) CCSM

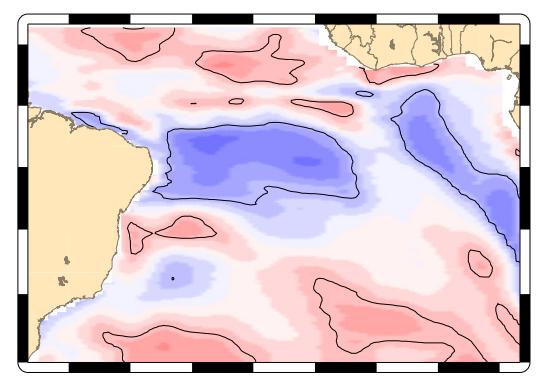

(d) ORCA12

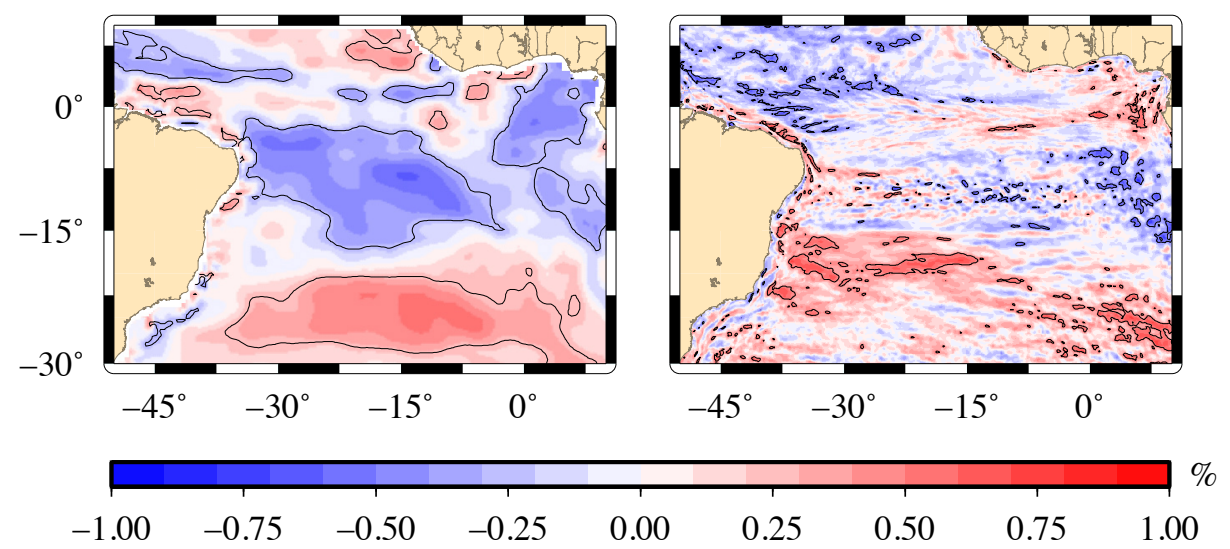

Figure 44: Correlation between the annual means of the bifurcation position between $500 \mathrm{~m}$ and $1000 \mathrm{~m}$ (calculated using the zero contour line of meridional velocity, as proposed by Rodrigues, Rothstein \& Winbush (2007)) and of the wind stress curl for SODA (a), CCSM (b), ORCA05 (c) and ORCA12 (d). Black contours mark the areas where the correlations coefficients are statistically significant at $95 \%$.

Table 15: Correlation between annual averages of NBUC transport anomaly at the top 1000m (Figure 45b).

\begin{tabular}{ccccccccc}
\hline & \multicolumn{2}{c}{ SODA } & \multicolumn{2}{c}{ CCSM } & \multicolumn{2}{c}{ ORCA05 } & \multicolumn{2}{c}{ ORCA12 $^{1}$} \\
& $\mathrm{R}^{2}$ & $\mathrm{p}$-value & $\mathrm{R}^{2}$ & $\mathrm{p}$-value & $\mathrm{R}^{2}$ & $\mathrm{p}$-value & $\mathrm{R}^{2}$ & $\mathrm{p}$-value \\
\hline SODA & & & $31.9 \%$ & 0.01 & $42.0 \%$ & $<0.01$ & $47.5 \%$ & 0.04 \\
CCSM & $31.9 \%$ & 0.01 & & & $89.8 \%$ & $<0.01$ & $29.7 \%$ & 0.21 \\
ORCA05 & $42.0 \%$ & $<0.01$ & $89.8 \%$ & $<0.01$ & & & $17.7 \%$ & 0.47 \\
ORCA12 $^{1}$ & $47.5 \%$ & 0.04 & $29.7 \%$ & 0.21 & $17.7 \%$ & 0.47 & & \\
\hline
\end{tabular}

${ }^{1}$ Correlations done using the period between 1989 and 2007.

found at $11^{\circ} \mathrm{S}$.

As mentioned above, good correlations between the NBUC transports at the surface (specially between CCSM and ORCA05 results) suggest a strong influence of the forcing on the variability. To check this hypothesis, a correlation between the wind stress curl and the transports detrended time series were done. The results are shown in Figure 47. Observing the relationship between the wind stress curl and the NBUC transports, the first thing to be noted is the similarity between CCSM and ORCA05 results. 
(a) Volume transport

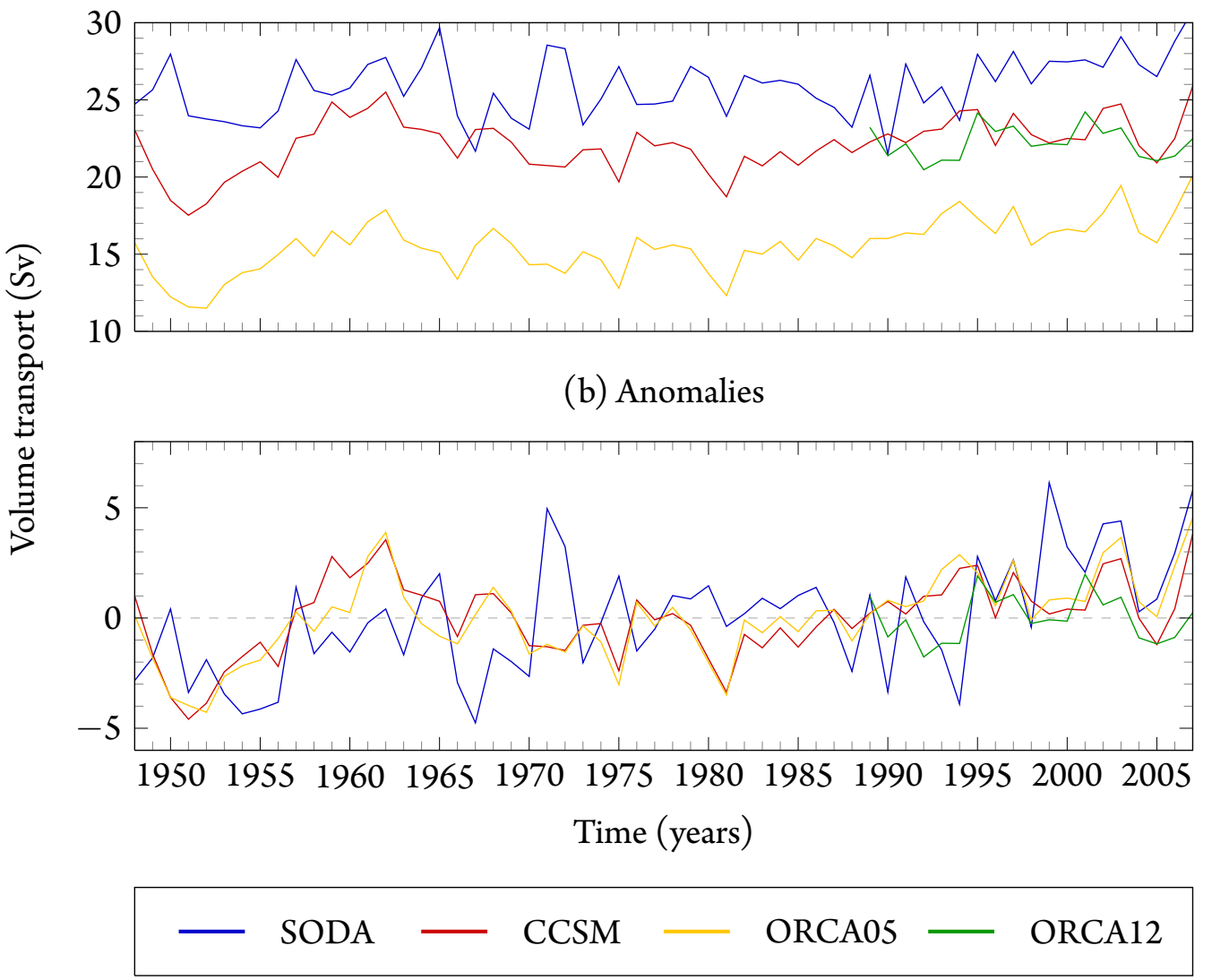

Figure 45: Volume transport (Sv) time series of NBUC at $11^{\circ} \mathrm{S}$, for SODA (blue), CCSM (red), ORCA05 (yellow) and ORCA12 (green) datasets, calculated at the top $1000 \mathrm{~m}$ as shown on Figure 32. The anomalies were calculated subtracting the seasonal cycle (Figure 33) monthly data, before averages.

Table 16: Correlation between annual averages of IWBC transport anomaly in the top 1000m (Figure 46).

\begin{tabular}{ccccccc}
\hline & \multicolumn{2}{c}{ SODA } & \multicolumn{2}{c}{ CCSM } & \multicolumn{2}{c}{ ORCA12 $^{1}$} \\
& $\mathrm{R}^{2}$ & $\mathrm{p}$-value & $\mathrm{R}^{2}$ & $\mathrm{p}$-value & $\mathrm{R}^{2}$ & $\mathrm{p}$-value \\
\hline SODA & & & $20.5 \%$ & 0.12 & $-14.2 \%$ & 0.56 \\
CCSM & $20.5 \%$ & 0.12 & & & $4.0 \%$ & 0.86 \\
ORCA12 $^{1}$ & $-14.2 \%$ & 0.56 & $4.0 \%$ & 0.86 & & \\
\hline \multicolumn{3}{c}{ Correlations done using the period between 1989 and 2007. }
\end{tabular}

These models, which NBUC time series are correlated in almost 90\%, present huge and negative correlations between $15^{\circ} \mathrm{S}$ and $0^{\circ}$ followed by positive correlations bellow $15^{\circ} \mathrm{S}$ (Figure $47 \mathrm{c}, \mathrm{e}$ ). This feature can also be observed in the SODA reanalysis and also in ORCA12 results, but with smaller areas of significant correlations, which could explain the significant correlations (at least $30 \%$, Table 15 ) between the reanalysis and all the other models. 
(a) Volume transport

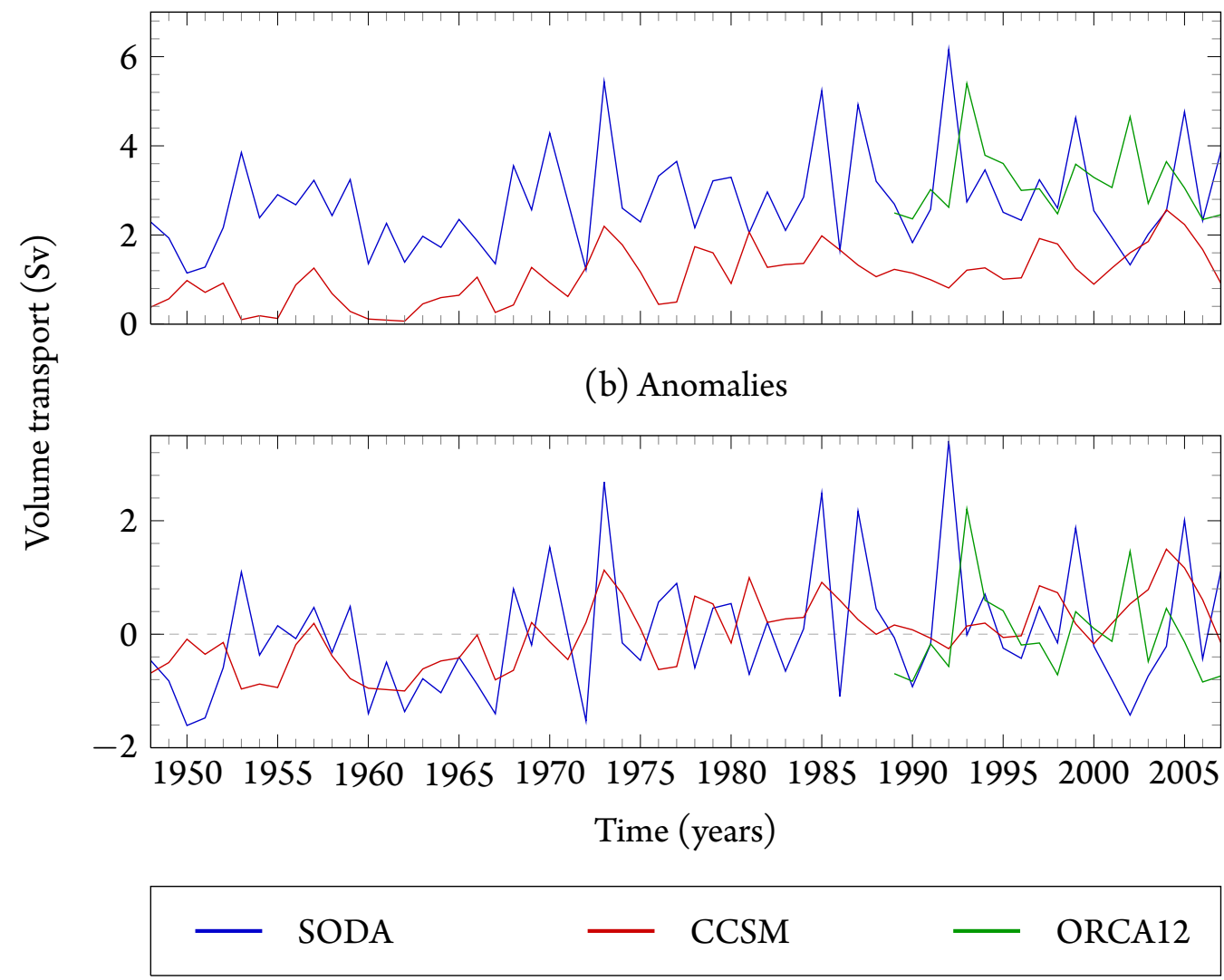

Figure 46: Volume transport (Sv) time series of IWBC at $27^{\circ} \mathrm{S}$, for SODA (blue), CCSM (red) and ORCA12 (green) datasets, calculated at the top $1000 \mathrm{~m}$ as shown on Figure 34 . The anomalies were calculated subtracting the seasonal cycle from monthly data, before averages.

Table 17: Trends of NBUC and IWBC transports, calculated in the top $1000 \mathrm{~m}$ (Figures 45 and 46), in $\mathrm{Sv} \cdot \mathrm{y}^{-1}$.

\begin{tabular}{ccccc}
\hline & SODA & CCSM & ORCA05 & ORCA12 \\
& & \multicolumn{2}{c}{$\left(\mathrm{Sv} \cdot \mathrm{y}^{-1}\right)$} \\
\hline NBUC & $0.04 \pm 0.01$ & $0.04 \pm 0.01$ & $0.06 \pm 0.01$ & $0.01 \pm 0.05$ \\
IWBC & $0.02 \pm 0.008$ & $0.03 \pm 0.004$ & & $-0.008 \pm 0.03$ \\
\hline
\end{tabular}

At intermediate depths the scenario is different: no correlations were found between the models' IWBC transport time series. Although a similar pattern can be observed in the correlations with the wind stress curl (but, with positive correlations between $15^{\circ} \mathrm{S}$ and the equator, and negative correlations bellow $15^{\circ} \mathrm{S}$ ), the absence of significant correlations between the outputs, indicates that the wind stress is not a common mechanism for IWBC variability. Also, the absence of results from two models with the same forcing difficults a robust conclusion for CCSM variability, despite of the significant areas of good correlations. The IWBC variability in the SODA reanalysis does not seem to be driven by the wind 
stress curl, but by other mechanisms such as buoyancy fluxes.
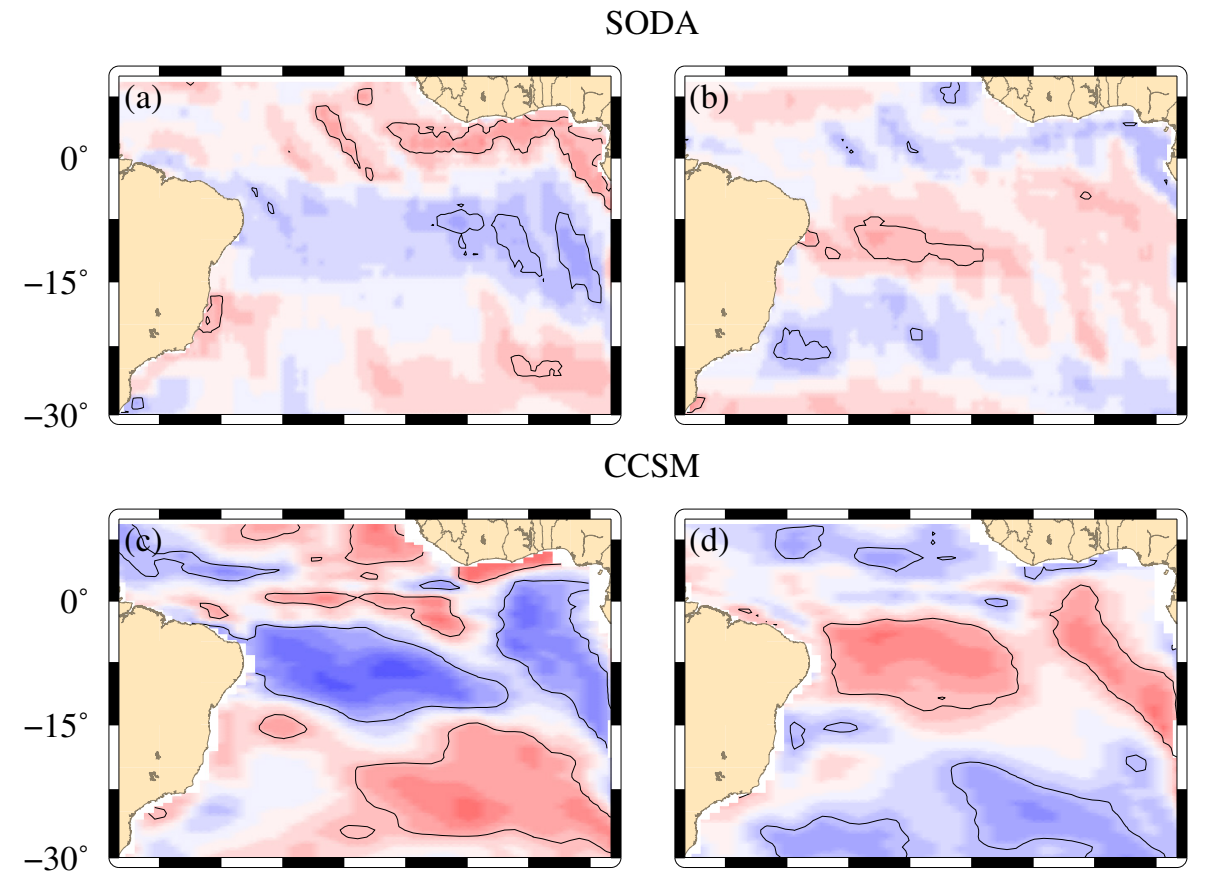

ORCA05

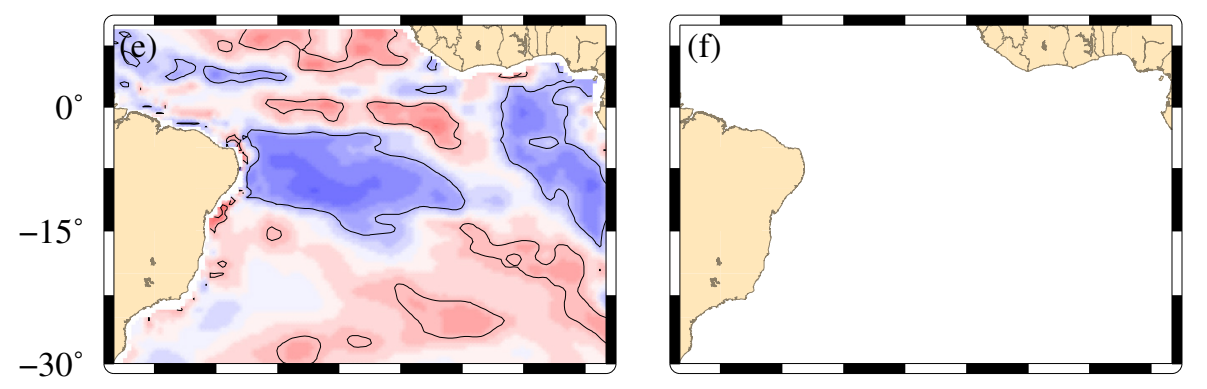

ORCA12

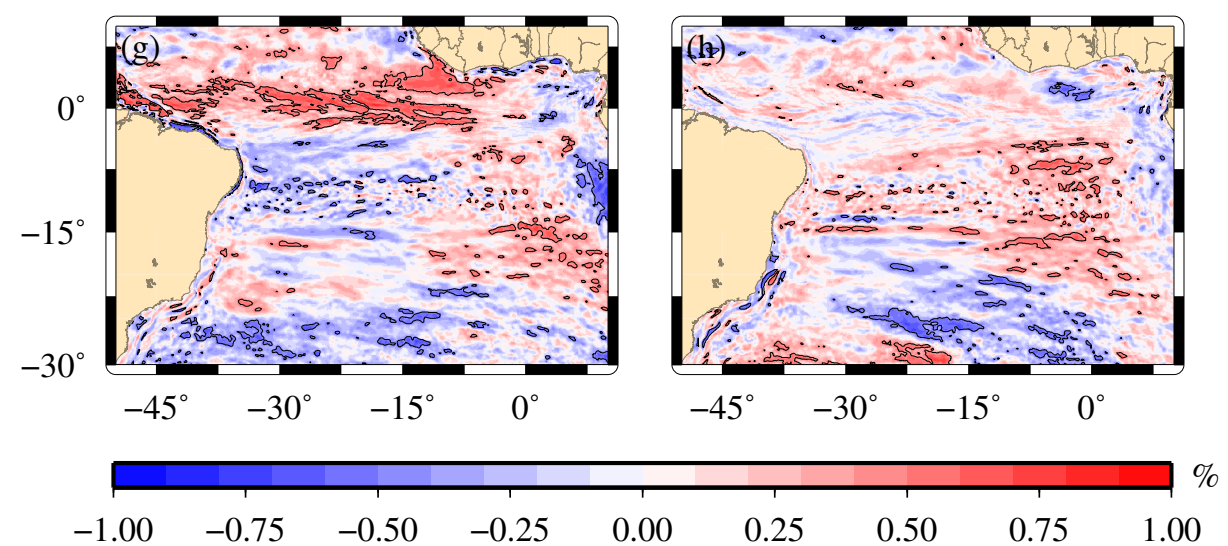

Figure 47: Correlation between the annual means of the transports of NBUC (left) and IWBC (right) and of the wind stress curl for SODA (a,b), CCSM (c,d), ORCA05 (e,f) and ORCA12 $(\mathrm{g}, \mathrm{h})$. Black contours mark the areas where the correlations coefficients are statistically significant at $95 \%$.

As NBUC transports seem to be linked to the wind stress curl, we calculate its correlation with the 
Sverdrup interior transport using Equation 2.12. The results, comparing their anomalies are shown in Figure 48.

(a) SODA

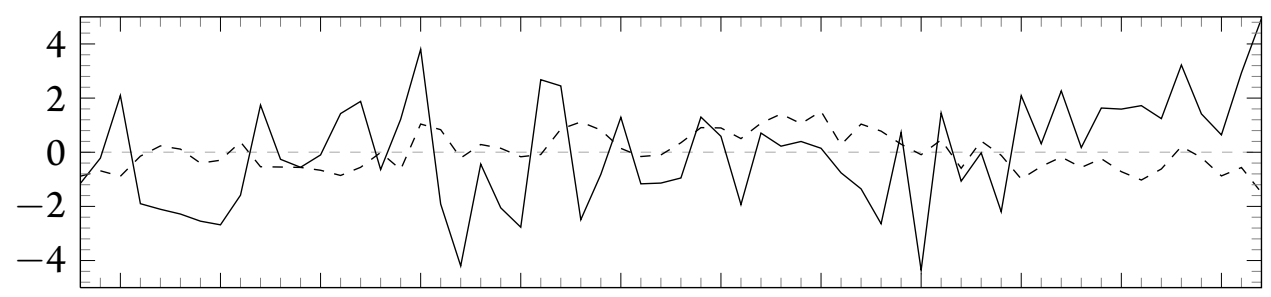

(b) CCSM

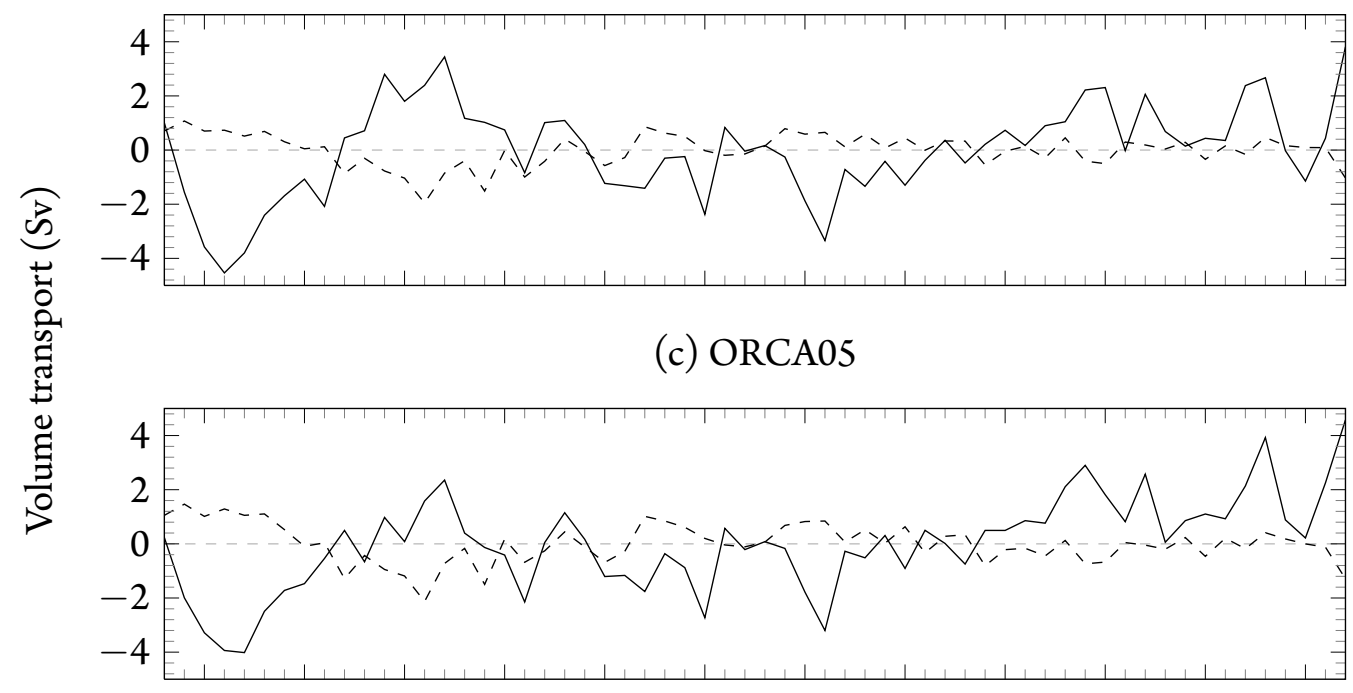

(d) ORCA12

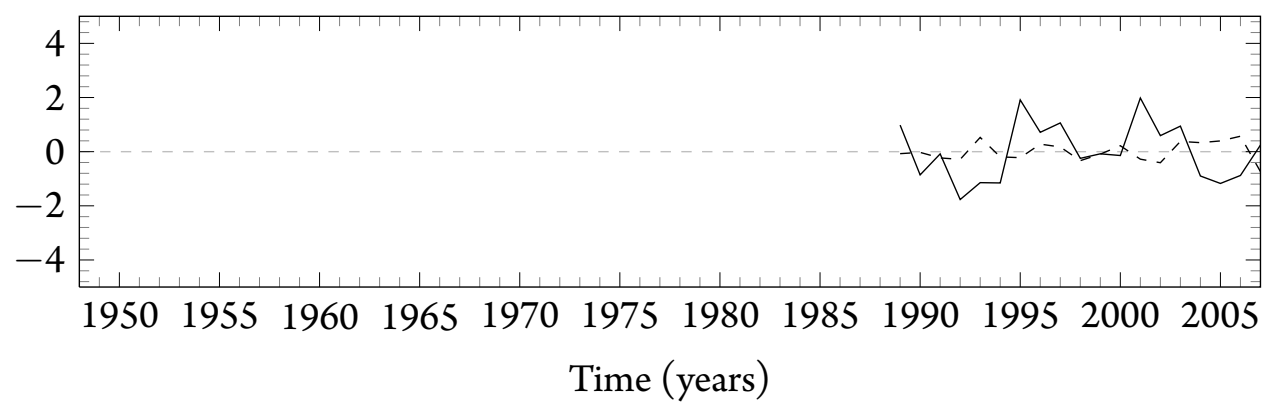

NBUC

- - - Interior Sverdrup transport

Figure 48: Anomalies of the NBUC (black) and Sverdrup interior transport (dashed) for (a) SODA, (b) CCSM, (c) ORCA05 and (d) ORCA12.

As expected, due to their common forcing, there is a great similarity between CCSM and ORCA05 Sverdrup interior transports. The correlation between each time series in each model are listed in the Table 18. As the NBUC timeseries for both models have a large correlation (almost 90\%), and their 
correlations with the Sverdrup interior transports are similiar, one can affirm that the variability of the NBUC at interannual timescales is explained mostly by the Sverdrup transport in CCSM and ORCA05 (the correlations are bigger than 50\%). The contribution of the wind stress in the variability of the NBUC transports is greater than $20 \%$ in SODA and ORCA 12 results, although they are not significant at $95 \%$.

Table 18: Correlation between annual averages of NBUC transport anomalies in the top $1000 \mathrm{~m}$ and the Sverdrup interior transport at $11^{\circ} \mathrm{S}$ (Figure 48).

\begin{tabular}{cccccccc}
\hline \multicolumn{2}{c}{ SODA } & \multicolumn{2}{c}{ CCSM } & \multicolumn{2}{c}{ ORCA05 } & \multicolumn{2}{c}{ ORCA12 } \\
$\mathrm{R}^{2}$ & $\mathrm{p}$-value & $\mathrm{R}^{2}$ & $\mathrm{p}$-value & $\mathrm{R}^{2}$ & $\mathrm{p}$-value & $\mathrm{R}^{2}$ & $\mathrm{p}$-value \\
\hline$-21.6 \%$ & 0.09 & $-61.4 \%$ & $<0.01$ & $-56.6 \%$ & 0.01 & $-26.3 \%$ & 0.28 \\
\hline \multicolumn{4}{c}{ Correlations done using the period between 1989 and 2007.}
\end{tabular}

From Section 3.1.1, it becomes clear that the bifurcation has an impact in the transport of these currents, particularly the NBUC: when the bifurcation is in its northernmost (southernmost) position, the northward transport is minimum (maximum). In this sense, negative correlations are expected also in interannual time scales. Table 19 presents the correlations at zero lag, using detrended time series, between the SEC bifurcation position and the IWBC/NBUC transports. All the models showed negative results, as expected. At intermediate depths, the correlations were bigger than 60\% (SODA and CCSM). In the surface layer, only ORCA05 results had statistically significant correlations. ORCA12 results also showed a good correlation, but, its short time series decreases the degrees of freedom and increases the confidence interval.

ORCA05 and CCSM data show great similarity in previous results (bifurcation position and NBUC transports), what suggests a strong link to their atmosphere forcing (CORE-II, Section 2.1.4). The absence of significant correlation between NBUC and the bifurcation position at the top $200 \mathrm{~m}$ was not expected. In fact, our results show that the transports (Figure $47 \mathrm{c}, \mathrm{e}$ ) and the bifurcation position (Figure $43 \mathrm{~b}, \mathrm{c})$ are correlated to the wind stress curl in different regions. For instance, significant negative correlations between the NBUC transports and the wind stress can be found in the east and west limits of the basin, while, positive correlations close to Africa are only found in ORCA05 (Figure 43c), not in CCSM (Figure 43b). Besides, the biggest correlations between the bifurcation position and the wind stress curl in CCSM occur close to the equator, while, for the NBUC transports, the most important correlations are close to the Brazilian coast at $11^{\circ} \mathrm{S}$. In ORCA05 results, the biggest correlations are in the west limit of the basin, close to $11^{\circ} \mathrm{S}$. So, these results suggest that although the wind stress curl is an important process controlling the bifurcation position at the top $200 \mathrm{~m}$ and the northward transport of the NBUC, only local wind stress (close to $11^{\circ} \mathrm{S}$ ) controls the direct relationship between the bifurcation position and the northward transports.

Still following this premise of a negative relationship between the bifurcation position and the northward transports, opposite trends for these two parameters are expected, both in surface and intermediate 
Table 19: Correlation between annual averages of NBUC/IWBC transport with the bifurcation position averaged in the top $200 \mathrm{~m} /$ between $500 \mathrm{~m}$ and $1000 \mathrm{~m}$, respectively.

\begin{tabular}{ccccccccr}
\hline & \multicolumn{2}{c}{ SODA } & \multicolumn{2}{c}{ CCSM } & \multicolumn{2}{c}{ ORCA05 } & \multicolumn{2}{c}{ ORCA12 $^{1}$} \\
& $\mathrm{R}^{2}$ & $\mathrm{p}$-value & $\mathrm{R}^{2}$ & $\mathrm{p}$-value & $\mathrm{R}^{2}$ & $\mathrm{p}$-value & $\mathrm{R}^{2}$ & $\mathrm{p}$-value \\
\hline NBUC & $-7.7 \%$ & 0.61 & $-20.0 \%$ & 0.12 & $-51.3 \%$ & $<0.01$ & $-38.2 \%$ & 0.11 \\
IWBC & $-60.1 \%$ & $<0.01$ & $-86.7 \%$ & $<0.01$ & & & $-7.4 \%$ & 0.76 \\
\hline
\end{tabular}

${ }^{1}$ Correlations done using the period between 1989 and 2007.

depths. Indeed, considering only significant results (when the errors are smaller than the linear trends) in the Tables 14 and 17, only ORCA05 presented opposite trends, while SODA and CCSM do not confirm our hypothesis. At intermediate depths, only CCSM show significant results, confirming our hypothesis.

\subsubsection{South Atlantic Meridional Overturning Circulation}

The NBUC and the IWBC are the main routes of the AMOC in the South Atlantic (SCHMITZ, 1995; BOEBEL et al., 1999; TALLEY, 2003; GANACHAUD, 2003; LUMPKIN; SPEER, 2003; SILVEIRA; CALADO; CASTRO, 2004). The AMOC stream function was calculated for all the model results in the top 5,250m between $0^{\circ} \mathrm{S}$ and $30^{\circ} \mathrm{S}$ according to Equation 1.1, Section 1.1. Figure 49 presents the climatological values for each dataset. One should remember that, for ORCA12, the time series is short and only values between 1989 and 2007 were averaged.

Our results for SODA reproduces well those presented by Kröger, Müller \& Storch (2012) using the same product. Comparing SODA upper branch of the SAMOC with the model results shows that the CCSM seems to better reproduce the depth of the northward transport, although with less intensity. Besides the differences in the vertical extent and intensity, for all the models examined, the SAMOC maximum transport is deeper $(\sim 1200 \mathrm{~m})$ in the southernmost limit of the section than close to the Equator $(\sim 1000 \mathrm{~m})$. The deep branch of the SAMOC is wider in the ORCA05 and ORCA12 simulations than in the other models and in the literature (RENNERMALM et al., 2007; McCLEAN et al., 2011).

Besides the difference in the vertical structure, compared to SODA, the models show closer results to the literature than the SODA reanalysis (Table 20). Rabe, Schott \& Köhl (2008), using the GECCO ocean model, calculated an AMOC of $13.5 \mathrm{~Sv}$ at $10^{\circ} \mathrm{S}$. ORCA05 has the smallest AMOC values, as already described by Danabasoglu et al. (2013) and this result agrees with lower NBUC transports (Table 3), inexistent IWBC (Figure 34) and deepest and strongest BC at $27^{\circ} \mathrm{S}$ (Table 4), linked to a farther north bifurcation at intermediate depths (Table 2).

Figures 50 and 51 show the time series for the vertical maximum of SAMOC at $11^{\circ} \mathrm{S}$ and $27^{\circ} \mathrm{S}$. Except for SODA, the models present similar interannual variability in both latitudes (Figures 50b and 


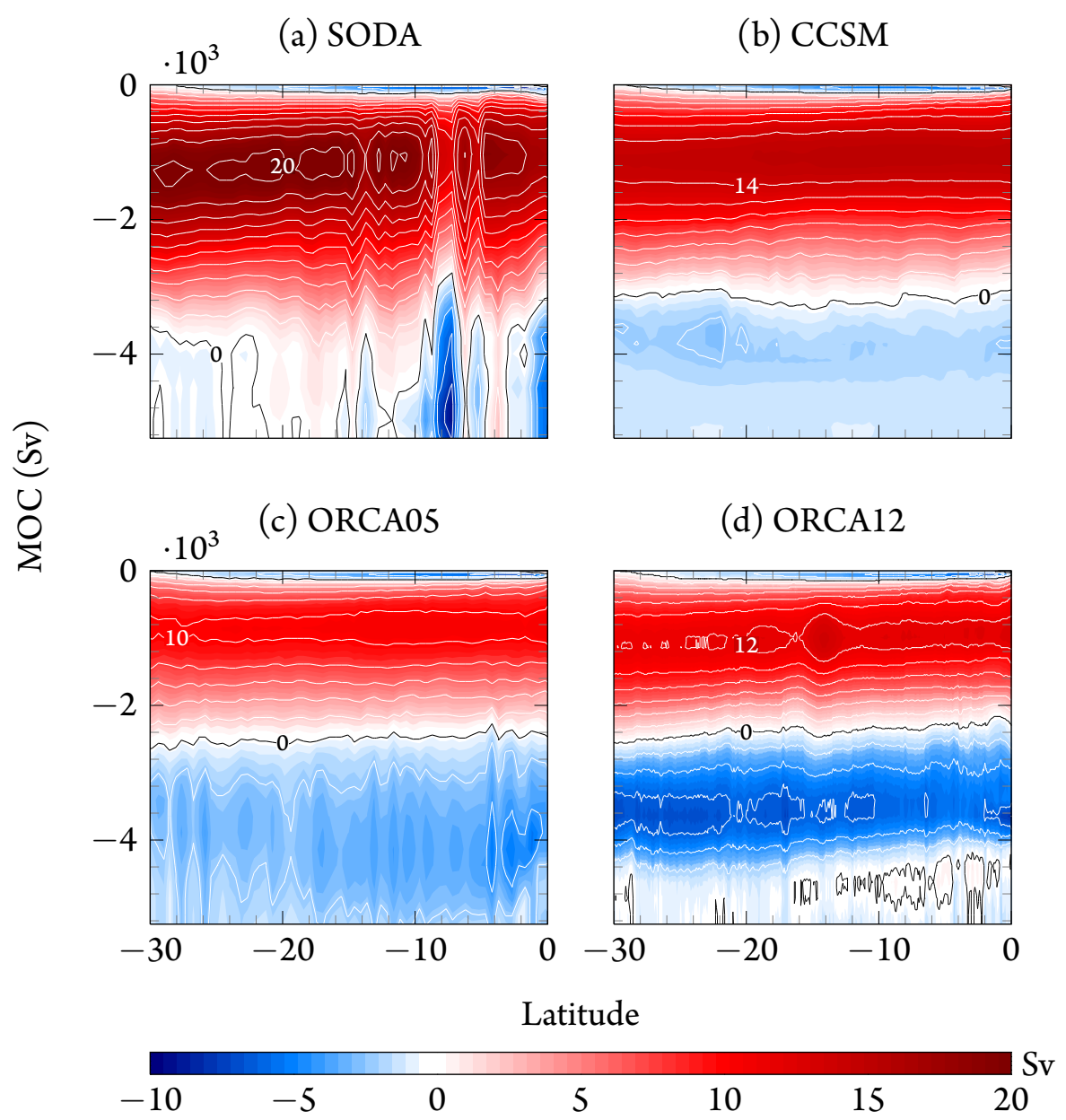

Figure 49: Climatological averages of South Atlantic Meridional Overturning Circulation (SAMOC), between $11^{\circ} \mathrm{S}$ and $30^{\circ} \mathrm{S}$, for SODA (a), CCSM (b), ORCA05 (c) and ORCA12 (d) datasets. Black contours indicate the zero (Sv) stream function. Contours each 2 Sv.

Table 20: South Atlantic MOC vertical maximum (Sv) averages at $11^{\circ} \mathrm{S}$ and $27^{\circ} \mathrm{S}$.

\begin{tabular}{ccccc}
\hline & SODA & $\begin{array}{c}\text { CCSM } \\
\left(\mathrm{Sv} \cdot \mathrm{y}^{-1}\right)\end{array}$ & ORCA05 & ORCA12 \\
\hline $11^{\circ} \mathrm{S}$ & $19.5 \pm 1.3$ & $16.2 \pm 1.0$ & $12.0 \pm 1.4$ & $12.4 \pm 0.9$ \\
$27^{\circ} \mathrm{S}$ & $20.1 \pm 0.9$ & $14.8 \pm 0.9$ & $10.3 \pm 1.4$ & $11.9 \pm 0.7$ \\
\hline
\end{tabular}

51b). The correlations between the time series show no correlations between the reanalysis and the other models (Tables 21 and 22).

As in the other results, there are big correlations between the models forced by CORE (greater than 90\%) that suggest a link with the forcing. MOC is influenced by the density structure of the Atlantic Ocean, small-scale mixing and buoyancy fluxes (IPCC, 2007). Using CORE-II, these models are under the influence of the same sea-air fluxes (such as momentum, heat and fresh water fluxes, see Sec- 
tion 2.1.4), with a direct impact in their AMOC (via buoyancy fluxes, for instance). AMOC is also a result of the meridional velocity integral across the basin, as described in the Section 2.2.3 which, in consequence, accounts the Sverdrup meridional transport, forced by the wind stress curl (Section 2.2.2.1). Moreover, as discussed in the Section 3.1.2.2, the NBUC, one of the main conduits of the AMOC showed to be driven by changes in the Sverdrup balance in CCSM and ORCA05 models. In this sense, big correlations between those models were expected.

(a) SAMOC maximum transport

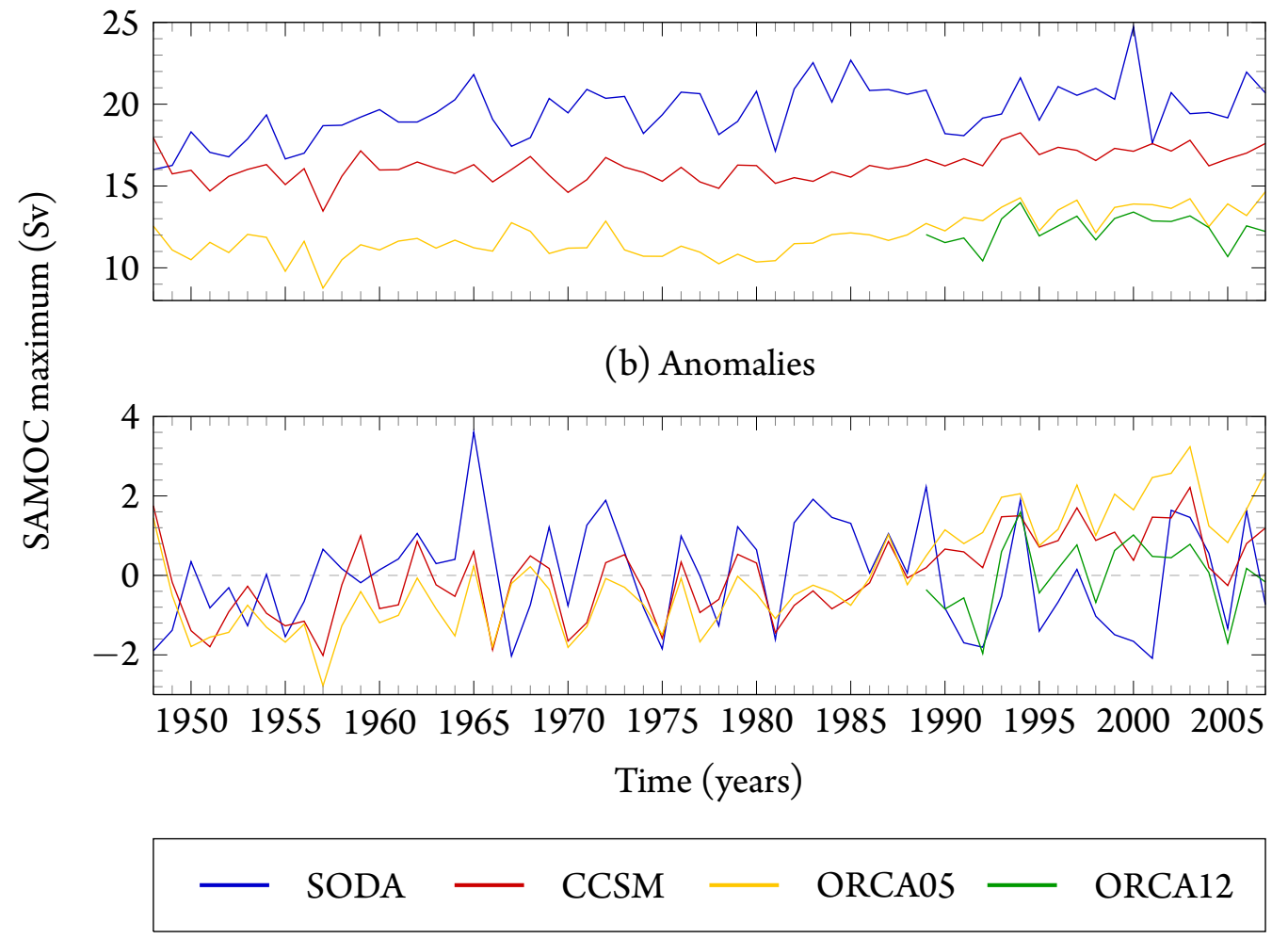

Figure 50: SAMOC maximum anomaly time series at $11^{\circ} \mathrm{S}$, for SODA (blue), CSSM (red), ORCA05 (yellow) and ORCA12 (green) datasets. The anomalies were calculated subtracting the seasonal cycle.

Table 21: Correlation between annual averages of SAMOC at $11^{\circ} \mathrm{S}$ (Figure 50b).

\begin{tabular}{ccccccccc}
\hline & \multicolumn{2}{c}{ SODA } & \multicolumn{2}{c}{ CCSM } & \multicolumn{2}{c}{ ORCA05 } & \multicolumn{2}{c}{ ORCA12 $^{1}$} \\
& $\mathrm{R}^{2}$ & $\mathrm{p}$-value & $\mathrm{R}^{2}$ & $\mathrm{p}$-value & $\mathrm{R}^{2}$ & $\mathrm{p}$-value & $\mathrm{R}^{2}$ & $\mathrm{p}$-value \\
\hline SODA & & & $7.2 \%$ & 0.58 & $-1.4 \%$ & 0.92 & $40.5 \%$ & 0.09 \\
CCSM & $7.2 \%$ & 0.58 & & & $90.0 \%$ & $<0.01$ & $68.7 \%$ & $<0.01$ \\
ORCA05 & $-1.4 \%$ & 0.92 & $90.0 \%$ & $<0.01$ & & & $64.2 \%$ & $<0.01$ \\
ORCA12 $^{1}$ & $40.5 \%$ & 0.09 & $68.7 \%$ & $<0.01$ & $64.2 \%$ & $<0.01$ & & \\
\hline
\end{tabular}

${ }^{1}$ Correlations done using the period between 1989 and 2007. 
(a) SAMOC maximum anomaly

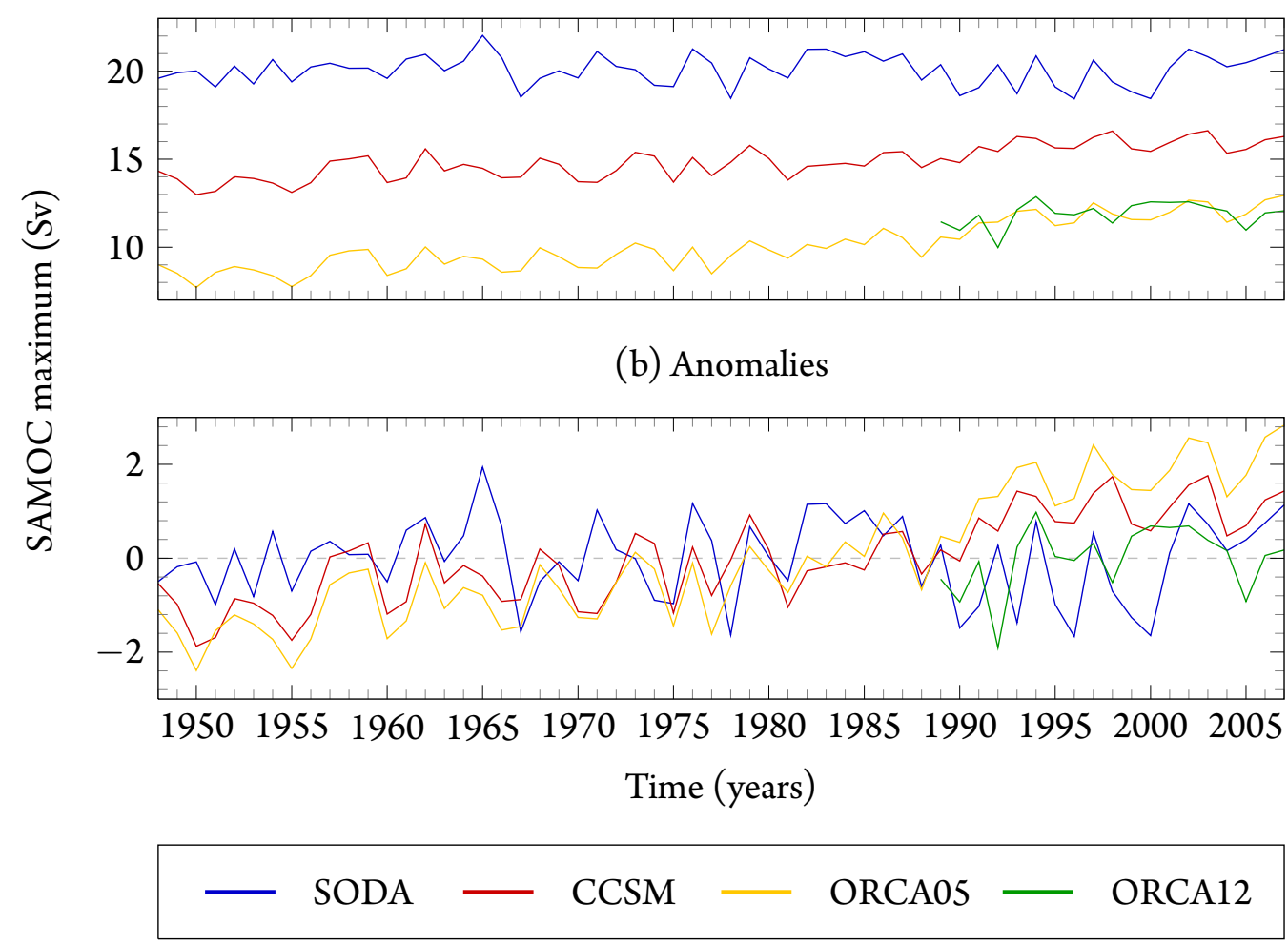

Figure 51: SAMOC maximum anomaly time series at $27^{\circ}$ S, for SODA (blue), CSSM (red), ORCA05 (yellow) and ORCA12 (green) datasets. The anomalies were calculated subtracting the seasonal cycle.

Table 22: Correlation between annual averages of SAMOC at $27^{\circ} \mathrm{S}$ (Figure 50b).

\begin{tabular}{ccccccccc}
\hline & \multicolumn{2}{c}{ SODA } & \multicolumn{2}{c}{ CCSM } & \multicolumn{2}{c}{ ORCA05 } & \multicolumn{2}{c}{ ORCA12 $^{1}$} \\
& $\mathrm{R}^{2}$ & $\mathrm{p}$-value & $\mathrm{R}^{2}$ & $\mathrm{p}$-value & $\mathrm{R}^{2}$ & $\mathrm{p}$-value & $\mathrm{R}^{2}$ & $\mathrm{p}$-value \\
\hline SODA & & & $11.4 \%$ & 0.39 & $10.4 \%$ & 0.43 & $9.2 \%$ & 0.70 \\
CCSM & $11.4 \%$ & 0.39 & & & $94.0 \%$ & $<0.01$ & $45.0 \%$ & 0.05 \\
ORCA05 & $10.4 \%$ & 0.43 & $94.0 \%$ & $<0.01$ & & & $45.8 \%$ & 0.05 \\
ORCA12 $^{1}$ & $9.2 \%$ & 0.70 & $45.0 \%$ & 0.05 & $45.8 \%$ & 0.05 & & \\
\hline
\end{tabular}

${ }^{1}$ Correlations done using the period between 1989 and 2007.

Figure 52 shows the anomalies of the AMOC, NBUC and Sverdrup transports calculated at $11^{\circ} \mathrm{S}$, in a similar way as done by Rabe, Schott \& Köhl (2008), in order to illustrate the discussion of the above proposed. The time series were filtered using a 4-year Hamming filter as described in the Section 2.2.3.1. Table 23 shows the correlations between these time series.

Larger (and negative) correlations are also found between NBUC and the Sverdrup transports (Table 23), compared to the previous analysis (Table 18). For CORE forced models, this correlation overreaches $70 \%$ in periods longer than 4 years. For the reanalysis and the ORCA12 models, the correlations are $38.5 \%$, but, due to its smaller time series, this correlation was not significant in the high resolution 
model.

Analysing Figure 52, it is easy to see how AMOC anomalies are dependent on the NBUC variability, in periods greater than 4 years, specially due to the trends found in both time series (not accounted in the correlation). Positive correlations, as expected, are always significant and, at least equal to $22 \%$ in all the models (Table 23). ORCA12 showed the biggest correlations (55\%), followed by CCSM and ORCA05. Correlations here, are, however, smaller than those found between the northward current and the Sverdrup transport.

Finally, there is a significant out of phase behaviour between the SODA reanalysis and the models when we account the correlation between AMOC and the Sverdrup transports. As expected, models show small, negative and not significant results, while, the reanalysis goes in the opposite way (Table 23).

The results in Table 23 confirm, that, for CCSM and ORCA05 results, the similarity between their AMOC time series is related to the forcing but not due to the wind stress, but because of the same sea-air fluxes.

The correlations between NBUC and AMOC are smaller than those found by Rabe, Schott \& Köhl (2008) (64\%), but, they confirm the influence of the western boundary current in the AMOC variability. Zhang et al. (2011), using the GFDL coupled model also showed that AMOC and the northward transports of NBUC, in time scales longer than 10 years are well correlated at zero lag (80\%). Our results corroborate with the author's, except for the reanalysis. Using a low-pass filtered at 10 years, the correlations between the time series are 5.4\% for SODA, 47\% for CCSM and 41.4\%. The results for ORCA12 were not considered because of its short time series.

Table 23: Correlation between annual averages of SAMOC (Figure 50b), NBUC (Figure 45b), and Sverdrup interior transports (Figure 48 ) at $11^{\circ} \mathrm{S}$.

\begin{tabular}{ccccccccc}
\hline & \multicolumn{2}{c}{ SODA } & \multicolumn{2}{c}{ CCSM } & \multicolumn{2}{c}{ ORCA05 } & \multicolumn{2}{c}{ ORCA12 $^{1}$} \\
& $\mathrm{R}^{2}$ & $\mathrm{p}$-value & $\mathrm{R}^{2}$ & $\mathrm{p}$-value & $\mathrm{R}^{2}$ & $\mathrm{p}$-value & $\mathrm{R}^{2}$ & $\mathrm{p}$-value \\
\hline NBUC \& Sverd. & $-38.5 \%$ & $<0.01$ & $-78.7 \%$ & $<0.01$ & $-74.7 \%$ & $<0.01$ & $-38.5 \%$ & 0.10 \\
NBUC \& AMOC & $21.7 \%$ & $<0.01$ & $46.6 \%$ & $<0.01$ & $33.8 \%$ & $<0.01$ & $55.0 \%$ & 0.01 \\
Sverd \& AMOC & $35.0 \%$ & $<0.01$ & $-10.7 \%$ & 0.41 & $-0.05 \%$ & 0.69 & $-13.0 \%$ & 0.59 \\
\hline
\end{tabular}

${ }^{1}$ Correlations done using the period between 1989 and 2007.

Unexpected negative results were found for ORCA05 when correlating the IWBC and AMOC filtered time series at $27^{\circ} \mathrm{S}$. ORCA12 results, even with its short time series, showed a positive correlation. For the SODA reanalysis the results were not significant. Negative correlations were unexpected since IWBC is one of the main branches of the AMOC, transporting AAIW, and so, when the northward transport of the IWBC increases, they should also increase in the AMOC.

Positive trends can be found in Figures 50 and 51. In the results of models forced by CORE-II (Section 2.1.4), a well marked inversion (from negative to positive anomalies) is well defined in 1985 (at $11^{\circ} \mathrm{S}$, Figure $50 \mathrm{~b}$ ) and 1990 (at $27^{\circ} \mathrm{S}$, Figure 51b). The calculated trends are shown in the Table 26. 
(a) SODA

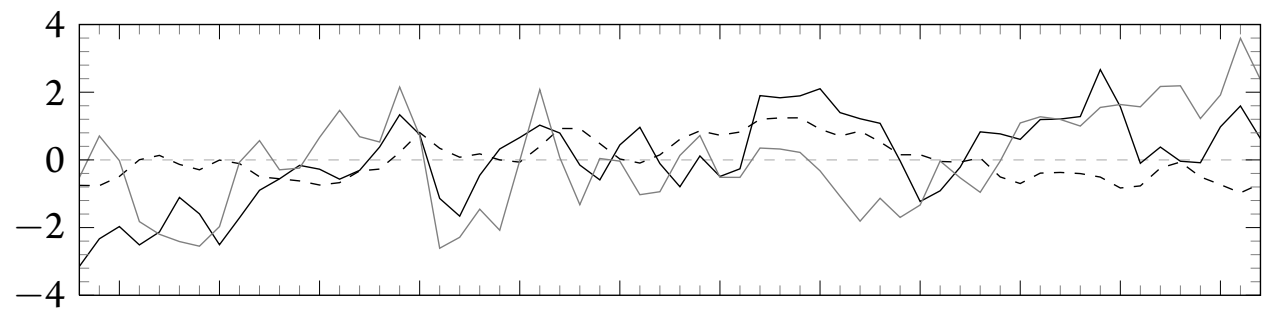

(b) CCSM

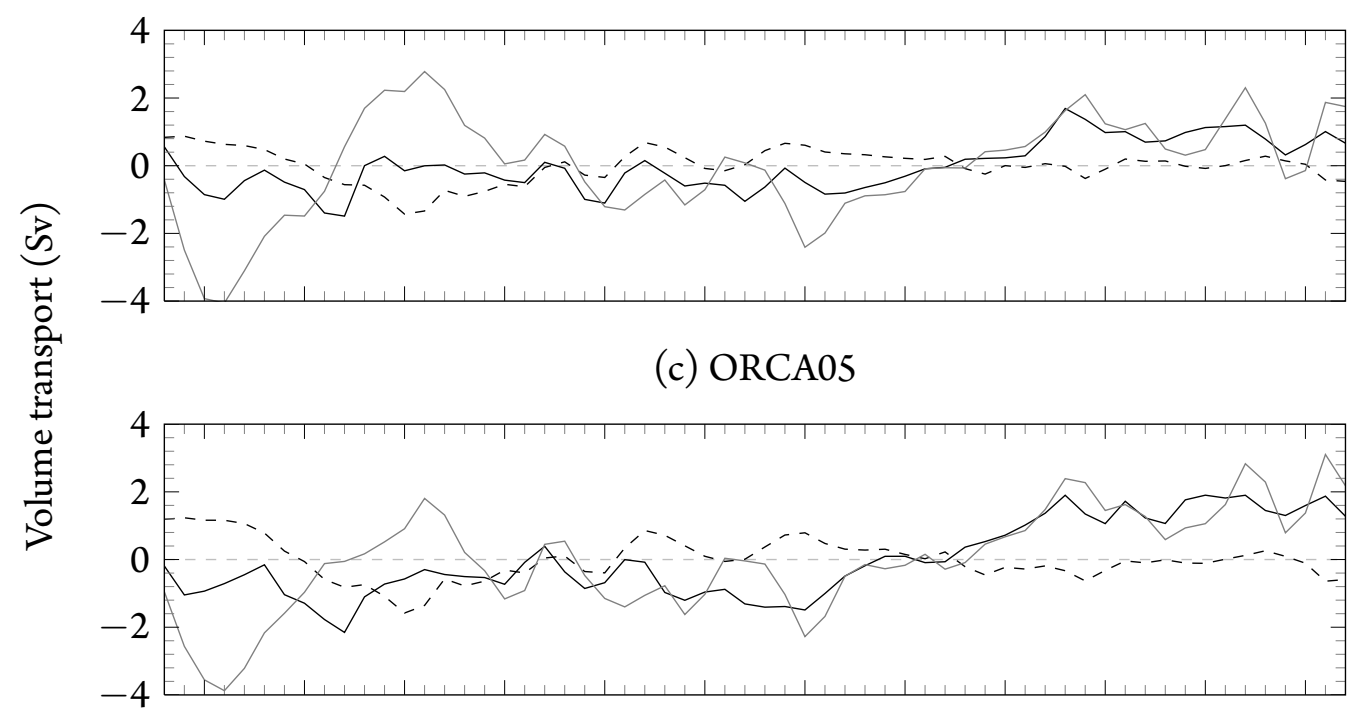

(d) ORCA12
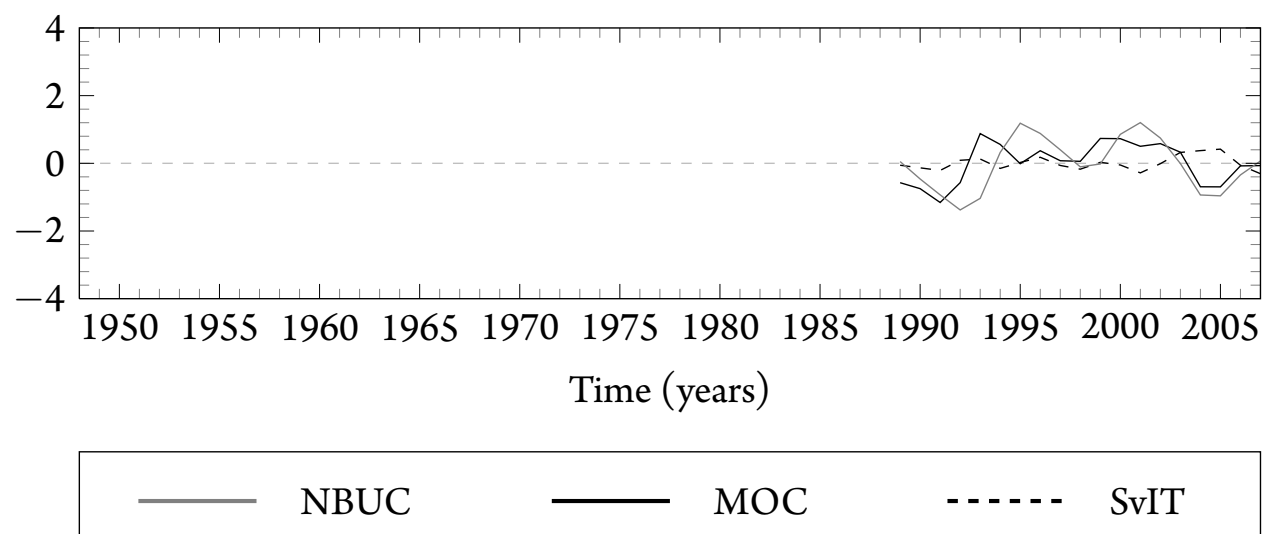

Figure 52: AMOC, Sverdrup interior and NBUC transport anomalies at $11^{\circ} \mathrm{S}$ for SODA (a), CSSM (b), ORCA05 (c) and ORCA12 (d) datasets.

An increase of AMOC was observed by Biastoch et al. (2008) using different ocean models forced by CORE at $26.5^{\circ} \mathrm{N}$ between 1960 and 2000, related to a positive trend of NAO.

Figure 53 shows the correlation between the NAO index, from NOAA, and our results for the AMOC and also for NBUC and IWBC. The NAO index has a positive trend $\left(4.8 \cdot y^{-1}\right)$, much bigger than those observed in our results for the AMOC. Figure 53 shows the correlation coefficients between 
Table 24: Correlation between annual averages of SAMOC (Figure 51b) and IWBC transports (Figure 46 ) at $27^{\circ} \mathrm{S}$.

\begin{tabular}{ccccccc}
\hline & \multicolumn{2}{c}{ SODA } & \multicolumn{2}{c}{ CCSM } & \multicolumn{2}{c}{ ORCA12 $^{1}$} \\
$\mathrm{R}^{2}$ & $\mathrm{p}$-value & $\mathrm{R}^{2}$ & $\mathrm{p}$-value & $\mathrm{R}^{2}$ & p-value & \\
\hline IWBC \& AMOC & $15.9 \%$ & 0.22 & $-43.5 \%$ & $<0.01$ & $59.2 \%$ & $<0.01$ \\
\hline
\end{tabular}

${ }^{1}$ Correlations done using the period between 1989 and 2007.

Table 25: Trends of South Atlantic MOC vertical maximum $\left(\mathrm{Sv} \cdot \mathrm{y}^{-1}\right)$ at $11^{\circ} \mathrm{S}$ and $27^{\circ} \mathrm{S}$, calculated from annual averaged anomalies (Figures $50 \mathrm{~b}$ and $51 \mathrm{~b}$ ).

\begin{tabular}{ccccc}
\hline & SODA & $\begin{array}{c}\text { CCSM } \\
\left(\mathrm{Sv} \cdot \mathrm{y}^{-1}\right)\end{array}$ & ORCA05 & ORCA12 \\
\hline $11^{\circ} \mathrm{S}$ & $0.05 \pm 0.01$ & $0.03 \pm 0.01$ & $0.05 \pm 0.01$ & $0.03 \pm 0.04$ \\
$27^{\circ} \mathrm{S}$ & $1.1 \cdot 10^{-3} \pm 0.01$ & $0.04 \pm 0.01$ & $0.07 \pm 0.01$ & $0.04 \pm 0.03$ \\
\hline
\end{tabular}

the AMOC and the NAO time series. Only ORCA05 and CCSM show significant correlations, confirming the results of Biastoch et al. (2008).

Table 26: Trends of South Atlantic MOC vertical maximum $\left(\mathrm{Sv} \cdot \mathrm{y}^{-1}\right)$ at $11^{\circ} \mathrm{S}$ and $27^{\circ} \mathrm{S}$, calculated from annual averaged anomalies (Figures $50 \mathrm{~b}$ and $51 \mathrm{~b}$ ).

\begin{tabular}{ccccc}
\hline & SODA & $\begin{array}{c}\text { CCSM } \\
\left(\mathrm{Sv} \cdot \mathrm{y}^{-1}\right)\end{array}$ & ORCA05 & ORCA12 \\
\hline $11^{\circ} \mathrm{S}$ & $0.05 \pm 0.01$ & $0.03 \pm 0.01$ & $0.05 \pm 0.01$ & $0.03 \pm 0.04$ \\
$27^{\circ} \mathrm{S}$ & $1.1 \cdot 10^{-3} \pm 0.01$ & $0.04 \pm 0.01$ & $0.07 \pm 0.01$ & $0.04 \pm 0.03$ \\
\hline
\end{tabular}

Good correlations were found between the bifurcation position at the surface and the AMOC (Table 27). As the bifurcation position is driven mainly by local changes in the position of the wind stress curl and the AMOC variability is not explained by changes in the wind (Table 23), NBUC seems to be the link between these two series.

Table 27: Correlation between annual averages of SAMOC and bifurcation position.

\begin{tabular}{ccccccccc}
\hline & \multicolumn{2}{c}{ SODA } & \multicolumn{2}{c}{ CCSM } & \multicolumn{2}{c}{ ORCA05 } & \multicolumn{2}{c}{ ORCA12 } \\
& $\mathrm{R}^{2}$ & $\mathrm{p}$-value & $\mathrm{R}^{2}$ & $\mathrm{p}$-value & $\mathrm{R}^{2}$ & $\mathrm{p}$-value & $\mathrm{R}^{2}$ & $\mathrm{p}$-value \\
\hline $\begin{array}{c}\mathrm{AMOC}_{11 S} \\
\& \mathrm{Bif}_{200}\end{array}$ & $0.9 \%$ & 0.94 & $-21.4 \%$ & 0.04 & $-37.1 \%$ & $<0.01$ & $-58.4 \%$ & $<0.01$ \\
$\begin{array}{c}\mathrm{AMOC}_{275} \\
\& \mathrm{Bif}_{500}\end{array}$ & $-37.9 \%$ & $<0.01$ & $1.2 \%$ & 0.93 & $-12.7 \%$ & 0.33 & $-42.3 \%$ & 0.07 \\
\hline
\end{tabular}


(a) SODA

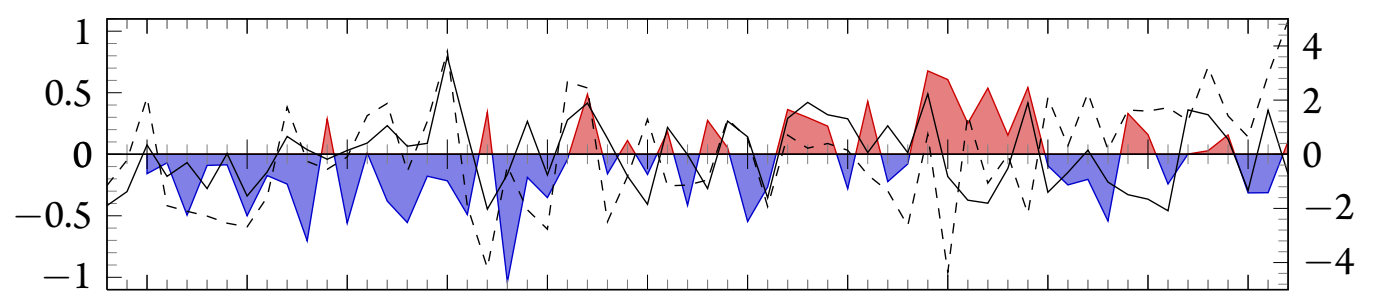

(b) CCSM

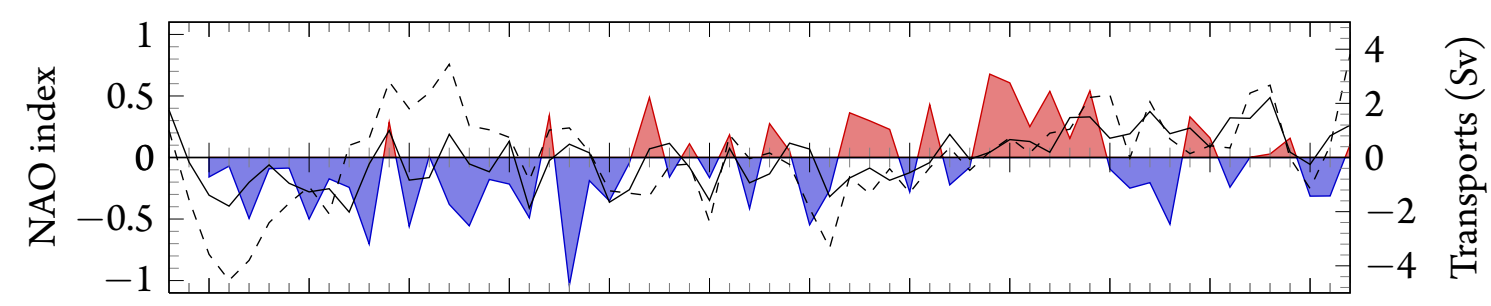

(c) ORCA05

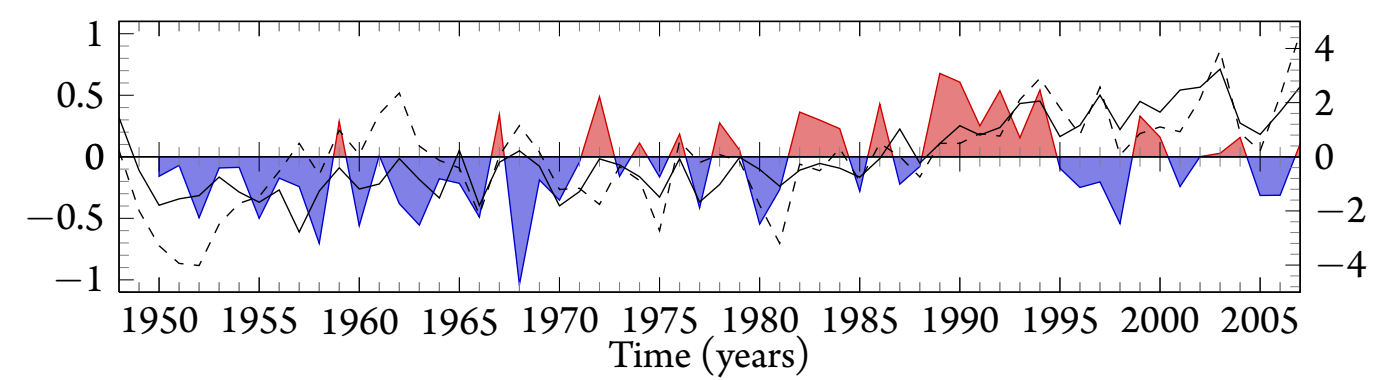

Figure 53: Relationship between NAO index (red and blue), AMOC (black) and NBUC (dashed) at $11^{\circ} \mathrm{S}$, for SODA (a), CSSM (b) and ORCA05 (c).

In most of our results in this section SODA was not (unexpectedly) able to reproduce the results found in the literature, mainly the observations. Schott \& Brandt (2007), Balmaseda et al. (2007), Köhl $\&$ Stammer (2008) report the challenge of faithfully simulating the decadal-to-multidecadal variability of the AMOC using ocean data assimilations based on different schemes. According to the authors, there appears to be no consistent low-frequency variability in AMOC transport variation in available data assimilation systems. Also, according to Kröger, Müller \& Storch (2012), when a model assimilates data, its salinity and temperature are not conserved which could compromise AMOC results from reanalysis, such as SODA, and hampers the reproduction of the observations. 


\subsection{Changes in the water masses linked to AMOC}

\subsubsection{Validation}

Salinity and temperature outputs of the ocean models are compared to the SODA reanalysis. We wish to verify if these models represent well the water mass structure of the South Atlantic.

First of all, a time-longitude averaged temperature-salinity diagram was constructed in the sections shown in Figure 19. The results can be seen in Figure 54. Once again, one should remember that, while SODA, CCSM and ORCA05 results cover the period from 1948 until 2007, the ORCA12 time series is shorter, and starts in 1989.

(a) $11^{\circ} \mathrm{S}$

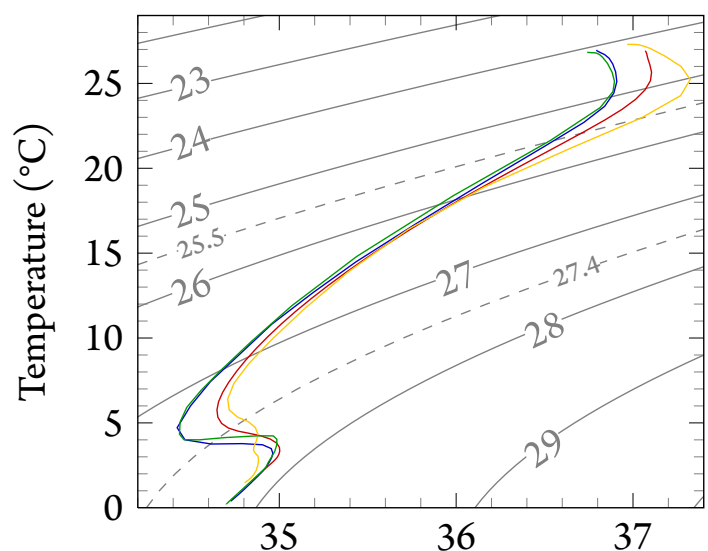

(b) $27^{\circ} \mathrm{S}$

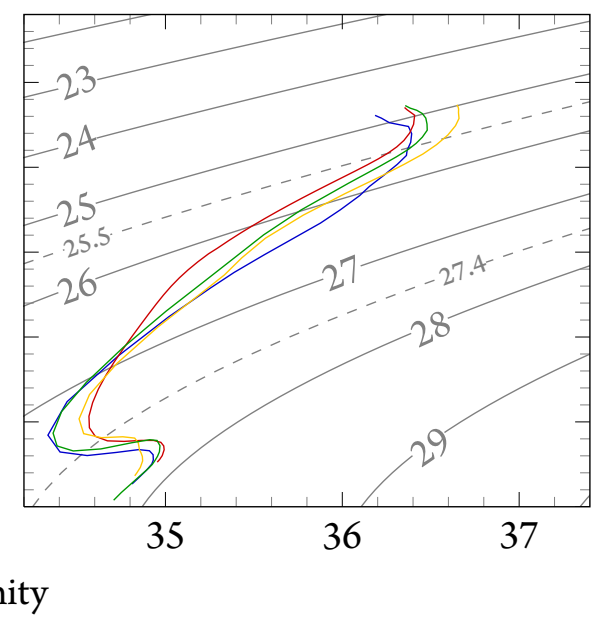

ORCA05

ORCA12

Figure 54: Temperature-salinity diagram using time-longitude averaged data at $11^{\circ} \mathrm{S}(\mathrm{a})$ and $27^{\circ} \mathrm{S}$ (b).

Comparing the curves in Figure 54, it is possible to observe that ORCA12 is the model that best reproduces SODA results, specially at intermediate and deep layers. At $11^{\circ} \mathrm{S}$ (Figure 54a) their curves are almost identical. Also, CORE forced models show saltier surface layers, with salinities greater than 37. ORCA05 also show bigger temperatures in the upper layer. In both sections, CORE forced models show a more saline AAIW and ORCA05 fails in reproduce the subsurface salinity maximum related to NADW (Figure 54a,b). This can be related to its weak AMOC (Figure 49, Section 3.1.2.3) (DANABASOGLU et al., 2013). These authors also show that the model seems to be unstable, and this feature might be related to numerical problems.

As discussed (STRAMMA; ENGLAND, 1999a), colder and fresher water masses in the upper layer, specially Tropical Water and ISACW, are observed at $27^{\circ} \mathrm{S}$ (Figure $54 \mathrm{~b}$ ), comparing the subtropical with the subtropical region. Differently from expected, in this section, in ORCA05 and CCSM models, SACW is not represented by a straight line. We can also verify an increase of the salinity minimum re- 
lated to AAIW from $27^{\circ} \mathrm{S}$ (Figure 54a) to $11^{\circ} \mathrm{S}$ (Figure 54b), as predicted in the literature (STRAMMA; ENGLAND, 1999a; SCHMID; SIEDLER; ZENK, 2000; TOMCZAK; GODFREY, 2003).

Figures 55 to 58 show the climatological sections of salinity and temperature at $11^{\circ} \mathrm{S}$ (Figures 55 and 56) and $27^{\circ} \mathrm{S}$ (Figures 56 and 58).
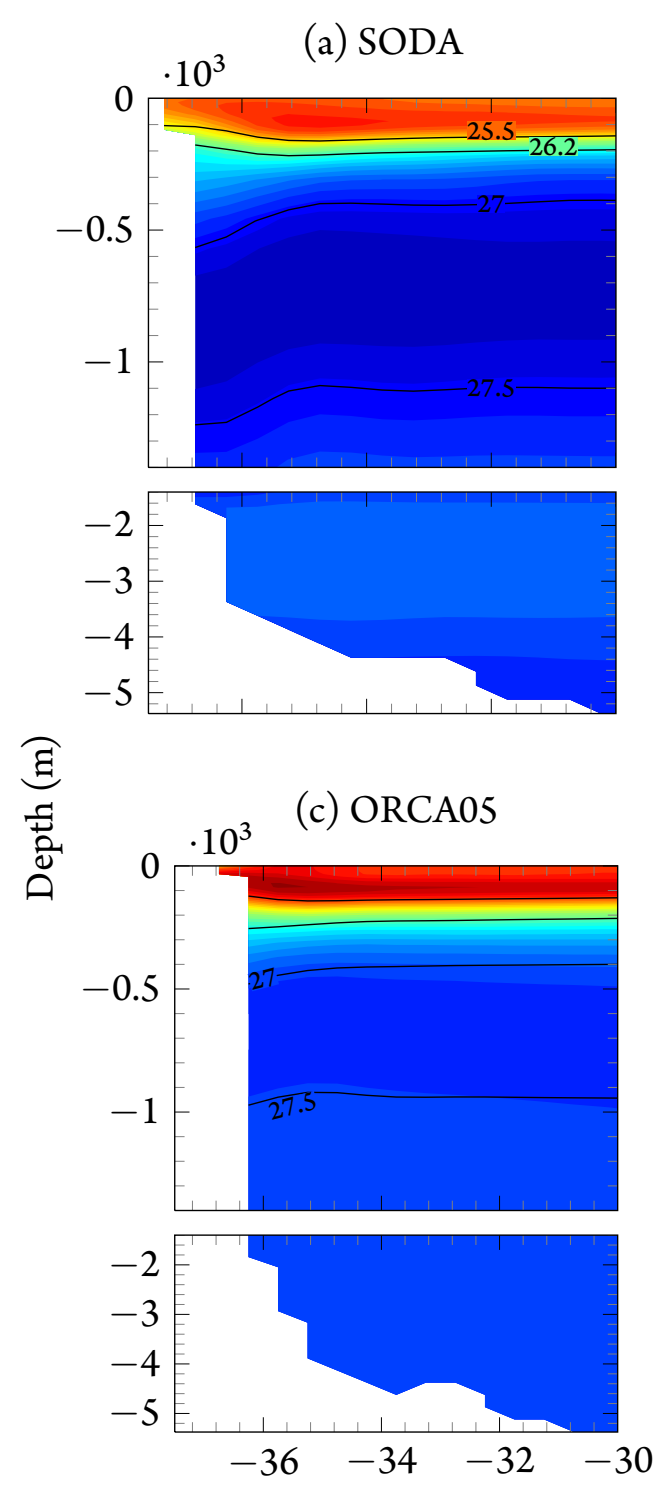

Longitude (b) CCSM
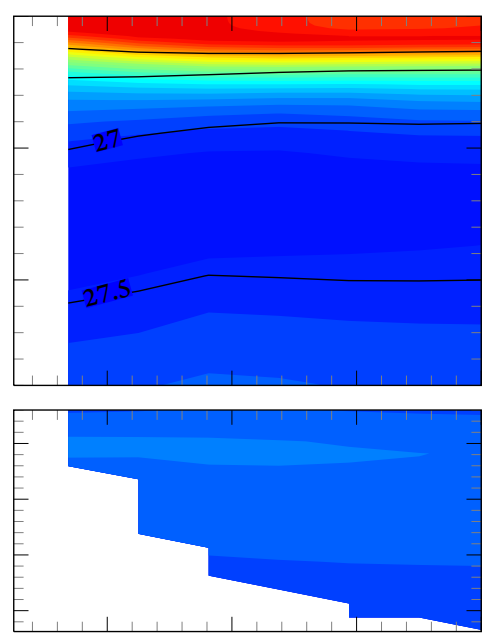

(d) ORCA12
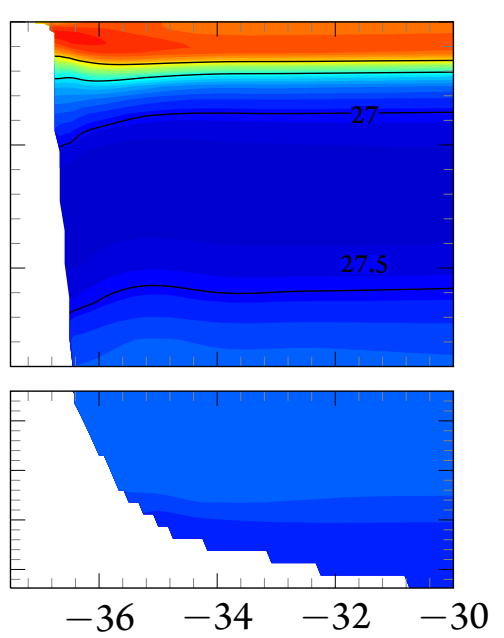

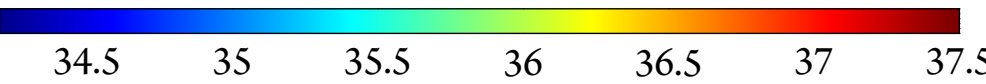

Figure 55: Climatological salinity at $11^{\circ} \mathrm{S}$, for SODA (a), CCSM (b), ORCA05 (c) and ORCA12 (d). Black contours indicate the limits of SACW (DONNERS; DRIJFHOUT; HAZELEGER, 2005) and AAIW (TALLEY, 1996).

At $11^{\circ} \mathrm{S}$ (Figure 55), as described above, CORE-II forced models (Figure 55b,c) show saltier surface waters (top $150 \mathrm{~m}$ ), but in all of them, the salinity maximum is found close to the coast. Waters lighter 
than $26.2 \mathrm{~kg} \cdot \mathrm{m}^{-3}$ occupy the first $250 \mathrm{~m}$ of the water column. SACW salinity, marked here by the isopycnals $25.5 \mathrm{~kg} \cdot \mathrm{m}^{-3}$ and $27 \mathrm{~kg} \cdot \mathrm{m}^{-3}$ varies from 34.5 to 36.5 in SODA and ORCA12 (Figures 55a,d). This range is similar to those found by Tomczak \& Godfrey (1994), Stramma \& England (1999a). CORE-II forced models low limits are, though, saltier than expected.

The salinity minimum related to the AAIW is detected between 500 and $1000 \mathrm{~m}$, as predicted (TOMCZAK; GODFREY, 2003). Moreover, as discussed before (e.g. Figure 54a), CCSM and ORCA05 results produce a saltier AAIW, when compared to the results of SODA, ORCA12, and other studies. According to Talley (1996), close to $11^{\circ} \mathrm{S}$, the AAIW typical salinity is 34.4 much lower than the values found in CCSM and ORCA05 models.

The $27.0 \mathrm{~kg} \cdot \mathrm{m}^{-3}$ and $27.4 \mathrm{~kg} \cdot \mathrm{m}^{-3}$ isopycnals do not follow the isohalines as seen in the surface layer, particularly CCSM and ORCA05, indicating greater influence of the temperature. Also, for these models, the area occupied by the AAIW is much smaller than in the others. In the ORCA05 results the $27.5 \mathrm{~kg} \cdot \mathrm{m}^{-3}$ isopycnal does not exceed the $1000 \mathrm{~m}$, while in SODA and ORCA12 results it reaches $1200 \mathrm{~m}$.

Bellow the AAIW, there is the subsurface salinity maximum that represents the NADW core. In the bottom, below $4000 \mathrm{~m}$, fresher waters are found, marking the presence of the AABW. As mentioned before (i.e. Figure 54a), ORCA05 results fail in reproduce this subsurface salinity maximum. Looking just to the salinity section, it is impossible to determine where the limit between the NADW and AABW is in this model (Figure 55c).

Examination of the temperature sections at $11^{\circ} \mathrm{S}$ (Figure 56) shows that the models are similar to each other compared to the results for salinity. As seen in Figure 54a, ORCA05 results have bigger surface temperatures. In all the results from the models, the ISACW (between 25.5 and $26.2 \mathrm{~kg} \cdot \mathrm{m}^{-3}$ ) is found in the thermocline, with temperatures varying from $15^{\circ} \mathrm{C}$ to $22^{\circ} \mathrm{C}$. According to Stramma \& England (1999a), temperatures between $5^{\circ} \mathrm{C}$ and $20^{\circ} \mathrm{C}$ characterize the SACW in the South Atlantic. Compared to these authors, in this section, SACW (between $25.5 \mathrm{~kg} \cdot \mathrm{m}^{-3}$ and $27 \mathrm{~kg} \cdot \mathrm{m}^{-3}$ ) is warmer $\left(10^{\circ} \mathrm{C}\right.$ to $\left.22^{\circ} \mathrm{C}\right)$.

Bigger differences between the model outputs are found in the AAIW layer. Historical data from Emery \& Meincke (1986), show that the AAIW varies from $2^{\circ} \mathrm{C}$ to $6^{\circ} \mathrm{C}$, Reid (1994) consider $3^{\circ} \mathrm{C}$ as the typical temperature of the AAIW in the SA. CORE-II forced models show warmer AAIW, with temperatures between $5^{\circ} \mathrm{C}$ and $8^{\circ} \mathrm{C}$, while SODA and ORCA12 results are closer to the literature. Below the AAIW, temperature differences between the models are not significative (Figure 56).

At $27^{\circ} \mathrm{S}$ (Figure 57), sea surface salinity is smaller than at $11^{\circ} \mathrm{S}$, since it is situated in a region of negative freshwater flux (precipitation predominance) whilst at $11^{\circ} \mathrm{S}$ the freshwater flux is positive (evaporation predominance) (TALLEY et al., 2011). Besides, at $27^{\circ} \mathrm{S}$, the $1 \mathrm{SACW}$ is shallower and occupies a wider layer than at $11^{\circ} \mathrm{S}$. Its limit with the SASTMW is also deeper $(\sim 300 \mathrm{~m})$. The SACW salinity ranges between 34.7 and 36.5 , similar to the values at $11^{\circ} \mathrm{S}$ and the those found in the literature (TOMCZAK; GODFREY, 1994; STRAMMA; ENGLAND, 1999a). These values are also close to those observed by Campos, Gonçalves \& Ikeda (1995). 


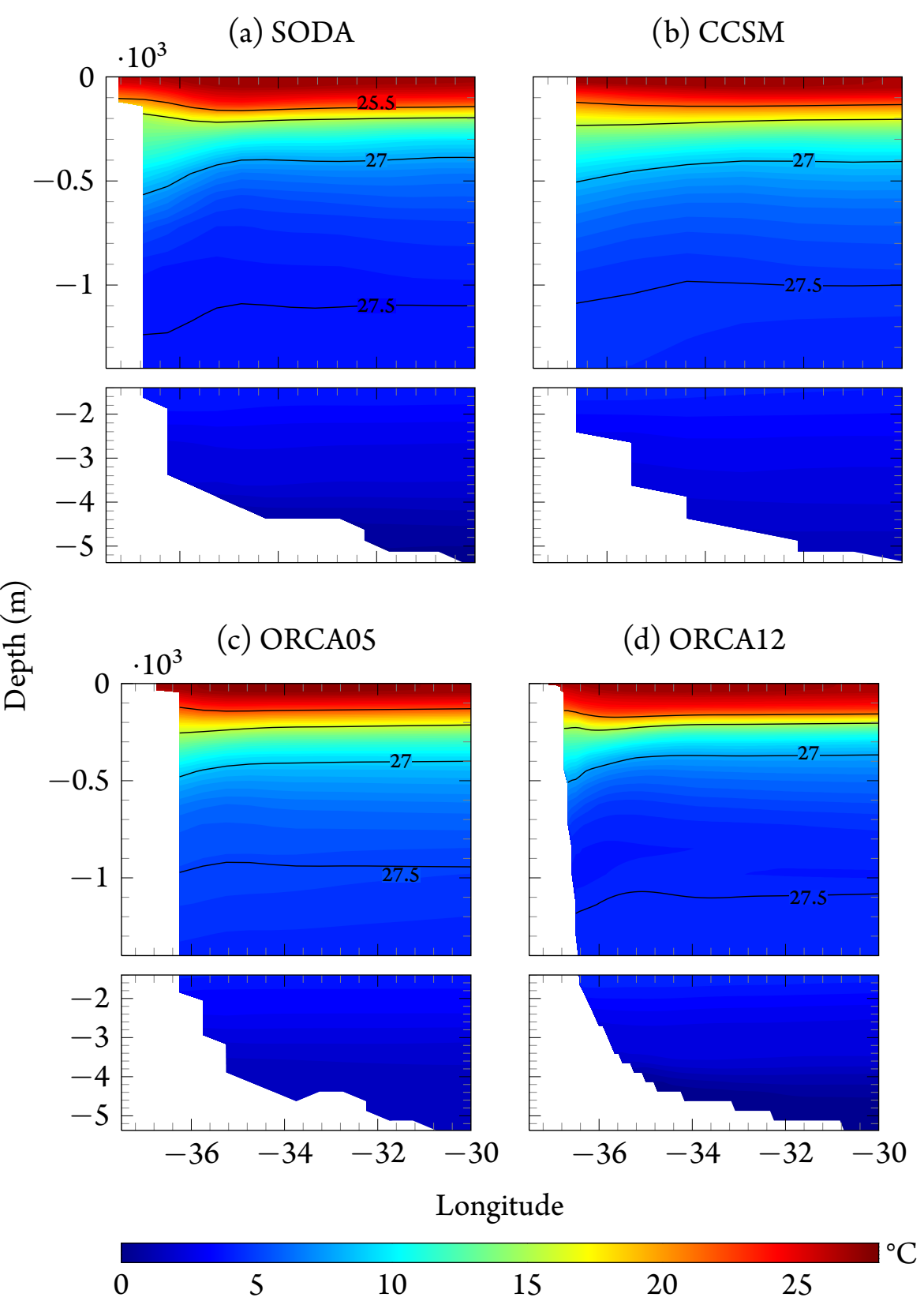

Figure 56: Climatological temperature at $11^{\circ} \mathrm{S}$, for SODA (a), CCSM (b), ORCA05 (c) and ORCA12 (d). Black contours indicate the limits of SACW (DONNERS; DRIJFHOUT; HAZELEGER, 2005) and AAIW (TALLEY, 1996).

Although the salinity minimum has decreased from $11^{\circ} \mathrm{S}$ to $27^{\circ} \mathrm{S}$ (e.g. Tomczak \& Godfrey (2003)), as in the northernmost section, CORE-II forced models show a saltier AAIW. In these model results, the salinity minimum is $34.4-34.5$ (Figure $57 \mathrm{~b}, \mathrm{c}$ ), greater than the values described by Tomczak \& Godfrey (2003) and those observed in SODA and ORCA12. The layer occupied by this water mass is wider in the SODA and ORCA12 results (between $600 \mathrm{~m}$ and $1350 \mathrm{~m}$, Figure $57 \mathrm{a}, \mathrm{d}$ ) than in CCSM and ORCA05 results (between $600 \mathrm{~m}$ and $1200 \mathrm{~m}$ ). In all of them, the AAIW layer is deeper.

In almost all model results one observes the presence of the NADW by its subsurface salinity max- 

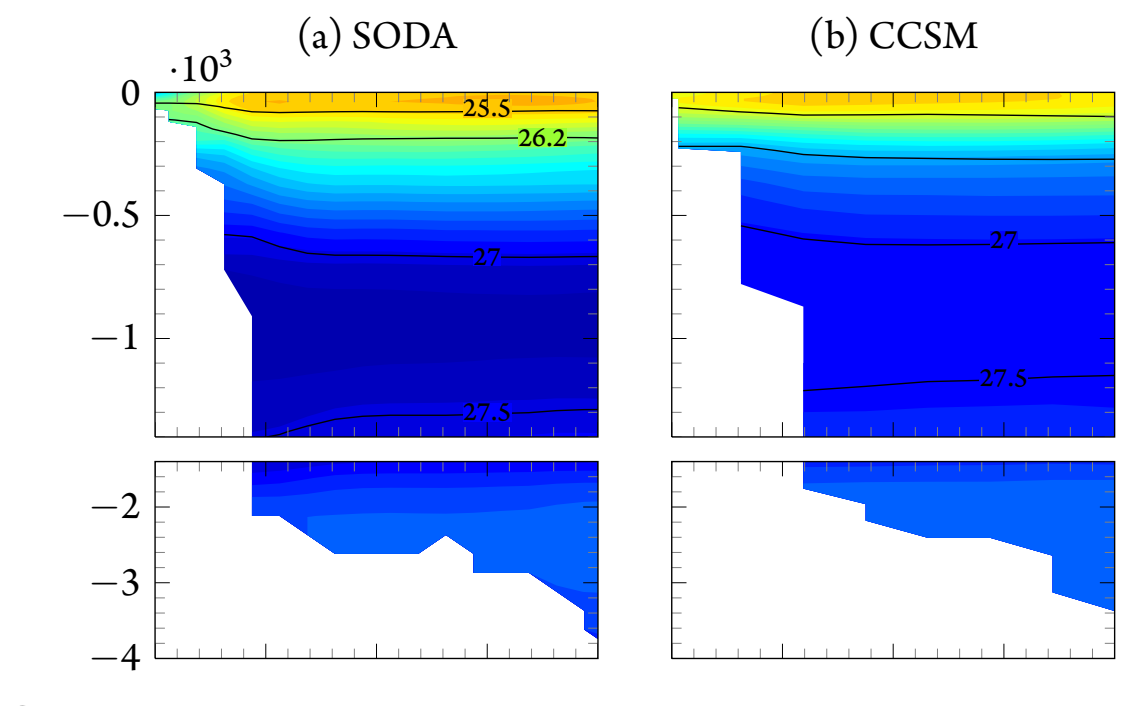

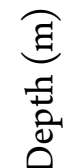

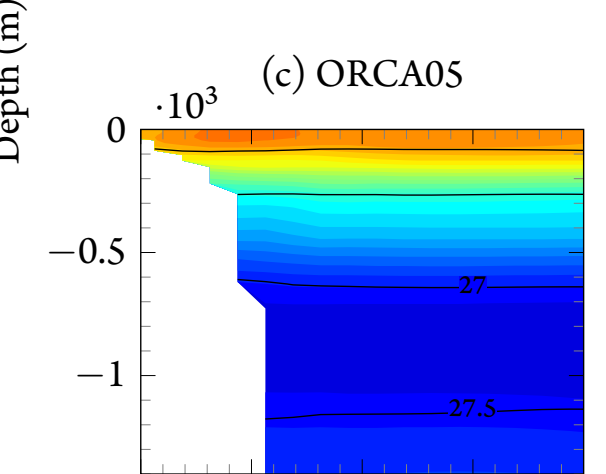

(d) ORCA12
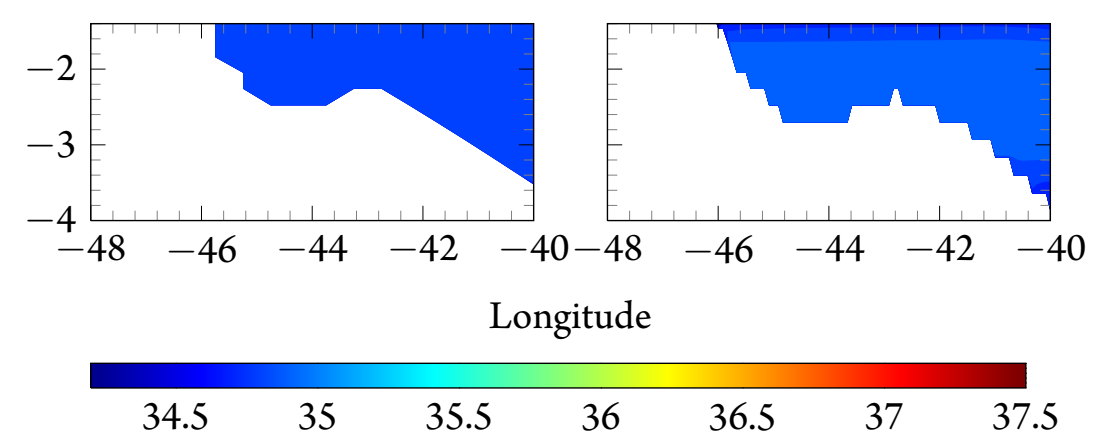

Figure 57: Climatological salinity at $27^{\circ} \mathrm{S}$, for SODA (a), CCSM (b), ORCA05 (c) and ORCA12 (d). Black contours indicate the limits of SACW (DONNERS; DRIJFHOUT; HAZELEGER, 2005) and AAIW (TALLEY, 1996).

imum. In ORCA05, however, as shown in Figure 54b and in Figure 55c, the presence of the NADW in this section is not marked by a salinity maximum.

Bellow the NADW, in SODA and ORCA12 one notes a minimal presence of the AABW, represented by the presence of fresher water bellow $3500 \mathrm{~m}$, since the section is too shallow to include such density water.

Once again, the temperature sections are more similar to each other than the salinity ones (Figure 58). The temperature in the top $100 \mathrm{~m}$ also decreased comparing to values found at $11^{\circ} \mathrm{S}$. SACW 
(between 25.5 and $26.2 \mathrm{~kg} \cdot \mathrm{m}^{-3}$ ) temperature ranges between $7^{\circ} \mathrm{C}$ and $20^{\circ} \mathrm{C}$, similar to the results of Campos, Gonçalves \& Ikeda (1995).

At intermediate layers, the water column is warmer for the CORE-II forced models (Figure $58 \mathrm{~b}, \mathrm{c}$ ). Although in all the models the temperature varies between $3^{\circ} \mathrm{C}$ and $6.5^{\circ} \mathrm{C}$, which coincides with previous studies (e.g. Emery \& Meincke (1986), Reid (1994)) in these models, the layer between $27 \mathrm{~kg} \cdot \mathrm{m}^{-3}$ and $27.5 \mathrm{~kg} \cdot \mathrm{m}^{-3}$ is dominated by temperatures greater than $5^{\circ} \mathrm{C}$.
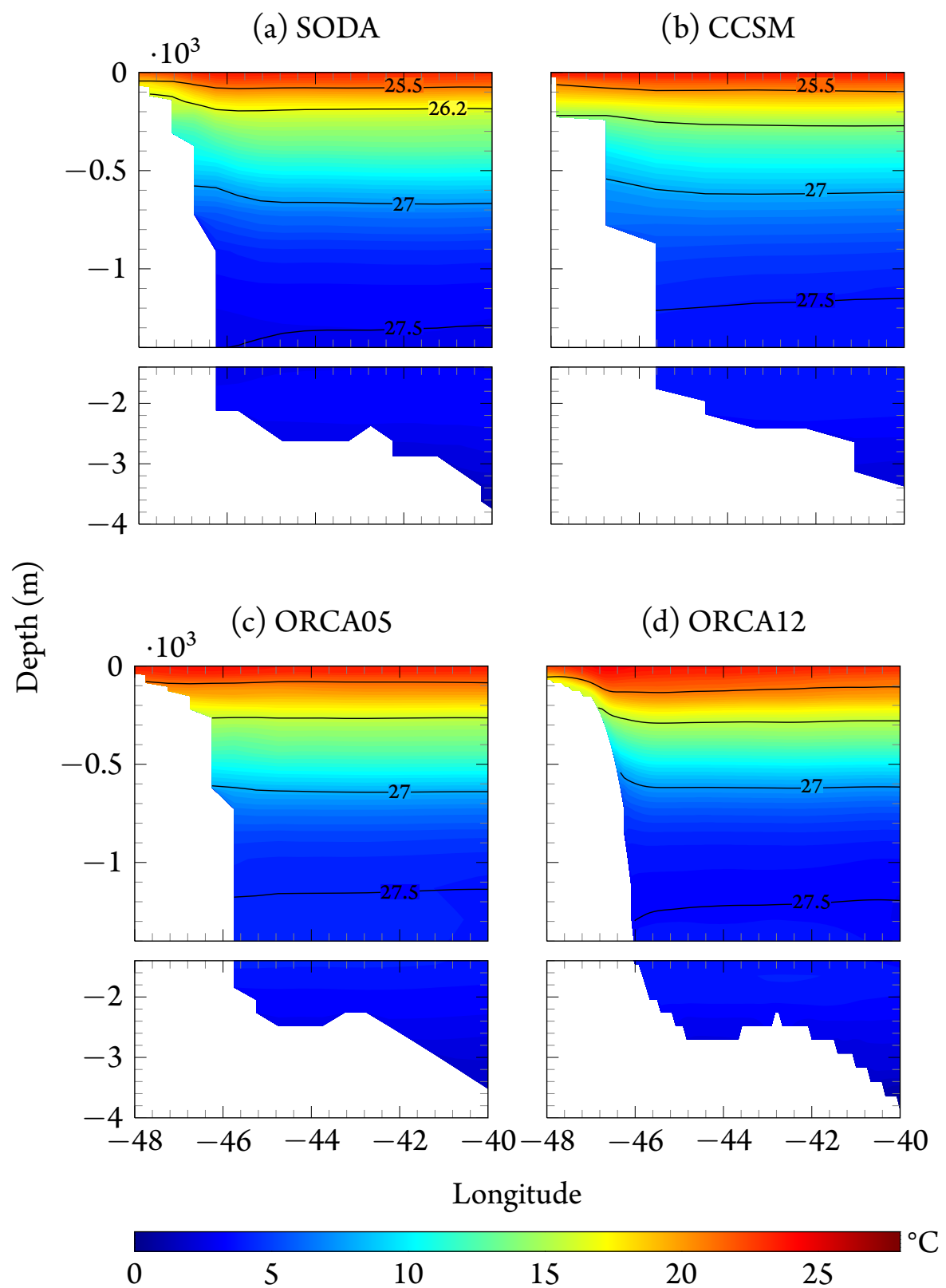

Figure 58: Climatological temperature at $27^{\circ} \mathrm{S}$, for SODA (a), CCSM (b), ORCA05 (c) and ORCA12 (d). Black contours indicate the limits of SACW (DONNERS; DRIJFHOUT; HAZELEGER, 2005) and AAIW (TALLEY, 1996).

To quantify the differences between all the model results used in this study and discussed in the 
climatological sections of salinity and temperature, and also assess some differences in these models variabilities, a Taylor's Diagram was elaborated. The results are shown in Figure 59.
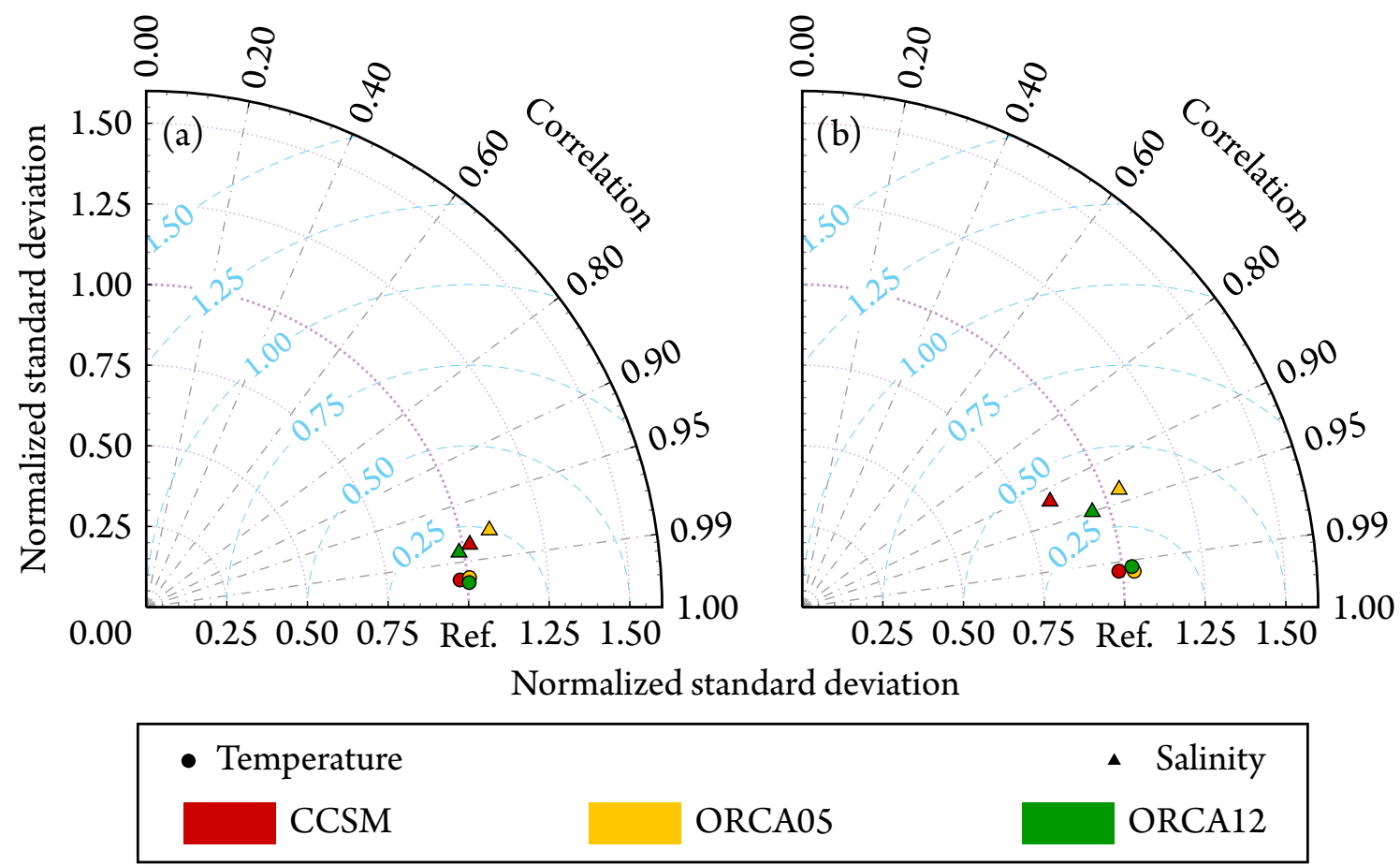

Figure 59: Taylor's Diagram for salinity and temperature data of CCSM, ORCA05 and ORCA12 at $11^{\circ} \mathrm{S}(\mathrm{a})$ and $27^{\circ} \mathrm{S}(\mathrm{b})$, using SODA as reference.

In both sections, temperature fields showed good correlations with SODA (greater than 99\%, Figure 59a,b), and standard deviations close to the reference. Compared to the SODA reanalysis, CORE-II forced models diverge more from SODA than ORCA12. In fact, at $11^{\circ} \mathrm{S}$ (Figure 59a), the great similarity between SODA and ORCA12, already seen in their climatological results (specially their salinitytemperature diagram, Figure 54a), is also observed in their variability, since, both salinity and temperature fields have normalised standard deviations close to 1, correlations higher than $98 \%$ and RSM smaller than 0.25 .

Big differences are seen in the salinity fields. At $11^{\circ} \mathrm{S}$, ORCA05 shows the smallest correlation (97\%) and the biggest standard deviation (difference of $\sim 7 \%$ ). This behaviour is probably related to its fresher NADW, which is evident in the Figure 54a. At $27^{\circ} \mathrm{S}$, as discussed before, the analysis of the climatological results, particularly Figure 54b, highlights that CCSM has a different salinity structure compared to SODA (lower salinities in SACW layers, saltier AAIW and reduced presence of the NADW). This can reflect in its variability resulting in lower correlation and higher differences between the standard deviations ( $\sim 22 \%$ ) as observed in the Figure 54b.

Taylor's Diagrams reveal that, besides their particularities and differences, all model results show correlations greater than $90 \%$ and reasonable standard deviations. 


\subsubsection{Water masses variability}

In this work, the interannual variability of the water masses carried by the western boundary currents that are part of the AMOC return flow is analyzed. Figures 60 and 61 show, by overlaying velocity contours on density fields, that the SACW and the AAIW are the main water masses carried by the NBUC and the IWBC.

At $11^{\circ} \mathrm{S}$, all the model results analyzed show that the core of the current carries the SACW. In COREII forced models, the NBUC carries a mixture of the ISACW and the SASTMW. But, in the SODA reanalysis and in ORCA12, the western boundary current carries the SASTMW (Figure 60).

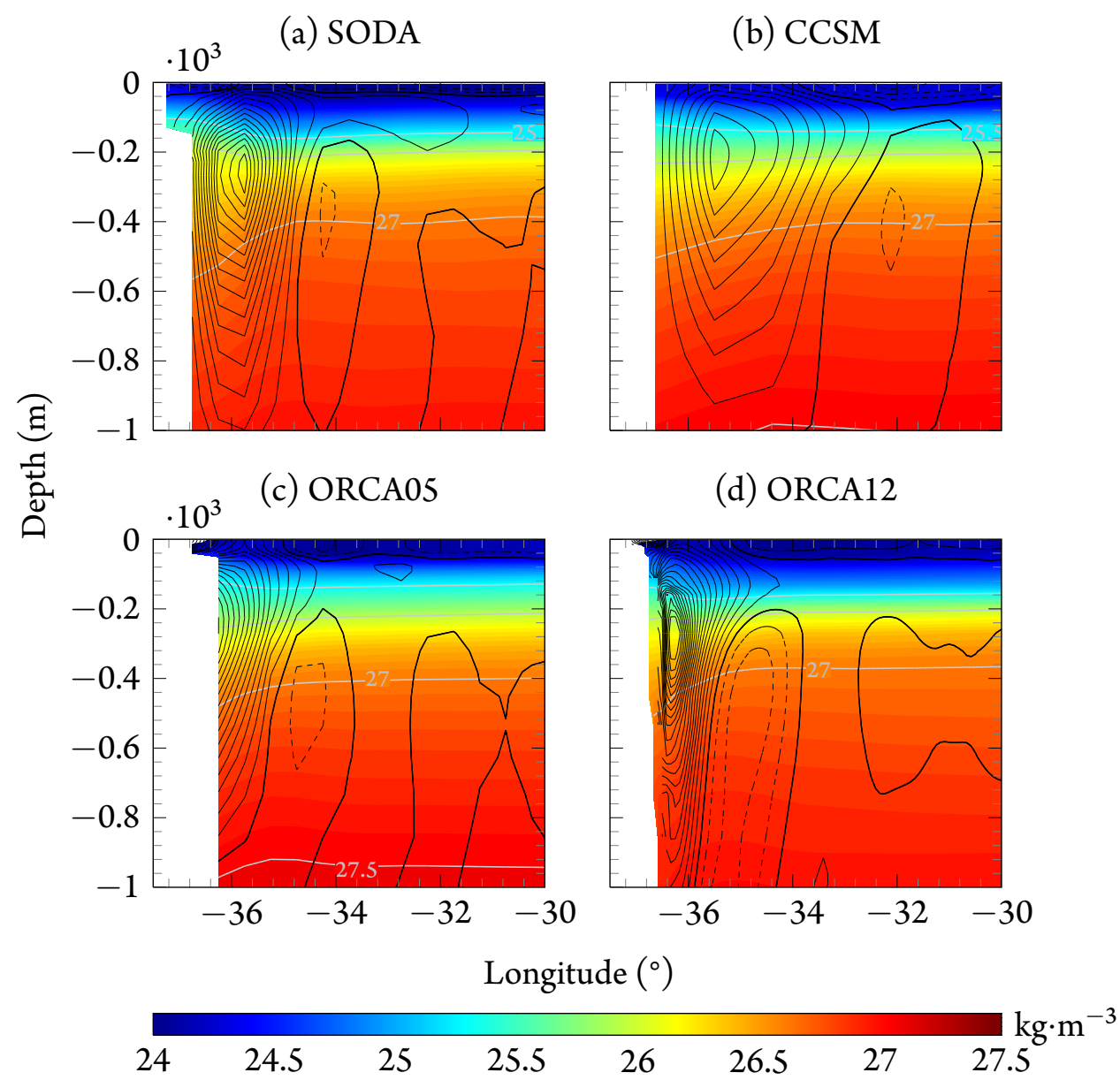

Figure 60: Velocity field $\left(\mathrm{m} \cdot \mathrm{s}^{-1}\right.$, black contours) superimposed on the density section $\left(\mathrm{kg} \cdot \mathrm{m}^{-3}\right)$ at $11^{\circ} \mathrm{S}$, for SODA (a), CCSM (b), ORCA05 (c) and ORCA12 (d). Dashed contours indicate negative flow. Contours at every $0.02 \mathrm{~m} \cdot \mathrm{s}^{-1}$. Light gray contours indicate the limits of SACW (DONNERS; DRIJFHOUT; HAZELEGER, 2005) and AAIW (TALLEY, 1996). Fields are an average (between 1948 and 2007 for SODA, CCSM and ORCA05 and between 1989 and 2007).

At $27^{\circ}$ S, however, the IWBC transports only the AAIW (Figure 61), while the SACW is carried by the BC. 


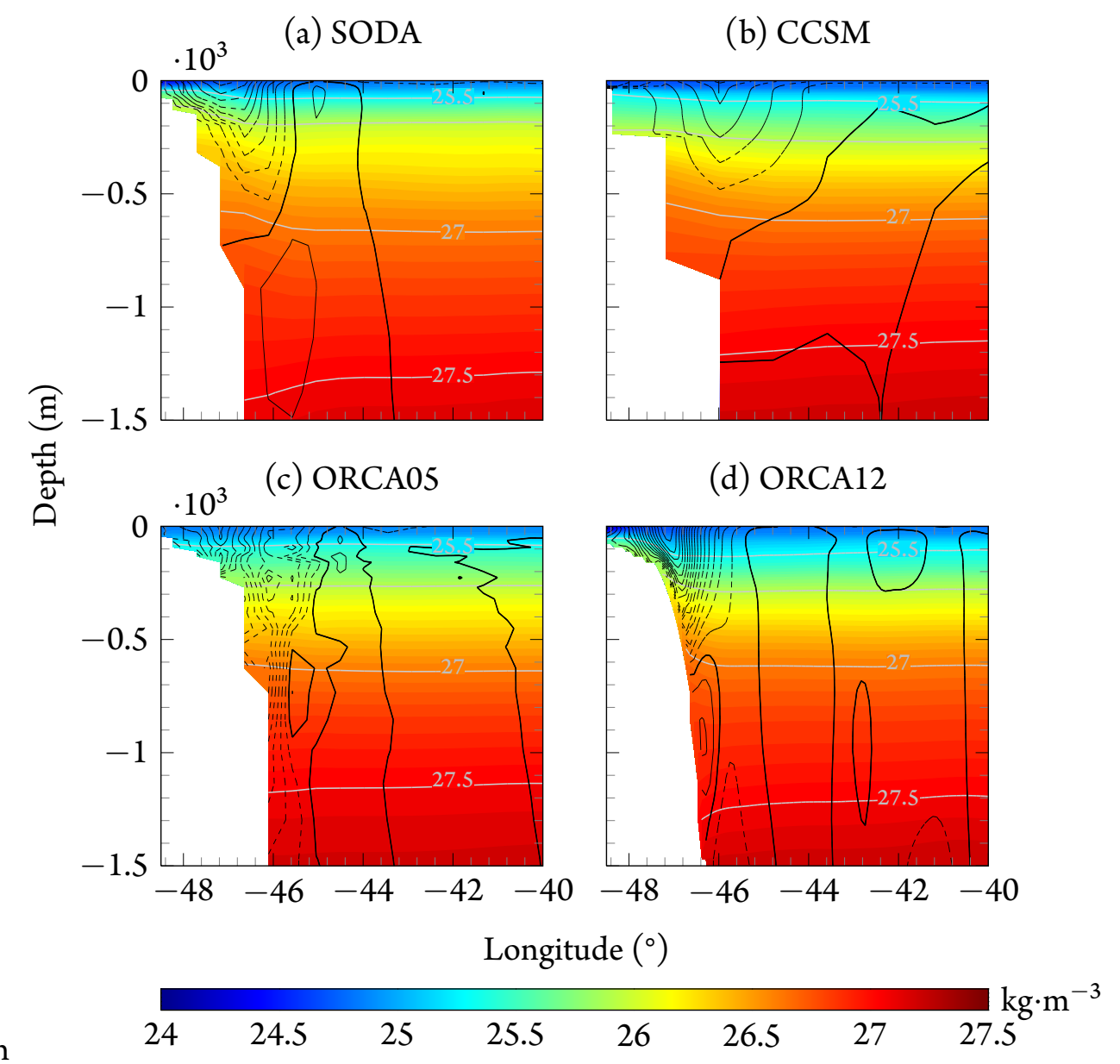

Figure 61: Velocity field $\left(\mathrm{m} \cdot \mathrm{s}^{-1}\right.$, black contours) superimposed on the density section $\left(\mathrm{kg} \cdot \mathrm{m}^{-3}\right)$ at $27^{\circ} \mathrm{S}$, for SODA (a), CCSM (b), ORCA05 (c) and ORCA12 (d). Dashed contours indicate negative flow. Contours at every $0.02 \mathrm{~m} \cdot \mathrm{s}^{-1}$. Light gray contours indicate the limits of SACW (DONNERS; DRIJFHOUT; HAZELEGER, 2005) and AAIW (TALLEY, 1996). Fields are an average (between 1948 and 2007 for SODA, CCSM and ORCA05 and between 1989 and 2007).

This result confirms previous studies that discuss the importance of the central and intermediate waters as indicators of changes in the AMOC (e.g. Garzoli \& Matano (2011)). OMP analysis was performed in order to determine the vertical position of the SACW and the AAIW cores at $11^{\circ} \mathrm{S}$ and $27^{\circ} \mathrm{S}$ as described in Section 2.2.6.

From Figure 54, the indices for the water masses types used in the OMP analysis were calculated, as described in Section 2.2.6. The results are shown in Tables 28 and 29. Our indices were compared to those found in the published literature, summarised in Table 30.

The temperature index for the ISACW, in all the model results, but mainly for ORCA05, exceeds the maximum range described by Mémery et al. (2000), using WOCE data close to the Brazilian coast. As described in Section 3.2.2, ORCA05 results show higher temperatures in the upper levels. COREII forced models have a saltier AAIW, compared to the other results (Figure 54, Section 3.2.2). The similarity of ORCA12 and SODA results is enhanced by the similarity of their salinity and temperature 
Table 28: Source water type parameters for each model at $11^{\circ} \mathrm{S}$. Parameters: mass conservation, temperature $\left(\theta_{0}\right.$, in $\left.{ }^{\circ} \mathrm{C}\right)$, salinity and potential vorticity $\left(\Pi\right.$, in $\left.10^{-8}(\mathrm{~m} \cdot \mathrm{s})^{-1}\right)$.

\begin{tabular}{|c|c|c|c|c|c|c|c|}
\hline & \multirow[t]{2}{*}{ Parameter } & \multicolumn{3}{|c|}{ SACW } & \multirow[t]{2}{*}{ AAIW } & \multirow[t]{2}{*}{ UCDW } & \multirow[t]{2}{*}{ Weight } \\
\hline & & ISACW & SAMW $^{1}$ & SAMW $^{2}$ & & & \\
\hline & Mass conservation. & & & 1 & & & 3 \\
\hline \multirow{3}{*}{ SODA } & $\theta_{0}$ & 21.6 & 12.8 & 8.2 & 3.8 & 3.7 & \multirow{2}{*}{2} \\
\hline & Salinity & 36.5 & 35.2 & 34.7 & 34.3 & 34.9 & \\
\hline & $\Pi$ & 0.03 & $2 \cdot 10^{-3}$ & $4 \cdot 10^{-3}$ & $2 \cdot 10^{-3}$ & $8 \cdot 10^{-4}$ & .1 \\
\hline \multirow{3}{*}{ CCSM } & $\theta_{0}$ & 22.1 & 13.0 & 8.9 & 5.0 & 4.0 & \multirow{2}{*}{2} \\
\hline & Salinity & 36.7 & 35.3 & 34.8 & 34.5 & 35.0 & \\
\hline & $\Pi$ & 0.03 & $2 \cdot 10^{-3}$ & $5 \cdot 10^{-3}$ & $2 \cdot 10^{-3}$ & $9 \cdot 10^{-4}$ & .1 \\
\hline \multirow{3}{*}{ ORCA05 } & $\theta_{0}$ & 22.9 & 13.2 & 8.2 & 6.5 & 3.3 & \multirow{2}{*}{2} \\
\hline & Salinity & 37.0 & 35.3 & 34.9 & 34.6 & 34.9 & \\
\hline & $\Pi$ & 0.03 & $3 \cdot 10^{-3}$ & $6 \cdot 10^{-3}$ & $3 \cdot 10^{-3}$ & $4 \cdot 10^{-4}$ & .1 \\
\hline \multirow{3}{*}{ ORCA12 } & $\theta_{0}$ & 21.6 & 12.6 & 8.1 & 4.0 & 4.1 & \multirow{2}{*}{2} \\
\hline & Salinity & 36.5 & 35.2 & 34.7 & 34.3 & 35.0 & \\
\hline & $\Pi$ & 0.04 & $2 \cdot 10^{-3}$ & $4 \cdot 10^{-3}$ & $2 \cdot 10^{-3}$ & $7 \cdot 10^{-4}$ & .1 \\
\hline
\end{tabular}

${ }^{1}$ Related to the isopycnal $26.6 \mathrm{~kg} \cdot \mathrm{m}^{-3} \cdot{ }^{2}$ Related to the isopycnal $27 \mathrm{~kg} \cdot \mathrm{m}^{-3}$.

Table 29: Source water type parameters for each model at $27^{\circ} \mathrm{S}$. Parameters: mass conservation, temperature $\left(\theta_{0}\right.$, in $\left.{ }^{\circ} \mathrm{C}\right)$, salinity and potential vorticity $\left(\Pi\right.$, in $\left.10^{-8}(\mathrm{~m} \cdot \mathrm{s})^{-1}\right)$.

\begin{tabular}{|c|c|c|c|c|c|c|c|}
\hline & \multirow[t]{2}{*}{ Parameter } & \multicolumn{3}{|c|}{ SACW } & \multirow[t]{2}{*}{ AAIW } & \multirow[t]{2}{*}{ UCDW } & \multirow[t]{2}{*}{ Weight } \\
\hline & & 1SACW & SAMW $^{1}$ & SAMW $^{2}$ & & & \\
\hline \multirow{4}{*}{ SODA } & Mass conservation. & & & 1 & & & 3 \\
\hline & $\theta_{0}$ & 21.2 & 13.0 & 7.8 & 2.5 & 3.3 & \multirow{2}{*}{2} \\
\hline & Salinity & 36.4 & 35.3 & 34.6 & 34.1 & 34.9 & \\
\hline & $\Pi$ & 0.06 & $5 \cdot 10^{-3}$ & 0.01 & $6 \cdot 10^{-3}$ & $2 \cdot 10^{-3}$ & .1 \\
\hline \multirow{3}{*}{ CCSM } & $\theta_{0}$ & 20.6 & 11.5 & 8.1 & 3.5 & 3.6 & \multirow{2}{*}{2} \\
\hline & Salinity & 36.2 & 35.1 & 34.9 & 34.4 & 34.9 & \\
\hline & $\Pi$ & 0.05 & 0.02 & $1 \cdot 10^{-3}$ & $6 \cdot 10^{-3}$ & $2 \cdot 10^{-3}$ & .1 \\
\hline \multirow{3}{*}{ ORCA05 } & $\theta_{0}$ & 21.7 & 15.3 & 12.9 & 3.5 & 3.2 & \multirow{2}{*}{2} \\
\hline & Salinity & 36.6 & 35.5 & 35.2 & 34.3 & 34.9 & \\
\hline & $\Pi$ & 0.04 & 0.02 & $1 \cdot 10^{-3}$ & $7 \cdot 10^{-3}$ & $1 \cdot 10^{-3}$ & .1 \\
\hline \multirow{3}{*}{ ORCA12 } & $\theta_{0}$ & 21.2 & 15.0 & 12.4 & 3.0 & 3.9 & \multirow{2}{*}{2} \\
\hline & Salinity & 36.4 & 35.4 & 35.1 & 34.2 & 34.9 & \\
\hline & $\Pi$ & 0.02 & 0.02 & $9 \cdot 10^{-4}$ & $6 \cdot 10^{-3}$ & $1 \cdot 10^{-3}$ & .1 \\
\hline
\end{tabular}

${ }^{1}$ Related to the isopycnal $26.6 \mathrm{~kg} \cdot \mathrm{m}^{-3} \cdot{ }^{2}$ Related to the isopycnal $27 \mathrm{~kg} \cdot \mathrm{m}^{-3}$.

index, mainly at $11^{\circ} \mathrm{S}$, and for the upper layers. As noted in Figure 54, the UCDW and also the NADW 
from the results of ORCA12 are warmer than in the results from SODA.

Few studies describes the potential vorticity distribution in the South Atlantic, specially related to the upper water masses used in this work. According to McCartney (1982), a characteristic of the Mode Water is its homogeneity, associated to a minimal vertical gradient of potential density and thus, potential vorticity. Mode waters obtained from the results for all model used here showed small potential vorticity values. Keffer (1985) presents maps of observed potential vorticity in the South Atlantic for the thermocline layers which correspond to the SASTMW, SAMW, and AAIW (summarised in Table 31). Our calculated values agree well with his results.

Table 30: Temperature and salinity characteristics of the source water masses according to the literature.

\begin{tabular}{ccccc}
\hline & $\begin{array}{c}\text { Temperature } \\
\left({ }^{\circ} \mathrm{C}\right)\end{array}$ & Salinity & $\begin{array}{c}\text { Density } \\
\left(\mathrm{kg} \cdot \mathrm{m}^{-3}\right)\end{array}$ & References \\
\hline ISACW & $16-21$ & $35.5-36.4$ & $25.5-26.2$ & $\begin{array}{c}\text { Donners, Drijfhout \& Hazeleger (2005) } \\
\text { Mémery et al. (2000) } \\
\text { SAMW }\end{array}$ \\
4-15 & $34.2-35.8$ & $26.5-27.1$ & $\begin{array}{c}\text { McCartney (1977) } \\
\text { Hanawa \& Talley (2001) }\end{array}$ \\
AAIW & $2-6$ & $33.8-34.8$ & $27.1-27.4$ & $\begin{array}{c}\text { Talley (1996) } \\
\text { Emery (2003) }\end{array}$ \\
UCDW & $3.4-4.0$ & $34.6-34.9$ & $27.55-27.75$ & $\begin{array}{c}\text { Tsuchiya, Talley \& McCartney (1994) } \\
\text { Hogg \& Thurnherr (2005) }\end{array}$ \\
\hline
\end{tabular}

Table 31: Potential vorticity characteristics of the source water masses according to the literature.

\begin{tabular}{cccc}
\hline & \multicolumn{2}{c}{$\left(\Pi\right.$, in $\left.10^{-8}(\mathrm{~m} \cdot \mathrm{s})^{-1}\right)$} & References \\
& $11^{\circ} \mathrm{S}$ & $27^{\circ} \mathrm{S}$ & \\
\hline SASTMW & \multicolumn{2}{c}{$1.5 \cdot 10^{-3}-0.02$} & \\
SAMW & $5 \cdot 10^{-3}-0.01$ & $0.01-0.02$ & Keffer $(1985)$ \\
AAIW & $2 \cdot 10^{-3}-3 \cdot 10^{-3}$ & $7 \cdot 10^{-3}-5 \cdot 10^{-3}$ & \\
\hline
\end{tabular}

From Figure 54, the salinity and the temperature in the isopycnals related to the SACW $\left(25.5 \mathrm{~kg} \cdot \mathrm{m}^{-3}\right.$ and $27.0 \mathrm{~kg} \cdot \mathrm{m}^{-3}$ ) and the AAIW (calculated using the mixed diagram, Section 2.2.6) were used to calculated the neutral densities, as described in the Section 2.2.7. Table 32 shows the neutral isopycnal calculated for each model and section.

Differences between the neutral densities for the SACW are small when compared to the potential densities because the influence of pressure is smaller. According to McDougall (1987), to calculate $\gamma_{n}$, reference level is slightly adjusted at each point, because of nonlinearity of the equation of state. Our values agree well with those found by Koltermann, Gouretski \& Jancke (2011), shown in the Figure 23, Section 2.2.7. 
Table 32: Neutral isopycnal $\left(\gamma_{n}, \mathrm{~kg} \cdot \mathrm{m}^{-3}\right)$ calculated in each model for each water masses, using the methodology of Jackett \& McDougall (1997) and Serazin (2011), described in the Section 2.2.7.

\begin{tabular}{ccccc}
\hline & Section & \multicolumn{2}{c}{ SACW } & AAIW \\
& & $\gamma_{n_{25.5}}$ & $\gamma_{n_{27.0}}$ & \\
\hline \multirow{2}{*}{ SODA } & $11^{\circ} \mathrm{S}$ & 25.52 & 27.11 & 27.42 \\
& $27^{\circ} \mathrm{S}$ & 25.53 & 27.11 & 27.42 \\
CCSM & $11^{\circ} \mathrm{S}$ & 25.52 & 27.10 & 27.42 \\
& $27^{\circ} \mathrm{S}$ & 25.51 & 27.10 & 27.54 \\
ORCA05 & $11^{\circ} \mathrm{S}$ & 25.52 & 27.09 & 27.29 \\
& $27^{\circ} \mathrm{S}$ & 25.52 & 27.10 & 27.46 \\
ORCA12 & $11^{\circ} \mathrm{S}$ & 25.52 & 27.11 & 27.40 \\
& $27^{\circ} \mathrm{S}$ & 25.52 & 27.11 & 27.44 \\
\hline
\end{tabular}

Section 3.2.2.1 shows the OMP results and changes in the salinity and temperature in the isopycnals related to the SACW, while Section 3.2.2.2 shows the same results for the AAIW.

\subsubsection{South Atlantic Central Water}

Figures 62 to 65 show the result of the OMP analysis for the SACW at $11^{\circ} \mathrm{S}$ and $27^{\circ} \mathrm{S}$ where a combination of the ISACW and the SAMW indices (Tables 28 and 29) was used to separate the SACW from the AAIW.

Figure 62 is a climatological distribution of the SACW at $11^{\circ} \mathrm{S}$. The first $150 \mathrm{~m}$ were ignored in this analysis due to its proximity to the mixed layer. In all models its possible to note the presence of the SACW core in the top $500 \mathrm{~m}$ (percentages greater than $80 \%$ ) coinciding with the isopycnal of $27.0 \mathrm{~kg} \cdot \mathrm{m}^{-3}$ (Figures 55 and 56 ). In the next $100-200 \mathrm{~m}$, there is a mixed layer where the partial contribution of the SACW decreases and the presence of the AAIW increases. This result agrees with Stramma \& England (1999a) and Silveira, Calado \& Castro (2004) that describes this interface between 500$700 \mathrm{~m}$, between 27.05 and $27.1 \mathrm{~kg} \cdot \mathrm{m}^{-3}$. The OMP analysis reveals that the SACW core is deeper close to the Brazilian coast, where the NBUC core is located (Figure 60).

The results at $27^{\circ} \mathrm{S}$ are similar. The $27 \mathrm{~kg} \cdot \mathrm{m}^{-3}$ isopycnal, between $600 \mathrm{~m}$ and $700 \mathrm{~m}$, is the bottom limit of the SACW core. Differently from the results of the other models, that have the first $500 \mathrm{~m}$ completely filled by SACW (100\%), SODA results present an average of $90-95 \%$ of SACW in the first $500 \mathrm{~m}$. Examination of its climatological temperature-salinity diagram (Figure 54b), shows a colder SACW, specially in the layer of the SASTMW $\left(26.2-26.6 \mathrm{~kg} \cdot \mathrm{m}^{-3}\right)$. This can be the cause of the unconformity between SODA reanalysis and the model results, as the index of this water mass is not included in the OMP analysis.

The mass balance constraint reinforces the good performance of the reanalysis. At $11^{\circ} \mathrm{S}$, the error associated with the OMP is smaller than $2 \%$ in almost all the water column analyzed (Figure 63). 


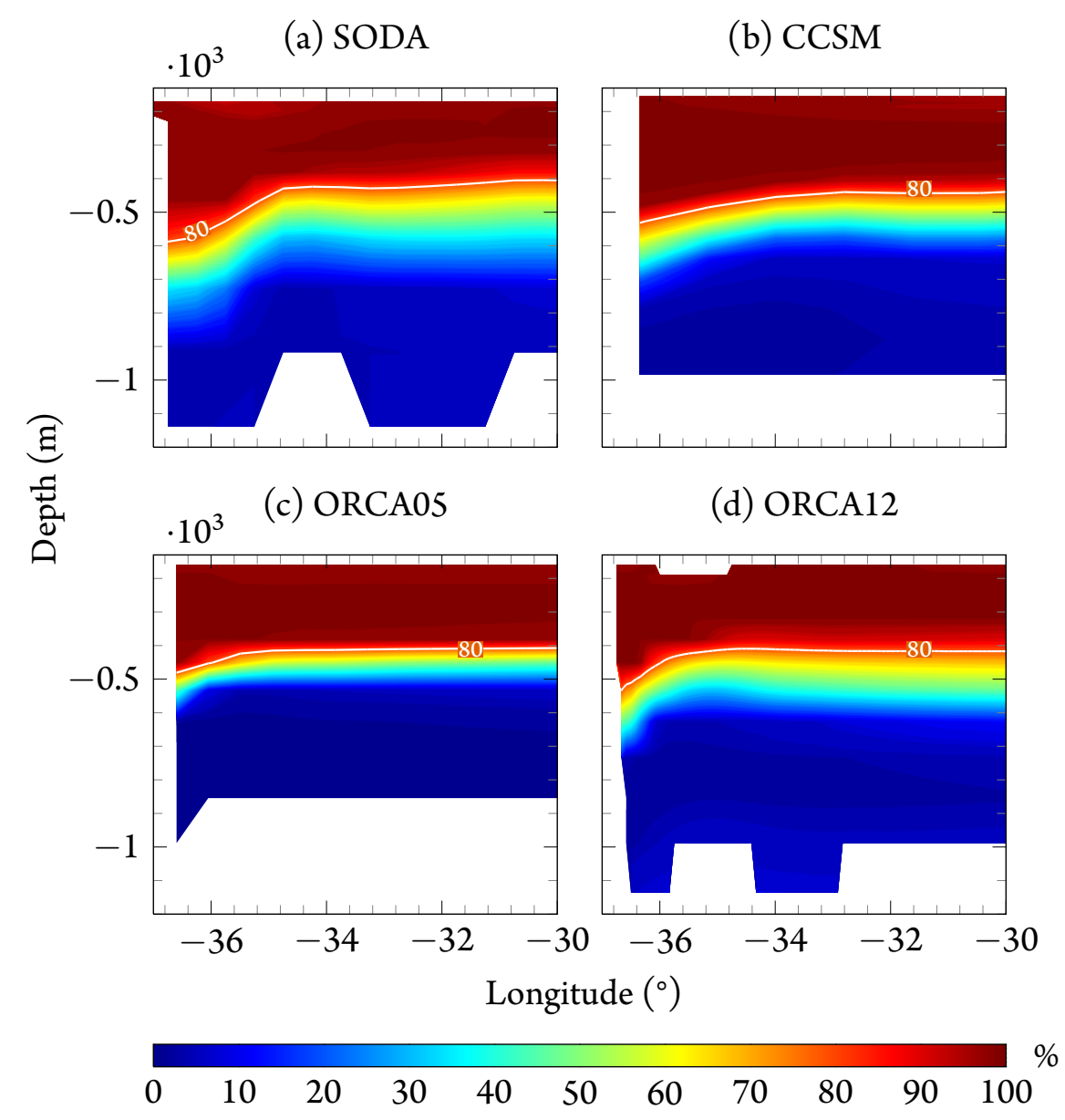

Figure 62: Climatological section of fractional contribution from SACW at $11^{\circ} \mathrm{S}$ for SODA (a), CCSM (b), ORCA05 (c) and ORCA12 (d). White contour marks the limit of the water mass core (80\%). Figures (a), (b) and (c) are an average of the results from 1948 to 2007, while the average done in figure (d) comprises the results from 1989 to 2007.

At $27^{\circ} \mathrm{S}$, the error is smaller than $1.5 \%$ for all models. According to Budillon et al. (2003), Tomczak (1981), Tomczak \& Large (1989), Tomczak \& Poole (1999) and Frants et al. (2013), the mass balance constraint is used as a measure of the uncertainty of the result and mass balance residuals of $5 \%$ or less are considered acceptable.

During the empirical tests to decide the best combination of weights for the OMP analysis, it was observed that if the importance of the potential vorticity was increased, the worse (better) the results for the SACW (AAIW), i.e., bigger (smaller) mass balance constraints. Bigger weights for temperature also changed the water masses distributions, reducing (increasing) the error in the SACW (AAIW) layer. Changes in the weight of the salinity increases the error in all the water column.

Sensitive tests reveal that, in general, raising (decreasing) the temperature of the ISACW in only $5 \%$, yields the SACW upper limit position deeper (shallower), and decreases (increases) the error at the upper levels. In the same way, elevating (reducing) the temperature of the SAMW in the same 5\% moves the core (the $80 \%$ limit) of the SACW to upper (deeper) layers with little differences in the final 
(a) SODA

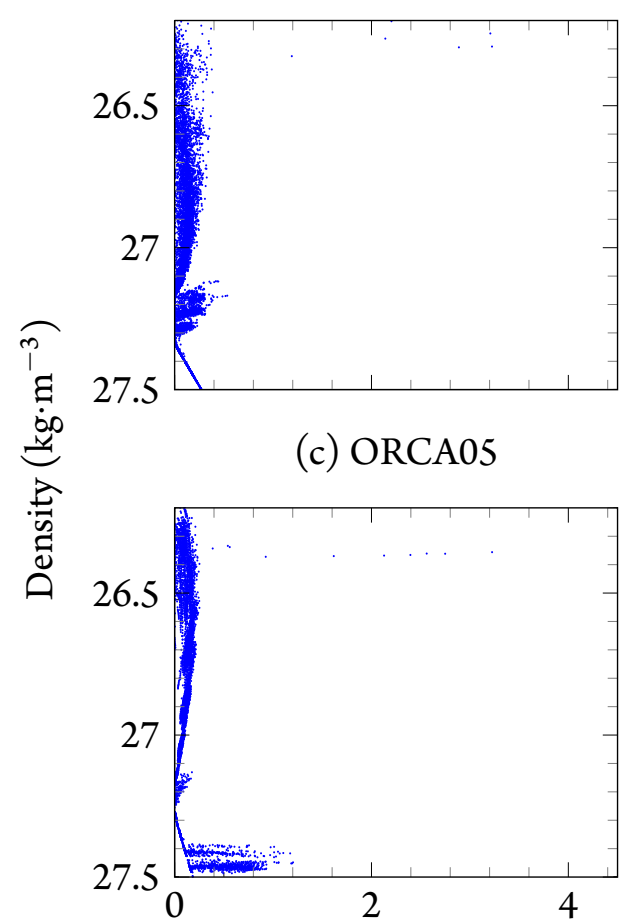

(b) CCSM

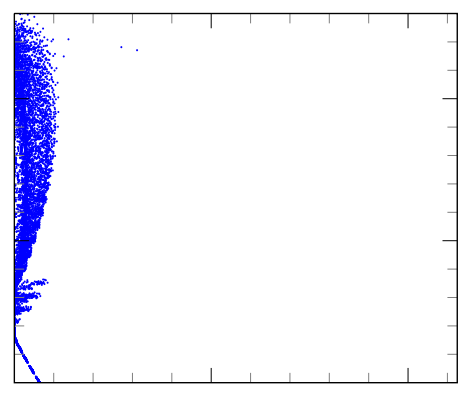

(d) ORCA12

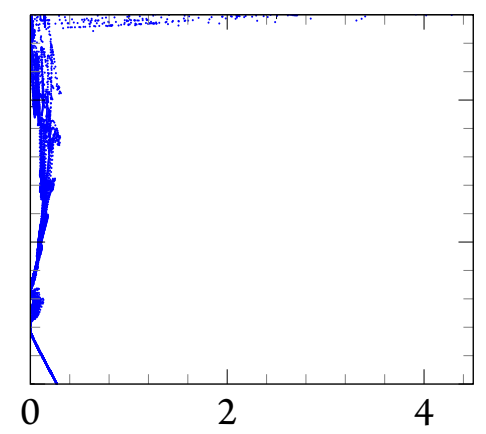

Mass conservation residual fit (\%)

Figure 63: Mass conservation residual fit (\%) for the OMP analysis at $11^{\circ} \mathrm{S}$ for SODA (a), CCSM (b), ORCA05 (c) and ORCA12 (d).

mass constraint. $5 \%$ of change in the temperature of the AAIW does not move significantly the position of the SACW core.

Changes in the AAIW salinity (also 5\%), however, have significant impact in the position of the SACW core, since the salinity minimum is the main characteristic of this water mass (e.g Talley (1996), Pickard, Emery \& Talley (2007)). The mass constraint, for the AAIW layer, can be two times greater. If the same changes are applied to the salinity of the ISACW there is no impact on the position of the SACW core. However, the same changes applied to the salinity of the SAMW restrict the SACW to the upper $250 \mathrm{~m}$ or less. The error in this case can exceed $10 \%$.

Potential vorticity changes do not generate large changes in the water mass distribution or in the error of the analysis.

When comparing all the model results, ORCA12 proved to be the most sensitive to the tests with known changes. For this model, and an increase or decrease of $5 \%$ in AAIW salinity parameter results in a SACW occupying the top $1000 \mathrm{~m}$. In this case, the mass constraint surpasses $15 \%$ for the AAIW layer (between $27 \mathrm{~kg} \cdot \mathrm{m}^{-3}$ and $27.5 \mathrm{~kg} \cdot \mathrm{cm}^{-3}$ ).

Figure 66 shows the anomalies of the SACW core ( $80 \%$ contour) position. The anomalies were constructed by subtracting the mean position of each longitude (Figures 62 and 64). Some interannual to interdecadal variability can be observed, and changes affect all the section most of the time. In 


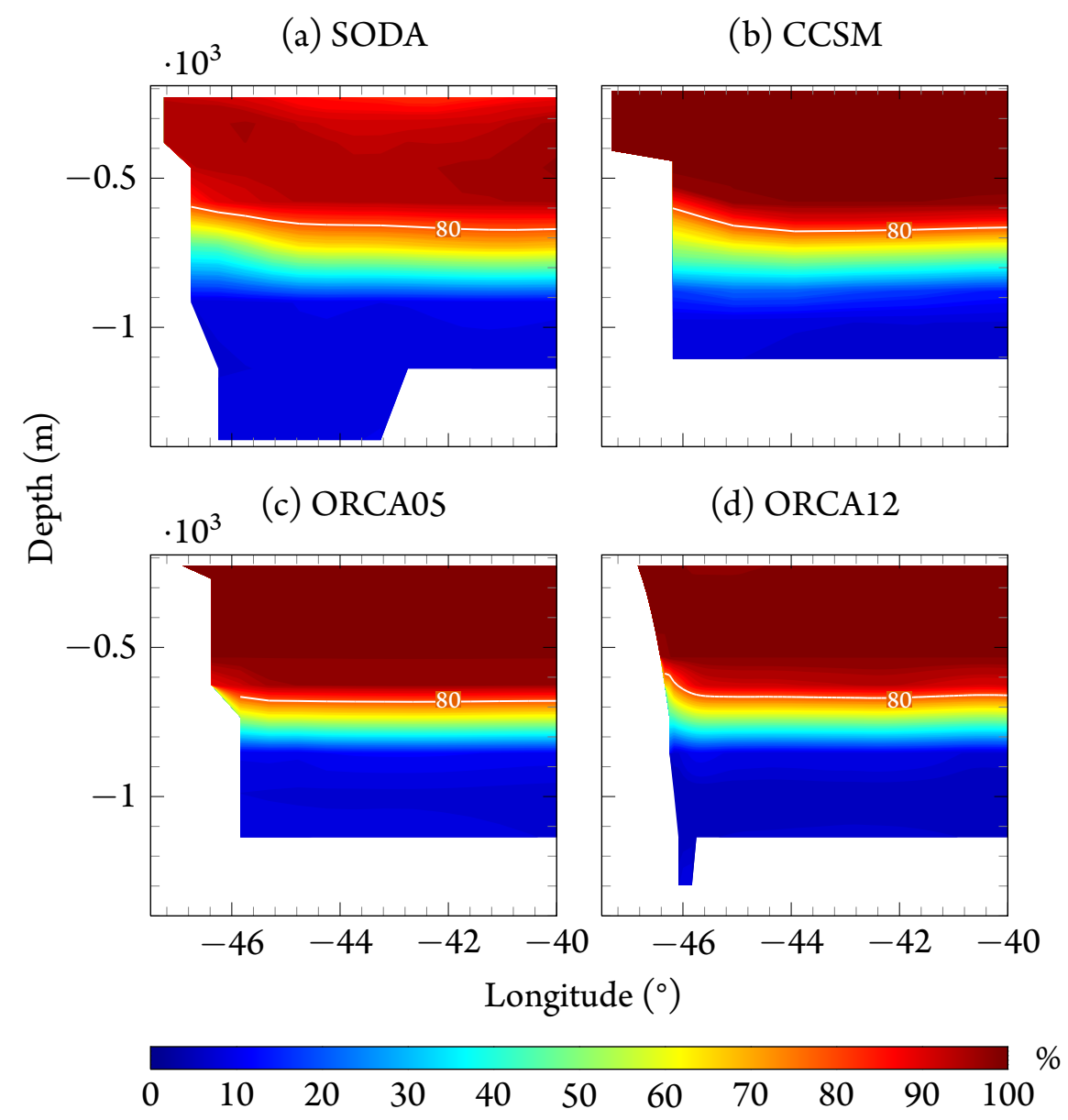

Figure 64: Climatological section of fractional contribution from SACW at $27^{\circ} \mathrm{S}$ for SODA (a), CCSM (b), ORCA05 (c) and ORCA12 (d). White contour marks the limit of the water mass core (80\%). Figures (a), (b) and (c) are an average of the results from 1948 to 2007, while the average done in figure (d) comprises the results from 1989 to 2007.

the SODA reanalysis the anomalies are larger (Figure 66a,e). Higher frequencies are found in SODA and ORCA12 results. In both sections, the similarity between the results of CORE-II forced models is evident, specially between 1948 and 1995 (Figure 66b,c,f,g). Excluding the trend, their correlations is greater than $80 \%$ in both sections (Tables 33 and 34), confirming the influence of the forcing.

At $11^{\circ} \mathrm{S}$ (Figures 66a-d and 67) it is possible to observe the deepening of the SACW core in the SODA reanalysis (mainly between $30^{\circ} \mathrm{S}$ and $34^{\circ} \mathrm{S}$, Figure 66a) and in CCSM. Their positive trends are shown in Table 35. At the same section, in the results for ORCA05 and ORCA12, the SACW core is getting shallower, (positive trends, Table 35).

Besides their similar variability, CORE-II forced models show opposite trends. This was not expected, since in all the previous analysis, despite differences in the mean value, their behavior was always very similar (e.g. Section 3.1.2).

Differently from the section at $11^{\circ} \mathrm{S}$, all the models show a positive trend of the SACW $80 \%$ contour, which means, a shallowing of the water mass core (Figures 66e-h and 67b). These trends are shown in 
(a) SODA

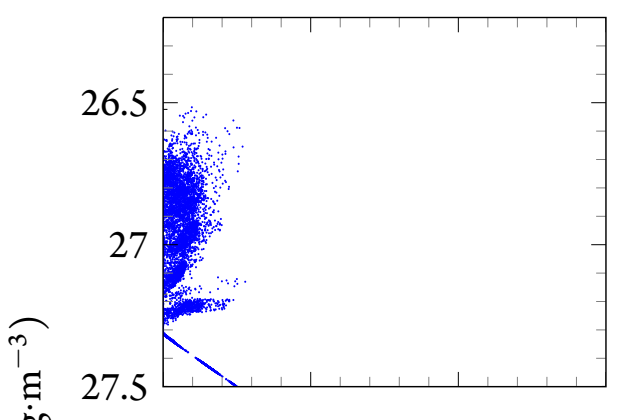

(c) ORCA05

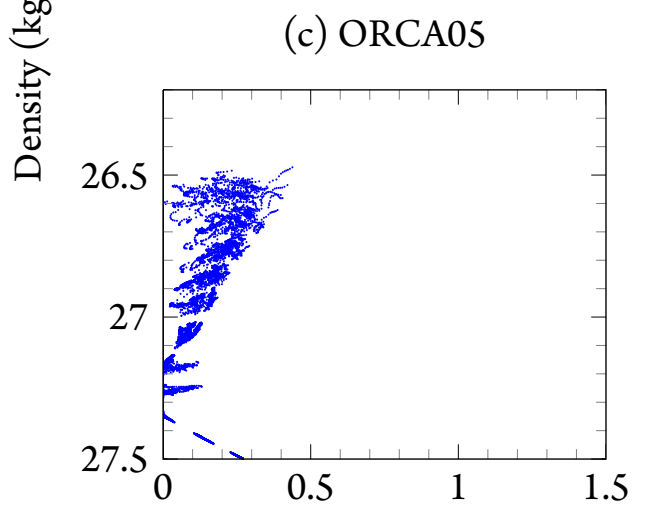

(b) CCSM

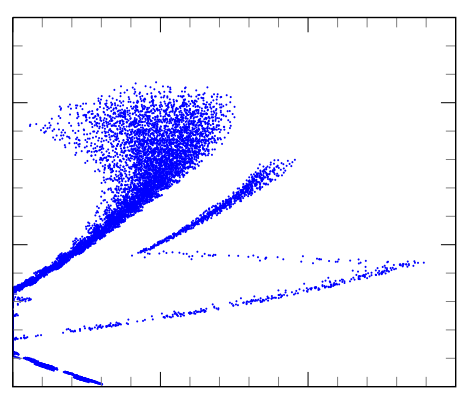

(d) ORCA12

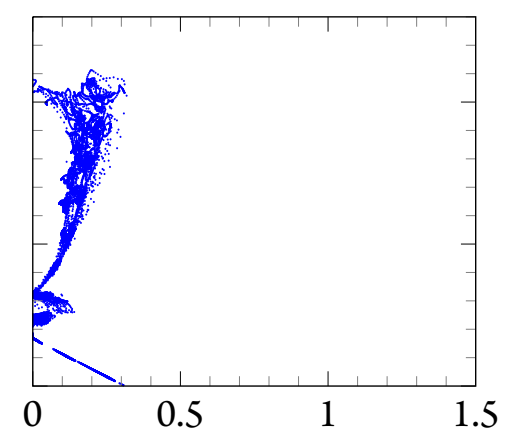

Mass conservation residual fit (\%)

Figure 65: Mass conservation residual fit (\%) for the OMP analysis at $27^{\circ} \mathrm{S}$ for SODA (a), CCSM (b), ORCA05 (c) and ORCA12 (d).

Table 33: Correlations of the SACW core vertical position from each model, averaged between $37^{\circ} \mathrm{S}$ and $30^{\circ} \mathrm{S}$ (Figure 67a).

\begin{tabular}{ccccccccc}
\hline & \multicolumn{2}{c}{ SODA } & \multicolumn{2}{c}{ CCSM } & \multicolumn{2}{c}{ ORCA05 } & \multicolumn{2}{c}{ ORCA12 $^{1}$} \\
& $\mathrm{R}^{2}$ & $\mathrm{p}$-value & $\mathrm{R}^{2}$ & $\mathrm{p}$-value & $\mathrm{R}^{2}$ & $\mathrm{p}$-value & $\mathrm{R}^{2}$ & $\mathrm{p}$-value \\
\hline SODA & & & $2.0 \%$ & 0.88 & $12.3 \%$ & 0.35 & $-43.4 \%$ & 0.06 \\
CCSM & $2.0 \%$ & 0.88 & & & $83.5 \%$ & $<0.01$ & $1.1 \%$ & 0.96 \\
ORCA05 $^{2}$ & $12.3 \%$ & 0.35 & $83.5 \%$ & $<0.01$ & & & $13.4 \%$ & 0.58 \\
ORCA12 $^{1}$ & $-43.4 \%$ & 0.06 & $1.1 \%$ & 0.96 & $13.4 \%$ & 0.58 & & \\
\hline
\end{tabular}

${ }^{1}$ Correlations done using the period between 1989 and 2007.

the Table 35, and they are larger than at $11^{\circ} \mathrm{S}$. CCSM results have the smallest trends, linked to the deepening in the end of the $20^{\text {th }}$ century, close to the Brazilian coast. ORCA12 results show larger trends, 3 times more than the ones on the reanalysis.

Excluding the trend, significant and positive correlations were found between the results of the CCSM, ORCA12 models and the SODA reanalysis. ORCA05 and ORCA12 results had also significant correlations (Table 34).

Changes in the position of the water masses core is linked to changes in their salinity and tempera- 
$11^{\circ} \mathrm{S}$

(a) SODA

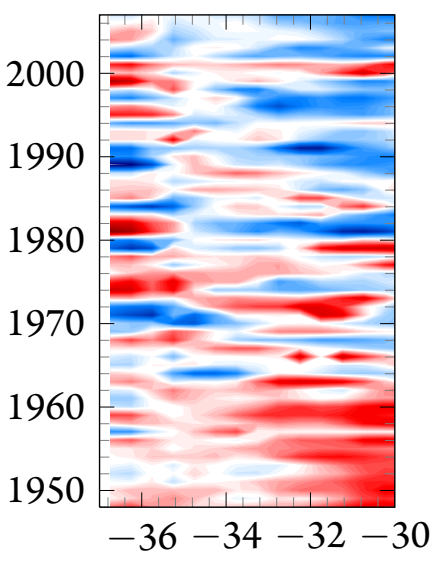

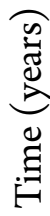

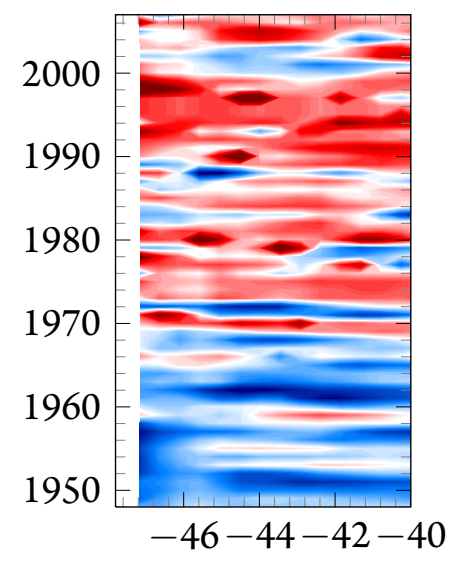

(b) CCSM

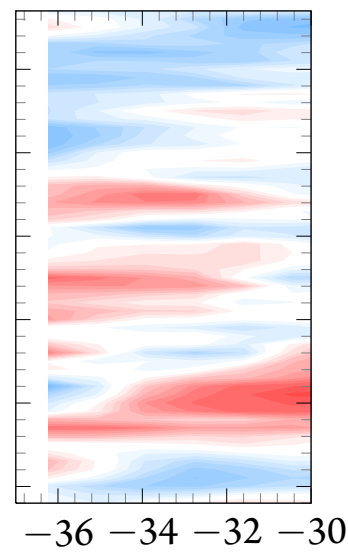

(c) ORCA05

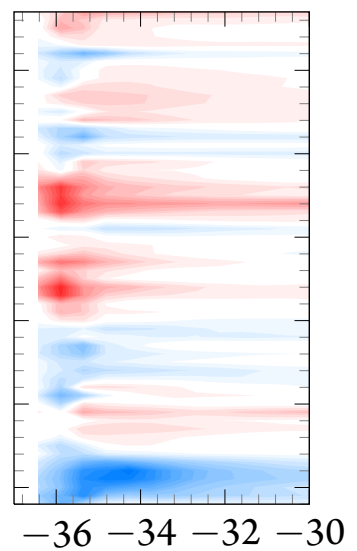

$27^{\circ} \mathrm{S}$ (g) ORCA05
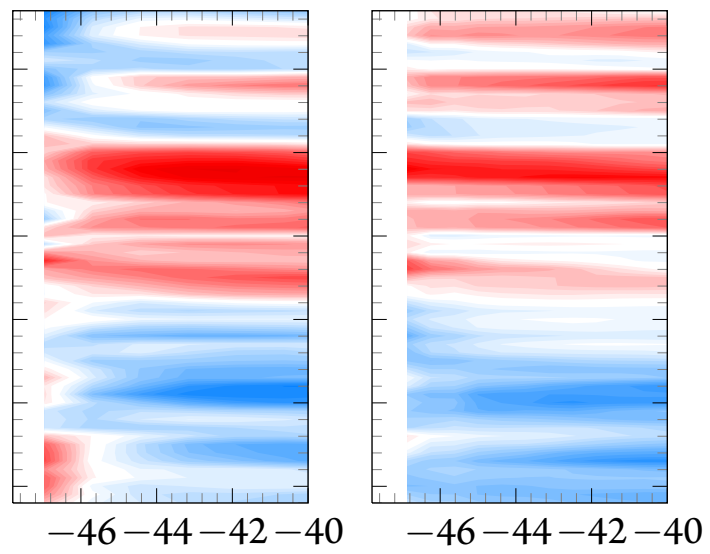

(h) ORCA12

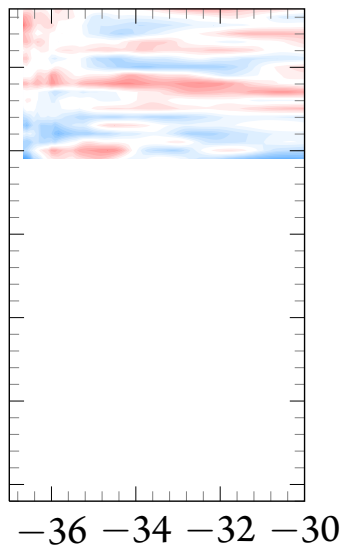

(d) ORCA12

Longitude $\left({ }^{\circ}\right)$

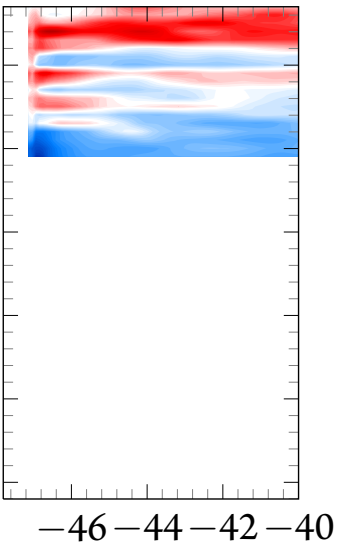

$\mathrm{m}$

$\begin{array}{lllllllllllll}-60 & -50 & -40 & -30 & -20 & -10 & 0 & 10 & 20 & 30 & 40 & 50 & 60\end{array}$

Figure 66: Hovmoller of anomalies of SACW core depth, for SODA (a,e), CCSM (b,f), ORCA05 $(\mathrm{c}, \mathrm{g})$ and ORCA12 (d,h), at $11^{\circ} \mathrm{S}$ (top) and $27^{\circ} \mathrm{S}$ (bottom). Anomalies were constructed by subtracting the mean position of the $80 \%$ contour for each longitude (Figures 62 and 64).

ture. So, changes in these properties projected onto the neutral surfaces of the main isopycnal of SACW were analyzed and are presented below.

Figures 68, 70, 72 and 74 show the Hovmöller Diagrams for the salinity and the temperature projected in the $\gamma_{n_{25.5}} \mathrm{~kg} \cdot \mathrm{m}^{-3}$ and $\gamma_{n_{27}} \mathrm{~kg} \cdot \mathrm{m}^{-3}$, the neutral surfaces related to the isopycnal considered the end-points of the SACW (DONNERS; DRIJFHOUT; HAZELEGER, 2005). The anomalies were constructed by subtracting from each longitude, its mean salinity/temperature values.

As in the Hovmöller Diagrams construct for the anomalies of the SACW position, the SODA re- 


\section{(a) $11^{\circ} \mathrm{S}$}

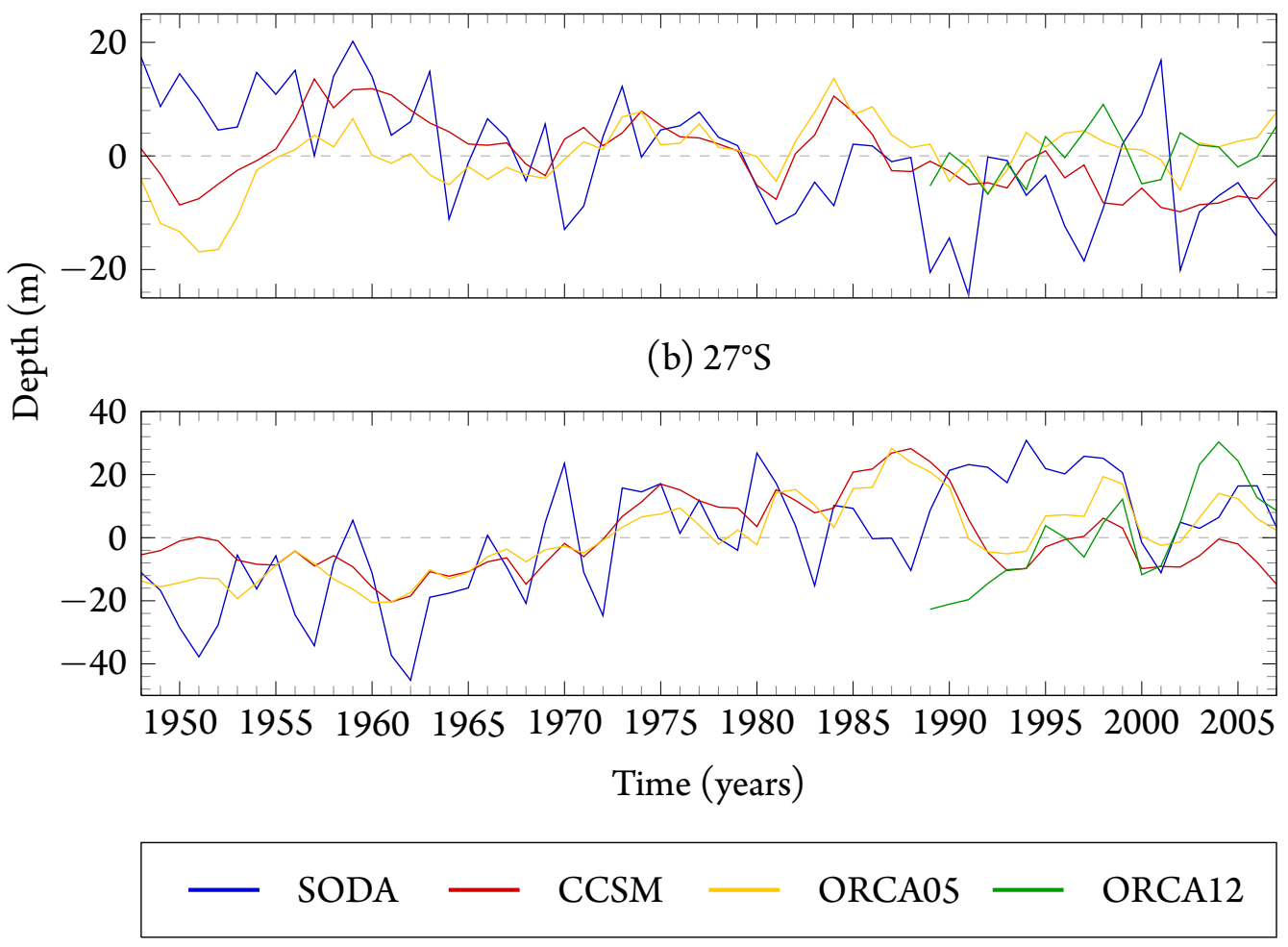

Figure 67: Time series of the anomalies of SACW depth core, at $11^{\circ} \mathrm{S}(\mathrm{a})$ and at $27^{\circ} \mathrm{S}(\mathrm{b})$ for SODA, CCSM, ORCA05 and ORCA12 (d).

Table 34: Correlations of the SACW core vertical position from each model, averaged between $48^{\circ} \mathrm{S}$ and $40^{\circ} \mathrm{S}$ (Figure 67b).

\begin{tabular}{ccccccccc}
\hline & \multicolumn{2}{c}{ SODA } & \multicolumn{2}{c}{ CCSM } & \multicolumn{2}{c}{ ORCA05 } & \multicolumn{2}{c}{ ORCA12 $^{1}$} \\
& $\mathrm{R}^{2}$ & $\mathrm{p}$-value & $\mathrm{R}^{2}$ & $\mathrm{p}$-value & $\mathrm{R}^{2}$ & $\mathrm{p}$-value & $\mathrm{R}^{2}$ & $\mathrm{p}$-value \\
\hline SODA & & & $26.7 \%$ & 0.04 & $15.9 \%$ & 0.23 & $44.8 \%$ & 0.04 \\
CCSM & $26.7 \%$ & 0.04 & & & $88.3 \%$ & $<0.01$ & $29.0 \%$ & 0.22 \\
ORCA05 & $15.9 \%$ & 0.23 & $88.3 \%$ & $<0.01$ & & & $46.2 \%$ & 0.05 \\
ORCA12 $^{1}$ & $44.8 \%$ & 0.04 & $29.0 \%$ & 0.22 & $46.2 \%$ & 0.05 & & \\
\hline
\end{tabular}

${ }^{1}$ Correlations done using the period between 1989 and 2007.

Table 35: Trends of the position of the SACW core ( $80 \%$ contour $)\left(\mathrm{m} \cdot \mathrm{y}^{-1}\right)$ at $11^{\circ} \mathrm{S}$ and $27^{\circ} \mathrm{S}$, calculated using anomalies (Figure 67).

\begin{tabular}{ccccc}
\hline & SODA & CCSM & ORCA05 & ORCA12 \\
& \multicolumn{4}{c}{$\left(\mathrm{m} \cdot \mathrm{y}^{-1}\right)$} \\
\hline $11^{\circ} \mathrm{S}$ & $-0.38 \pm 0.06$ & $-0.17 \pm 0.04$ & $0.16 \pm 0.04$ & $0.29 \pm 0.17$ \\
$27^{\circ} \mathrm{S}$ & $0.71 \pm 0.11$ & $0.17 \pm 0.09$ & $0.48 \pm 0.06$ & $2.30 \pm 0.39$ \\
\hline
\end{tabular}


analysis show greater variability compared to the other models, in both sections and neutral surfaces (Figures 68a,e, 70a,e, 72a,e and 74a,e).

$11^{\circ} \mathrm{S}$

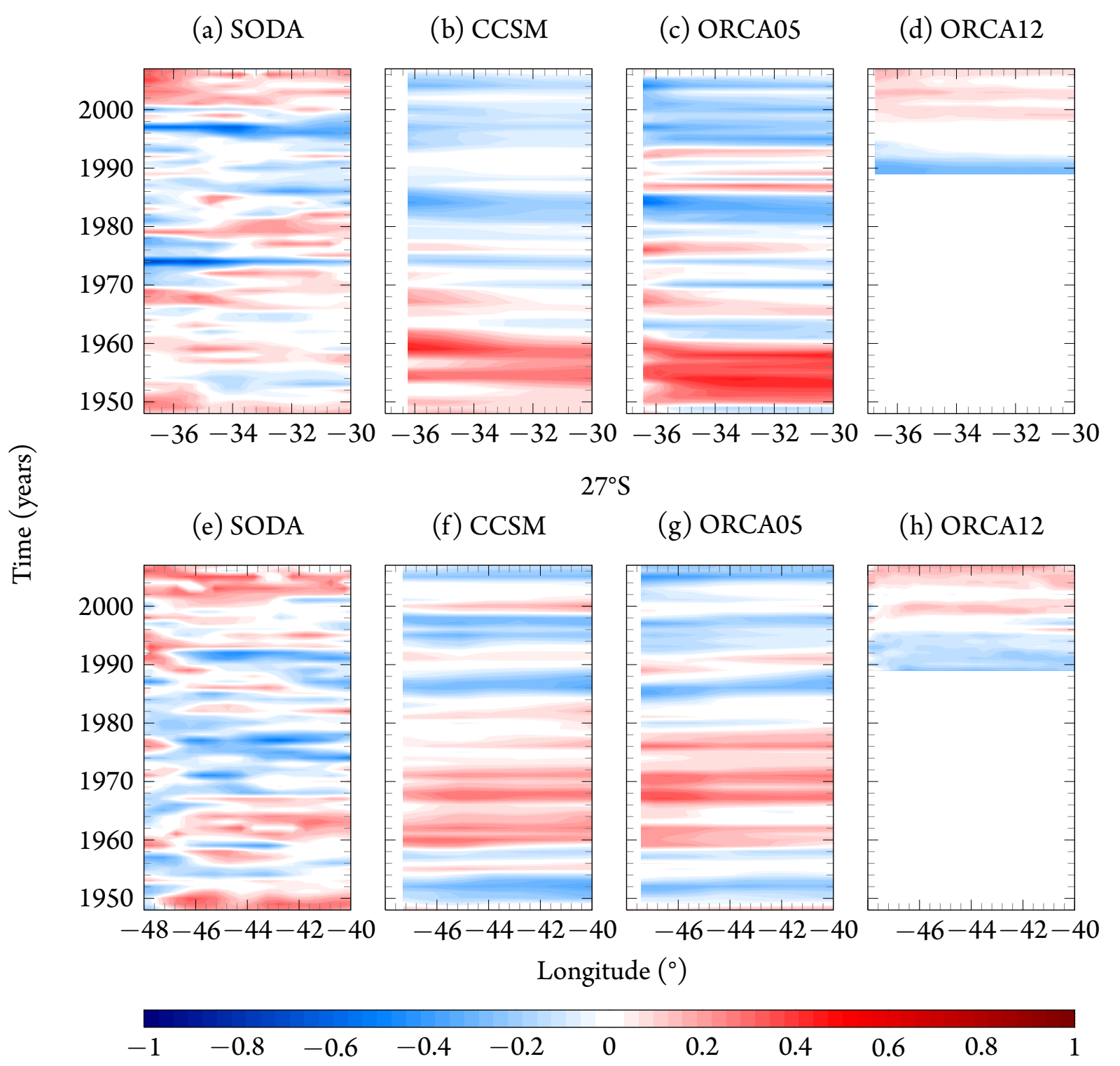

Figure 68: Hovmoller of anomalies of the salinity projected in the $\gamma_{n_{25.5}} \mathrm{~kg} \cdot \mathrm{m}^{-3}$ neutral surface for SODA $(\mathrm{a}, \mathrm{e}), \operatorname{CCSM}(\mathrm{b}, \mathrm{f}), \operatorname{ORCA05}(\mathrm{c}, \mathrm{g})$ and ORCA12 (d,h), at $11^{\circ} \mathrm{S}($ top $)$ and $27^{\circ} \mathrm{S}$ (bottom).

At $11^{\circ} \mathrm{S}$ a sequence of positive anomalies is replaced by a period of decrease in the salinity and in the temperature between 1985-2000, followed by a period of positive anomalies at the end of the time series (Figures 68a, and 70a). Instead of this period of negative anomalies, the trend for the salinity projected in the neutral surface $\gamma_{n_{25.5}}$ is positive (Table 38). The same variability in the end of the $20^{\text {th }}$ century and the beggining of the $21^{\text {st }}$ century are also observed in the ORCA12 results (Figures $68 \mathrm{~d}$, 
and 70d). However, when the trends are not considered, SODA and ORCA12 results show negative (but not significant) correlations (Table 40).

(a) $11^{\circ} \mathrm{S}$

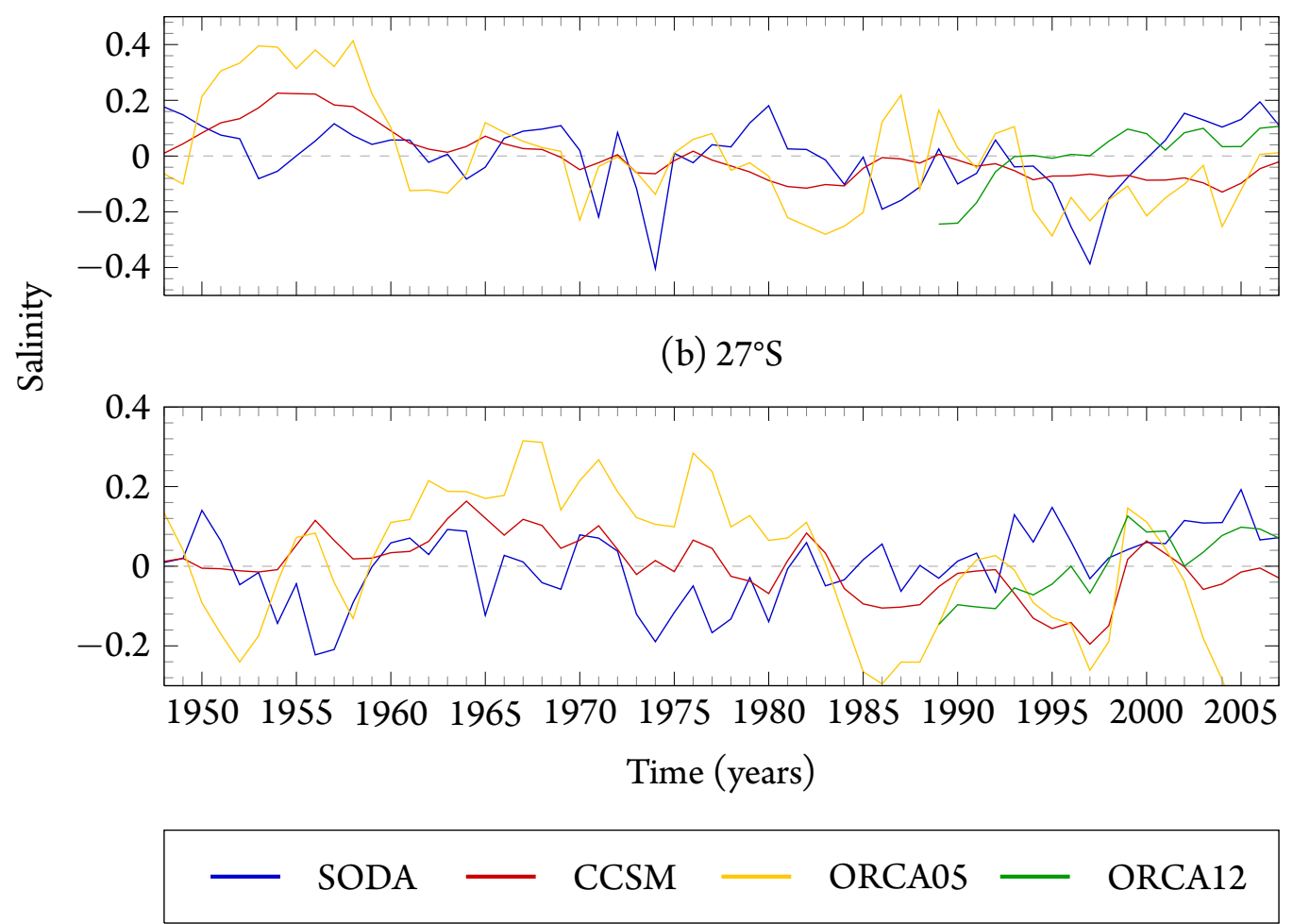

Figure 69: Time series of the salinity anomalies projected in the $\gamma_{n_{25.5}}$ neutral surface, related to SACW, at $11^{\circ} \mathrm{S}$ and $27^{\circ} \mathrm{S}$ for SODA, CCSM, ORCA05 and ORCA12.

Once again, CORE-II forced models show similar results. Despite the bigger anomalies in ORCA05, the correlation between their salinity time series projected onto the neutral surface related to the isopycnal $25.5 \mathrm{~kg} \cdot \mathrm{m}^{-3}\left(\gamma_{n 25.5}\right)$ is superior than $80 \%$ (Table 40$)$. Besides the interannual variability (Figure 69a), there is a clear decrease in the salinity (Table 38), with correspondences to the temperature (Figures 70b,c and 71a).

Table 36: Correlation between annual averages the salinity projected at the neutral surface of $\gamma_{n_{25.5}}$ related to the SACW, averaged between $37.5^{\circ} \mathrm{W}$ and $30^{\circ} \mathrm{W}$, at $11^{\circ} \mathrm{S}$ (Figure $69 \mathrm{a}$ ).

\begin{tabular}{ccccccccc}
\hline & \multicolumn{2}{c}{ SODA } & \multicolumn{2}{c}{ CCSM } & \multicolumn{2}{c}{ ORCA05 } & \multicolumn{2}{c}{ ORCA12 $^{1}$} \\
& $\mathrm{R}^{2}$ & $\mathrm{p}$-value & $\mathrm{R}^{2}$ & $\mathrm{p}$-value & $\mathrm{R}^{2}$ & $\mathrm{p}$-value & $\mathrm{R}^{2}$ & $\mathrm{p}$-value \\
\hline SODA & & & $3.8 \%$ & 0.77 & $11.3 \%$ & 0.39 & $-33.6 \%$ & 0.16 \\
CCSM & $3.8 \%$ & 0.77 & & & $83.3 \%$ & $<0.01$ & $-38.6 \%$ & 0.10 \\
ORCA05 & $11.3 \%$ & 0.39 & $83.3 \%$ & $<0.01$ & & & $-31.7 \%$ & 0.18 \\
ORCA12 $^{1}$ & $-33.6 \%$ & 0.16 & $-38.6 \%$ & 0.10 & $-31.7 \%$ & 0.18 & & \\
\hline
\end{tabular}

${ }^{1}$ Correlations done using the period between 1989 and 2007. 


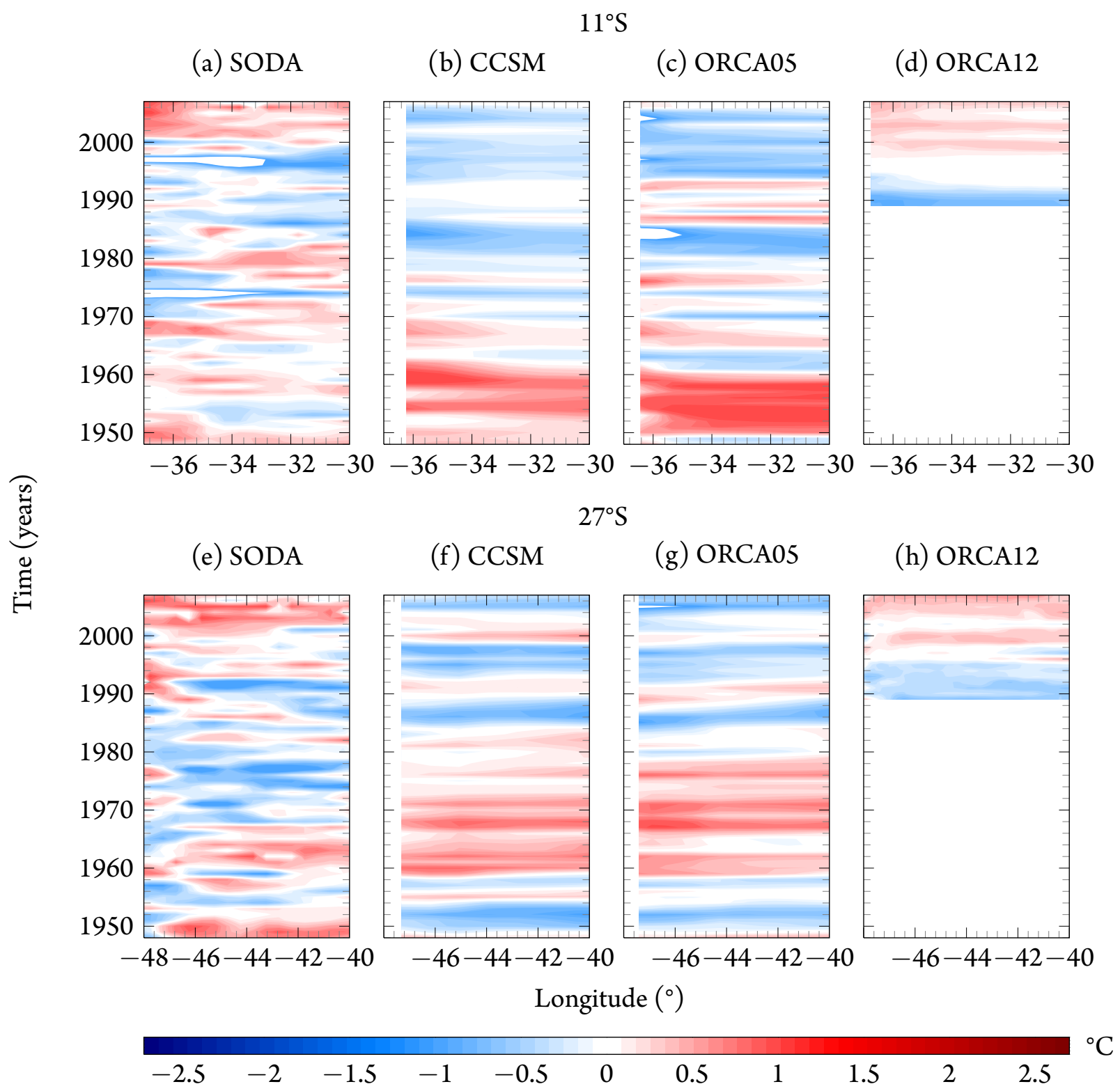

Figure 70: Hovmöller of the anomalies of the temperature projected in the $\gamma_{n_{25.5}}$ neutral surface, related to SACW, at $11^{\circ} \mathrm{S}$ (top) and $27^{\circ} \mathrm{S}$ (bottom) for SODA (a,e), CCSM (b,f), ORCA05 (c,g) and ORCA12 (d,h).

At $27^{\circ} \mathrm{S}$, trends are positive in the results of SODA and ORCA12, while CORE-II forced models show an opposite trend (Table 38).

With the climate changing and the increase of sea surface temperatures, the hydrological cycle is expected to be intensified (IPCC, 2007; McCARTHY et al., 2012). Therefore there is an increase in the salinity in the water exposed to high evaporation regions (CURRY; DICKSON; YASHAYAEV, 2003). In this scenario, negative trends found in CORE-II forced models were not expected, and do not agree with previous studies. Curry, Dickson \& Yashayaev (2003), using observed salinities between late 1950s 


\section{(a) $11^{\circ} \mathrm{S}$}

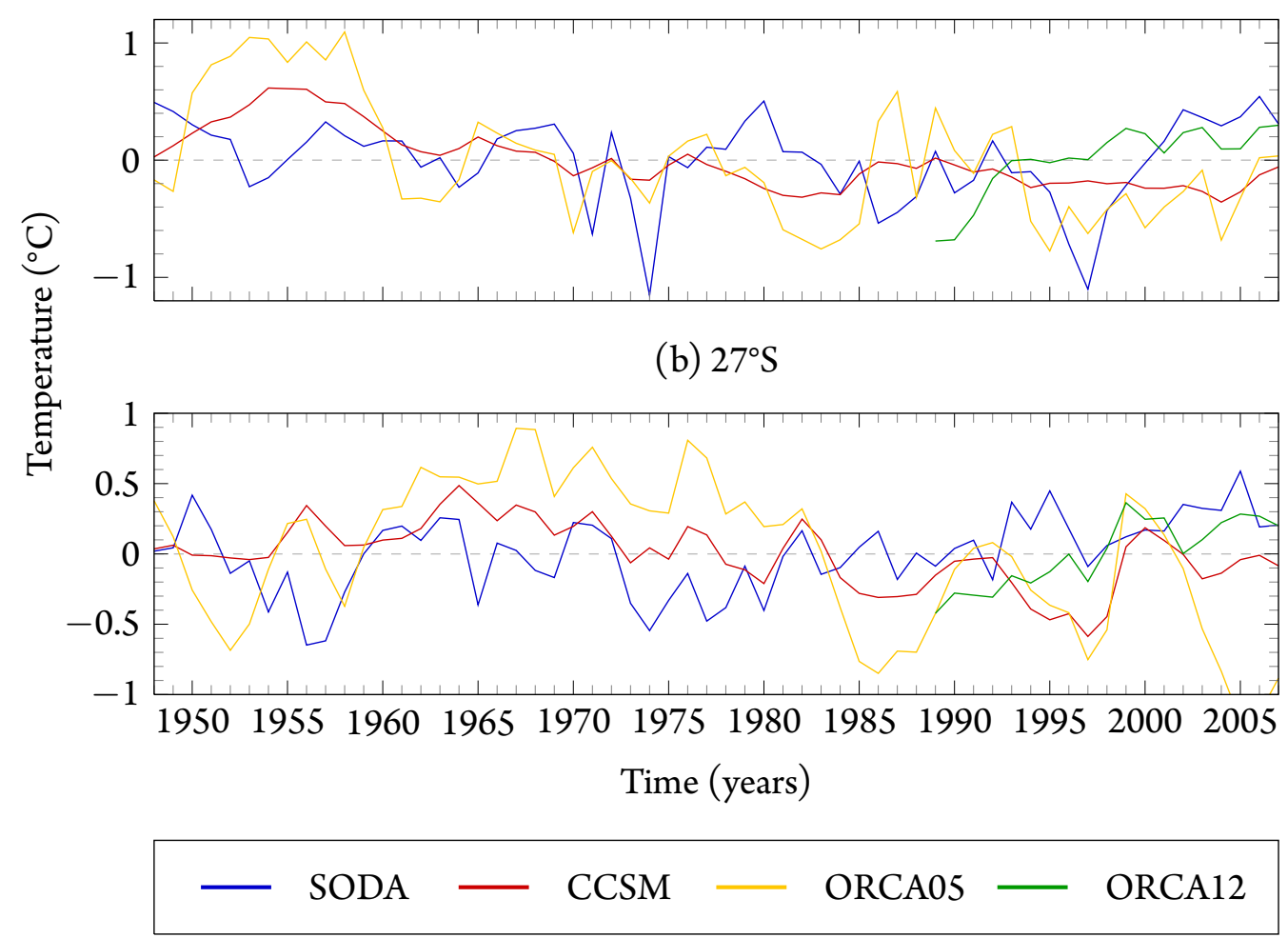

Figure 71: Time series of the temperature anomalies projected in the $\gamma_{n_{25.5}}$ neutral surface, related to SACW, at $11^{\circ} \mathrm{S}$ and $27^{\circ} \mathrm{S}$ for SODA, CCSM, ORCA05 and ORCA12.

Table 37: Correlation between annual averages the salinity projected at the neutral surface of $\gamma_{n_{25.5}}$ related to the SACW, averaged between $48.5^{\circ} \mathrm{W}$ and $40^{\circ} \mathrm{W}$, at $27^{\circ} \mathrm{S}$ (Figure $69 \mathrm{~b}$ ).

\begin{tabular}{ccccccccc}
\hline & \multicolumn{2}{c}{ SODA } & \multicolumn{2}{c}{ CCSM } & \multicolumn{2}{c}{ ORCA05 } & \multicolumn{2}{c}{ ORCA12 $^{1}$} \\
& $\mathrm{R}^{2}$ & $\mathrm{p}$-value & $\mathrm{R}^{2}$ & $\mathrm{p}$-value & $\mathrm{R}^{2}$ & $\mathrm{p}$-value & $\mathrm{R}^{2}$ & $\mathrm{p}$-value \\
\hline SODA & & & $4.6 \%$ & 0.73 & $-11.9 \%$ & 0.36 & $10.3 \%$ & 0.67 \\
CCSM & $4.6 \%$ & 0.73 & & & $62.6 \%$ & $<0.01$ & $38.2 \%$ & 0.11 \\
ORCA05 & $-11.9 \%$ & 0.36 & $62.6 \%$ & $<0.01$ & & & $60.4 \%$ & $<0.01$ \\
ORCA12 $^{1}$ & $10.3 \%$ & 0.67 & $38.2 \%$ & 0.11 & $60.4 \%$ & $<0.01$ & & \\
\hline
\end{tabular}

${ }^{1}$ Correlations done using the period between 1989 and 2007.

and 1990s, show that, between $25^{\circ} \mathrm{S}$ and $35^{\circ} \mathrm{N}$, there was an increase of the salinity (up to 0.5 ) in the neutral density of $\gamma_{n}=25.5 \mathrm{~kg} \cdot \mathrm{m}^{-3}$. A warming in this neutral surface, in this region, was also observed (up to $2^{\circ} \mathrm{C}$ ). These trends agree with our results for SODA and ORCA12 (Table 38).

In the low latitude Atlantic, the factors building positive salinity anomalies must also involve some combination of dynamic and thermo-dynamic processes: altered circulation, precipitation patterns and intensified trade winds (MOULIN et al., 1997), enhanced evaporation rates due to warming of the surface ocean (McCARTHY et al., 2012).

At $27^{\circ} \mathrm{S}$, there is a sudden change in salinity anomalies in the beginning of the 1960's (negative to 
positive anomalies) and in the beginning of the 1980s (positive to negative anomalies). This period of strong positive anomalies (of around 20 years) could coincide with the negative phase of AMO (KNIGHT; FOLLAND; SCAIFE, 2006) and agrees with the observations of Arz, Pätzold \& Wefer (1999) and Chiessi et al. (2009). According to these authors, during negative phases of AMO, there is a reduction of the AMOC, with leads to an increase of South Atlantic temperature. Our time series do show a shift that could be associated with the AMO but are nonetheless too short for further speculations.

Table 38: Trends of the salinity projected in the neutral surface $\left(\gamma_{n_{25.5}}\right)$ related to the SACW at $11^{\circ} \mathrm{S}$ and $27^{\circ} \mathrm{S}$ (Figure 69).

\begin{tabular}{ccccc}
\hline & SODA & CCSM & ORCA05 & ORCA12 \\
& & \multicolumn{2}{c}{$\left(\mathrm{y}^{-1}\right)$} & \\
\hline $11^{\circ} \mathrm{S}$ & $0.002 \pm 0.004$ & $-0.017 \pm 0.002$ & $-0.018 \pm 0.003$ & $0.06 \pm 0.0 .007$ \\
$27^{\circ} \mathrm{S}$ & $0.007 \pm 0.002$ & $-0.005 \pm 0.003$ & $-0.010 \pm 0.003$ & $0.05 \pm 0.0 .005$ \\
\hline
\end{tabular}

From the sensitive test, it was observed that changes in the STW salinity and temperature would impact the position of the water mass core. Thus, once again, excluding the trends, the time series of the SACW core ( $80 \%$ contour, Figure 67$)$ and the salinity projected onto $\gamma_{n_{25.5}}$ were correlated. The results are presented in the Table 39.

The results show that, in general, an increase of the salinity of the ISACW leads to a deepening of the SACW core. However, this relationship was only significant in the SODA reanalysis, where the correlations are higher than $30 \%$ (Table 39).

Table 39: Correlation between annual averages the salinity projected at the neutral surface of $\gamma_{n_{25.5}}$ (Figure 69) and the SACW core position (Figure 67), at $11^{\circ} \mathrm{S}$ and $27^{\circ} \mathrm{S}$.

\begin{tabular}{ccccccccc}
\hline & \multicolumn{2}{c}{ SODA } & \multicolumn{2}{c}{ CCSM } & \multicolumn{2}{c}{ ORCA05 } & \multicolumn{2}{c}{ ORCA12 $^{1}$} \\
& $\mathrm{R}^{2}$ & $\mathrm{p}$-value & $\mathrm{R}^{2}$ & $\mathrm{p}$-value & $\mathrm{R}^{2}$ & $\mathrm{p}$-value & $\mathrm{R}^{2}$ & $\mathrm{p}$-value \\
\hline $11^{\circ} \mathrm{S}$ & $-31.7 \%$ & 0.01 & $-3.7 \%$ & 0.77 & $-14.1 \%$ & 0.28 & $14.1 \%$ & 0.56 \\
$27^{\circ} \mathrm{S}$ & $-32.5 \%$ & 0.01 & $-18.2 \%$ & 0.16 & $-0.1 \%$ & 0.93 & $5.3 \%$ & 0.82 \\
\hline
\end{tabular}

${ }^{1}$ Correlations done using the period between 1989 and 2007.

The same kind of the analysis was done for the SAMW, its lower limit was used to identify the SACW in the OMP analysis (Section 2.2.6). Figures 72 to 75 show the results for the salinity and temperature projected onto the neutral surface related to the isopycnal $27 \mathrm{~kg} \cdot \mathrm{m}^{-3}\left(\gamma_{n_{27.0}}\right)$.

Comparing all the Hovmöller diagrams iit s observed that the results for SODA show higher variability, with more intense anomalies, and an increase in salinity and temperature at $\gamma_{n_{27.0}}$ is evident in both sections (Figures 72a,e and 74a,e). Trends are shown in Tables 40 and 39. 


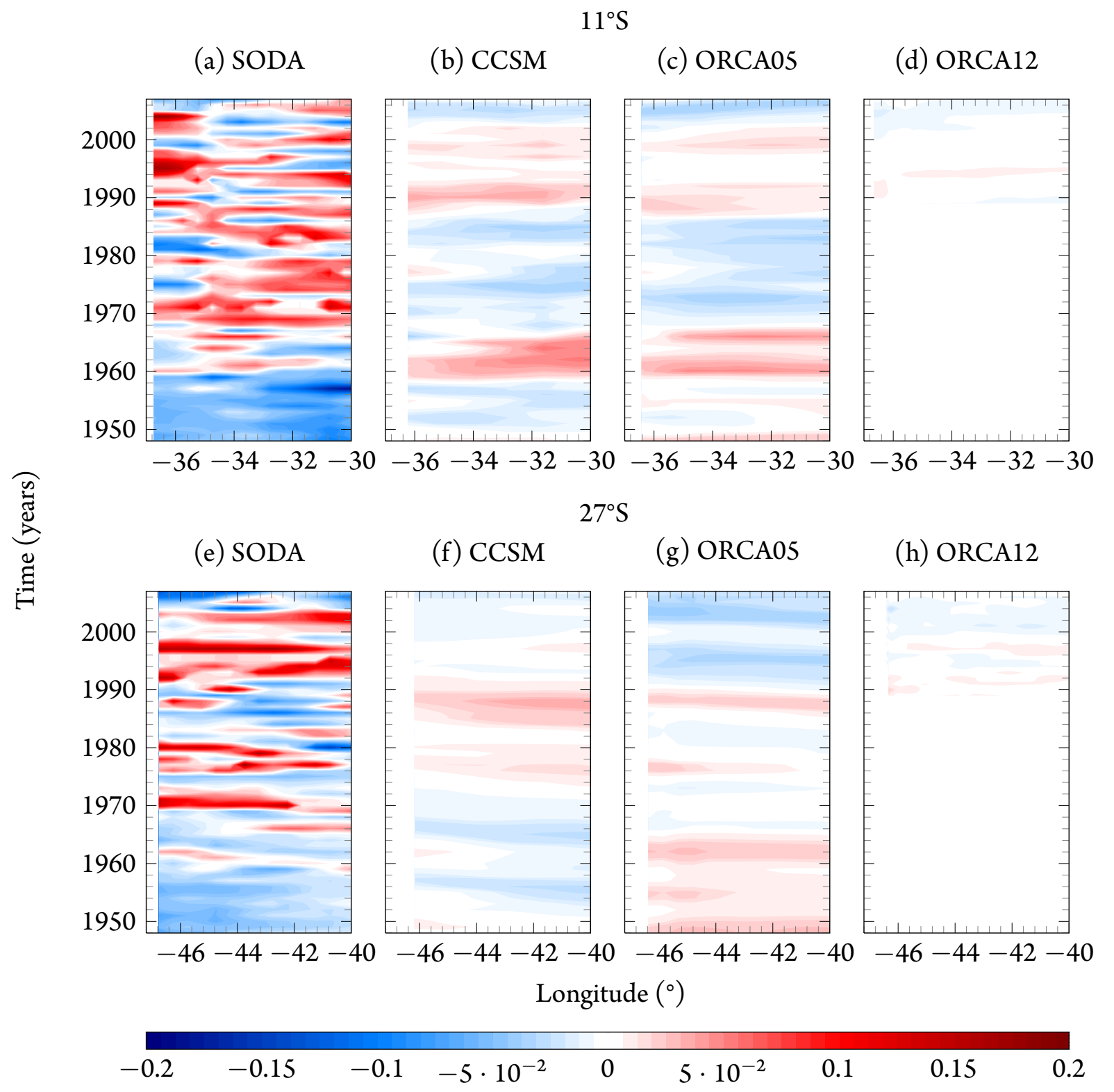

Figure 72: Hovmöller of anomalies of the salinity projected in the $\gamma_{n_{27.0}} \mathrm{~kg} \cdot \mathrm{m}^{-3}$ neutral surface for SODA $(\mathrm{a}, \mathrm{e}), \operatorname{CCSM}(\mathrm{b}, \mathrm{f}), \operatorname{ORCA05}(\mathrm{c}, \mathrm{g})$ and ORCA12 (d,h), at $11^{\circ} \mathrm{S}(\mathrm{top})$ and $27^{\circ} \mathrm{S}$ (bottom).

CORE-II forced models show similar results. The correlation between their time series (Figure 73) is greater than $50 \%$ (Table 39). In both sections, there are well marked periods of positive and negative anomalies.

For these models, salinity and temperature anomalies seem to be out of phase, with negative anomalies happening between 1970 and 1990 at $11^{\circ} \mathrm{S}$ and positive anomalies at $27^{\circ} \mathrm{S}$ for the same period (Figures 73 and 75).

Garabato et al. (2009), using observations in the Drake Passage, between 1969 and 2005, show 
similar oscillations in temperature and salinity time series of the SAMW, compared to our results at $27^{\circ} \mathrm{S}$. The authors observed a salinity and temperature increase on density surfaces during the $1970 \mathrm{~s}$, with a possible peak during the 1980s (since there was no observations during this period). This trend then rreverses in the 1990s. In the end of the time series, (2005), they registered the coldest and freshest SAMW. This period of positive anomalies in the salinity and in the temperature coincides with the warm phase of the Interdecadal Pacific Oscillation (IPO), calculated by Parker et al. (2007). As shown by Folland et al. (2002) and Parker et al. (2007), among others, a decadal-scale increase (decrease) in the IPO index is associated with surface warming (cooling) around the SAMW formation area of the southeast Pacific-Drake Passage and with a northeastward (southeastward) migration of the South Pacific Convergence Zone that is consistent with a positive (negative) anomaly in the winter-mean evaporation in the region.

(a) $11^{\circ} \mathrm{S}$

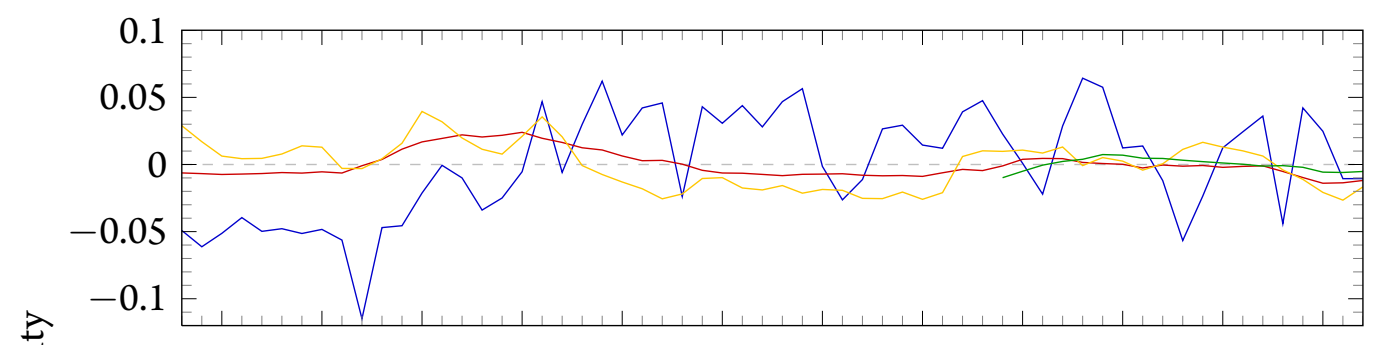

(b) $27^{\circ} \mathrm{S}$

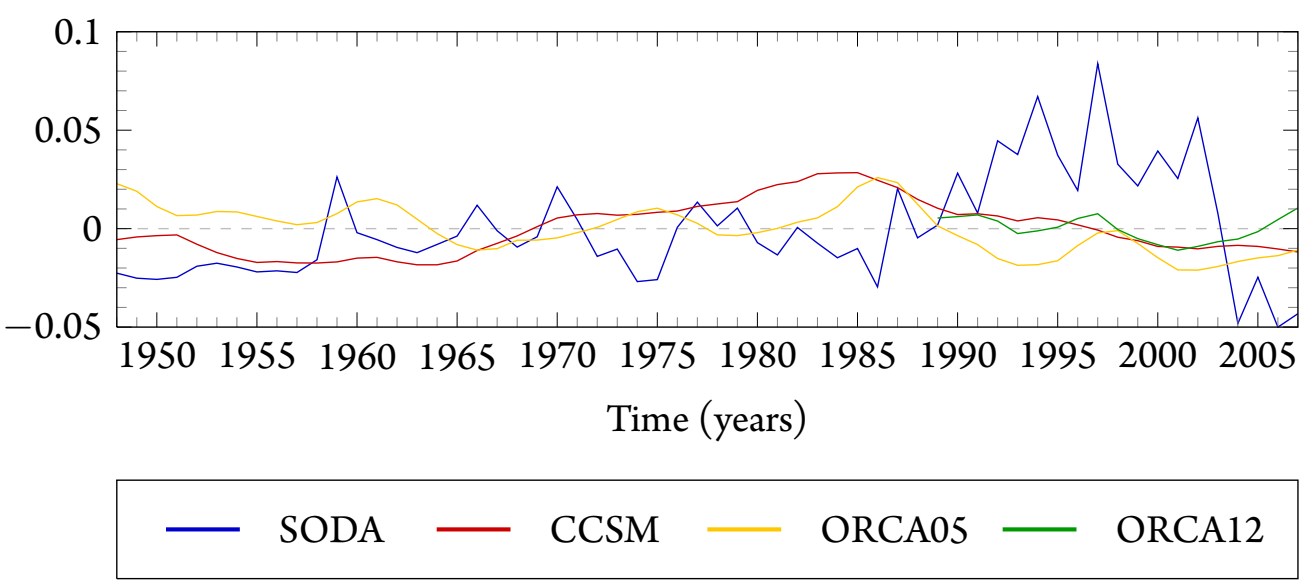

Figure 73: Time series of the salinity anomalies projected in the $\gamma_{n_{27.0}}$ neutral surface, related to SACW, at $11^{\circ} \mathrm{S}$ and $27^{\circ} \mathrm{S}$ for SODA, CCSM, ORCA05 and ORCA12.

Differences in the SACW between $11^{\circ} \mathrm{S}$ and $27^{\circ} \mathrm{S}$ were also observed by Curry, Dickson \& Yashayaev (2003). According to these authors, in the South Atlantic, salinity in this isopycnal has been observed to increase $0.05-0.1$ (psu) at $11^{\circ} \mathrm{S}$, while it has decreased between $0.03-0.05$ at $27^{\circ} \mathrm{S}$. Observations were done between 1955 and 1999. Positive trends in the salinity of the SAMW on the $\gamma_{n_{2} 7.0}$ found in the SODA result at $27^{\circ} \mathrm{S}$ disagrees with Curry, Dickson \& Yashayaev (2003).

Correlations between the salinity projected onto the $\gamma_{n_{27.0}} \mathrm{~kg} \cdot \mathrm{m}^{-3}$ neutral surface (Figure 73) and 


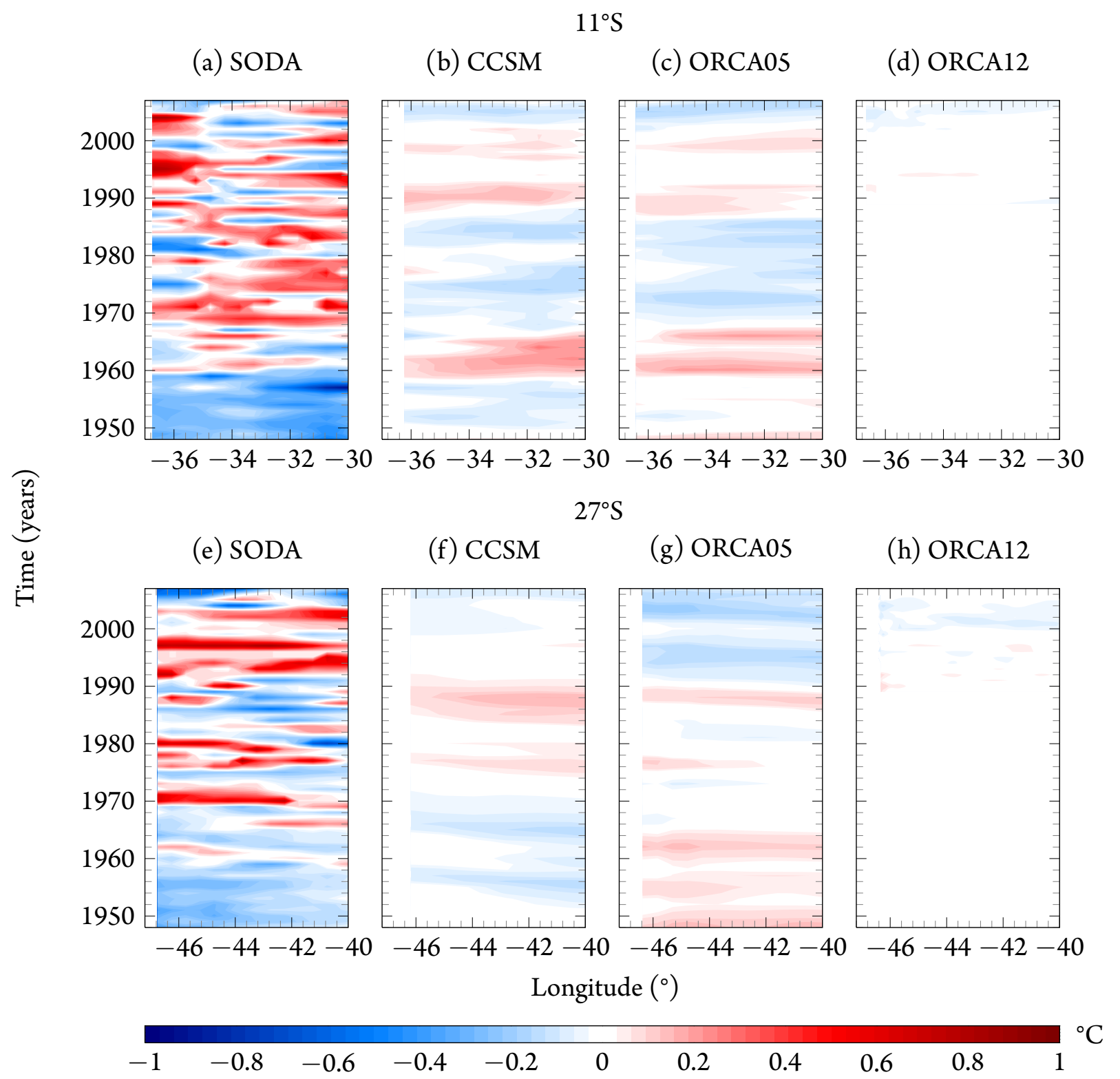

Figure 74: Hovmöller of the anomalies of the temperature projected in the $\gamma_{n_{27.0}}$ neutral surface, related to SACW, at $11^{\circ} \mathrm{S}$ (top) and $27^{\circ} \mathrm{S}$ (bottom) for SODA (a,e), CCSM (b,f), ORCA05 $(\mathrm{c}, \mathrm{g})$ and ORCA12 (d,h).

the position of the SACW core (80\% contour, Figure 67) are shown below. Results show that the variability of the SACW position is linked to variations in the SAMW $\left(\gamma_{n_{27.0}}\right)$, articularly at $27^{\circ} S$.

\subsubsection{Antarctic Intermediate Water}

Figures 76 and 78 show the results of the second OMP analysis, separating the core of the AAIW. The indices in this analysis are listed in Tables 28 and 29. At $11^{\circ} \mathrm{S}$ the similarity between the ORCA12 and SODA results is reflected in their salinity, temperature and potential vorticity of the source water pa- 
(a) $11^{\circ} \mathrm{S}$

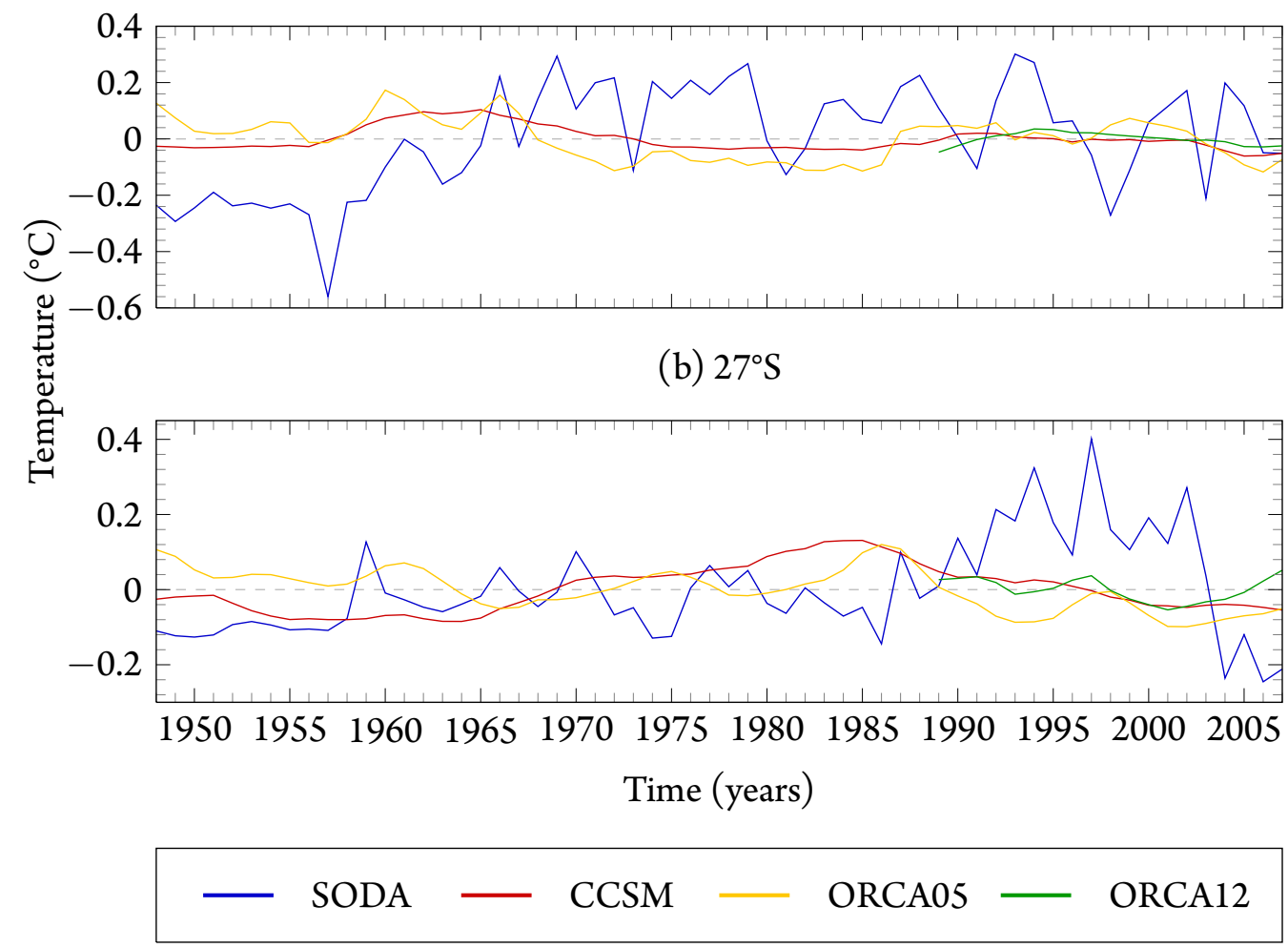

Figure 75: Time series of the temperature anomalies projected in the $\gamma_{n_{27.0}}$ neutral surface, related to SACW, at $11^{\circ} \mathrm{S}$ and $27^{\circ} \mathrm{S}$ for SODA, CCSM, ORCA05 and ORCA12.

Table 40: Correlation between annual averages the salinity projected at the neutral surface of $\gamma_{n_{27.0}}$ related to the SACW, averaged between $37.5^{\circ} \mathrm{W}$ and $30^{\circ} \mathrm{W}$, at $11^{\circ} \mathrm{S}$ (Figure $73 \mathrm{a}$ ).

\begin{tabular}{ccccccccc}
\hline & \multicolumn{2}{c}{ SODA } & \multicolumn{2}{c}{ CCSM } & \multicolumn{2}{c}{ ORCA05 } & \multicolumn{2}{c}{ ORCA12 $^{1}$} \\
& $\mathrm{R}^{2}$ & $\mathrm{p}$-value & $\mathrm{R}^{2}$ & $\mathrm{p}$-value & $\mathrm{R}^{2}$ & $\mathrm{p}$-value & $\mathrm{R}^{2}$ & $\mathrm{p}$-value \\
\hline SODA & & & $-18.1 \%$ & 0.17 & $-17.8 \%$ & 0.17 & $6.5 \%$ & 0.79 \\
CCSM & $18.1 \%$ & 0.17 & & & $54.8 \%$ & $<0.01$ & $55.8 \%$ & 0.10 \\
ORCA05 & $-17.8 \%$ & 0.17 & $54.8 \%$ & $<0.01$ & & & $27.6 \%$ & 0.25 \\
ORCA12 $^{1}$ & $6.5 \%$ & 0.79 & $55.8 \%$ & 0.10 & $27.6 \%$ & 0.25 & & \\
\hline
\end{tabular}

${ }^{1}$ Correlations done using the period between 1989 and 2007.

rameters, even though all the model results are similar. The major differences are found in the indices for the UCDW. The absence of the salinity maximum related to the NADW in the ORCA05 model results does not interfere with the salinity index of the UCDW. However, ORCA05 has the coldest UCDW and half of the potential vorticity compared to the other model results. At $27^{\circ} \mathrm{S}$ the indices are not so uniform, but are in general in agreement with what is found in the literature (i.e. Tables 30 and 31). It is important to note that the same parameters were used for AAIW in both OMP analysis.

Even though there are deficiencies in representing the SACW (using only one SWT, as described in Section 2.2.6), the methodology applied in this work allowed us to properly isolate the core of the 
Table 41: Correlation between annual averages the salinity projected at the neutral surface of $\gamma_{n_{27.0}}$ related to the SACW, averaged between $48.5^{\circ} \mathrm{W}$ and $40^{\circ} \mathrm{W}$, at $27^{\circ} \mathrm{S}$ (Figure $73 \mathrm{~b}$ ).

\begin{tabular}{ccccccccc}
\hline & \multicolumn{2}{c}{ SODA } & \multicolumn{2}{c}{ CCSM } & \multicolumn{2}{c}{ ORCA05 } & \multicolumn{2}{c}{ ORCA12 $^{1}$} \\
& $\mathrm{R}^{2}$ & $\mathrm{p}$-value & $\mathrm{R}^{2}$ & $\mathrm{p}$-value & $\mathrm{R}^{2}$ & $\mathrm{p}$-value & $\mathrm{R}^{2}$ & $\mathrm{p}$-value \\
\hline SODA & & & $-2.2 \%$ & 0.86 & $-24.7 \%$ & 0.06 & $-41.8 \%$ & 0.07 \\
CCSM & $-2.2 \%$ & 0.86 & & & $54.1 \%$ & $<0.01$ & $63.2 \%$ & $<0.01$ \\
ORCA05 & $-24.7 \%$ & 0.06 & $54.1 \%$ & $<0.01$ & & & $58.1 \%$ & 0.01 \\
ORCA12 $^{1}$ & $-41.8 \%$ & 0.07 & $63.2 \%$ & 0.01 & $58.1 \%$ & 0.01 & & \\
\hline
\end{tabular}

${ }^{1}$ Correlations done using the period between 1989 and 2007.

Table 42: Trends of the salinity projected in the neutral surface $\left(\gamma_{n_{27.0}}\right)$ related to the SACW at $11^{\circ} \mathrm{S}$ and $27^{\circ} \mathrm{S}$ (Figure 69).

\begin{tabular}{ccccc}
\hline & SODA & CCSM & ORCA05 & ORCA12 \\
& & \multicolumn{2}{c}{$\left(\mathrm{y}^{-1}\right)$} & \\
\hline $11^{\circ} \mathrm{S}$ & $0.005 \pm 0.002$ & $1 \cdot 10^{-4} \pm 0.002$ & $-0.001 \pm 3 \cdot 10^{-4}$ & $0.003 \pm 4 \cdot 10^{-4}$ \\
$27^{\circ} \mathrm{S}$ & $0.004 \pm 0.002$ & $-1 \cdot 10^{-4} \pm 0.003$ & $-0.003 \pm 4 \cdot 10^{-4}$ & $0.004 \pm 0.001$ \\
\hline
\end{tabular}

Table 43: Correlation between annual averages the salinity projected at the neutral surface of $\gamma_{n_{27.0}}$ (Figure 69) and the SACW core position (Figure 67), at $11^{\circ} \mathrm{S}$ and $27^{\circ} \mathrm{S}$.

\begin{tabular}{ccccccccc}
\hline & \multicolumn{2}{c}{ SODA } & \multicolumn{2}{c}{ CCSM } & \multicolumn{2}{c}{ ORCA05 } & \multicolumn{2}{c}{ ORCA12 $^{1}$} \\
& $\mathrm{R}^{2}$ & $\mathrm{p}$-value & $\mathrm{R}^{2}$ & $\mathrm{p}$-value & $\mathrm{R}^{2}$ & $\mathrm{p}$-value & $\mathrm{R}^{2}$ & $\mathrm{p}$-value \\
\hline $11^{\circ} \mathrm{S}$ & $3.5 \%$ & 0.79 & $27.1 \%$ & 0.03 & $-38.5 \%$ & $<0.01$ & $19.3 \%$ & 0.43 \\
$27^{\circ} \mathrm{S}$ & $27.2 \%$ & 0.03 & $77.0 \%$ & $<0.01$ & $60.1 \%$ & $<0.01$ & $18.4 \%$ & 0.45 \\
\hline
\end{tabular}

${ }^{1}$ Correlations done using the period between 1989 and 2007.

AAIW, in both sections. Obviously, these limitations had consequences. Comparing the first (Figures 62 and 64) and the second (Figures 76 and 78) OMP analysis it is easy to verify the differences in the resulting layers of mixing between SACW and AAIW. In the second OMP due to the index of a lighter SAMW $\left(26.6 \mathrm{~kg} \cdot \mathrm{m}^{-3}\right.$ - versus the end-point $27.0 \mathrm{~kg} \cdot \mathrm{m}^{-3}$ in the first analysis), there is a larger mixed layer in the results for all the models, with a larger presence of the AAIW, mainly, between $500 \mathrm{~m}$ and $700 \mathrm{~m}$ at $11^{\circ} \mathrm{S}$ (Figure 76 ) and between $600 \mathrm{~m}$ and $800 \mathrm{~m}$ (Figure 78 ) at $27^{\circ} \mathrm{S}$.

At $11^{\circ} \mathrm{S}$ (Figure 76) the analysis show a good representation of the expected position of the AAIW core, compared to the climatological sections of salinity, temperature and density (e.g. Figures 55, 56 and 60 ), in which at $11^{\circ} \mathrm{S}$ the AAIW lies between $550 \mathrm{~m}$ and $1200 \mathrm{~m}$. The $27 \mathrm{~kg} \cdot \mathrm{m}^{-3}$ and $27.55 \mathrm{~kg} \cdot \mathrm{m}^{-3}$ isopycnals coincide here with the line of $50 \%$ of water mass contribution, which agrees with the results of Stramma \& England (1999a), Silveira, Calado \& Castro (2004), Hogg \& Thurnherr (2005) that consider these isopycnals as transition limits. As in the results for the SACW (Figure 62), the water 
mass concentrates close to the Brazilian coast (greater percentages and also wider layer), where one can find the core of the IWBC (Figure 60). The $80 \%$ contour follows the density contours, being deeper close to the South America coast (while the opposite happens with SACW layer).

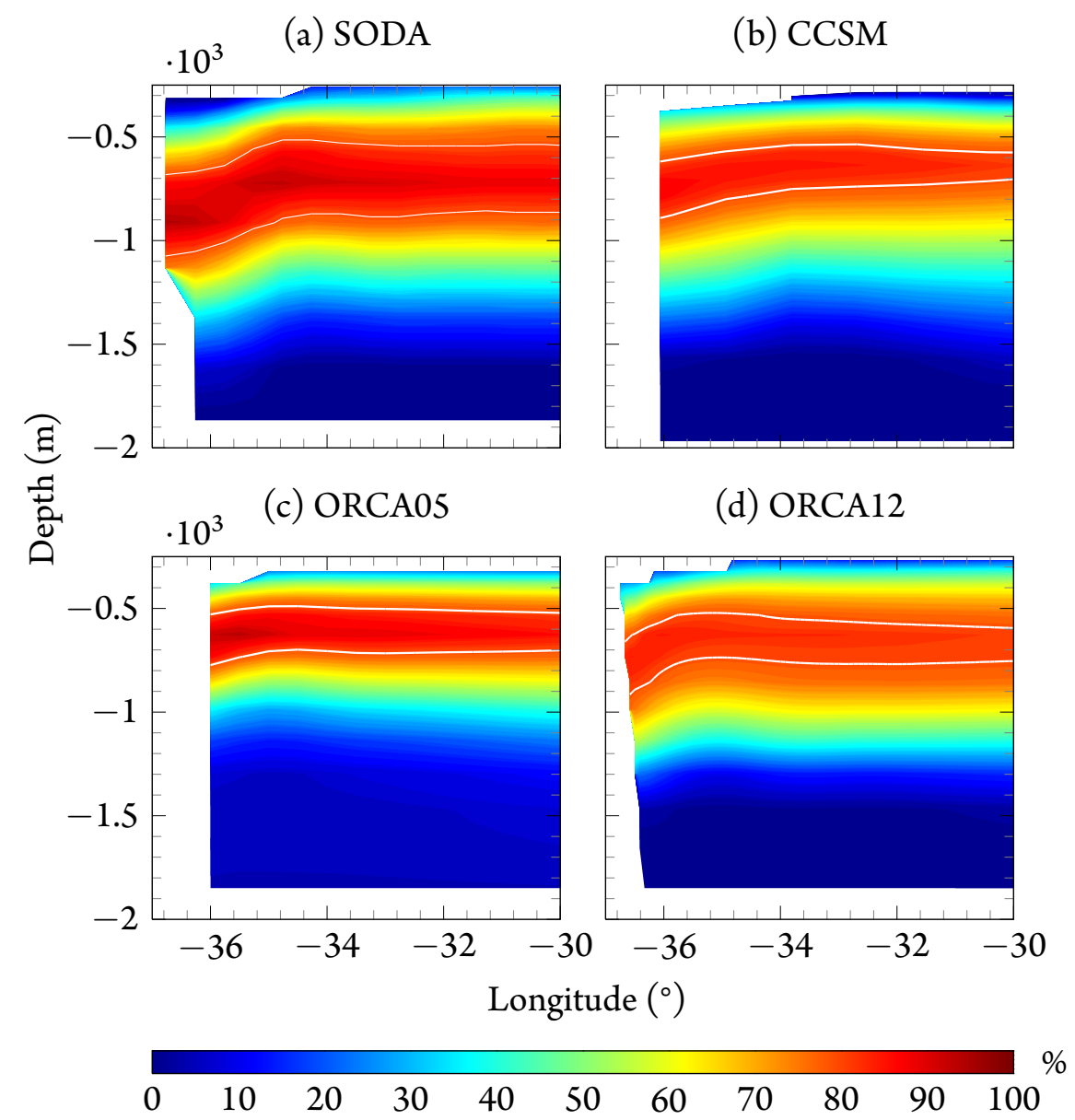

Figure 76: Climatological section of fractional contribution from AAIW at $11^{\circ} \mathrm{S}$ for SODA (a), CCSM (b), ORCA05 (c) and ORCA12 (d). White contour marks the limit of the water mass core (80\%). Figures (a), (b) and (c) are an average of the results from 1948 to 2007, while the average done in figure (d) comprises the results from 1989 to 2007.

The mass conservation residual fit plots (Figure 77) are consistent with the limitations of the methodology applied. The error for the SACW layer increases toward the lower densities, and are much bigger than those found in the previous OMP analysis for this section (Figure 63). ORCA12 results are an exception, since larger errors are related to the UCDW (Figure 77d). Theses results show the good performance of the OMP analysis, since the mass balance constraint is within the acceptable limits (BUDILLON et al., 2003; TOMCZAK, 1981; TOMCZAK; LARGE, 1989; TOMCZAK; POOLE, 1999; FRANTS et al., 2013).

At $27^{\circ} \mathrm{S}$ (Figure 78 ) the AAIW core occupies the layer between $700 \mathrm{~m}$ and $1200 \mathrm{~m}$, being deeper in the CCSM model results (Figure 78b) and shallower in the results of ORCA05 (Figure 78c). Compared to the other models, the AAIW core is narrower in the SODA reanalysis, specially in the east part of 
(a) SODA

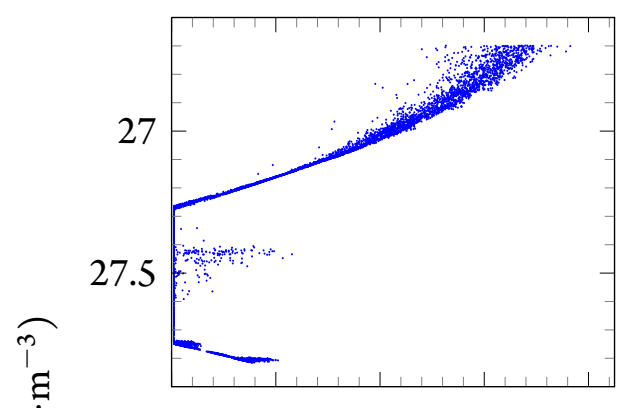

(c) ORCA05

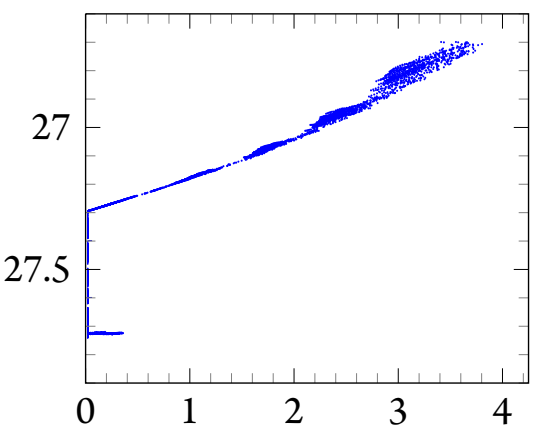

(b) CCSM

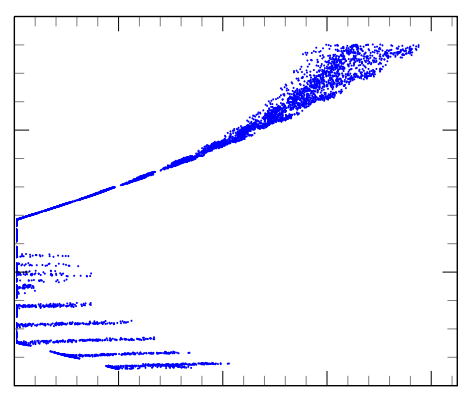

(d) ORCA12

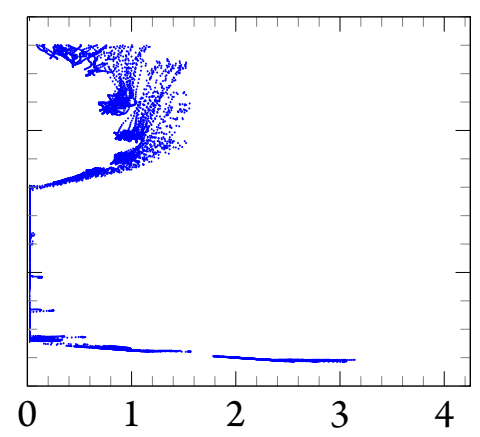

Mass conservation residual fit (\%)

Figure 77: Mass conservation residual fit (\%) for the second OMP analysis at $11^{\circ} \mathrm{S}$ for SODA (a), $\operatorname{CCSM}(\mathrm{b}), \operatorname{ORCA05}(\mathrm{c})$ and ORCA12 (d).

the section. The 50\% contour agrees well with the isopycnals that indicate the upper and lower limits of the AAIW (STRAMMA; ENGLAND, 1999a; SILVEIRA; CALADO; CASTRO, 2004; HOGG; THURNHERR, 2005), which can be seen in Figure 61.

The mass balance constraint is presented in Figure 79. In this section, the error is maximum in the transition layer, between AAIW and SACW, as consequence of the simplified representation of the second water mass. The errors do not exceed the 5\%. The exception is the CCSM model results (maximum mass conservation residual fit: 12\%, increasing toward lighter layers, similar to Figure 77). From Figure 54, it is possible to note that the SAMW is less saline while the AAIW of this model is saltier which can affect the AAIW distribution in the OMP analysis.

The sensitivity of the indices was tested again. As in the previous OMP analysis, changing in 5\% the temperature of the SACW causes small alterations in the position of the AAIW core: it gets shallower (deeper) with higher (lower) temperatures, and the error increases. The results are also influenced slightly by changes in the AAIW temperature. A warmer SWT in this case results in a wider AAIW core, although within this layer, the percentage of AAIW hardly reaches 90\%. Changes in the UCDW temperature have little effects in the AAIW core, but a warmer SWT can reduce (increase) the mixing layer between these water masses.

Meanwhile, salinity plays a fundamental role in the success of the OMP analysis. Lower SAMW 


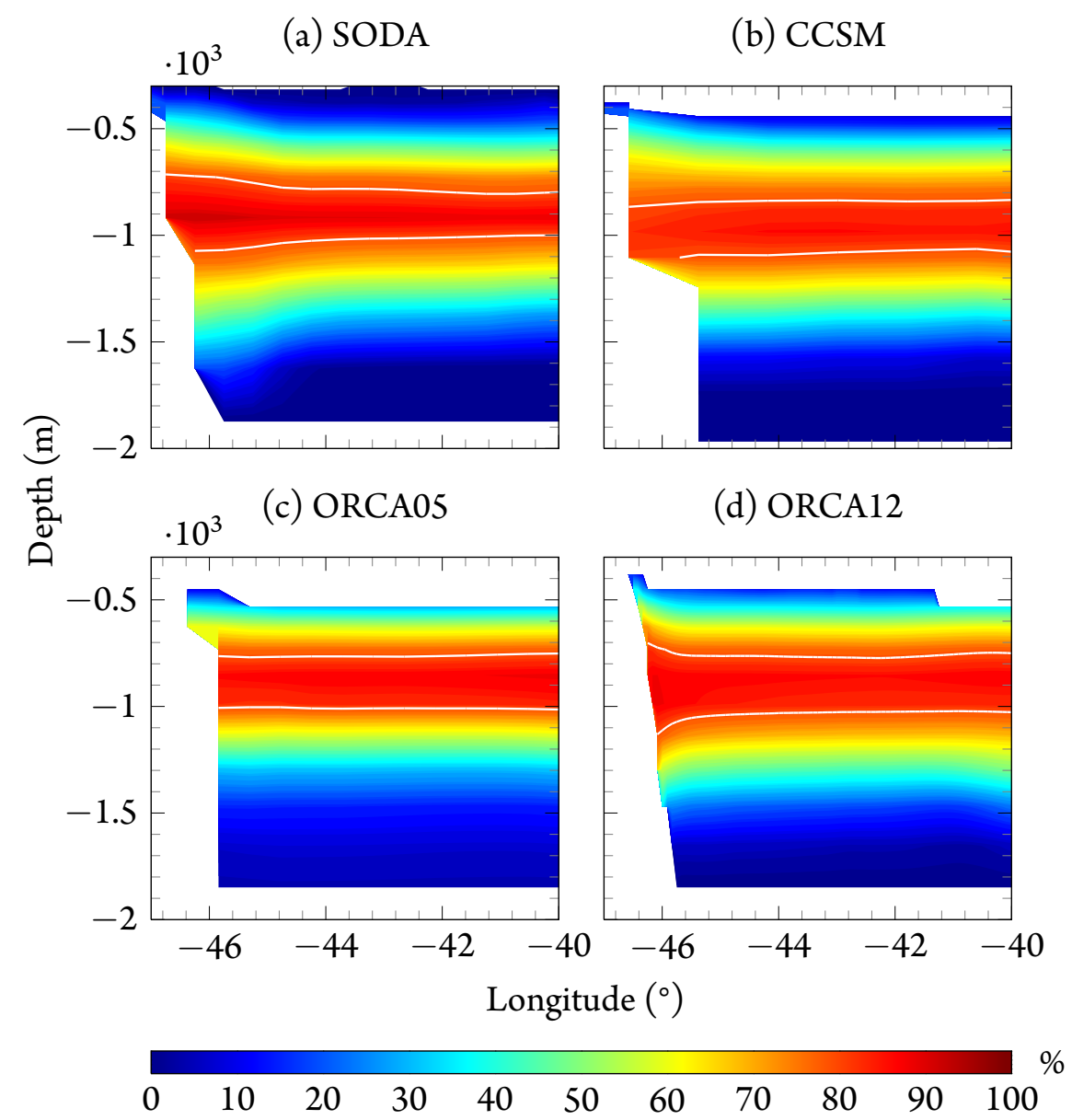

Figure 78: Climatological section of fractional contribution from AAIW at $27^{\circ} \mathrm{S}$ for SODA (a), CCSM (b), ORCA05 (c) and ORCA12 (d). White contour marks the limit of the water mass core (80\%). Figures (a), (b) and (c) are an average of the results from 1948 to 2007, while the average done in figure (d) comprises the results from 1989 to 2007.

salinities (5\%) decreases the mixed layer between the SACW and the AAIW, but the mass distribution of the intermediate water mass in its core does not exceeds 70\%. Saltier SAMW increases the AAIW core (area where the percentage of this water mass is greater than $80 \%$ ), but it spreads to the SACW layers. In both cases, the error does not overpass 5\%. Changes in the AAIW salinity (in both directions) have important implications for the analysis. The OMP analysis can not properly separate the water mass, percentages do not exceed $40 \%$ and the error can be greater than $30 \%$. Changing the salinity parameter in the deep water masses increases de mixing between the AAIW and the UCDW. Decreasing $5 \%$ the salinity of the UCDW deepens the AAIW core until $2000 \mathrm{~m}$ at $11^{\circ} \mathrm{S}$, which does not agree with observational studies (e.g. Talley (1996)).

Figure 80 shows the results of the vertical extension of the AAIW core at $11^{\circ} \mathrm{S}$ and $27^{\circ} \mathrm{S}$, calculated as the vertical distance between the $80 \%$ contours (Section 2.2.6). In all the model results, the vertical extension of the AAIW core ranges between 200 and $460 \mathrm{~m}$. SODA results have wider AAIW cores compared to the other models results, mainly at $11^{\circ} \mathrm{S}$ (as observed in the Figure 76a) and before 1960 
(a) SODA

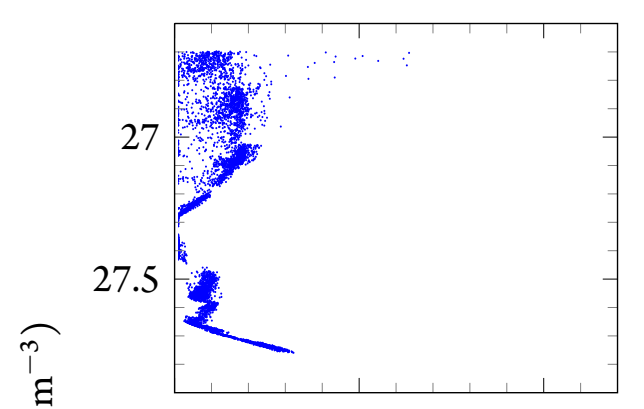

(c) ORCA05

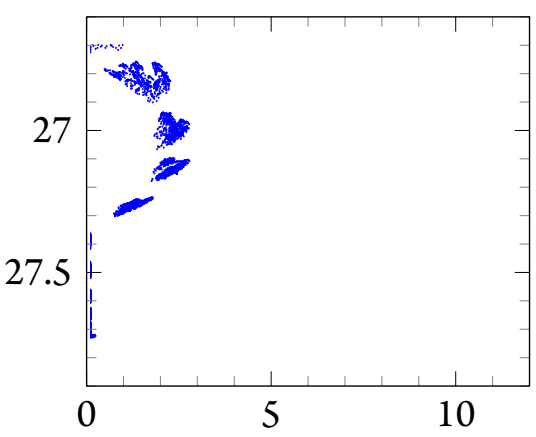

(b) CCSM

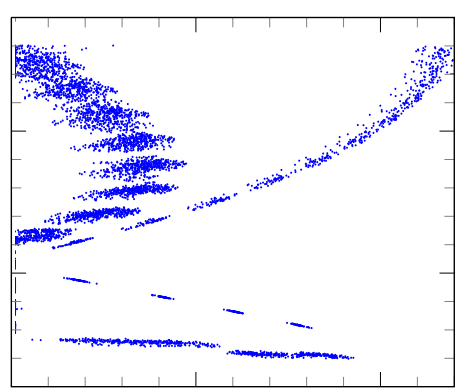

(d) ORCA12

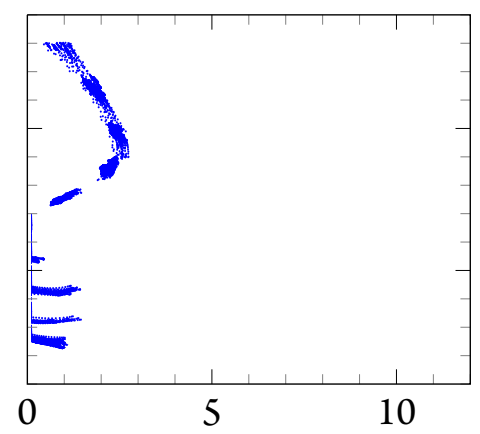

Mass conservation residual fit (\%)

Figure 79: Mass conservation residual fit (\%) for the second OMP analysis at $27^{\circ} \mathrm{S}$ for SODA (a), $\operatorname{CCSM}(\mathrm{b})$, ORCA05 (c) and ORCA12 (d).

that coincides with the period of a small number of observations to be assimilated in the reanalysis. It is possible to observe a eastward decrease of the vertical extension of the AAIW core at $11^{\circ} \mathrm{S}$ (Figure 80ad) and at $27^{\circ} \mathrm{S}$ (Figure $80 \mathrm{e}, \mathrm{h}$ ). CCSM and ORCA05 results at $11^{\circ} \mathrm{S}$ show a wider AAIW core between 1970 and 1990 (Figure 80b,c).

Figure 81 shows the anomalies of the vertical extension of the AAIW core. SODA and ORCA12 results are marked by an interannual variability (Figure 81a,d,e,h) while CORE-II forced models show variabilities with longer periods (Figure $81 \mathrm{~b}, \mathrm{c}, \mathrm{f}, \mathrm{g}$ ). At $11^{\circ} \mathrm{S}$, between the late $1960 \mathrm{~s}$ and the early $1970 \mathrm{~s}$ (Figure $81 \mathrm{~b}, \mathrm{c}$ ) there is a clear shift in the anomalies (negative to positive). Another shift happens between the end of 1980 and the beginning of 1990 (positive to negative anomalies)

Observing the longitude-averaged time series, it is easy to note the similarity between CCSM and ORCA05 results (Figure 82 ). At $11^{\circ} \mathrm{S}$ the correlations are larger than $70 \%$ and at $27^{\circ} \mathrm{S}, 48 \%$ (Tables 44 and 45 ). At $11^{\circ} \mathrm{S}$, ORCA12 results show negative correlations with the SODA reanalysis and also positive correlations with CCSM model results (Table 44).

Observing the trends (Table 46), only ORCA05 results show an increase in the AAIW layer at $11^{\circ} \mathrm{S}$. SODA results show the biggest trend, and the AAIW decreases more than $120 \mathrm{~m}$ during the 60 years analyzed. Larger trends can be found between 1960 and 1965, when positive anomalies are replaced by negative ones (Figure $81 \mathrm{a}$ ). At $27^{\circ} \mathrm{S}$, model results show a different scenario, with an increase in the 


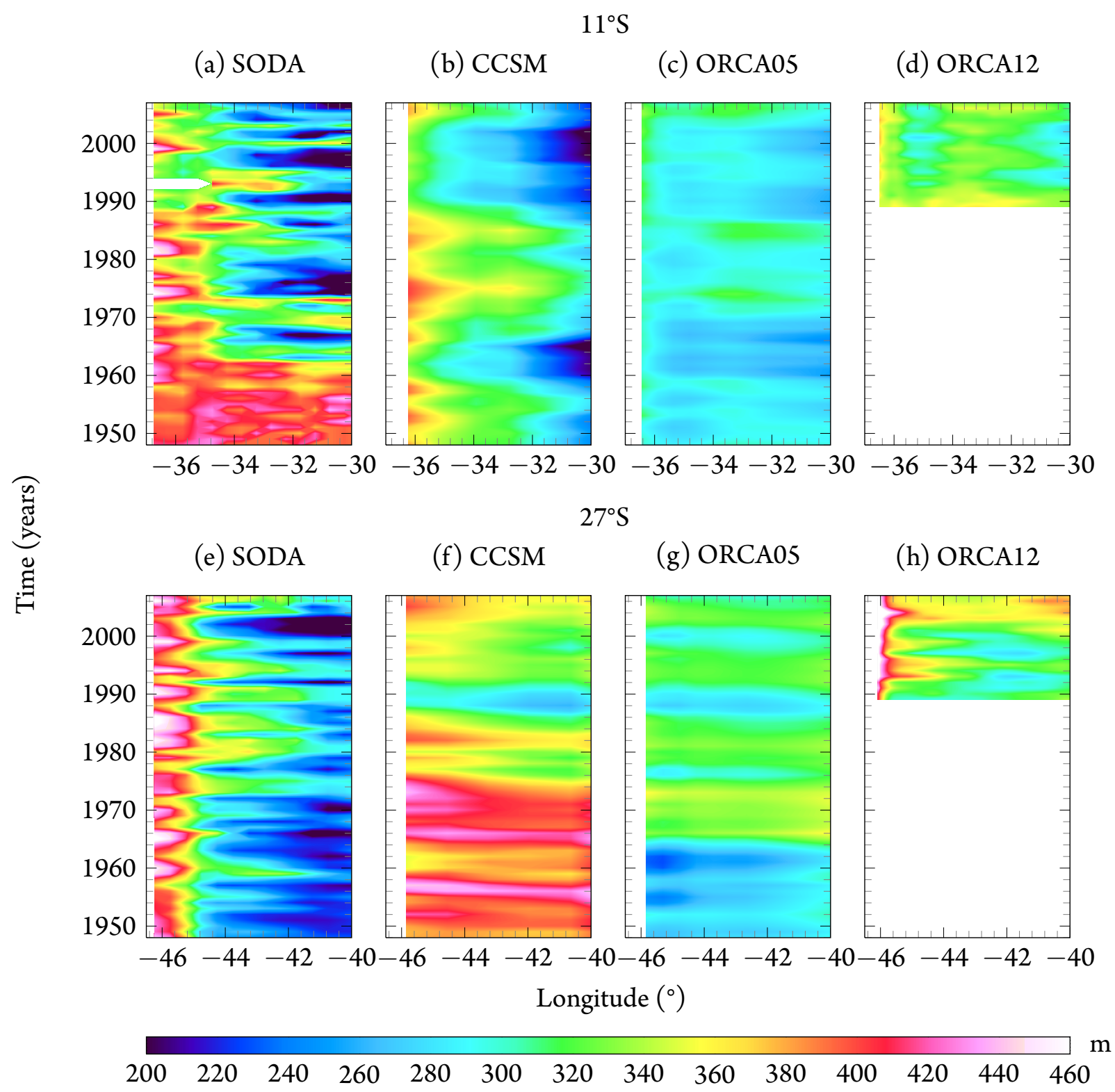

Figure 80: Hovmoller of the vertical extension of AAIW core for SODA (a,e), CCSM (b,f), ORCA05 (c,g) and ORCA12 (d,h), at $11^{\circ} \mathrm{S}$ (top) and $27^{\circ} \mathrm{S}$ (bottom). The vertical extension was constructed the depth position of the top and the bottom $80 \%$ contour.

\section{AAIW layer.}

The sensitive tests showed that the results of the OMP analysis are related mainly to salinity changes. Figure 83 shows the results for the salinity anomalies calculated in the $\gamma_{n_{A A I W}}$ neutral surface (Table 32). Results show that SODA presents a more frequent variability with larger amplitudes in both sections (Figure 83a,d). As in other results (e.g. Figure 68), CORE-II forced models show variabilities with longer periods ( $\sim 20$ years), with salinity minimum between 1970 and 1990 at $11^{\circ} \mathrm{S}$ (Figure 83b,c). Their similarity is expressed in the large correlation of their longitude-averaged time series, shown in 


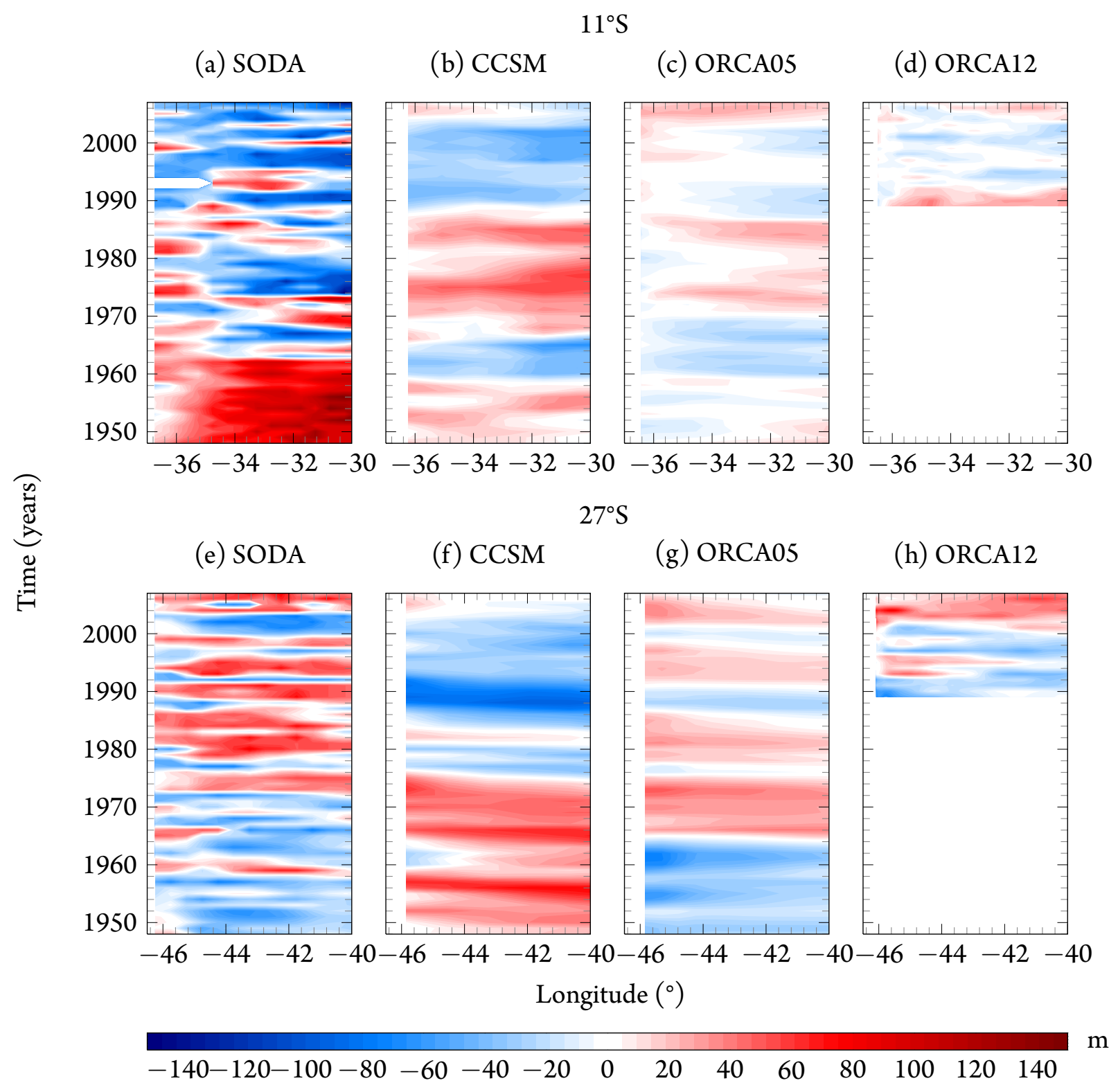

Figure 81: Hovmoller of the anomalies of the vertical extension of AAIW core for SODA (a,e), $\operatorname{CCSM}(\mathrm{b}, \mathrm{f}), \operatorname{ORCA05}(\mathrm{c}, \mathrm{g})$ and $\mathrm{ORCA} 12(\mathrm{~d}, \mathrm{~h})$, at $11^{\circ} \mathrm{S}$ (top) and $27^{\circ} \mathrm{S}$ (bottom). The anomalies were constructed by subtracting the mean vertical extension from each year of result.

Figure 84 (almost 78\%, Table 47), excluding the trend, suggesting a connection with the forcing. At $27^{\circ} \mathrm{S}$ their correlations were smaller $(\sim 40 \%$, Table 48$)$. It is possible to note negative correlations between CCSM and SODA results (Tables 47 and 48).

As expected, changes in the temperature projected in the $\gamma_{n_{A A I W}}$ neutral surfaces follow the modifications in the salinity. Observing the results shown in Figures 83 to 85, summarized in Table 49, model results show an increase in the AAIW salinity and temperature at $11^{\circ} \mathrm{S}$ (except for ORCA05 results) while the opposite is observed at $27^{\circ} \mathrm{S}$ (except for CCSM). Schmidtko \& Johnson (2012) also 
(a) $11^{\circ} \mathrm{S}$

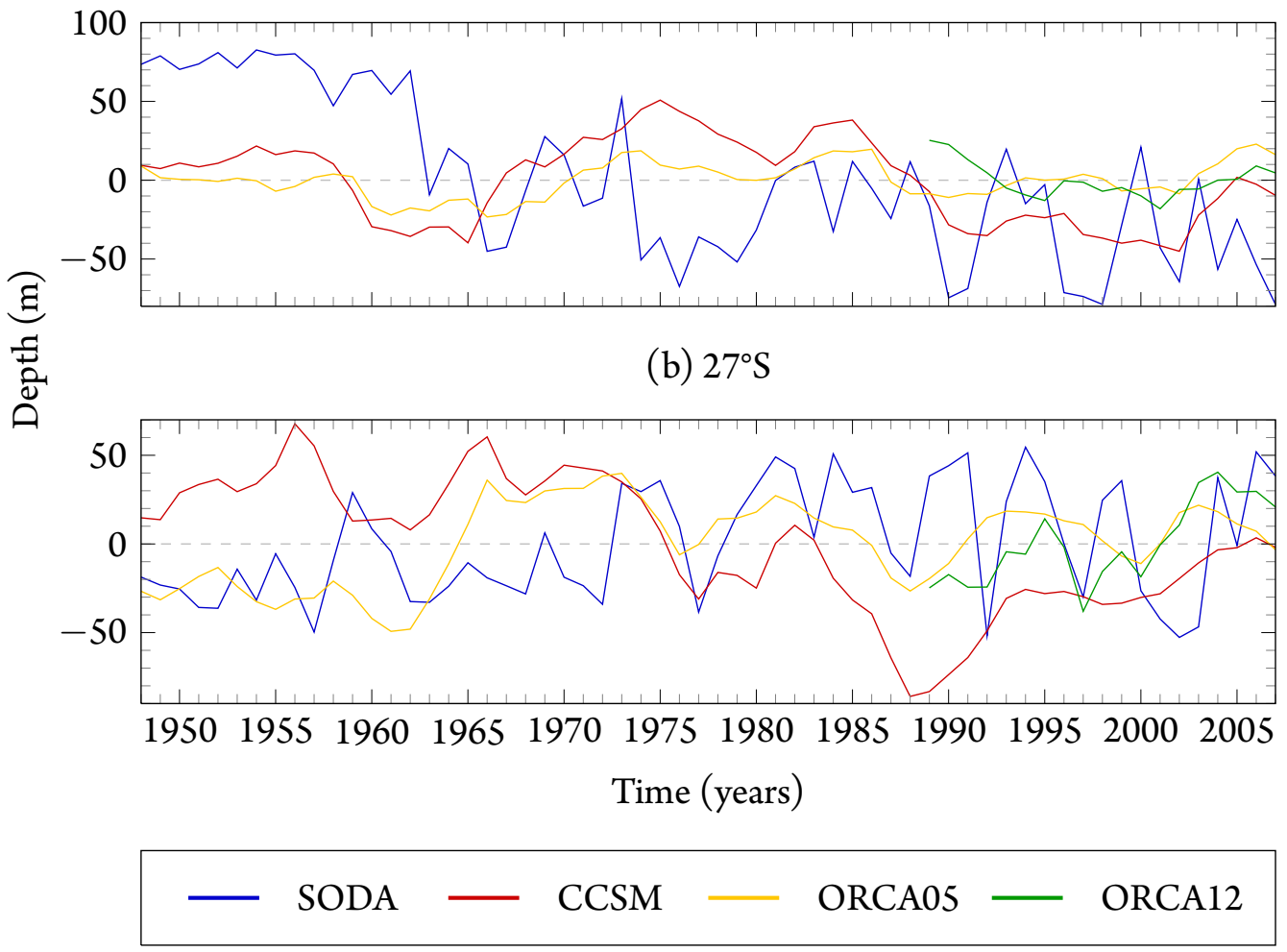

Figure 82: Time series of the anomalies of the vertical extension of the AAIW core, at $11^{\circ} \mathrm{S}(\mathrm{a})$ and at $27^{\circ} \mathrm{S}(\mathrm{b})$ for SODA, CCSM, ORCA05 and ORCA12 (d).

Table 44: Correlations between annual averages of the vertical extension of the SACW core from each model, averaged between $37^{\circ} \mathrm{S}$ and $30^{\circ} \mathrm{S}$ (Figure 82a).

\begin{tabular}{ccccccccc}
\hline & \multicolumn{2}{c}{ SODA } & \multicolumn{2}{c}{ CCSM } & \multicolumn{2}{c}{ ORCA05 } & \multicolumn{2}{c}{ ORCA12 $^{1}$} \\
& $\mathrm{R}^{2}$ & $\mathrm{p}$-value & $\mathrm{R}^{2}$ & $\mathrm{p}$-value & $\mathrm{R}^{2}$ & $\mathrm{p}$-value & $\mathrm{R}^{2}$ & $\mathrm{p}$-value \\
\hline SODA & & & $-18.9 \%$ & 0.15 & $9.1 \%$ & 0.49 & $-43.4 \%$ & 0.06 \\
CCSM & $-18.9 \%$ & 0.15 & & & $74.2 \%$ & $<0.01$ & $58.9 \%$ & 0.01 \\
ORCA05 & $9.1 \%$ & 0.49 & $74.2 \%$ & $<0.01$ & & & $35.8 \%$ & 0.13 \\
ORCA12 $^{1}$ & $-39.9 \%$ & 0.09 & $58.9 \%$ & 0.01 & $35.8 \%$ & 0.13 & & \\
\hline
\end{tabular}

${ }^{1}$ Correlations done using the period between 1989 and 2007.

observed this same dipole when analyzed the salinity minimum trend from ARGO data. This inversion of salinity and temperature trends in neutral surfaces linked to the AAIW was observed by Curry, Dickson \& Yashayaev (2003), using observational data collected close to the Brazilian coast, between 1955 and 1999.

The AAIW $\left(\gamma_{n_{\text {AAIW }}}\right)$ and the SAMW $\left(\gamma_{n_{27.0}}\right)$ show similar oscillation in results of the CORE-II forced models at $11^{\circ} \mathrm{S}$ (Figures 72b,c, $74,83 \mathrm{~b}, \mathrm{c}$ and 85b,c). As discussed before, Folland et al. (2002) and Parker et al. (2007), this positive salinity/temperature anomalies coincide with the period of the positive phase of IPO, between 1970 and 1990, since it leads a surface warming in the SAMW area. Garabato 
Table 45: Correlation between annual averages of the vertical extension of the AAIW core at $11^{\circ} \mathrm{S}$, averaged between $48^{\circ} \mathrm{S}$ and $40^{\circ} \mathrm{S}$ (Figure $82 \mathrm{~b}$ ).

\begin{tabular}{ccccccccc}
\hline & \multicolumn{2}{c}{ SODA } & \multicolumn{2}{c}{ CCSM } & \multicolumn{2}{c}{ ORCA05 } & \multicolumn{2}{c}{ ORCA12 $^{1}$} \\
& $\mathrm{R}^{2}$ & $\mathrm{p}$-value & $\mathrm{R}^{2}$ & $\mathrm{p}$-value & $\mathrm{R}^{2}$ & $\mathrm{p}$-value & $\mathrm{R}^{2}$ & $\mathrm{p}$-value \\
\hline SODA & & & $13.8 \%$ & 0.30 & $7.1 \%$ & 0.59 & $34.0 \%$ & 0.15 \\
CCSM & $13.8 \%$ & 0.30 & & & $48.0 \%$ & $<0.01$ & $34.3 \%$ & 0.15 \\
ORCA05 & $7.1 \%$ & 0.59 & $48.0 \%$ & $<0.01$ & & & $43.1 \%$ & 0.07 \\
ORCA12 $^{1}$ & $34.0 \%$ & 0.15 & $34.3 \%$ & 0.15 & $43.1 \%$ & 0.07 & & \\
\hline
\end{tabular}

${ }^{1}$ Correlations done using the period between 1989 and 2007.

Table 46: Trends of the vertical extension of the AAIW core at $11^{\circ} \mathrm{S}$ and $27^{\circ} \mathrm{S}$, (Figure 82).

\begin{tabular}{ccccc}
\hline & SODA & CCSM & ORCA05 & ORCA12 \\
& & \multicolumn{2}{c}{$\left(\mathrm{m} \cdot \mathrm{y}^{-1}\right)$} & \\
\hline $11^{\circ} \mathrm{S}$ & $-2.2 \pm 0.25$ & $-0.53 \pm 0.19$ & $0.18 \pm 0.08$ & $-0.77 \pm 0.45$ \\
$27^{\circ} \mathrm{S}$ & $0.7 \pm 0.22$ & $-1.4 \pm 0.2$ & $0.61 \pm 0.16$ & $3.1 \pm 0.65$ \\
\hline
\end{tabular}

Table 47: Correlation between annual averages the salinity projected at the neutral surface of $\gamma_{n_{A A I W}}$, averaged between $37.5^{\circ} \mathrm{W}$ and $30^{\circ} \mathrm{W}$, at $11^{\circ} \mathrm{S}$ (Figure $84 a$ ).

\begin{tabular}{ccccccccc}
\hline & \multicolumn{2}{c}{ SODA } & \multicolumn{2}{c}{ CCSM } & \multicolumn{2}{c}{ ORCA05 } & \multicolumn{2}{c}{ ORCA12 $^{1}$} \\
& $\mathrm{R}^{2}$ & $\mathrm{p}$-value & $\mathrm{R}^{2}$ & $\mathrm{p}$-value & $\mathrm{R}^{2}$ & $\mathrm{p}$-value & $\mathrm{R}^{2}$ & $\mathrm{p}$-value \\
\hline SODA & & & $-30.2 \%$ & 0.02 & $-12.8 \%$ & 0.33 & $-25.1 \%$ & 0.30 \\
CCSM & $-30.2 \%$ & 0.02 & & & $77.8 \%$ & $<0.01$ & $25.0 \%$ & 0.30 \\
ORCA05 & $-12.8 \%$ & 0.33 & $77.8 \%$ & $<0.01$ & & & $-20.3 \%$ & 0.41 \\
ORCA12 $^{1}$ & $-25.1 \%$ & 0.30 & $25.0 \%$ & 0.30 & $-20.3 \%$ & 0.41 & & \\
\hline
\end{tabular}

${ }^{1}$ Correlations done using the period between 1989 and 2007.

Table 48: Correlation between annual averages the salinity projected at the neutral surface of $\gamma_{n_{A A I}}$, averaged between $48.5^{\circ} \mathrm{W}$ and $40^{\circ} \mathrm{W}$, at $27^{\circ} \mathrm{S}$ (Figure $84 \mathrm{~b}$ ).

\begin{tabular}{ccccccccc}
\hline & \multicolumn{2}{c}{ SODA } & \multicolumn{2}{c}{ CCSM } & \multicolumn{2}{c}{ ORCA05 } & \multicolumn{2}{c}{ ORCA12 $^{1}$} \\
& $\mathrm{R}^{2}$ & $\mathrm{p}$-value & $\mathrm{R}^{2}$ & $\mathrm{p}$-value & $\mathrm{R}^{2}$ & $\mathrm{p}$-value & $\mathrm{R}^{2}$ & $\mathrm{p}$-value \\
\hline SODA & & & $-43.8 \%$ & $<0.01$ & $-10.7 \%$ & 0.42 & $20.5 \%$ & 0.40 \\
CCSM & $-43.8 \%$ & $<0.01$ & & & $40.6 \%$ & $<0.01$ & $19.7 \%$ & 0.42 \\
ORCA05 & $-10.7 \%$ & 0.42 & $40.6 \%$ & $<0.01$ & & & $51.9 \%$ & 0.02 \\
ORCA12 $^{1}$ & $20.5 \%$ & 0.40 & $19.7 \%$ & 0.42 & $51.9 \%$ & 0.02 & & \\
\hline
\end{tabular}

et al. (2009), using observational data collected at the Drake Passage only observed the effect of IPO oscillation in SAMW neutral surfaces. However, this oscillation seems to be negative correlated to changes 


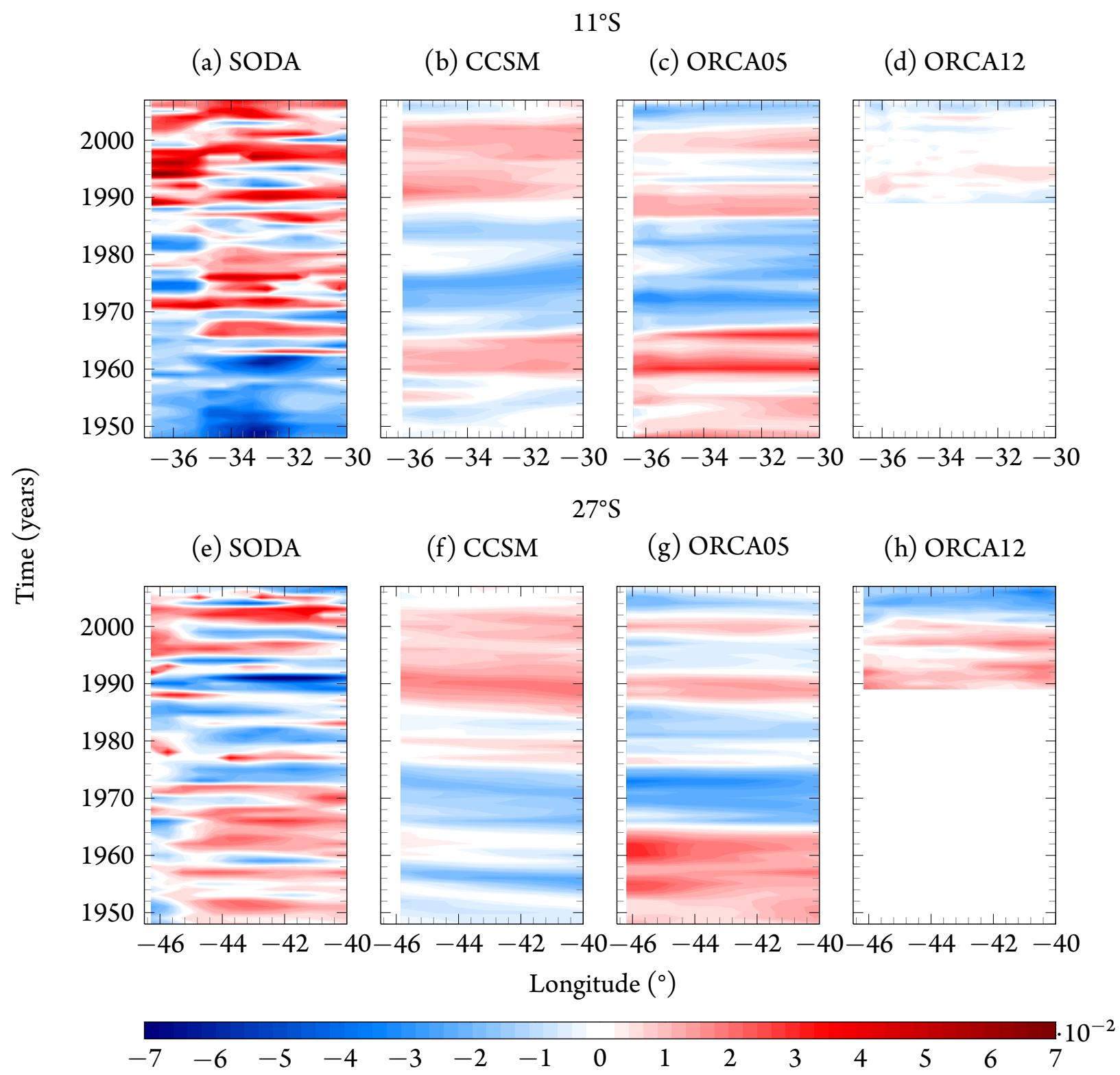

Figure 83: Hovmöller of anomalies of the salinity projected in the $\gamma_{n_{A A I W}} \mathrm{~kg} \cdot \mathrm{m}^{-3}$ neutral surface for $\operatorname{SODA}(\mathrm{a}, \mathrm{e}), \operatorname{CCSM}(\mathrm{b}, \mathrm{f}), \operatorname{ORCA05}(\mathrm{c}, \mathrm{g})$ and ORCA12 (d,h), at $11^{\circ} \mathrm{S}\left(\right.$ top) and $27^{\circ} \mathrm{S}$ (bottom).

in the AAIW, mainly in CORE-II forced model results. Even though part of the AAIW is formed in the southeast Pacific Ocean, as a by-product of the SAMW, formed in a deep convective mixed layer, our results seems to be out of phase with those found by these authors, since during the positive phase of the IPO there is a decrease in the AAIW and the SAMW salinities and temperatures (Figures 72, 72, 83 and 85 ). These results are not robust since our time series are not long enough to analyze a significant number of whole cycles.

Correlations between the annual averages of the salinity projected at the neutral surface of $\gamma_{n_{\text {AAIW }}}$ 


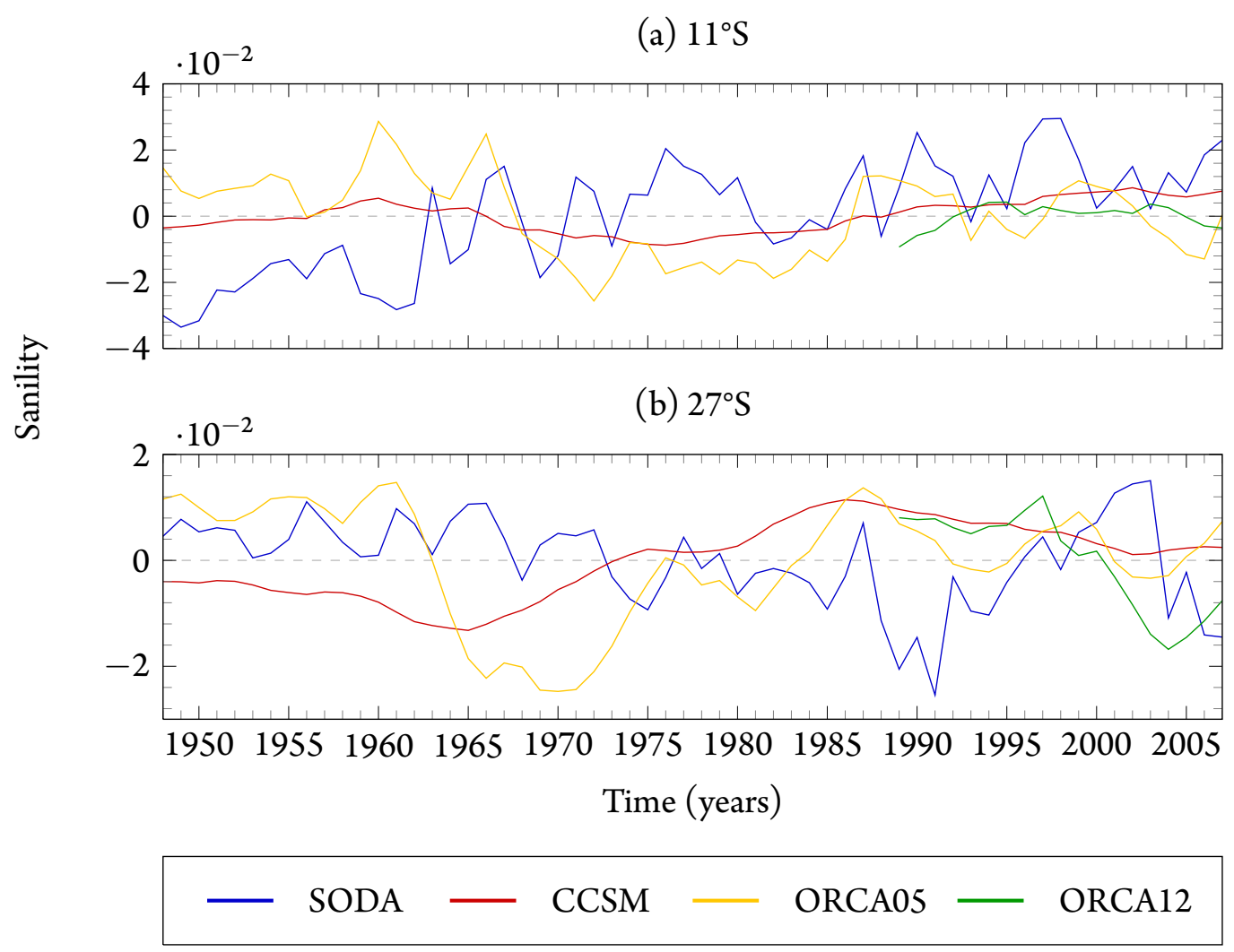

Figure 84: Time series of the salinity anomalies projected in the $\gamma_{n_{A A I W}}$ neutral surface, at $11^{\circ} \mathrm{S}$ and $27^{\circ} \mathrm{S}$ for SODA, CCSM, ORCA05 and ORCA12.

Table 49: Trends of the salinity projected in the neutral surface $\left(\gamma_{n_{A A I W}}\right)$ at $11^{\circ} \mathrm{S}$ and $27^{\circ} \mathrm{S}$ (Figure 84).

\begin{tabular}{ccccc}
\hline & SODA & CCSM & ORCA05 & ORCA12 \\
& & & \\
\hline$\left.y^{-1}\right)$ & & \\
\hline $11^{\circ} \mathrm{S}$ & $7 \cdot 10^{-4} \pm 8 \cdot 10^{-5}$ & $1 \cdot 10^{-4} \pm 3 \cdot 10^{-5}$ & $-2 \cdot 10^{-4} \pm 9 \cdot 10^{-5}$ & $2 \cdot 10^{-4} \pm 1 \cdot 10^{-4}$ \\
$27^{\circ} \mathrm{S}$ & $-2 \cdot 10^{-4} \pm 6 \cdot 10^{-5}$ & $3 \cdot 10^{-4} \pm 4 \cdot 10^{-5}$ & $-3 \cdot 10^{-5} \pm 8 \cdot 10^{-5}$ & $-0.002 \pm 2 \cdot 10^{-4}$ \\
\hline
\end{tabular}

(Figure $84 \mathrm{~b}$ ) and changes in the vertical extension of the AAIW core (Figure 82 ) at $11^{\circ} \mathrm{S}$ and $27^{\circ} \mathrm{S}$ show that the AAIW layer is strongly related to changes in its salinity. High and negative correlations presented in Table 50 show that an increase (decrease) in the salinity in the AAIW layer results in a narrower vertical extension of the water mass. 


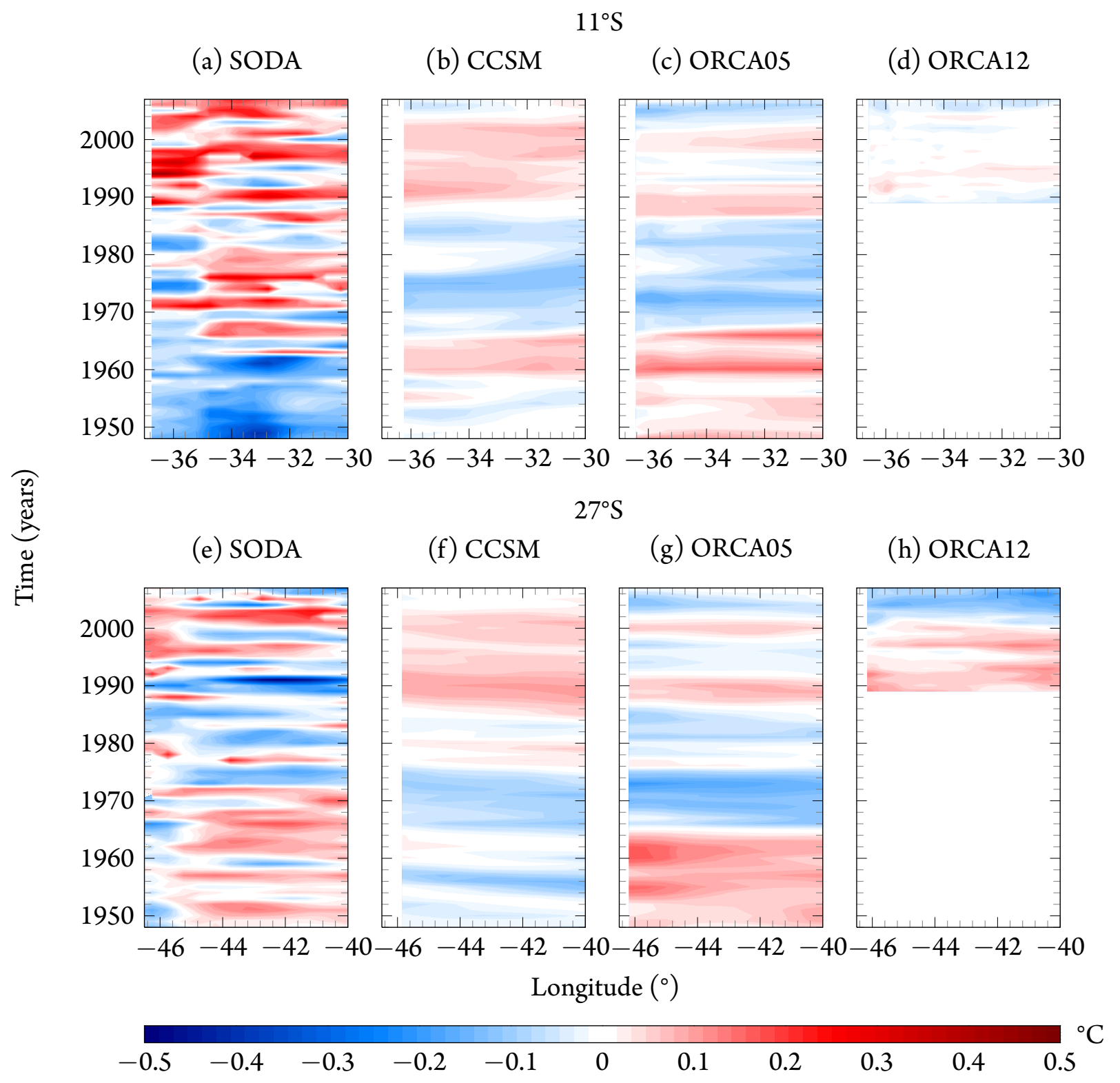

Figure 85: Hovmöller of anomalies of the temperature projected in the $\gamma_{n_{A A I W}} \mathrm{~kg} \cdot \mathrm{m}^{-3}$ neutral surface for SODA (a,e), CCSM (b,f), ORCA05 (c,g) and ORCA12 (d,h), at $11^{\circ} \mathrm{S}$ (top) and $27^{\circ} \mathrm{S}$ (bottom).

Table 50: Correlation between the annual averages of the salinity projected at the neutral surface of $\gamma_{n_{\text {AAIW }}}$ (Figure 84b) and changes in the vertical extension of the AAIW core (Figure 82) at $11^{\circ} \mathrm{S}$ and $27^{\circ} \mathrm{S}$.

\begin{tabular}{ccccccccc}
\hline & \multicolumn{2}{c}{ SODA } & \multicolumn{2}{c}{ CCSM } & \multicolumn{2}{c}{ ORCA05 } & \multicolumn{2}{c}{ ORCA12 $^{1}$} \\
& $\mathrm{R}^{2}$ & $\mathrm{p}$-value & $\mathrm{R}^{2}$ & $\mathrm{p}$-value & $\mathrm{R}^{2}$ & $\mathrm{p}$-value & $\mathrm{R}^{2}$ & $\mathrm{p}$-value \\
\hline $11^{\circ} \mathrm{S}$ & $-82.6 \%$ & $<0.01$ & $-83.4 \%$ & $<0.01$ & $-61.5 \%$ & $<0.01$ & $-88.5 \%$ & $<0.01$ \\
$27^{\circ} \mathrm{S}$ & $-68.9 \%$ & $<0.01$ & $-64.9 \%$ & $<0.01$ & $-89.3 \%$ & $<0.01$ & $-69.5 \%$ & $<0.01$ \\
\hline
\end{tabular}

${ }^{1}$ Correlations done using the period between 1989 and 2007. 


\section{Conclusion}

In this work, the role of the South Atlantic in the AMOC variability was studied and changes in its currents and water masses were addressed through the analysis of different model results (different origins and resolutions) and an ocean reanalysis result. As described in the Section 2.1, SODA is an ocean model (POP), forced by the 20Crv2 winds (COMPO et al., 2011), with $0.5^{\circ}$ of horizontal resolution, which assimilates observational data (CARTON et al., 2000a; CARTON et al., 2000b; CARTON; GIESE, 2006; CARTON; GIESE, 2008). CCSM here referred to as the results obtained with the Ocean Model Component (POP) of the CCSM (Coupled Climate System Model) which is coupled to a sea-ice model (CICE) forced by CORE-II data, with $1^{\circ}$ of horizontal resolution (COLLINS et al., 2006). ORCA05 and ORCA12 are also results from an ocean model (OPA) coupled to a sea-ice model (LIM) (BERNARD et al., 2006; MADEC, 2008; VANCOPPENOLLE et al., 2009). ORCA05 has $0.5^{\circ}$ of horizontal resolution and is also forced by CORE-II data while ORCA12 is a fully eddy-resolving simulation forced by the reanalysis ERA-Interim.

The variability of the SEC bifurcation position, with respect to interannual to multidecadal time scales, is a new result with great relative importance in the context of climate change, due to its link with the NBUC/IWBC transports which feed directly into the AMOC. A number of significant results were found while connecting the variability of the SEC bifurcation with AMOC changes.

We were able to reproduce the results of Rodrigues, Rothstein \& Winbush (2007): all models analyzed could reproduce the SEC bifurcation position and their seasonal variability in the upper $200 \mathrm{~m}$, which is linked to changes in the NBUC/BC system and are driven by changes in the wind stress curl.

However, only the SODA reanalysis could reproduce the seasonal cycle of the SEC bifurcation position observed by Rodrigues, Rothstein \& Winbush (2007) in the first $1000 \mathrm{~m}$. The cause of the differences is still an open question, probably related to the different numerics and deep layer spin-up time scales.

A significant result of this study is the link of the upper limit of the Subtropical Gyre at intermediate depths to a weaker AMOC, observed in the ORCA05 results which is also discussed by Danabasoglu et al. (2013). This feature affects the results related to the interannual variability of the AMOC and its link to the western boundary currents and the SEC bifurcation position, since the latitude chosen to analyze the variability of the IWBC was not suitable for this model.

For periods longer than a year, CCSM and ORCA05 show very similar bifurcation position time series, even though ORCA05 results fails to reproduce the southernmost extension of the bifurcation position. This strongly suggests that the atmospheric forcing is dominating the processes linked to the variability of the SEC position. In fact, as in the seasonal cycle, the SEC bifurcation is influenced by 
changes in the wind stress curl and the results are similar for almost all models. For the SODA reanalysis, however, the correlations with the wind stress curl were minimal and the mechanism that drives the bifurcation variability in this case is not well understood.

Correlations between the CORE-II forced models also suggest a link between the NBUC transports and the forcing. When correlated to the wind stress curl, the results of all models show, similar behaviour. The results comparing the NBUC transport with the Sverdrup interior transport, show that, even in the SODA reanalysis, part of the variability of the NBUC can be explained by the wind stress curl variability, via Sverdrup balance.

The SEC seasonal cycle described by Schott et al. (2005), Rodrigues, Rothstein \& Winbush (2007), Silva et al. (2009), shows that the northernmost position of the bifurcation is related to the smallest northward volume transports. Our results show that this behaviour exists at interannual timescales too. Negative correlations were found in all datasets, but they are only significant for ORCA05 results, even though good correlations with the wind were observed in both series, especially in the CORE-II forced models.

Examination of the AMOC series calculated in this work (as the vertical maximum of the zonally integrated meridional velocities), yields similarity between the results for ORCA and CCSM. However, little of the Sverdrup transports variability can explain AMOC variance among the model results, which desagree with Rabe, Schott \& Köhl (2008), Zhang et al. (2011) results. SODA reanalysis results, on the other hand, show positive and significant correlations, even though at $11^{\circ} \mathrm{S}$ the direction of the AMOC transport and the Sverdrup transport are opposites.

Good correlations were found between the SEC bifurcation at the surface and the AMOC. As the bifurcation position is driven mainly by local changes in the position of the wind stress curl and the AMOC variability is not explained by changes in the wind, the NBUC seems to be the link between them.

Observing the trends, all the results from the models (with exception of ORCA05) show an equatorward movement of the bifurcation position, which is in agreement with recent studies showing a scenario of expansion (40\%) of the subtropical gyre (GARZOLI; MATANO, 2011).

Still considering the seasonal cycle, the northward displacement of the SEC bifurcation position could lead to a decrease in the NBUC transports. Our results do not confirm this idea: positive trends indicating an increase of the northward transports of the western boundary current were found for all the models results considered. This is related to the positive trends of the AMOC, linked to the increase in the NAO index, as found by Biastoch et al. (2008).

Good correlations, albeit not as high as at the surface, were also observed between the time series of the bifurcation position, averaged between $500 \mathrm{~m}$ and $1500 \mathrm{~m}$, which also suggest a link with the forcing. The correlation maps of the SEC bifurcation position with the wind stress curl show similar values for both CCSM and ORCA05 results, with larger correlations in the latter, that can be related to its weak AMOC.

As there was no IWBC-related northward transport calculated for ORCA05, since the SEC bifur- 
cation happens north of $27^{\circ} \mathrm{S}$ (and thus, the IWBC in this section is southward, as part of the BC), there is no evidence of clear link between the IWBC and the wind in CORE-II forced models. The results in SODA, CCSM and ORCA12 show the correlations displayed in a dipole pattern, with positive (negative) correlations north (south) of around $15^{\circ} \mathrm{S}$.

Unlike what occurs at the surface, at intermediate depths there is a negative correlation between the SEC bifurcation variability and the transport of the IWBC. This agrees with the observations of Rodrigues, Rothstein \& Winbush (2007) at seasonal time scales, describing that when the bifurcation is in its southernmost (northernmost) position, the IWBC northward transport is maximum (minimum).

The relationship between the IWBC and the AMOC could not be well defined within our results. The results from CCSM show a negative correlation, while ORCA12 showed a strong and positive result. The SODA reanalysis does not yield a significant correlation. There is no robust conclusion for the direct link between the IWBC and the AMOC. A negative correlation between the SEC bifurcation and the AMOC variability, was observed in the SODA and ORCA12 results. Correlations for the CORE-II forced models were not significant.

When we look at the long term trend, the results are more robust. Negative trends for the SEC bifurcation position and positive trends for the IWBC and the AMOC transports are found which is consistent with the seasonal cycle dynamics described earlier. Positive trends in the transports are related to the increase of the NAO index.

At intermediate depths the results are not conclusive. The IWBC current was not well developed or in the case of ORCA05 was absent.

Schott \& Brandt (2007), Balmaseda et al. (2007), Köhl \& Stammer (2008) report the challenge of faithfully simulating the decadal-to-multidecadal variability of the AMOC using ocean data assimilations based on different schemes. According to the authors, there appears to be no consistent lowfrequency variability in the AMOC transport variation in available data assimilation systems which is consistent with the lack of the AMOC variability in the SODA reanalysis. Furthermore, according to Kröger, Müller \& Storch (2012), when a model assimilates data, its salinity and temperature are not conserved.

In the second part of this work the interannual variability of the water masses carried by the western boundary currents, which are part of the AMOC return flow is analyzed.

The analysis of the vertical sections and the salinity-temperature diagrams show that the results of CORE-II forced models present saltier water masses in the upper layers (Tropical Water, SACW and AAIW). ORCA05 results show a shallower AAIW. These model results also fails in reproduce the subsurface salinity maximum related to the NADW. Both results agree with the weak AMOC presented by this model.

These variations can also be observed on Taylor's Diagram. The results of the CORE-II forced models show some differences in their variability compared to the reanalysis SODA, mainly in the salinity. Despite the variations, all model results analyzed show correlations greater than $90 \%$ and reasonable standard deviations. 
OMP analysis proved to be an effective way of separating the water masses. The use of two different water mass types to represent the SACW was indeed the best way to separate this water mass, confirming the results of Klein \& Tomczak (1994) and Poole \& Tomczak (1999). However, due to limitations in the number of different available data, it was impossible to maintain two different SWT to represent the SACW in order to separate the AAIW, and only one SWT was used. Despite this restriction, the OMP analysis resulted in a well positioned core, when compared to the literature (e.g. Talley (1996), Tomczak \& Godfrey (2003), Pickard, Emery \& Talley (2007)). In both cases, the good performance of the OMP analysis is enchanced by their good mass constraint results (smaller than 5\%, as suggested by Tomczak (1981), Tomczak \& Large (1989), Tomczak (1999), Budillon et al. (2003) and Frants et al. (2013).

For both water masses, the right definition of the salinity index proved to be an important feature for the success of the OMP analysis. In the ocean, the range of temperatures is larger than the range of salinities, which makes little changes in the latter more relevant to the definition of the water mass core.

In general, the time series of the SACW and AAIW cores of the reanalysis SODA present bigger anomalies. In SODA and ORCA12 results, an interannual variability can be observed. For the results of CORE-II forced models variabilities at longer time scales (inter to multidecadal) show to be an important feature. This pattern can be also observed in the salinity and in the temperature projected in the neutral surface layer related to this water masses.

The salinity and the temperature projected in the neutral surface related to the ISACW $\left(\gamma_{n_{25.5}} \mathrm{~kg} \cdot \mathrm{m}^{-3}\right)$ in CCSM and ORCA05 results, mainly at $27^{\circ} \mathrm{S}$, could be linked to the AMO, since the period of strong positive anomalies (between 1960 and 1980) coincides with the negative phase of AMO (KNIGHT; FOLLAND; SCAIFE, 2006). According to Arz, Pätzold \& Wefer (1999) and Chiessi et al. (2009), during AMO negative phase there is a reducing of AMOC, which leads an increase of South Atlantic temperature.

In the SAMW layer $\left(\gamma_{n_{27.0}} \mathrm{~kg} \cdot \mathrm{m}^{-3}\right)$, salinity and temperature could be linked to the IPO. Our results at $27^{\circ} \mathrm{S}$ agree with the observations of Garabato et al. (2009) done at the Drake Passage. Folland et al. (2002) and Parker et al. (2007) show that the IPO index is associated with surface warming (cooling) around the SAMW formation area of the southeast Pacific-Drake Passage and with a northeastward (southeastward) migration of the South Pacific Convergence Zone that is consistent with a positive (negative) anomaly in the winter-mean evaporation in the region. Results at $11^{\circ} \mathrm{S}$, both for the SAMW and for the AAIW $\left(\gamma_{n_{A A I W}} \mathrm{~kg} \cdot \mathrm{m}^{-3}\right)$ show to be out of phase, and, during the period of positive phase of IPO, there is a decrease in the salinity and in the temperature projected in the surfaces related to this water mass.

Changes in the position of the SACW core seems to be related to changes in the ISACW $\left(\gamma_{n_{25.5}} \mathrm{~kg} \cdot \mathrm{m}^{-3}\right)$ : an increase of the salinity on this neutral surface leads in a deepening of the SACW core. However, this negative correlation was only significative in the SODA results. Positive correlations were found between SACW core position time series and the salinity projected in the neutral surface related to the SAMW: an increase of the salinity in this neutral surface leads in a shallowing of the SACW core. This 
relationship was significant in SODA, CCSM and ORCA05 results.

The vertical extension of the AAIW core seems to be strongly related to the changes in the salinity of this water mass: negative correlations, always larger than $60 \%$, show that a decrease in the salinity increases the vertical extension of the AAIW core in both sections.

Trend analysis show an increase of the the ISACW salinity in the results of SODA and ORCA12 which agrees with the observations of Curry, Dickson \& Yashayaev (2003) for this region, while COREII forced models show opposite results. This same pattern can be noted in the SAMW salinity trends. While Curry, Dickson \& Yashayaev (2003) observed positive trends north of $20^{\circ} \mathrm{S}$, which agrees with our results for SODA and ORCA12, they also found negative trends south of it, with agrees with COREII forced models results.

The relationship between the trend of the SACW core position and the salinity projected in the neutral surfaces is a complicate scenario. At $11^{\circ} \mathrm{S}$, SODA and CCSM show negative trends, showing a deepening of the SACW core, while ORCA05 and ORCA12 show positive trends. At $27^{\circ} \mathrm{S}$, all the models show a shallowing of the SACW core. From the correlations obtained (excluding the trend), we expected that, in case of positive (negative) correlations between the salinity in a given neutral surface and the vertical position of the SACW core, similar trends, both negative or positive (opposite trends) would be found. However, considering only the significantly statistical results it is not possible to determine which trend is more important to the long term changes in the SACW core position.

Finally, AAIW results confirm the observations of Curry, Dickson \& Yashayaev (2003) and Schmidtko \& Johnson (2012): positive trends north of $20^{\circ} \mathrm{S}$ while a decrease in the AAIW salinity is observed south of it in the SA. Trends of the vertical extension of the AAIW core show that this water mass is occupying less space in the water column due to an increasing of the salinity in the neutral surfaces at $11^{\circ} \mathrm{S}$, while the opposite happens at $27^{\circ} \mathrm{S}$. 


\section{Bibliography}

ANDRONOVA, N. G.; SCHLESINGER, M. E. Causes of global temperature changes during the $19^{\text {th }}$ and $20^{\text {th }}$ centuries. Geophys. Res. Lett., v. 27, p. 2137-2140, 2000.

AOKI, S.; BINDOFF, N. L.; CHURCH, J. A. Interdecadal watermass changes in the Southern Ocean between $30^{\circ} \mathrm{E}$ and $160^{\circ} \mathrm{E}$. Geophys. Res. Lett., v. 32, 2005.

ARBIC, B. K.; OWENS, W. B. Climatic warming of Atlantic Intermediate Waters. J. Clim., v. 14, p. 4091-4108, 2001.

ARZ, H. W.; PÄTZOLD, J.; WEFER, G. The deglacial history of the western tropical Atlantic as inferred from high resolution stable isotope records off northeastern Brazil. Earth Planet. Sc. Lett., v. 167, p. 105-117, 1999.

BAILEY, D. A.; RHINES, P. B.; HÄKKINEN, S. Formation and pathways of North Atlantic Deep Water in a coupled ice-ocean model of the Arctic-North Atlantic Oceans. Clim. Dyn., v. 25, p. 497-516, 2005.

BALMASEDA, M. A. et al. Historical reconstruction of the Atlantic meridional overturning circulation from the ECMWF operational ocean reanalysis. Geophys. Res. Lett., v. 34, p. L23615, 2007.

BARNSTON, A. G.; LIVEZEY, R. E. Classification, seasonality and persistence of low-frequency atmospheric circulation patterns. Mon. Wea. Rev., v. 115, p. 1083-1126, 1987.

BERNARD, B. et al. Impact of prtial steps and momentum advection schemes in a global ocean circulation model at eddy permitting resolution. Ocean Dyn., v. 56, n. 5-6, p. 543-567, 2006.

BIASTOCH, A. et al. Causes of interannual-decadal variability in the Meridional Overturning Circulation of the midlatitude North Atlantic Ocean. J. Climate, v. 21, p. 6599-6615, 2008.

BIASTOCH, A.; BÖNING, C. W.; LUTJEHARMS, J. R. E. Agulhas leakage dynamics affects decadal variability in Atlantic overturning circulation. Nature, v. 456, p. 489-492, 2008.

BINDOFF, N. L.; CHURCH, J. A. Warming of the water column in the southwest Pacific Ocean. Nature, v. 357, p. 59-62, 1992.

BINDOFF, N. L.; MCDOUGALL, T. J. Decadal changes along an Indian Ocean section at $32^{\circ} \mathrm{S}$ and their interpretation. J. Phys. Oceanogr., v. 30, p. 1207--1222, 2000.

BINGHAM, R. J. et al. Meridional coherence of the North Atlantic meridional overturning circulation. Geophys. Res. Let., v. 34, p. L23606, 2007.

BOEBEL, O. et al. The intermediate depth circulation of the western South Atlantic. Geophys. Res. Lett., v. 26, n. 21, p. 3329-3332, 1999.

BOEBEL, O. et al. Flow and recirculation of Antarctic Intermediate Water across Rio Grande Rise. J. Geophys. Res., v. 102, p. 20967-20986, 1997. 
BOEBEL, O. et al. Intermediate water in the Brazil-Malvinas Confluence Zone: a Lagrangian view. Journal of Geophys. Res, v. 104, 1999.

BOLVIN, G. J. H. R. F. A. D. T.; GU, G. Improving the Global Precipitation record: GPCP version 2.1. Geo. Res. Lett., v. 36, p. L17808, 2009.

BONHOURE, D. et al. The South Equatorial System Current. 2004. Rosenstiel School of Marine and Atmospheric Science. Ocean Surface Currents. $<$ http://oceancurrents.rsmas.miami.edu/atlantic/south-equatorial.html $>$. Access: March, $5^{\text {th }}$ of 2013.

BÖNING, C. W. et al. Decadal variability of subpolar gyre transport and its reverberation in the North Atlantic overturning. Geophys. Res. Let., v. 33, p. L21S01, 2006.

BRAUWERE, A. D. et al. Water mass distributions in the Southern Ocean derived from parametric analysis of mixing water masses. J. Geophys. Res., v. 112, p. C02021, 2007.

BRODEAU, L. et al. An ERA40-based atmospheric forcing for global ocean circulation models. Ocean Modell., v. 31, p. 88-104, 2010.

BROECKER, W. S. The great Conveyor Belt. Oceanography, v. 4, p. 79-89, 1991.

BRYAN, K. A numerical method for the study of the circulation of the world ocean. J. Comput. Phys., v. 4, p. 347-376, 1969.

BRYDEN, H. L.; LONGWORTH, H. R.; CUNNINGHAM, S. A. Slowing of the Atlantic Meridional Overturning Circulation at $26.5^{\circ}$ N. Nature, v. 438, p. 655-657, 2005.

BRYDEN, H. L.; MCDONAGH, E. L.; KING, B. A. Changes in ocean water mass properties: Oscillations or trends? Science, v. 300, p. 2086-2088, 2003.

BUDILLON, G. et al. An optimum multiparameter mixing analysis of the shelf waters in the ross sea. Antarctic Sci., v. 15, p. 105-118, 2003.

BÖNING, C. W. et al. The response of the Antarctic Circumpolar Current to recent climate change. Nat. Geosci., v. 1, p. 864-869, 2008.

CAMPOS, E. D. J.; GONÇALVES, J. E.; IKEDA, Y. Water mass characteristics and geostrophic circulation in the South Brazil Bigth: summer of 1991. J. Geophys. Res., v. 99, p. 537-550, 1995.

CARMACK, E. C.; FOSTER, T. D. On the flow of water out of the Weddell Sea. Deep Sea Res. Part A, v. 22, n. 11, p. 711-724, nov. 1975.

CARTON, J. et al. A Simple Ocean Data Assimilation analysis of the global upper ocean 1950-95. part 1: Methology. J. Phys. Oceanogr., v. 30, p. 294-309, 2000.

CARTON, J. et al. A Simple Ocean Data Assimilation analysis of the global upper ocean 1950-95. part 2: Results. J. Phys. Oceanogr., v. 30, p. 311-326, 2000.

CARTON, J. A.; GIESE, B. S. SODA: Reanalysis of Ocean Climate. Mon. Wea. Rev, 2006.

CARTON, J. A.; GIESE, B. S. A reanalysis of ocean climate using Simple Ocean Data Assimilation (SODA). Mon. Weather Rev., v. 136, p. 2999-301, 2008. 
CHANG, R. et al. Oceanic link between abrupt changes in the North Atlantic Ocean and African monsoon. Nat. Geosci., v. 1, p. 444-448, 2008.

CHELTON, D. B. et al. Geographical variability of the first baroclinic Rossby radius of deformation. J. Phys. Oceanogr., v. 28, p. 433-460, 1998.

CHIESSI, C. M. et al. Possible impact of the Atlantic Multidecadal Oscillation on the South American summer monsoon. Geophys. Res. Lett., v. 36, p. L21707, 2009.

CIRANO, M. et al. Circulação oceânica de meso-escala na região oeste do Atlântico Sul com base no modelo de circulação global OCCAM. Rev. Bras. Geof., v. 24, n. 2, p. 209-230, 2006.

CLIVAR. CLIVAR Working Group on Ocean Model Development: Co-ordinated Ocean-Ice Reference Experiments. 2010. <http://www.clivar.org/organization/wgomd/core/core_II.php>. Access: July 26th 2010.

COLES, V. J. et al. Changes in Antartic Bottom Water properties in the western South Atlantic in the late 1980s. J. Geophys. Res., v. 101, p. 8957-8970, 1996.

COLLINS, W. D. et al. The Community Climate System Model Version 3 (CCSM3). J. Climate, v. 19, p. 2122-2143, 2006.

COMPO, G. P. et al. The Twentieth Century Reanalysis Project. Q. J. R. Meteorol. Soc., v. 137, p. 1-28, 2011.

COWARD, A.; CUEVAS, B. de. The OCCAM 66 Level Model: Physics, initial conditions and external forcing. Southampton, U. K., 2005. v. 99, 83 p.

COX, M. D. A baroclinic model of the world ocean: Preliminary results. In: Numerical Models of the Ocean Circulation. Washington, DC: National Academy of Sciences, 1975. p. 107-118.

CROWLEY, T. North Atlantic Deep Water cools the southern hemisphere. Paleoceanography, v. 7, p. 489-497, 1992.

CUNNINGHAM, S. A. et al. Temporal variability of the Atlantic meridional overturning circulation at $26.5^{\circ}$. Science, v. 317, p. 935-938, 2007.

CURRY, R.; DICKSON, B.; YASHAYAEV, I. A change in the freshwater balance of the Atlantic Ocean over the past four decades. Nature, v. 426, p. 826-829, 2003.

DAI, A.; TRENBERTH, K. E. Estimates of freshwater discharge from continents: Latitudinal and seasonal variations. J. Hydrometeorol, v. 3, p. 660-687, 2002.

DANABASOGLU, G. et al. The CCSM4 Ocean Component. J. Climate, v. 25, p. 1361-1389, 2012.

DANABASOGLU, G. et al. North Atlantic Simulations in Coordinated Ocean-ice Reference Experiments phase II (CORE-II). Part I: Mean states. Ocean Modelling, 2013. Submitted.

DEE, D. et al. The era-interim reanalysis: configuration and performance of the data assimilation system. Q. J. Roy. Meteorol. Soc., v. 137, p. 553-597, 2011.

DELECLUSE, G. M. nad P.; IMBARD, M.; LEVY, C. OPA8.1 Ocean general Circulation Model reference manual. France, $1998.91 \mathrm{p}$. 
DELWORTH, T. L.; MANN, M. E. Observed and simulated multidecadal variability in the northern hemisphere. Clim. Dyn., v. 16, p. 661-676, 2000.

DENGLER, M. et al. Break-up of the Atlantic deep western boundary current into eddies at $8^{\circ} \mathrm{S}$. Nature, v. 432, p. 1018-1020, 2004.

DESHAYES, J. et al. Oceanic hindcast simulations at high resolution suggest that the Atlantic MOC is bistable. Geophys. Res. Let., In revision, 2012.

DONNERS, J.; DRIJFHOUT, S. S.; HAZELEGER, W. Water mass transformation and subduction in the South Atlantic. J. Phys. Oceanog., v. 35, p. 1841-1860, 2005.

DRIJFHOUT, S. S.; WEBER, S. L.; SWALUW, E. v. The stability of the MOC as diagnosed from model projections for pre-industrial, present and future climates. Clim. Dyn., v. 37, p. 1575-1586, 2011.

DURACK, P. J.; WIJFFELS, S. E. Fifty-year trends in global ocean salinities and their relationship to broad-scale warming. J. Climate, v. 23, p. 4342-4362, 2010.

EDEN, C.; WILLEBRAND, J. Neutral density revisited. Deep-Sea Res. Part II: Topical Studies in Oceanography, v. 46, p. 33-54, 1999.

EDEN, C.; WILLEBRAND, J. Mechanism of interannual to decadal variability of the North Atlantic circulation. J. Clim., v. 14, p. 2266-2280, 2001.

EMERY, W. J. Water types and water masses. In: Ocean circulation. Second. [S.l.]: Elsevier Ltd, 2003.

EMERY, W. J.; MEINCKE, J. Global water masses: summary and review. Oceanologica Acta, v. 9, p. 383-391, 1986.

ENFIELD, D. B.; MESTAS-NUFIEZ, A. M.; TRIMBLE, P. J. The Atlantic multidecadal oscillation and its relation to rainfall and river flows in the continental U.S. Geophys. Res. Lett., v. 28, p. 2077-2080, 2001.

EVANS, D. L.; SIGNORINI, S. R. Vertical structure of the Brazil Current. Nature, v. 315, p. 48-50, 1985.

FAHRBACH, E. et al. Formation and discharge of deep and bottom water in the northwestern Weddell Sea. J. Mar. Res., v. 53, n. 4, p. 515-538, jul. 1995.

FICHEFET, T.; MAQUEDA, M. A. M. Modelling the influence of snow accumulation and snow-ice formation on the seasonal cycle of the Antarctic sea-ice cover. Climate Dyn., v. 15, p. 251-268, 1999.

FOLLAND, C. K. et al. Predictability of northeast Brazil rainfall and real-time forecast skill, 1987-98. J. Clim., v. 14, p. 1937-1958, 2001.

FOLLAND, C. K.; PARKER, D. E.; PALMER, T. N. Sahel rainfall and worldwide sea temperatures, 1901--85. Nature, v. 320, p. 602-607, 1986.

FOLLAND, C. K. et al. Relative influences of the Interdecadal Pacific Oscillation and ENSO on the South Pacific Convergence Zone. Geophys. Res. Lett, v. 29, p. 21-1-21-4, 2002.

FRANTS, M. et al. Optimal multiparameter analysis of source water distributions in the Southern Drake Passage. Deep-Sea Res. II, v. 90, p. 31-42, 2013. 
GANACHAUD, A. Large-scale mass transports, water mass formation and diffusivities estimated from world ocean circulation experiment (woce) hydrographic data. J. Geophys. Res., v. 108, p. 3213, 2003.

GANACHAUD, A.; WUNSCH, C. Improved estimates of global ocean circulation, heat transport and mixing from hydrographic data. Nature, v. 408, p. 453-457, 2000.

GARABATO, A. C. N. et al. Variability of Subantarctic Mode Water and Antarctic Intermediate Water in the Drake Passage during the late-twentieth and early-twenty-first centuries. J. Climate, v. 22, n. 13, p. 3661--3688, 2009.

GARY, S. F. et al. Deciphering the pathways for the deep limb of the Meridional Overturning Circulation. Deep Sea Res. II, v. 58, p. 1781-1797, 2011.

GARZOLI, S. L.; BARINGER, M. O. Meridional heat transport determined with expendable bathythermographs. part III:South Atlantic Transport. Deep-Sea Res. I, v. 54, p. 1402-1420, 2007.

GARZOLI, S. L. et al. South Atlantic meridional fluxes. Deep-Sea Res. I, v. 71, p. 21-32, 2013.

GARZOLI, S. L.; MATANO, R. The South Atlantic and the Atlantic Meridional Overturning Circulation. Deep-Sea Res II, v. 58, p. 1837-1847, 2011.

GOES, M. et al. Retroflections of the north brazil current during february 2002. Deep-Sea Res., v. 52, p. 647-667, 2005.

GOES, M. et al. Changes in subduction in the South Atlantic Ocean during the 21st century in the CCSM3. J. Geophys. Res., v. 35, 2008.

GOLDENBERG, S. B. et al. The recent increase in Atlantic hurricane activity: Causes and implications. Science, v. 293, p. 474-479, 2001.

GORDON, A. L. South atlantic thermocline ventilation. Deep Sea Res. A, v. 28, p. 1239-1264, 1981.

GORDON, A. L. Interocean exchange of thermocline water. J. Geophys. Res., v. 91, p. 5037-5046, 1986.

GORDON, A. L.; GREENGROVE, C. L. Geostrophic circulation of the Brazil-Falkland confluence. Deep Sea Res., v. 33, p. 573-585, 1986.

GORDON, A. L. et al. Thermocline and intermediate water communication between the South Atlantic and Indian Oceans. J. Geophys. Res. Oceans, v. 97, p. 7223-7240, 1992.

GOURIOU, Y. et al. Deep circulation in the Equatorial Atlantic Ocean. Geophys. Res. Lett., v. 28, p. 819-822, 2001.

GREGORY, J. M.; SAENKO, O. A.; WEAVER, A. J. The role of the Atlantic freshwater balance in the hysteresis of the meridional overturning circulation. Climate Dyn., v. 21, p. 707-717, 2003.

GRIFFIES, S. M. Fundamentals of Ocean Climate Models. [S.l.]: Princeton University Press, 2004. $495 \mathrm{p}$.

HANAWA, K.; TALLEY, L. D. Mode waters. In: Ocean circulation and climate. [S.I.]: Academic Press, 2001.p. 373-386. 
HANSEN, J. E. et al. A closer look at United States and global surface temperature change. J. Geophys. Res., v. 106, p. 23947-23963, 2001.

HARPER, S. Thermocline ventilation and pathways of tropical-subtropical water mass exchange. Tellus, v. 52A, p. 330-345, 2000.

HAZELEGER, W.; VRIES, P. de; FRIOCOURT, Y. Sources of the Equatorial Undercurrent in the Atlantic in a high-resolution ocean model. J. Phys. Oceanogr., v. 33, p. 677-693, 2003.

HELM, K. P.; BINDOFF, N. L.; CHURCH, J. A. Changes in the global hydrological-cycle inferred from ocean salinity. Geophys. Res. Lett., v. 37, p. L18701, 2010.

HODSON, D. L.; SUTTON, R. T. The impact of resolution on the adjustment and decadal variability of the Atlantic Meridional Overturning Circulation in a coupled climate model. Clim. Dyn, v. 39, p. 3057-3073, 2012.

HOERLING, M. P.; HURRELL, J. W.; XU, T. Tropical origins for recent North Atlantic climate change. Science, v. 292, p. 90-92, 2001.

HOGG, N. G.; OWENS, W. B. Direct measurement of the deep circulation within the Brazil Basin. Deep-Sea Res. II, v. 46, p. 335-353, 1999.

HOGG, N. G.; THURNHERR, A. M. A zonal pathway for NADW in the South Atlantic. J. of Oceanog., v. 61, p. 493-507, 2005.

HOLTE, J.; TALLEY, L. A new algorithm for finding mixed layer depths with applications to Argo data and Subantarctic Mode Water formation. J. Atmos. Ocean. Tech., v. 26, p. 1920-1939, 2009.

HUANG, B. et al. AMOC variations in 1979-2008 simulated by NCEP operational ocean data assimilation system. Clim. Dyn, v. 38, p. 513-525, 2012.

HURRELL, J. W. Decadal trends in the North Atlantic Oscillation regional temperatures and precipitation. Science, v. 269, p. 676-679, 1995.

HURRELL, J. W.; KUSHNIR, Y.; VISBECK, M. The north atlantic oscillation. Science, v. 291, p. 603-604, 2011.

INUI, T. et al. Wind stress effects on subsurface pathways from the subtropical to tropical atlantic. J. Phys. Oceanogr., v. 32, p. 2257-2276, 2002.

IPCC. Climate Change 2001: The Scientific Basis, Contribution of Working Group I to the Third Assessment Report of the Intergovernmental Panel on Climate Change. Cambridge, United Kingdom: Cambrigde University Press, 2001. 881 p.

IPCC. Climate Change 2007: Synthesis Report. Contribution of Working Groups I, II and III to the Fourth Assessment Report of the Intergovernmental Panel on Climate Change. Geneva, Switzerland: IPCC, 2007. $104 \mathrm{p}$.

JACKETT, D. R.; MCDOUGALL, T. J. A neutral density variable for the world's oceans. J. Phys. Oceanogr., v. 27, p. 237-263, 1997.

JAYNE, S. R.; MAROTZKE, J. The dynamics of ocean heat transport variability. Rev. Geophys, v. 39, p. $385-411,2001$. 
JOHNS, W. E. et al. Annual cycle and variability of the North Brazil Current. J. Phys. Oceanog., v. 28, p. 103-128, 1998.

JOHNS, W. E.; ZANTOPP, R.; GONI, G. Cross-gyre transport by North Brazil Current rings. In: GONI, G. J.; MALANOTTE-RIZZOLI, P. (Ed.). Interhemispheric Water Exchange in the Atlantic Ocean. [S.1.]: Elsevier, 2003. p. 411-441.

JOHNSON, G. C.; ORSI, A. H. Southwest Pacific Ocean water-mass changes between 1968/69 and 1990/91. J. Climate, v. 10, p. 306-316, 1997.

KALNAY, E. et al. The NCEP/NCAR 40-Year Reanalysis Project. Bull. Amer. Meteor. Soc., v. 77, p. 437-470, 1996.

KANZOW, T. et al. Observed flow compensation associated with the MOC at $26.5^{\circ} \mathrm{N}$ in the Atlantic. Science, v. 317, p. 938-941, 2007.

KAPLAN, A. et al. Analyses of global sea surface temperature 1856-1991. J. Geophys. Res., v. 103, p. 18,567-18,589, 1998.

KEFFER, T. The ventilation in world's ocean: maps of potential vorticity field. J. Phys. Oceanog., v. 15, p. 509-523, 1985.

KERR, R. Distribuição, mistura e variabilidade das massas de água profundas do Mar de Weddell, Antártica. 147 f. Dissertação (Master) — Fundação Universidade do Rio Grande, Rio Grande, RS, 2006.

KERR, R.; WAINER, I.; MATA, M. M. Representation of the weddell sea deep water in the ocean component of the NCAR-CCSM model. Antartic Science, v. 21, p. 301-312, 2009.

KERR, R. A. A North Atlantic climate pacemaker for the centuries. Science, v. 288, p. 1984-1985, 2000.

KLEIN, B.; TOMCZAK, M. Identification of diapycnal mixing through optimum multiparameter analysis. Evidence for unidirectional diapycnal mixing in the front between North and South Atlantic Central Water. J. Geophys. Res., v. 99, p. 25,275-25,280, 1994.

KNIGHT, J. R. et al. A signature of persistent natural thermohaline circulation cycles in observed climate. Geophys Res Lett, v. 32, p. L20708, 2005.

KNIGHT, J. R.; FOLLAND, C. K.; SCAIFE, A. A. Climate impacts of the Atlantic Multidecadal Oscillation. Geophys. Res. Let., v. 33, p. L17706, 2006.

KÖHL, A.; STAMMER, D. Variability of the meridional overturning in the North Atlantic from the 50-year GECCO state estimation. J. Phys. Oceanogr., v. 38, p. 1913-1930, 2008.

KOLTERMANN, K. P.; GOURETSKI, V.; JANCKE, K. Hydrographic Atlas of the World Ocean Circulation Experiment (WOCE). Volume 3: Atlantic Ocean. International WOCE Project Office, Southampton, UK: [s.n.], 2011.

KRÖGER, J.; MÜLLER, W. A.; STORCH, J.-S. von. Impact of different ocean reanalyses on decadal climate prediction. Clim. Dyn., v. 39, p. 795-810, 2012.

KUHLBRODT, T. et al. On the driving processes of the Atlantic meridional overturning circulation. Rev. Geophys., v. 45, p. RG2001, 2007. 
LAMB, P. J.; PEPPLER, R. A. North Atlantic Oscillation: concept and and application. Bull. Amer. Meteor. Soc., p. 1218-1225, 1987.

LARGE, W. G.; YEAGER, S. G. The global climatology of an interannually varying air-se flux data set. Clim. Dyn., v. 33, p. 341-364, 2009.

LATIF, M. et al. Is the thermohaline circulation changing? J. Climate, v. 19, p. 4631-4637, 2006.

LAZAR, A. et al. Seasonality of the ventilation of the tropical atlantic thermocline in an ocean general circulation model. J. Geophys. Res., v. 107, p. 3104, 2002.

LAZAR, I. W. A.; SOLOMON, A. Tropical extra-tropical thermocline water mass exchanges in the Community Climate Model v.3. Part I: the Atlantic Ocean. Ocean Sci., v. 2, p. 137-146, 2006.

LEGEAIS, J.-F.; OLLITRAULT, M.; ARHAN, M. Lagrangian observations in the Intermediate Western Boundary Current of the South Atlantic. Deep-Sea Res.-II, v. 85, p. 109-126, 2013.

LEVITUS, S. Annual cycle of temperature and heat storage in the world ocean. J. Phys. Oceanogr., v. 14, p. 727-746, 1984.

LOZIER, M. S. Deconstructing the Conveyor Belt. Science, v. 328, p. 1507-1511, 2010.

LUMPKIN, R.; GARZOLI, S. L. Near-surface circulation in the tropical Atlantic Ocean. Deep Sea Res., v. 52, p. 495-518, 2005.

LUMPKIN, R.; SPEER, K. Large-scale vertical and horizontal circulation in the North Atlantic Ocean. J. Phys. Oceanogr., v. 33, p. 1902-1920, 2003.

LUMPKIN, R.; SPEER, K. Global Ocean Meridional Overturning. J. Phys. Oceanogr., v. 37, p. 2550-2562, 2007.

MADEC, G. NEMO Ocean Engine: Version 3.0. France, 2008. 209 p.

MALANOTTE-RIZZOLI, P. et al. Water mass pathways between the subtropical and tropical ocean in a climatological simulation of the North Atlantic ocean circulation. Dynam. Atmos. Oceans, v. 32, p. 331-371, 2000.

MAMAYEV, O. I. Temperature-salinity analisys of world ocean waters. [S.l.]: Elsevier Scientific Publishing Company, 1975.374 p.

MANABE, S.; STOUFFER, R. Coupled ocean-atmosphere model response to freshwater input: Comparison to Younger Dryas event. Paleoceanography, v. 12, p. 321-336, 1997.

MANABE, S.; STOUFFER, R. J. Two stable equilibria of a coupled ocean-atmosphere model. J. Climate, v. 1, p. 841-866, 1988.

MARENGO, J. A. et al. Climatology of the low-level jet east of the Andes as derived from the NCEP-NCAR reanalyses: Characteristics and temporal variability. J. Clim., v. 17, p. 2261-2280, 2004.

MARSH, R. et al. Recent changes in the North Atlantic circulation simulated with eddy-permitting and eddy-resolving ocean models. Ocean Modelling, v. 28, p. 226-239, 2009. 
MCCARTHY, G.; MCDONAGH, E. L.; KING, B. A. Decadal variability of thermocline and intermediate waters at $24^{\circ} \mathrm{S}$ in the South Atlantic. J. Phys. Oceanogr., v. 41, p. 157-165, 2011.

McCARTHY, G. D. et al. On the sub-decadal variability ofSouth Atlantic Antarctic Intermediate Water. Geophys. Res. Lett., v. 39, p. L10605, 2012.

McCARTNEY, M. Subantarctic Mode Water. In: ANGEL, M. V. (Ed.). A voyage of discovery: George Deacon 70th anniversary volume. Oxford: Pergamon Press, 1977.p. 103-119.

McCARTNEY, M. The subtropical recirculation of mode waters. J. Mar. Res., v. 40, p. 427--464, 1982.

McCARTNEY, M. Crossing of the Equator by the Deep Western Boundary Current in the western Atlantic Ocean. J. Phys. Oceanog., v. 23, p. 1953--1974, 1993.

McCLEAN, J. L. et al. A prototype two-decade fully-coupled fine-resolution CCSM simulation. Ocean Model., v. 39, p. 10-30, 2011.

MCDONAGH, E. L.; KING, B. A. Oceanic fluxes in the South Atlantic. J. Phys. Oceanogr., v. 35, p. 109-122, 2005.

McDOUGALL, T. J. Neutral surfaces. J. Phys. Oceanog., v. 17, p. 1950-1964, 1987.

MEDHAUG, I.; FUREVIK, T. North Atlantic $20^{\text {th }}$ century multidecadal variability in coupled climate models: sea surface temperature and ocean overturning circulation. Ocean Sci., v. 7, p. 389-404, 2011.

MEEHL, G. A. et al. Global climate projections. In: SOLOMON, S. et al. (Ed.). Climate Change 2007: The Physical Science Basis. Cambridge, United Kingdom and New York, NY, USA: Cambridge University Press, 2007.

MEREDITH, M. P. et al. On the sources of Weddell Gyre Antartic Bottom Water. J. Geophys. Res., v. 105, n. C1, p. 1093-1104, jan. 2000.

MODEL, F. Warmwasserheizung europas. Ber. Deut. Wetterdienstes, v. 12, p. 51-60, 1950.

MOLINARI, R. L. Observations of eastward currents in the tropical South Atlantic Ocean: 1978-1980. J. Geophys. Res, v. 87, p. 9707-9714, 1982.

MOLINARI, R. L. Sea-surface temperature and dynamic height distributions in the central tropical South Atlantic Ocean. Oceanologica Acta, v. 6, p. 30-34, 1983.

MOLINARI, R. L.; VOITURIEZ, B.; DUNCAN, P. Observations in the subthermocline under current of the equatorial South Atlantic Ocean: 1978-1980. Oceanologica Acta, v. 4, p. 451-456, 1981.

MOULIN, C. et al. Control of atmospheric export of dust from North Africa by the North Atlantic Oscillation. Nature, v. 387, p. 691-694, 1997.

MÜLLER, T. J. et al. Direct measurements of the western boundary currents between $20^{\circ} \mathrm{S}$ and $28^{\circ} \mathrm{S}$. J. Phys. Res., v. 103, n. C3, p. 5429-5437, 1998.

MUNK, W.; WUNSCH, C. Abyssal recipes II: energetics of tidal and wind mixing. Deep-Sea Res. I, v. 45, p. 1977-2010, 1998. 
MÉMERY, L. et al. The water masses along the western boundary of the south and equatorial Atlantic. Prog. Oceanog., v. 47, p. 69-98, 2000.

OPPENHEIM, A. V.; SCHAFER, R. Discrete-Time Signal Processing. Prentice-Hall: [s.n.], 1989. $447-448 \mathrm{p}$.

PARKER, D. et al. Decadal to multidecadal variability and climated change background. J. Geophys. Res., v. 112, p. D18115, 2007.

PEDLOSKY, J. Geophysical Fluid Dynamics. Second. [S.l.]: Springer-Verlag, 1987. 710 p.

PEDLOSKY, J. Ocean Circulation Theory. [S.1.]: Springer, 1996. 453 p.

PETERSON, R. G.; STRAMMA, L. Upper-level circulation in the South Atlantic Ocean. Prog. Oceanograf., v. 26, p. 1-73, 1990.

PETERSON, R. G.; WHITWORTH-III, T. The subantarctic and polar fronts in relation to deep water masses through the southwestern atlantic. J. Geophys. Res., v. 9J, p. 10817-10838, 1989.

PICKARD, G. L.; EMERY, W. J.; TALLEY, L. D. Descriptive Physical Oceanography. [S.1.]: Elsevier, 2007. $137 \mathrm{p}$.

POOLE, R.; TOMCZAK, M. Optimum multiparameter analysis of the water mass structure in the atlantic ocean thermocline. Deep-Sea Res. I, v. 46, p. 1895-1921, 1999.

PROVOST, C. et al. Subtropical mode waters in the South Atlantic Ocean. J. Geophys. Res., v. 104, p. 21033-21049, 1999.

PROVOST, C. et al. Hydrographic conditions in the brazil-malvinas confluence during austral summer 1990. J. Geophys. Res., v. 100, p. 10655-10678, 1995.

RABE, B.; SCHOTT, F. A.; KÖHL, A. Mean circulation and variability of the Tropical Atlantic during 1952-2001 in the GECCO assimilation fields. J. Phys. Oceanog., v. 38, p. 177-192, 2008.

REID, J. L. On the total geostrophic circulation of the North Atlantic Ocean. Flow patterns, tracers and transports. Progr. Oceanogr., v. 33, p. 1-92, 1994.

RENNERMALM, A. K. et al. Relative sensitivity of the Atlantic Meridional Overturning circulation to river discharge into Hudson Bay and the Arctic Ocean. J. Geophys. Res.: Biogeoscien., v. 112, p. -, 2007.

RINTOUL, S. R. South Atlantic interbasin exchange. J. Geophys. Res., v. 96, p. 2675-2692, 1991.

RODGERS, J. L.; NICEWANDER, W. A. Thirteen ways to look at the correlation coefficient. The American Statistician, v. 42, p. 59-66, 1988.

RODRIGUES, R. R.; ROTHSTEIN, L. M.; WINBUSH, M. Seasonal variability of the South Equatorial Current bifurcation in the Atlantic Ocean: a numerical study. J. Phys. Oceanogr., v. 37, p. 16-30, 2007.

ROWELL, D. P. The impact of Mediterranean SSTs on the Sahelian rainfall season. J. Clim., v. 16, p. 849-862, 2003. 
ROWELL, D. P. et al. Variability of summer rainfall over tropical north-africa (1906-92) observations and modelling. Q. J. R. Meteorol. Soc., v. 121, p. 669-704, 1995.

RUIJTER, W. P. M. D. et al. Indian-Atlantic inter-ocean exchanges: dynamics, estimation and impact. J. Geophys. Res., v. 104, p. 20885-20910, 1999.

SAENKO, O. A.; WEAVER, A. J.; GREGORY, J. M. On the link between the two modes of the ocean thermohaline circulation and the formation of global-scale water masses. J. Climate, v. 16, p. 2797-2801, 2003.

SANTOSO, A.; ENGLAND, M. Antarctic Intermediate Water circulation and variability using a coupled climate model. J. Phys. Oceanogr., v. 34, p. 2160-2179, 2004.

SANTOSO, A.; ENGLAND, M. H.; HIRST, A. C. Circumpolar Deep Water Circulation and variability in a Coupled Climate Model. J. Phys. Oceanogr., v. 36, p. 1523-1552, 2005.

SAUNDERS, P. M. et al. Decadal changes in the North Atlantic and Pacific meridional overturning circulation and heat flux. J. Phys. Oceanog., v. 38, p. 2104-2107, 2008.

SCHLITZER, R. Electronic Atlas of WOCE hydrographic and tracer data now available. Eos Trans. $A G U$, v. 81, p. 45, 2000.

SCHMID, C.; SIEDLER, G.; ZENK, W. Dynamics of intermediate water circulation in the Subtropical South Atlantic. J. Phys. Oceanograf., v. 30, p. 3191-3211, 2000.

SCHMIDTKO, S.; JOHNSON, G. C. Multidecadal warming and shoaling of Antarctic Intermediate Water. J. Clim., v. 25, p. 207-221, 2012.

SCHMITZ, W. J. On the interbasin scale termohaline circulation. Rev. Geophys., v. 3, p. 151-173, 1995.

SCHOTT, F.; BÖNING, C. W. The WOCE model in the western equatorial Atlantic: upper-layer circulation. J. of Geophys. Res, v. 96, p. 6993-7004, 1991.

SCHOTT, F. A.; BRANDT, P. Circulation and deep water export of the Subpolar North Atlantic during the 1990s. AGU, Washington, D. C.: Geophys. Monogr. Ser., 2007. 91-118 p.

SCHOTT, F. A. et al. On the boundary flow off Brazil at 5-10 $0^{\circ}$ and its connection to the interior tropical Atlantic. Geophys. Res. Lett., v. 29, p. 1840, 2002.

SCHOTT, F. A. et al. The shallow and deep western boundary circulation of the south atlantic at $5^{\circ}-11^{\circ}$ S. J. Am. Meteorol. Soc., v. 35, p. 2031-2053, 2005.

SCHOTT, F. A. et al. On mean and seasonal currents and transports at the western boundary of the equatorial Atlantic. J. Geophys. Res., v. 98, p. 14353--14368, 1993.

SCHOTT, F. A.; STRAMMA, L.; FISCHER, J. The warm water inflow into the western tropical atlantic boundary regime, spring 1994. J. Geophys. Res., v. 100, p. 24745-24760, 1995.

SCHUCKMANN, K. von. Intraseasonal variability in the southwestern and central tropical Atlantic Ocean. 140 p. Thesis (Phd) - Christian Albrechts Univ. Kiel, Kiel, Germany, 2006.

SEMTNER, A. J. Modeling ocean circulation. Science, v. 269, p. 1379-1385, 1995. 
SERAZIN, G. An approximate Neutral Density variable for the world's oceans. 2011.85 p.

SIJP, W. P.; ENGLAND, M. H. Sensitivity of the Atlantic thermohaline circulation and its stability to basin-scale variations in vertical mixing. J. Climate, v. 19, p. 5467-5478, 2006.

SILVA, M. A. et al. High-resolution regional ocean dynamics simulation in the southwestern tropical Atlantic. Ocean Modell., v. 30, p. 1-29, 2009.

SILVEIRA, I. C. A. d.; CALADO, L.; CASTRO, B. M. On the baroclinic structure of the Brazil Current-Intermediate Western Boundary Current system at $22^{\circ}-23^{\circ}$ S. Geophys. Res. Lett., v. 31, p. L14308, 2004.

SILVEIRA, I. C. A. d.; MIRANDA, L. B. de; BROWN, W. S. On the origins of the North Brazil Current. J. Geophys. Res., v. 99, p. 22501-22512, 1994.

SILVEIRA, I. C. A. d. et al. A Corrente do Brasil ao largo da costa leste brasileira. Rev. Bras. Oceanogr., v. 48 , n. 2, p. 171-183, 2000.

SMITH, D. M. et al. Skilful multi-year predictions of Atlantic hurricane frequency. Nat. Geosci., v. 3, p. 846-849, 2010.

SMITH, R. D.; DUKOWICZ, J. K.; MALONE, R. C. Parallel Ocean General Circulation Modeling. Physica D, v. 60, p. 38-61, 1992.

SPEER, K.; RINTOUL, S. R.; SLOYAN, B. The diabatic Deacon cell. J. Phys. Oceanogr., v. 30, p. 3212-3222, 2000.

SPEICH; BLANKE, B.; CAI, W. Atlantic Meridional Overurturning and the Southern Hemisphere Supergyre. Geophys. Res. Let., v. 34, 2007.

SPEICH, S. et al. Tasman Leakage: a new route for the global conveyor belt. Geophys. Res. Lett., v. 29, p. 1416, 2002.

SPEICH, S.; GARZOLI, S. L.; PIOLA, A. A monitoring system forthe South Atlantic as a component of the MOC. In: HALL, J.; HARRISON, D. E.; STAMMER, D. (Ed.). Proceedings of the MOC: Sustained Ocean Observations and Information for Society. Venice, Italy: ESA Publication, 2010.

SROKOSZ, M. et al. Past, present and future change in the atlantic meridional overturning circulation. Bull. Amer. Meteorol. Soc., v. 93, p. 1663-1676, 2012.

STEWART, R. H. Introduction to Physical Oceanography. [S.l.]: Texas A\&M University, 2008. 345 p. Eletronic book.

STOUFFER, R. J. et al. Investigating the causes of the response of the thermohaline circulation to past and future climate changes. J. Clim., v. 19, p. 1365-1387, 2006.

STRAMMA, L. Geostrophic transport of the South Equatorial Current in the Atlantic. J. Mar. Res., v. 49, p. 281-294, 1991.

STRAMMA, L.; ENGLAND, M. On the water masses and mean circulation of the South Atlantic Ocean. J. Geophys. Res., v. 104, n. C9, p. 20863-20883, 1999. 
STRAMMA, L.; ENGLAND, M. The water masses and mean circulation of the South Atlantic Ocean. Nature, v. 400, p. 440-443, 1999.

STRAMMA, L.; FISCHER, J.; REPPIN, J. The North Brazil Undercurrent. Deep-Sea Res. I., v. 42, p. 773-795, 1995.

STRAMMA, L.; PETERSON, R. The south atlantic current. J. Phys. Oceanogr., v. 20, p. 846-859, 1990.

STRAMMA, L. et al. Upper ocean circulation in the western tropical Atlantic in boreal fall 2000. Deep Sea Res. Part I, v. 52, p. 221-240, 2005.

STRAMMA, L.; SCHOTT, F. The mean flow field of the tropical Atlantic Ocean. Deep Sea Res. Part II, v. 46, p. 270-303, 1999.

SVERDRUP, H. U. Wind-driven currents in a baroclinic ocean: with application to the equatorial currents of the eastern Pacific. P Natl Acad Sci, v. 33, p. 318-326, 1947.

SØRENSEN, J. V. T.; RIBBE, J.; SHAFFER, G. Antartic Intermadiate Water Mass formation in ocean general circulation models. J. Phys. Oceanogr., v. 31, p. 32958-3311, 2001.

SÉVELLEC, F.; FEDOROV, A. V. Stability of the Atlantic meridional overturning circulation and stratification in a zonally averaged ocean model: Effects of fresh water flux, Southern Ocean winds, and diapycnal diffusion. Deep-Sea Res. II, v. 58, p. 1927-1943, 2011.

TALLEY, L. Antarctic Intermediate Water in the South Atlantic: The South Atlantic: Present and Past Circulation. [S.l.]: Springer-Verlag, 1996.219-238 p.

TALLEY, L. D. Shallow, intermediate and deep overturning components of the global heat budget. J. Phys. Oceanogr., v. 33, p. 530-560, 2003.

TALLEY, L. D. et al. Descriptive Physical Oceanography: An Introduction. Sixth edition. [S.l.]: Elsevier, $2011.560 \mathrm{p}$.

TALLEY, L. D.; SPRINTALL, J. Deep expression of the Indonesian throughflow: Indonesian Intermediate Water in the South Equatorial Current. J. Geophys. Res., v. 110, 2005.

TAYLOR, K. E. Summarizing multiple aspects of model performance in a single diagram. J. Geophys. Res., v. 106, n. D7, p. 7183-7192, 2001.

THOMMAS, M. Sverdrup Balance and Three Dimensional Variability of the Meridional Overturning Circulation. 168 p. Thesis (Phd) - School of Environmental Sciences of the University of East Anglia, London, U.K., 2012.

TOGGWEILER, J. R.; SAMUELS, B. Effect of Drake Passage on the Global Thermohaline Circulation. Deep-Sea Res. I, v. 42, p. 477-500, 1995.

TOMCZAK, M. A multi-parameter extension of temperature/salinity diagram techniques for the analysis of non-isopycnal mixing. Prog. Oceanogr., v. 10, p. 147-171, 1981.

TOMCZAK, M. Some historical, theorical and applied aspects of quantitative water mass analysis. J. Mar. Res., n. 57, p. 275-303, 1999. 
TOMCZAK, M.; GODFREY, J. S. Regional Oceanography: An Introduction. London: Pergamon, 1994. $422 \mathrm{p}$.

TOMCZAK, M.; GODFREY, J. S. Regional Oceanography: an Introduction. Second. [S.l.]: Daya Publishing House, 2003.390 p.

TOMCZAK, M.; LARGE, D. G. B. Optimum multiparameter analysis of mixing in the thermocline of the eastern Indian Ocean. J. Geophys. Res., v. 94, p. 16141-16149, 1989.

TOMCZAK, M.; LIEFRINK, S. Interannual variations of water mass volumes in the Southern Ocean. J. Atmos. Ocean Sci., v. 10, p. 31-42, 2005.

TOMCZAK, M.; POOLE, R. Optimum multiparameter analysis of the water mass structure in the Atlantic Ocean thermocline. Deep-sea Res. I, v. 46, p. 1895-1921, 1999.

TRENBERTH, K. E.; CARON, J. M. Estimates of meridional atmosphere and ocean heat transports. J. Clim., v. 14, p. 3433-3443, 2001.

TSUCHIYA, M.; TALLEY, L. D.; McCARTNEY, M. S. Water-mass distributions ih the western South Atlantic: a section from South Georgia Island (54S) northward accross the equator. J. Mar. Res., v. 52, p. 55-81, 1994.

VANCOPPENOLLE, M. et al. Simulating the mass balance and salinity of Arctic and Antarctic sea ice. 1. model description and validation. Ocean Modelling, v. 27, p. 33-53, 2009.

VELEDA, D. et al. Intraseasonal variability of the North Brazil Undercurrent forced by remote winds. J. Geophys. Res., v. 117, p. C11024, 2012.

VELLINGA, M.; WOOD, R. A. Global climatic impacts of a collapse of the Atlantic thermohaline circulation. Clim. Change, v. 54, p. 251-267, 2002.

VELLINGA, M.; WU, P. Low-latitude freshwater influence on centennial variability of the Atlantic thermohaline circulation. J. Clim., v. 17, p. 4498-4511, 2004.

VERTENSTEIN, M. et al. CCSM4.0 User's Guide. [S.1.], 2010. 126 p.

VIVIER, F.; PROVOST, C. Direct velocity measurements in the Malvinas current. J. Geophys. Res., v. 104, p. 21083-21103, 1999.

VRIES, P. de; WEBER, S. L. The Atlantic freshwater budget as a diagnostic for the existence of a stable shut down of the meridional overturning circulation. Geophys. Res. Lett., v. 32, p. L09606, 2005.

WEIJER, W. et al. Response of the Atlantic overturning circulation to south atlantic sources of buoyancy. Global Planet. Change, v. 34, p. 292-311, 2002.

WIENDERS, N.; ARHAN, M.; MERCIER, H. Circulation at the western boundary of the South and Equatorial Atlantic: Exchanges with the ocean interior. J. Mar. Res., v. 58, p. 1007--1039, 2000.

WILSON, W. D.; JOHNS, E.; MOLINARI, R. L. Upper layer circulation in the western tropical North Atlantic Ocean during august 1989. J. Geophys. Res., v. 99, p. 22513-22523, 1994.

WONG, A. P. S.; BINDOFF, N. L.; CHURCH, J. A. Large-escale freshening of intermediate waters in the Pacific and Indian oceans. Nature, n. 400, p. 440-443. 
WONG, A. P. S.; BINDOFF, N. L.; CHURCH, J. A. Freshwater and heat changes in the North and South Pacific Oceans between the 1960s and 1985-94. J. Climate, v. 14, p. 1613-1633, 2001.

WOOD, R. A.; VELLINGA, M.; THORPE, R. Global warming and thermohaline circulation stability. Phil. Trans. R. Soc. Lond., v. 361, p. 1961-1974, 2003.

WUNSCH, C. What is the thermohaline circulation? Science, v. 298, p. 1179-1181, 2002.

WUNSCH, C. The decadal mean ocean circulation and Sverdrup balance. J. Mar. Res., v. 69, p. 417-434, 2011.

WÜST, G. Schichtung und zirkulation des Atlantischen Ozeans. Wiss. Ergeb. Dt. Atl. Exp. Meteor., v. 6, p. 1-288, 1935.

ZHANG, D.; MCPHADEN, M. J.; JOHNS, W. E. Observational evidence for flow between the subtropical and tropical Atlantic: The Atlantic subtropical cells. J. Phys. Oceanogr., v. 33, p. 1783-1797, 2003.

ZHANG, D. et al. Multidecadal variability of the North Brazil Current and its connection to the Atlantic Meridional Overturning Circulation. J. Geophys. Res., v. 116, p. C04012, 2011.

ZHANG, R.; DELWORTH, T. L. Simulated tropical response to a substantial weakening of the Atlantic thermohaline circulation. J. Clim., v. 18, p. 1853-1860, 2005.

ZHANG, R.; DELWORTH, T. L. Impact of Atlantic multidecadal oscillations on India/Sahel rainfall and Atlantic hurricanes. Geophys. Res. Lett., v. 33, p. L17712, 2006. 